\begin{abstract}
UNIVERSIDADE DE SÃO PAULO - USP
FACULDADE DE FILOSOFIA, LETRAS E CIÊNCIAS HUMANAS

DEPARTAMENTO DE GEOGRAFIA

PROGRAMA DE PÓS-GRADUAÇÃO EM GEOGRAFIA HUMANA
\end{abstract}

CARMEN LUCIA VERGUEIRO MIDAGLIA

\title{
PROPOSTA DE IMPLANTAÇÃO DO ÍNDICE DE ABRANGÊNCIA ESPACIAL DE MONITORAMENTO - IAEM POR MEIO DA ANÁLISE DA EVOLUÇÃO DA REDE DE QUALIDADE DAS ÁGUAS SUPERFICIAIS DO ESTADO DE SÃO PAULO
}

VERSÃO CORRIGIDA 


\section{PROPOSTA DE IMPLANTAÇÃO DO ÍNDICE DE ABRANGÊNCIA ESPACIAL DE MONITORAMENTO - IAEM POR MEIO DA ANALISE DA EVOLUÇÃO DA REDE DE QUALIDADE DAS ÁGUAS SUPERFICIAIS DO ESTADO DE SÃO PAULO}

Tese apresentada ao Programa de PósGraduação em Geografia Humana do Departamento de Geografia da Faculdade de Filosofia, Letras e Ciências Humanas da Universidade de São Paulo para obtenção do título de Doutora em Geografia.

Orientador: Prof. Dr. Reinaldo Paul Pérez Machado

VERSÃO CORRIGIDA

SÃO PAULO 
Autorizo a reprodução e divulgação total e parcial deste trabalho, por qualquer meio convencional ou eletrônico, para fins de estudos e pesquisas, desde que citada a fonte.

Este exemplar foi revisado e alterado em relação à versão original, sob responsabilidade única do autor e com a anuência de seu orientador.

São Paulo, 10 de junho de 2011

Assinatura do autor

Assinatura do orientador

Catalogação na Publicação

Serviço de Documentação do Departamento de Geografia

Faculdade de Filosofia, Letras e Ciências Humanas

Universidade de São Paulo

Midaglia, Carmen Lucia Vergueiro,

Proposta de Implantação do Índice de Abrangência Espacial de Monitoramento - IAEM por meio da Análise da Evolução da Rede de Qualidade das Águas Superficiais do Estado de São Paulo; Carmen Lucia Vergueiro Midaglia;

Orientador: Reinaldo Paul Pérez Machado - São Paulo, 2009

Tese de Doutorado - Programa de Pós-Graduação do Departamento de Geografia. Área de Concentração: Geografia Humana - Faculdade de Filosofia, Letras e Ciências Humanas da Universidade de São Paulo - USP

1.Índice de Monitoramento. 2.Rede de Monitoramento de Águas. 3. SIG. 4. Análise Espacial 5. Análise Multi-critério. 6.Densidade Demográfica 
Aos Rios, que, como os homens, nascem pequenos e frágeis e precisam vencer obstáculos até o fim de sua trajetória!

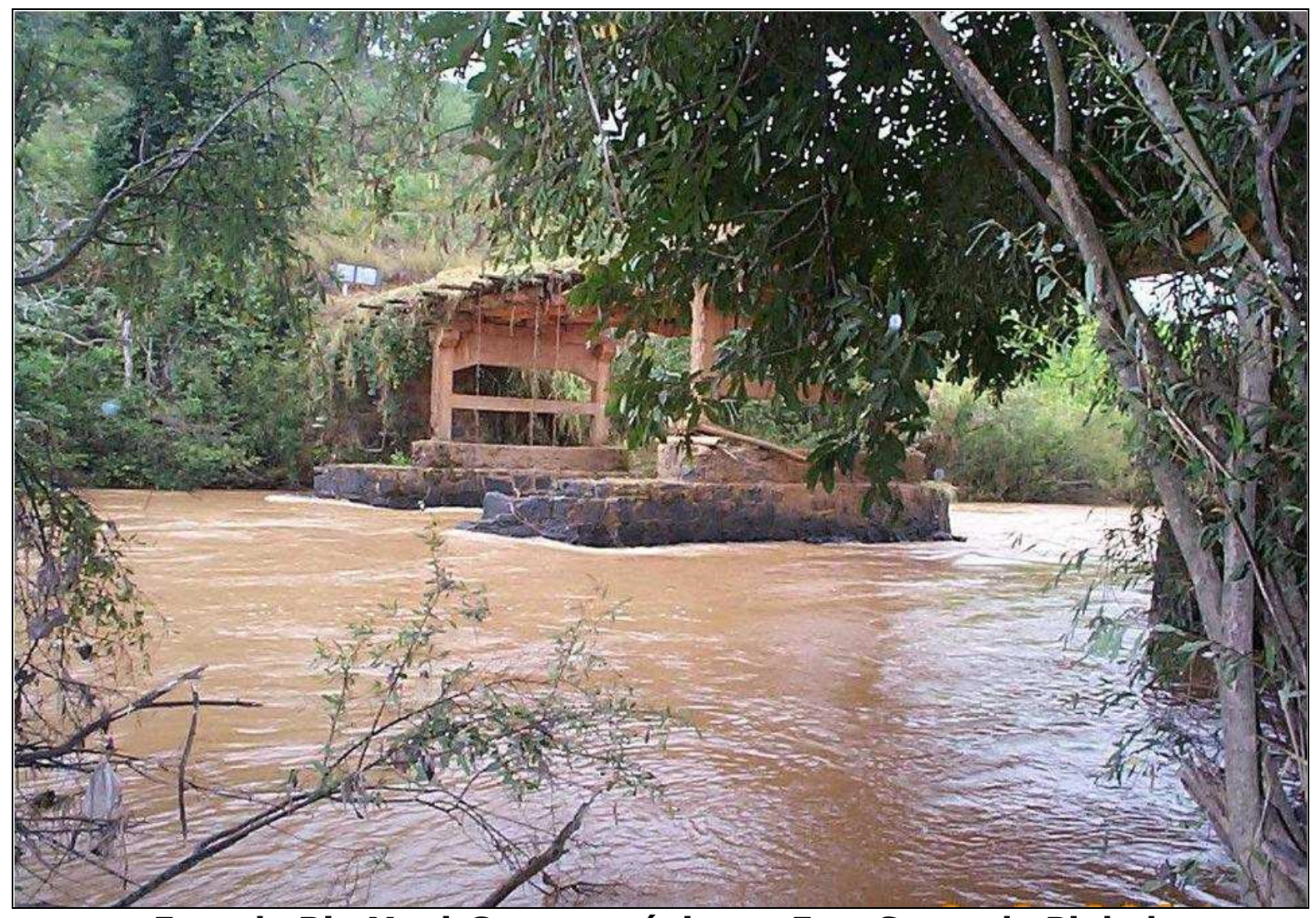

Foto do Rio Mogi-Guaçu, próximo a Esp. Santo do Pinhal. Autor: C. L. Midaglia (2004). 


\section{AGRADECIMENTOS}

O caminho de construção deste trabalho foi mais difícil e mais lento do que podia se imaginar, mas não teria chegado até aqui sem a ajuda dos meus familiares, professores, colegas geógrafos da pós-graduação, amigos distantes e próximos através do mundo virtual, e outros tantos colaboradores a quem são devidos agradecimentos especiais:

Ao meu orientador, Reinaldo Paul Pérez Machado, pelos aconselhamentos, críticas, idéias e amizade durante o desenvolvimento da dissertação.

Ao Renato, Lucas e Nina, desculpas pelo tempo roubado e muito obrigada pela paciência e assistência diária. A meu pai, Luciano por acreditar sempre que estudando eu conseguiria vencer.

Ao Diretor do Departamento de Geografia da FFLCH-USP, Prof. Jurandyr Ross, pelo permanente apoio e a todos outros Professores que se dispõem a ouvir, orientar e principalmente repassar o conhecimento com os seus alunos, tornando real o aprendizado, tais como os dedicados Prof. Dr. Marcello Martinelli, Prof. Dr. Mario de Biasi, Prof. Dr. Adilson A. Abreu, Prof. Dr. J. Bueno Conti e Profa. Dra. Maria Helena Simielli.

A Profa. Dra. Cleide Rodrigues, pela oportunidade de fazer estágio no PAE- Programa de Estágio acadêmico supervisionado, na disciplina de Hidrografia, em 2006, e pela co-orientação.

Aos meus colegas do Departamento de Geografia da FFLCH-USP que contribuíram de forma direta e indireta para a realização deste trabalho. E em especial ao empenho do geógrafo Fernando Kawakubo, na orientação da montagem da plataforma de análise no ambiente GIS do ILWIS e a geógrafa Rúbia Morato na assistência no LASERE-USP.

Aos colegas de trabalho, geógrafa Ap. Cristina Camolez e Dr. C. Palombo pelos livros emprestados e ao Eng. Uladyr Nayme da CETESB, pelo apoio. Agradeço aos meus companheiros de viagens em visita a rios e reservatórios em todo o Estado, Adelino Ribeiro, Gordella (Oswaldo Atanagildo) e Rivellino (Jair Moura). 
Ao Prof. Dick van der Zee, do ITC de Enschede, por transferir conhecimento contínuo, repassando textos e imagens, enviando livros e CDs, de assuntos especialmente selecionados para me agradar.

Aos meus ex-colegas do ITC, Ivan Z. Basic, J. Henrique Vilas-Boas, Ronald Job Vargas, Estuardo Lira e outros tantos, como Rodolfo Veltri e Lucia Ohi, pelo apoio on-line vindo de toda parte do mundo.

A CETESB, pelo apoio e liberação parcial das atividades profissionais para a execução deste trabalho de Doutorado, e em especial ao meu chefe Nelson Menegon Jr. por ter aberto a possibilidade de retomar os estudos.

Aos meus estagiários e ex-estagiários da CETESB, em especial Érica Tachibana, que dividiu opiniões importantes na construção do índice e teve paciência de editar as tabelas de cálculo, e a Monserrat R. Aguilar, Lukas J. Minnich e Fernando Malavolta no auxílio cotidiano da rotina de pequenas grandes tarefas.

Ao Nelson A.Caetano, pela assistência na administração da FFLCH e a Ana Lucia Pereira pelo seu apoio na secretaria da pós-graduação da Geografia. 


\section{RESUMO}

MIDAGLIA, Carmen Lucia Vergueiro. Proposta de implantação do Índice de Abrangência Espacial de Monitoramento - IAEM por meio da análise da evolução da rede de qualidade das águas superficiais do Estado de São Paulo. 230f. Tese (Doutorado), Faculdade de Filosofia, Letras e Ciências Humanas, Universidade de São Paulo, 2009.

Esta pesquisa de doutorado faz uma avaliação correlacional entre a evolução espacial da rede de monitoramento de qualidade das águas interiores do Estado de São Paulo, através do número de pontos de amostragem e sua respectiva densidade espacial ao longo dos 30 anos de sua existência e o crescimento populacional, através da densidade populacional dos municípios inseridos nas 22 unidades de gerenciamento de recursos hídricos do Estado de São Paulo. Analisa também se estes pontos mantiveram a capacidade de representar o status da qualidade da água em função do crescimento populacional, e se é necessário expandir ou adensar a rede em determinadas regiões. Esta comparação ficou mais racional com o uso dos recursos das geotecnologias e da análise multicritério aplicada ao planejamento e gerenciamento de recursos hídricos, com a construção do SIG SP_WATERNET e através da criação de um índice de avaliação do monitoramento que relaciona as 22 unidades espacialmente e ao longo do período estudado. Este índice pode ressaltar o grau de abrangência e de vulnerabilidade da rede de monitoramento das águas interiores superficiais no Estado de São Paulo.

Palavras-chave: SIG; Geotecnologias; Índices de Qualidade de Água; Densidade de Redes de Monitoramento de água; Densidade Demográfica; Gestão de Recursos Hídricos; Gerenciamento de água; Análise ambiental; Análise espaço-temporal; Análise Multi-critério. 


\begin{abstract}
MIDAGLIA, Carmen Lucia Vergueiro. Proposal of implementation for an Spatial Coverage Monitoring Index - SCMI by temporal analysis of the evolution of the inland waters quality network of São Paulo State. $230 f$. Tese (Doutorado), Faculdade de Filosofia, Letras e Ciências Humanas, Universidade de São Paulo, 2009.
\end{abstract}

This is a correlational Ph.D. research aiming at evaluating the spatial evolution of the monitoring network of inland surface waters of State of São Paulo, through the number of sampling points and its density throughout 30 years and the population growth (urbanization) and the population density in the 22 units of water management units of the São Paulo State. It also analyzes if these points had kept the capacity to represent the status of the quality of the water in function of the population growth, and if it is necessary to expand or to rearrange the network in some regions. This comparison was more rational with the use of the resources of the geo-information applied for water resources planning and management, with the construction of SIG SP_WATERNET and with the proposal of a multi-criteria evaluation monitoring index concerning the 22 water management units throughout a studied period. This index can point out the coverage or the vulnerability of the monitoring efficiency of the surface waters network of São Paulo State.

Keywords: GIS; Geo-technologies; Water Quality Index; Water Information System; Water Monitoring density network; Demography density; Water Spatial Support System; Water Management; Environmental Analysis; Multi-criteria evaluation. 


\section{LISTA DE FIGURAS}

Figura 1 - Os fatores e as características da Terra..................26

Figura 2 - Símbolo da Década da Água.............................. 34

Figura 3 - Vista do Estado de São Paulo e a Divisão por

UGRHIS. 35

Figura 4 - Exemplo típico de rede de amostragem para monitoramento para múltiplos fins.

Figura 5 - Município de Marília, com área fracionada em 3 UGRHIs.

Figura 6 - Divisão geral das águas do estado de São Paulo em UGRHIS e Bacias Hidrográficas.

Figura 7 - Variação dos níveis de OD no Rio Pinheiros em 2008.

Figura 8 - Exemplo de laudo CETESB do ponto BAGU 02700 na captação de Araçatuba

Figura 9 - Procedimento para codificação de Pontos de Monitoramento da CETESB.

Figura 10 - Evolução Geral dos Tipos de Monitoramento de Qualidade de Água operados pela CETESB.

Figura 11 - Mosaico de Fotos da Rede de Monitoramento

Cetesb com 30 anos de Amostragem 79,80

Figura 12 - Faixas de classificação do IQA nos Estados

Brasileiros.

Figura 13 - Evolução do Número de pontos com IQA calculado no Estado de São Paulo.

Figura 14 - Critérios para distribuição da Rede de Monitoramento EUROWATERNET.

Figura 15 - Mapa de São Paulo - Número de Pontos necessários por UGRHI para atender a Densidade Recomendada pelo critério (CEE/EEA) 
Figura 16 - Evolução da densidade da rede para os anos de 1978, 1988, 1998 e 2008 segundo o critério CEE .......................................................... 98

Figura 17 - Densidade da rede de Monitoramento de Portugal por bacias.

Figura 18 - Evolução dos resultados do monitoramento na Bacia do Sena (1985-2007) para 15 parâmetros......103

Figura 19 - Divisão da Holanda pelas 27 Províncias de Água......105 Figura 20 - Quadro Comparativo Nacional de Monitoramento....106 Figura 21 - Visualização plena do Layer "redeagua" (pontos inseridos no ILWIS) na tela em escala 1: 4.000.000.

Figura 22 - Recorte Espacial dentro do SIG SP_WATERNET -

$$
\text { Lat: }-20^{\circ} 00 /-25^{\circ} 00 \mathrm{~S} \times \text { Long: }-45^{\circ} 00 /-53^{\circ} 00 \mathrm{w} . . .117
$$

Figura 23 - Sistema de coordenadas adotadas para

Georeferenciamento das bases.

Figura 24 - Inserção de pontos no Layer redeagua.

Figura 25 - Pontos de amostragem verificados no Google Earth ........................................... 125

Figura 26 - Exemplo de conflito típico de limites de bases. 126

Figura 27 - Análise de correlação espacial em 2008 com distância de 25 km

Figura 28 - Exemplo de representação utilizando divisão de Voronoi.

Figura 29 - Exemplo de divisão para obtenção de áreas de domínios de pontos da rede de água superficial...132

Figura 30 - Análise Espacial por Interpolação com Média Móvel - Médias do IQA referente ao ano de 1998 com distância de $250 \mathrm{~km}$ de raio.

Figura 31 - Tela de entrada para a função de análise de cálculo da Média Móvel. 
Figura 32 - Cenário para grandes cidades do Mundo.

Figura 33 - Evolução do Tratamento de esgotos no Estado de São Paulo............................................... 153

Figura 34 - Estruturação Racional da Análise Multi-critério........160

Figura 35 - Fases da Análise Multi-critério.........................164

Figura 36 - Comparação entre os dois tipos de padronização para critério valor médio do IQA-2008.

Figura 37 - Comparação entre os dois tipos de padronização para critério custo-Atribuição da UGRHI

Figura 38 - Índice de Abrangência Espacial do Monitoramento das Águas Superficiais do Estado de São Paulo Analise Temporal para anos selecionados

Figura 39- Cenário do IAEM 1980 por UGRHI com médias por pontos com classificação IQA 1980

Figura 40 - Cenário do IAEM 1991 por UGRHI com médias por pontos com classificação IQA 1991

Figura 41 - Cenário do IAEM 1995 por UGRHI com médias por pontos com classificação IQA 1995

Figura 42 -Cenário do IAEM em 1996 por UGRHI com médias por pontos com classificação IQA-1996

Figura 43 - Cenário do IAEM em 2000 por UGRHI com médias por pontos com classificação do IQA 2000.

Figura 44 - Cenário do IAEM em 2004 por UGRHI com médias por pontos com classificação do IQA-2004.

Figura 45 - Cenário do IAEM em 2008 por UGRHI com médias por pontos com classificação do IQA-2008. 205

Figura 46 - Somatória Geral do IAEM para o Estado de São Paulo 209 


\section{LISTA DE TABELAS}

Tabela 1 - Limites para o Parâmetro fósforo 48

Tabela 2 - Aproveitamento Energético do Rio Tietê. 51

Tabela 3 -Evolução da distribuição dos pontos quando por zonas hidrográficas (1978 e 1993).

Tabela 4 - Resultados das médias do IQA de pontos com 30 anos de existência.

Tabela 5-Tabela de pesos de parâmetros para cálculo do IQA.

Tabela 6 - Faixas de classificação do IAP.

Tabela 7 - Faixas de classificação do IET. .88

Tabela 8 -Densidade Ideal de pontos da rede de Monitoramento Paulista segundo critério da CEE e situação de déficit ou superávit. .96

Tabela 9 - Comparação da Análise de correlação espacial 1978 e 2008 com distância de 25 km.

Tabela 10 - Exemplo simplificado para os dois tipos de padronização para Benefícios.

Tabela 11 - Exemplo simplificado para os dois tipos de padronização para custo.

Tabela 12 - Síntese das variáveis da Análise Multi-critério segundo Custos e Benefícios.

Tabela 13 - Ranking de critérios conforme as preferências dos critérios

Tabela 14 - Análise Multicriterial do Monitoramento das Águas Superficiais do Estado de São Paulo: Ano 1980

Tabela 15 - Análise Multicriterial do Monitoramento das Águas Superficiais do Estado de São Paulo: 
Tabela 16 - Análise Multicriterial do Monitoramento das Águas Superficiais do Estado de São Paulo: Ano 1995

Tabela 17 - Análise Multicriterial do Monitoramento das Águas Superficiais do Estado de São Paulo: Ano 1996

Tabela 18 - Análise Multicriterial do Monitoramento das Águas Superficiais do Estado de São Paulo: Ano 2000.

Tabela 19 - Análise Multicriterial do Monitoramento das Águas Superficiais do Estado de São Paulo: Ano 2004.

Tabela 20 - Análise Multicriterial do Monitoramento das Águas Superficiais do Estado de São Paulo: Ano 2008

Tabela 21 - Divisão do IAEM em classes de Abrangência Espacial do Monitoramento.

Tabela 22 - Síntese da Evolução do IAEM - Índice de Abrangência Espacial do Monitoramento.

Tabela 23 - Evolução do IAEM por classes no período de estudo. 


\section{LISTA DE QUADROS}

Quadro 1 - Estado de São Paulo dividido em 22 UGRHIS com atribuição e principais usos da Água.................54

Quadro 2 - Rio Tietê através das UGRHIS no Estado de São Paulo.

Quadro 3 - Partes da Bacia Hidrográfica do Rio Grande no Território Paulista.

Quadro 4 - Classes dos rios e reservatórios amostrados por ano.

Quadro 5 - Fundação de Laboratórios no Interior do Estado de São Paulo.

Quadro 6 - Origem dos Layers do Banco SP_WATERNET.

Quadro 7 - Formatos do ILWIS.

Quadro 8 - Posição em termos de tamanho da população das Regiões Metropolitanas existentes no Estado de São Paulo em relação as demais Brasileiras 


\section{LISTA DE MAPAS}

Mapa 1 - Pontos da Rede de Monitoramento da Qualidade das Águas-Ano 1983

Mapa 2 - IET- Índice do Estado Trófico da Água- Níveis em 2008

Mapa 3 - Panorama da Evolução da Rede de Monitoramento das águas Superficiais do Estado de São Paulo por meio da Análise Espacial das Médias Móveis do IQA-150 km

Mapa 4 - Panorama da Evolução da Densidade Populacional (hab./ $\mathrm{Km}^{2}$ ) no Estado de São Paulo por meio da Análise Espacial das Médias Móveis $\mathbf{- 1 5}$ km

Mapa 5 - Panorama do Estado de São Paulo segundo representação dos critérios selecionados para construção do IAEM- 1980.

Mapa 6 - Panorama do Estado de São Paulo segundo representação dos critérios selecionados para construção do IAEM- 2008.

Mapa 7 - Panorama da Evolução do IAEM - Índice de Abrangência Espacial do Monitoramento no Estado de São Paulo (1980-2008).

Mapa 8 - Média Estadual do IQA entre 1978-2008 .236 


\section{LISTA DE SÍMBOLOS E SIGLAS}

$\begin{array}{ll}\mu \mathrm{m} & \text { micróns } \\ \mathrm{mg} / \mathrm{L} & \text { miligrama por litro } \\ \mathrm{Cu} & \text { cobre } \\ \mathrm{Fe} & \text { ferro } \\ \mathrm{P} & \text { fósforo } \\ \mathrm{N} & \text { nitrogênio } \\ \text { Zn } & \text { zinco } \\ \text { AHP } & \text { Analytic Hierarchy Process } \\ \text { CAD } & \text { Computer Aided Design } \\ \text { DBMS } & \text { Database Management System } \\ \text { DF } & \text { Data Flow } \\ \text { DSS } & \text { Decision Support System } \\ \text { DXF } & \text { Drawing Interchange File Format } \\ \text { ER } & \text { Entity Relationship } \\ \text { ETM+ } & \text { Enhaced Tematic Mapper, plus } \\ \text { GIS } & \text { Geographic Information System } \\ \text { GPS } & \text { Global Positional system } \\ \text { GCP } & \text { Ground Control Points } \\ \text { GEMS/Water } & \text { Global Environmental Monitoring System/Water } \\ \text { IAP } & \text { Índice de Qualidade de Águas Brutas para Fins de } \\ & \text { Abastecimento Público } \\ \text { IB } & \text { Índice de Balneabilidade } \\ \text { ID } & \text { Identificador único } \\ \text { IET } & \text { Índice de Estado Trófico } \\ \text { ISTO } & \text { Índice das Substâncias Tóxicas e Organolépticas } \\ \text { IQA } & \text { Índice de Qualidade de Água } \\ \text { IVA } & \text { Índice de Qualidade de Águas para Proteção da Vida } \\ & \text { Aquática } \\ \text { ILWIS } & \text { Integrated Land and Water Information System } \\ \text { LRIS } & \text { Land Resource Information System } \\ \text { LU } & \text { Land Unit } \\ \text { LUP } & \text { Land Use Planning } \\ \text { NC } & \text { Não Calculado } \\ \text { MCE } & \text { Multi-Criteria Evaluation } \\ \text { PPA } & \text { Plano Plurianual } \\ \text { RS } & \text { Remote Sensing } \\ \text { SR } & \text { Sensoriamento Remoto } \\ \text { SSDM } & \text { Structured System Development Methodology } \\ \text { TM } & \text { Tematic Mapper } \\ \text { pH } & \text { Potencial hidrogeniônico } \\ \text { OD } & \text { Oxigênio Dissolvido } \\ & \\ & \\ & \end{array}$


DBO

CETESB

CETESB

$\mathrm{CRH}$

$\mathrm{CBHS}$

CONAMA

CONCAR

DAEE

EIA

EMPLASA

FEAM

IGAM

IBGE

INPE

OMS

ONG

ONU

$\mathrm{PCH}$

PDI

PERH

PNUMA

RMBS

RMC

RMSP

SABESP

SEADE

SEAQUA

SIG

SIGRHI

SIRGAS

SPRING

UC

UGRHI

CEE

CMMAD

CNUMAD

CNUMAH

EPA

ITC
Demanda Biológica (ou Bioquímica) de Oxigênio

Companhia Ambiental do Estado de São Paulo (após 2009)

Companhia de Tecnologia de Saneamento Ambiental (até julho de 2009)

Conselho estadual de Recursos Hídricos

Comitês de Bacias Hidrográficas

Conselho Nacional do Meio Ambiente

Comissão Nacional de Cartografia

Departamento de Águas e Energia Elétrica

Estudo de Impacto Ambiental

Empresa Metropolitana de planejamento Metropolitano S/A

Fundação Estadual de Meio Ambiente

Instituto Mineiro de Gestão das Águas

Instituto Brasileiro de Geografia e Estatística

Instituto Nacional de Pesquisas Espaciais

Organização Mundial de Saúde

Organização Não-governamental

Organização das Nações Unidas

Pequenas Centrais Hidrelétricas

Processamento Digital de Imagens

Plano Estadual de Recursos Hídricos

Programa das Nações Unidas para o Meio Ambiente

Região Metropolitana da Baixada Santista

Região Metropolitana de Campinas

Região Metropolitana de São Paulo

Companhia de Saneamento Básico do Estado de São Paulo

Fundação Sistema Estadual de Análise de Dados

Sistema Estadual de Administração da Qualidade Ambiental, Proteção, Controle e Desenvolvimento do Meio Ambiente e Uso Adequado dos Recursos Naturais

Sistema de Informação Geográfica

Sistema Integrado de Gerenciamento de Recursos Hídricos Sistema de Referência Geocêntrico para as Américas

Sistema de Processamento de Informações Georreferenciadas

Unidade de Conservação

Unidade de Gerenciamento de Recursos Hídricos

Comunidade Econômica Européia

Comissão Mundial sobre Meio Ambiente e Desenvolvimento

Conferência das Nações Unidas para o Meio Ambiente e Desenvolvimento

Conferência das Nações Unidas sobre o Meio Ambiente Humano

Environmental Protection Agency

ITC-Faculty of Geo-Information Science and Earth Observation 


\section{SUMÁRIO}

APRESENTAÇÃO

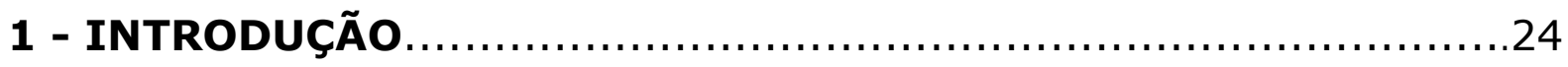

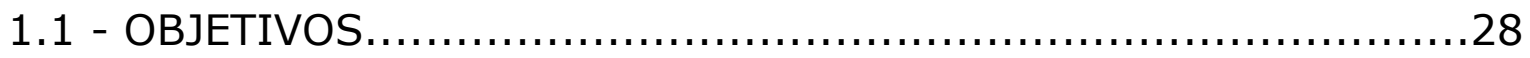

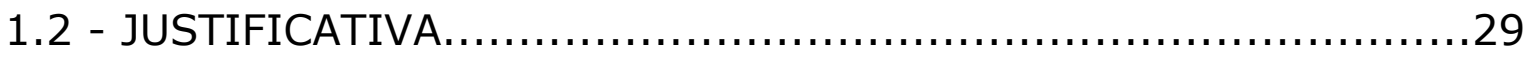

1.3 - HIPÓTESE PRINCIPAL........................................... 30

1.4 - HIPÓTESE SUBJACENTE.......................................... 31

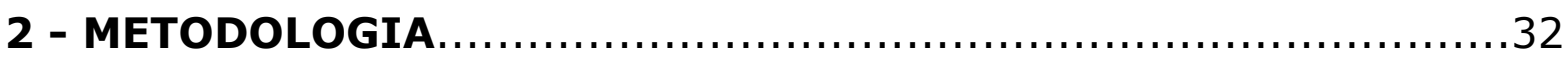

2.1 - RECURSOS TEÓRICO-METODOLÓGICOS...........................32

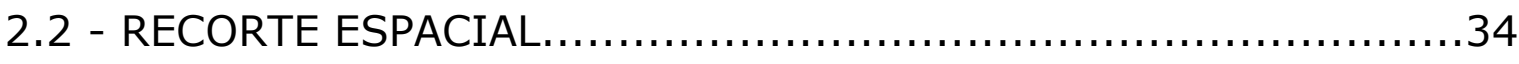

2.3 - RECORTE TEMPORAL.............................................. 35

2.4 - ANÁLISE ESPACIAL............................................... 36

2.5 - FUNDAMENTOS TEÓRICO-METODOLÓGICOS........................38

2.5.1 - Relacionamentos das Geotecnologias dentro da Moderna Geografia com outras ciências...................38

3 - BASES CONCEITUAIS SOBRE O MONITORAMENTO DA QUALIDADE AMBIENTAL DAS ÁGUAS SUPERFICIAIS

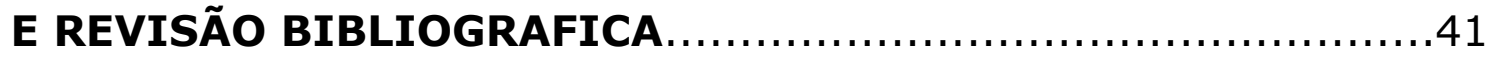

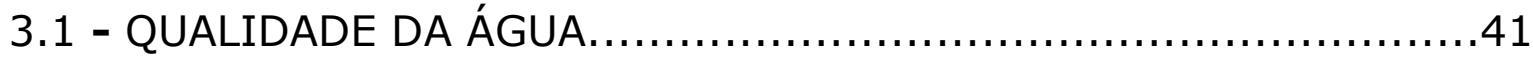

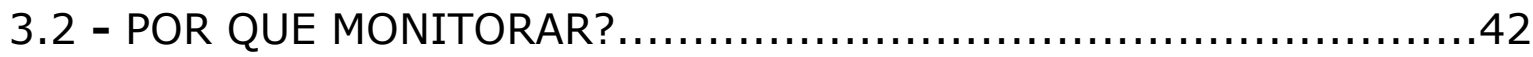

3.3 - OS RIOS DO ESTADO DE SÃO PAULO E A QUALIDADE DE ÁGUA.

4 - EVOLUÇÃo DA LEGISLAÇÃo NO ESTAdO DE SÃo PAULO NO GERENCIAMENTO DOS RECURSOS HÍDRICOS.

4.1 - A CLASSIFICAÇÃO E ENQUADRAMENTO DOS CORPOS D'ÁGUA. 
5 - A REDE DE QUALIDADE DE ÁGUAS SUPERFICIAIS

PAULISTA - BREVE HISTÓRICO.

6 - ÍNDICE DE QUALIDADE DAS ÁGUAS - IQA.

6.1 - A RAZÃO DA EXISTÊNCIA DOS ÍNDICES DE QUALIDADE DE ÁGUA E SUA EVOLUÇÃO. TENDÊNCIAS DE CIÊNCIAS

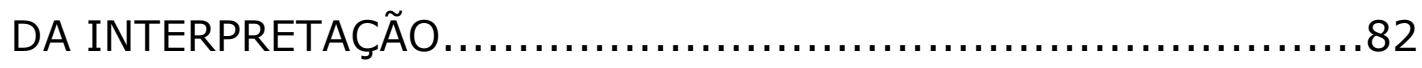

6.2 - A RELAÇÃO DE PONTOS POR ÁREA: DENSIDADE ESPACIAL DA REDE DE MONITORAMENTO SUPERFICIAL DA CETESB........90

6.3 - EXEMPLOS DE REDES E DENSIDADE DE MONITORAMENTO EM OUTROS PAÍSES.

7 - DESENVOLVIMENTO DO PROJETO GIS SP_WATERNET

7.1 - OS PRINCIPAIS MÉTODOS DE ABORDAGEM DA CARTOGRAFIA MODERNA.

7.2 - CONSIDERAÇÕES SOBRE A ESCOLHA DA PLATAFORMA DE GEOPROCESSAMENTO.

7.3 - METODOLOGIA DE CONSTRUÇÃO DO GIS WATERNET. 112

7.4 - AQUISIÇÃO DE BASES PARA ANALISE ESPACIAL..................115

7.5 - PRODUTOS ESPERADOS ........................................ 118

7.6 - PRINCIPAIS FORMATOS DO ILWIS..............................121

8. DO DADO DO PONTO A INFORMAÇÃO: A CARACTERIZAÇÃO GEOGRÁFICA DOS PONTOS DE MONITORAMENTO DA REDE DE QUALIDADE DE ÁGUA - A CONSTRUÇÃo DA BASE PARA ANÁLISE ESPACIAL.

8.1 - ALGUNS TIPOS DE ANÁLISE ESPACIAL UTILIZADAS

EM GEOTECNOLOGIAS

8.2 - ANÁLISE ESPACIAL COM A OPERAÇÃO PONTO MAIS

PRÓXIMO (NEAREST POINT) DO ILWIS

8.3 - ANÁLISE ESPACIAL COM A MÉDIA MÓVEL - MOVING 
AVERAGE DO ILWIS.

\section{9 - A URBANIZAÇÃO E QUALIDADE AMBIENTAL DOS}

RECURSOS HÍDRICOS.

9.1 - A URBANIZAÇÃO DO ESTADO DE SÃO PAULO....................137

9.2 - OS RIOS DAS GRANDES CIDADES: FUTUROS CANAIS DE ESGOTO SEMELHANTES À CIDADE DE SÃO PAULO? 144

9.3 - DADOS DE POPULAÇÃO. 154

\section{0 - A ANÁLISE MULTI-CRITÉRIO E A GERAÇÃO DO ÍNDICE} DE ABRANGÊNCIA ESPACIAL DO MONITORAMENTO.

10.1 - A IMPORTÂNCIA DA PADRONIZAÇÃO.

10.2 - FASE DE DEFINIÇÃO DE PRIORIDADES E DE ATRIBUIÇÃO DOS PESOS.

10.3 - O IAEM - ÍNDICE DA ABRANGÊNCIA ESPACIAL DO MONITORAMENTO DA QUALIDADE DA ÁGUA.

10.4 - PRINCIPAIS RESULTADOS DO NOVO ÍNDICE. 185

10.5 - INTERPRETAÇÃO DOS RESULTADOS DA ANÁLISE MULTI-CRITÉRIO PARA O IAEM.

10.6 - CENÁRIO DO IAEM PARA O ANO DE 1980 190

10.7 - CENÁRIO DO IAEM PARA O ANO DE 1991

10.8 - CENÁRIOS DO IAEM PARA OS ANOS 1995 E 1996 194

10.9 - CENÁRIOS DO IAEM PARA OS ANOS 2000

10.10 - CENÁRIO DO IAEM PARA OS ANOS 2004 199

10.11 - CENÁRIO DO IAEM PARA OS ANOS 2008. 203

CONCLUSÕES 212

REFERÊNCIAS BIBLIOGRÁFICAS .214

ANEXOS. .230 


\section{APRESENTAÇÃO}

A velocidade da evolução tecnológica, presente em todas as áreas do conhecimento, faz com que de tempos em tempos as pessoas envolvidas nesse universo busquem oportunidades de adquirir, atualizar e, se possível, contribuir com novas interpretações para as diversas formas de leitura dos problemas ambientais atuais.

No começo de 2005 senti necessidade de retornar aos estudos e procurei o Departamento de Geografia da Universidade de São Paulo com esse intuito. Quando do ingresso no Programa de Pós-Graduação em Geografia Humana em nível de Doutorado estive primeiramente sob a orientação acadêmica do Prof. Dr. Marcello Martinelli. Posteriormente, em março de 2006, a orientação passou a ser feita pelo Prof. Dr. Reinaldo Paul Pérez Machado, ambos pertencentes ao Departamento de Geografia Humana da FFLCH. É sempre importante resgatar, consolidar e desenvolver novos conhecimentos na área de Geografia, e sintonizá-los com minha atividade profissional, exercida ao longo de mais de 20 anos na CETESB- Companhia Ambiental de São Paulo.

A riqueza de conhecimentos oferecida em ambas às instituições, quer seja pela multidisciplinaridade que a área ambiental exige do profissional que atua nesse seguimento, quer seja pelo fato da Geografia ser ainda uma das últimas escolas que oferece a possibilidade de transdisciplinariedade, favorece que conhecimentos valiosos e variados adicionem e mesclem-se em novas tentativas de compreensão do espaço e as suas interações sócio-ambientais do mundo real. E é esta faceta de conhecimento abrangente e holístico que, no meu entendimento, pode oferecer abundantes elementos que possibilitam a compreensão do espaço e suas multi-interações através do tempo.

O segundo motivo é a grande preocupação com a intensa pressão sobre os corpos hídricos e a possível perda de sua integridade ecológica, em virtude do crescimento das áreas urbanizadas em todo mundo. Até as 
áreas mais remotas e outrora desprezadas já estão ocupadas, se para moradias, ou qualquer outra atividade relacionada à exploração dos recursos naturais, em cujo processo o uso da água está incluso.

Tendo em vista que não podemos almejar com uma diminuição espontânea da pressão exercida pelos usos antrópicos do planeta, qualquer que seja o cenário futuro, a presença e a demanda por água limpa, se possível potável, será sempre desejável e muito valorizada. Portanto, considero imprescindível neste momento, uma maior participação da Geografia no cenário do planejamento territorial e ambiental, com destaque para a gestão de recursos hídricos.

A água enquanto tema já esteve presente em outros momentos da minha vida acadêmica, tais como no ano de 1986, quando procurei aperfeiçoamento no exterior, em um curso de pós-graduação no ITC (Faculty of Geo-Information Science and Earth Observation), com sede em Enschede - Holanda, onde apresentei como trabalho de conclusão do curso Rural and Land Ecology Survey estudos de análise comparativa sobre o potencial turístico do número de cachoeiras existentes em cada um dos vales, cujas cachoeiras foram identificadas conforme seu L.U.T. (Land Utilization Type), apropriadas para usos de recreação e lazer no norte da Tailândia, através do relatório "Analysis of the Recreational Resources of the Mae Sa Valley Area".

No período de 1990 a 1994, voltei ao Departamento de Geografia da USP, para a realização do mestrado, que versava sobre o tema "Turismo e Meio Ambiente no Litoral Paulista - Dinâmica da Balneabilidade nas Praias", que também vinculava o uso do litoral para o lazer, e vinculava o tema com a perda da qualidade de águas costeiras.

Agora, dando prosseguimento aos estudos, desenvolvi durante este doutoramento, um novo índice que procura interpretar o desempenho do monitoramento da CETESB através da evolução espacial da densidade da rede de monitoramento, e das respectivas médias de índices de qualidade de água, estabelecendo uma correlação entre o crescimento populacional através da evolução da taxa de densidade populacional, e em função do 
macro-uso do solo no Estado de São Paulo. Os reflexos desse crescimento podem ser visualizados por esta análise espacial. O intuito é estabelecer um indicador que sintetize a abrangência espacial da rede, apoiado por uma plataforma de geoprocessamento desenvolvida no SIG (Sistema de Informação Geográfico), Integrated Land and Water Information System - ILWIS que subsidiará este estudo. Uma vez consolidado, poderá ser usado para favorecer estudos de alterações e ampliação de rede de monitoramento, diagnósticos ambientais e instrução de políticas públicas de proteção ambiental e o uso adequado dos recursos hídricos, não somente para o Estado de São Paulo, mas para outros estados ou municípios que tenham planos diretores, zoneamento e mapeamento de uso do solo. 


\section{1 - INTRODUÇÃO}

A conservação dos recursos naturais é hoje um grande desafio para a sociedade; e a água é com certeza um dos recursos mais preciosos a ser preservado. A possibilidade de uso de geotecnologias aplicada ao gerenciamento dos recursos hídricos transformou-se hoje, em instrumento importante na compreensão da dinâmica da água, tanto para seu gerenciamento integrado quanto para a análise espacial das variáveis que interferem em sua qualidade.

Para a elaboração deste estudo, foram utilizados alguns instrumentos integrantes das geotecnologias tais como: GPS (Geographic Posicion System), GIS (Geoinformation System), Sensoriamento Remoto e softwares desenvolvidos para análise espacial. Essas técnicas modernas estão presentes em vários ramos de pesquisa atuais da Geografia, o que permite ao Geógrafo consolidar e integrar várias áreas de conhecimento da Geografia, no pleno exercício de suas atividades. Na gestão de recursos hídricos, é essencial concatenar respostas para poder entender e superar as limitações impostas pelo meio físico e, ao mesmo tempo, atender aos anseios do bem estar das populações. O planejamento quando bem executado poderia fornecer o equilíbrio necessário nas tomadas de decisão sobre uso e gerenciamento de bacias hidrográficas, manejo e irrigação da agricultura, aproveitamento energético dos recursos naturais, controle e prevenção de enchentes e o monitoramento da poluição das águas superficiais, subterrâneas e costeiras.

Este estudo pretende resgatar e integrar as informações sobre qualidade de água dos recursos hídricos do Estado de São Paulo ao longo dos últimos 30 anos, buscando a sua sistematização dentro de um SIG para entender a distribuição espacial de dados com o propósito de analisar a qualidade da água, com a capacidade de relacioná-los com estudos de trechos críticos que já sofrem impacto ambiental. 
A Natureza é a soma de um grande número de variáveis ambientais e, na tentativa de representá-la fielmente, vários dados são gerados todos os dias. Também são muitas as intervenções humanas cotidianas que interferem na qualidade do recurso hídrico, quer seja para abastecimento humano ou industrial, geração de energia, agricultura, transporte, recreação ou principalmente quando usados para o lançamento de efluentes domésticos ou industriais. Esses usos e os reflexos de nossa vida em sociedade resultam nos chamados impactos antrópicos e nas respostas naturais do meio físico. Estamos assim, todos expostos as transformações em qualquer que seja a escala: local, regional ou mesmo como estamos vendo mais recentemente, em amplitude global.

A interpretação de um momento na natureza requer que sejam trabalhados praticamente ao mesmo tempo e de modo integrado inúmeras facetas, que são fundamentais para compreender a dinâmica das relações entre o Homem e o meio ambiente. Transportando-se estas mesmas relações para 0 ambiente fluvial de rios e reservatórios percebemos a presença de nossa existência através dos impactos no ambiente aquático, que é demandado de modo intermitente por múltiplos usuários a sua volta, e notamos que a vida de outros seres que ali habitam é relegada a um segundo plano ou praticamente esquecida. Portanto, a tarefa de monitorar estas alterações com sensibilidade para atender a tantos não é uma tarefa simples.

Segundo Zonneveld (1989), estas interações ocorrem dentro de um ambiente cósmico, regidos pelas relações existentes da ecologia da paisagem (ciência que investiga as relações entre as ciências naturais meio biótico - com processos e enfoques analíticos das ciências humanas) onde os grandes atributos dividem-se em partes, por ele definidas como L.U. (Land Units) ${ }^{1}$, que se integram e interagem entre si, seguem hierarquias dentro da teoria holística, conforme figura 1, a seguir:

\footnotetext{
1 "The land unit, as an expression of landscape as a system, is a fundamental concept in landscape ecology. It is an ecologically homogeneous tract of land at
} 
Figura 1 - Os fatores e as características da Terra.

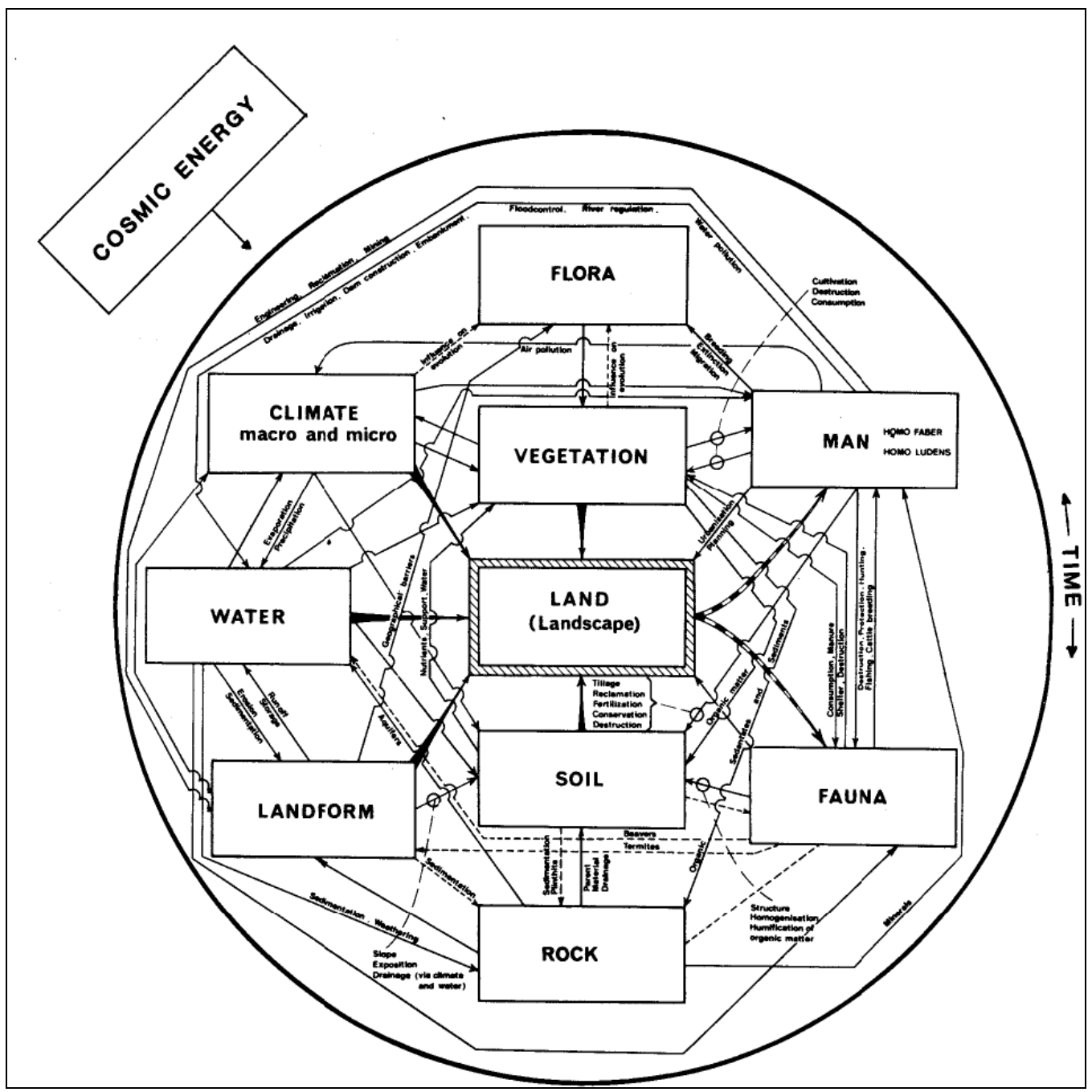

Fonte: ZONNEVELD, 1989, p.69.

Dentre suas principais contribuições, destaca-se que a Ecologia da Paisagem ajuda a compreender a teoria holística: "Holism is based on the hypothesis that nature consists of a hierarchy of 'wholes' (holons): quarks - protons - atoms - molecules - minerals - living cells - tissues organisms - population - society" (ZONNEVELD, 1989, p.70). Afinal, tenta descrever de forma hierárquica o papel da natureza e da sociedade dentro de um sistema total.

the scale at issue. It provides a basis for studying topologic as well as chorologic landscape ecology relationships." (ZONNEVELD, 1989, p.67) 
Dentro da concepção de sistema, as formas e as paisagens, como se fossem parte de um ser, percebem e registram os fenômenos que ocorrem em seu entorno. É um processo que não tem fim e necessita constantemente de interpretações, quer sejam elas globais (agregadoras de vários componentes), ou segmentadas e detalhadas como em unidades de paisagem.

O autor destaca ainda que cada pesquisador deve se sentir livre para tentar obter esta visão: "Within the land unit approach there is considerable freedom in the way in which the various land attribute data are 'integrated"' (ZONNEVELD, 1989, p.67). No entanto, ressalta que o mesmo deve ater-se principalmente a tentar responder algumas perguntas: Qual é o atributo dominante no seu estudo? Solo, água ou clima? Depois, tentar caracterizar os fatores que influenciam estes atributos em termos de hierarquia, e verificar as relações com os demais componentes analisados. Nas palavras do autor, temos:

Which land attribute is dominant? The question of dominance has three aspects: 1 . Which attribute determines (in the first place) the character of the unit? 2. Which attribute determines its quality for a certain purpose? 3. Which attribute determines the map image, or the pattern? (ZONNEVELD, 1989, p.75)

E ele mesmo nos responde:

A land unit survey aims at mapping such land units. This is done by simultaneously using characteristics of the most obvious (mappable) land attributes: landform, soil and vegetation (including human alteration of these three). The land unit is the basis of the map legend but may be expressed via these three land attributes. The more dynamic land attributes, such as certain animal populations and water fluxes, are less suitable as diagnostic criteria, but often links units by characteristics information/energy fluxes. (ZONNEVELD, 1989, p.67)

Neste estudo, as Land Unit serão as UGRHIs (Unidades de Gerenciamento de Recurso Hídrico) paulista, que foram delimitadas artificialmente baseadas no conceito de bacia hidrográfica, ainda que não 
atendam exatamente o conceito proposto por Zonnenveld, enquanto um sistema bem definido firmadas principalmente em unidades naturais, mas que de certa forma se aproximam delas enquanto partes de uma bacia hidrográfica.

Portanto, do ponto de vista interativo, entre o espaço dominado pela natureza e o espaço dominado pelo homem, o desenvolvimento desta análise está apoiado na necessidade desta constante aquisição, manipulação e compreensão dos fluxos de dados com importância espacial, tais como os monitoramentos, necessários para acompanhar e avaliar as interferências antrópicas sobre as múltiplas finalidades de uso dos recursos hídricos. E, por conseguinte, a necessidade de tradução da realidade ambiental em forma de mapas sínteses.

\section{$1.1-$ OBJETIVOS}

Os objetivos principais deste estudo são: fazer uma análise espacial e temporal da evolução dos pontos da rede de monitoramento pertencentes à rede de qualidade ambiental nos principais rios paulistas no que tange à contaminação e à possível perda da qualidade, por recepção e exposição direta dos mesmos por águas contaminadas por lançamentos de cargas poluidoras, especialmente de origem doméstica, que, em muitos casos, não possuem qualquer tipo de tratamento e avaliar assim a performance da rede.

O instrumento proposto para a realização destas análises é um SIG, que permite relacionar os resultados das medias anuais do IQA (Índices de Qualidade de Água), desde a primeira publicação de seus resultados em 1978, ou seja, no período correspondente a 30 anos de existência da rede de monitoramento. No período referido, o fenômeno da urbanização e a intensificação do uso e ocupação do solo, sem o devido planejamento, provocaram alterações prejudiciais ao meio ambiente. Como resultado, este trabalho identificou as áreas mais sensíveis a este processo, que são 
evidenciadas através de um índice proposto que verifica, entre outras coisas, a vulnerabilidade da rede de monitoramento. Áreas estas que, uma vez identificadas, poderão se tornar prioritárias em termos de recuperação na elaboração de políticas públicas e na aplicação de recursos financeiros, como na tomada de decisão por parte dos gestores dos recursos hídricos em comitês de bacia hidrográfica de sua competência, fato este bastante desafiador frente às pressões ambientais que incidem sobre este tema.

\section{2 - JUSTIFICATIVA}

A análise espacial auxiliada por um SIG permite identificar áreas mais vulneráveis à perda de qualidade através do IQA-CETESB, ao longo de 30 anos de existência da rede, e poderá retratar como e onde o fenômeno da urbanização provocou as alterações e modificações do uso do solo (urbano) mais prejudiciais e identificar quais prioridades de ação para conservação da qualidade de água poderia ajudar a interromper esse processo de queda de qualidade de água.

A análise temporal e espacial, enquanto resultado da interpretação do conjunto das variáveis (ambientais e sociais) apresentado nesta pesquisa, juntamente com índice resultante da avaliação multi-critério das densidades espaciais demográficas e de cobertura do monitoramento da água, possibilitará a compreensão e o entendimento da necessidade de manutenção, atualização e evolução da rede de monitoramento de águas superficiais no Estado.

Tal índice permitirá a discussão da necessidade ou não, da redução, adaptação ou ampliação do número de pontos, ou auxiliará no desenho de futuras redes de monitoramento, a fim de atender aos propósitos da aplicação de políticas públicas mais vigorosas, que venham a ser definidas, de modo a proteger e recuperar os recursos hídricos do Estado de São Paulo. 
Já o uso da geotecnologia, esta presente neste projeto de estudo através do Sistema de Informações Geográficas (SP_WATERNET), que foi criado especialmente para servir de plataforma para resgate de antigos resultados e visualização das análises espaço-temporal. Enquanto produto, esses mapas poderão balizar as tomadas de decisão por parte do poder público e da iniciativa privada, tanto para o direcionamento da aplicação de recursos públicos voltados às prioridades do saneamento ambiental, quanto para os investimentos privados nas bacias hidrográficas, dentro dos limites territoriais do Estado de São Paulo.

Ressalte-se ainda que os resultados esperados para este estudo devem permitir a identificação e a análise crítica dos problemas ambientais, na representação espacial do tema, bem como as expectativas futuras para as coleções de águas superficiais no Estado de São Paulo.

\section{3 - HIPÓTESE PRINCIPAL}

Este estudo pretende verificar como o crescimento da rede de monitoramento de águas interiores da CETESB acompanhou ao longo dos seus mais de 30 anos de existência o ritmo da presença do ciclo gerador de pressão sobre os recursos hídricos onde a Pressão Populacional (PP) e a Pressão Antrópica (PA) sobre uso do solo atuam em conjunto sobre o Impacto sobre Recurso Hídrico (IRI) que resulta na perda do status da qualidade das Águas. A urbanização demanda cada vez mais água em quantidade e em qualidade (mais limpa) e devolve cada vez mais a água com pior qualidade (mais suja). Caso o fenômeno da urbanização e do adensamento populacional das cidades tenham correlação espacial com a queda da qualidade da água, pretende-se apresentar um novo índice que os integre. 


\section{4 - HIPÓTESE SUBJACENTE}

A relação entre os dois fenômenos será baseada na criação de um índice de abrangência da rede do monitoramento superficial paulista. Ele vai ser obtido através da avaliação multi-critério entre o fator ambiental, que será composto por variáveis referentes ao gerenciamento da qualidade da água: número de pontos existentes, o valor médio do IQA destes pontos e o índice de densidade de pontos de monitoramento utilizado pela CEE (Comunidade Européia) e por variáveis atreladas ao fator antrópico, que incorporam atributos socioeconômicos (uso do solo preponderante para cada unidade de gerenciamento de recursos hídricos e a densidade populacional que habita esta área). O novo índice então, de forma sintética, seria competente tanto para avaliar a abrangência espacial do monitoramento nas várias UGRHIs, como para contemplar a influência que os fenômenos espaciais descritos estariam tendo através dos anos, e, avaliando enfim o desempenho da rede de monitoramento. 


\section{2 - METODOLOGIA}

\section{1 - RECURSOS TEÓRICO-METODOLÓGICOS}

\section{- Campos de conhecimento}

O Estado de São Paulo, através de suas Secretarias Estaduais de Recursos Hídricos e de Meio Ambiente, e autarquias, tais como DAEE, $\mathrm{CTH}$, CETESB, entre outros órgãos integrantes do SEAQUA- Sistema Estadual de Administração da Qualidade Ambiental, Proteção, Controle e Desenvolvimento do Meio Ambiente e Uso Adequado dos Recursos Naturais, dispõe de uma série de informações ambientais imprescindíveis que fornecem subsídios para a interpretação e para identificação de possíveis corpos hídricos cujas com águas e sedimentos estejam contaminados, degradados e em estado de morte.

Baseado na riqueza de dados sobre qualidade de água que são gerados pela rede de monitoramento de águas superficiais da CETESB e divulgados anualmente através de seus relatórios e, considerando-se também relatos e opiniões da população que convive com rios que não oferecem mais atrativos, nem mesmo como composição paisagística, pode-se notar que a população percebe a queda de qualidade na água e não consegue entender se a rede de monitoramento, nos dias de hoje, é capaz de para atender as necessidades de avaliação em função da área de estudo que abrange. A percepção é de que a presença do Estado, no que se refere a monitoramento, é sempre insuficiente, ou seja, o Estado não constata o que esta acontecendo. 
Tal fato demonstra que em função do crescimento populacional do Estado de São Paulo, a demanda por água de boa qualidade tanto para o abastecimento, quanto para as demais atividades que envolvem grande volume de consumo deste bem - indústria e agricultura - a rede de monitoramento parece ter ficado pequena (insuficiente). E, embora nunca tenha parado de se expandir, a rede é algumas vezes questionada, se representa com segurança e equivalência espacial, os reflexos do uso das águas superficiais no Estado de São Paulo. Indubitavelmente, o que não se compreende realmente é que depois de monitorados e identificados os impactos nos rios, estas fontes de poluição deveriam ter suas causas minimizadas e controladas, a fim de devolver a condição de qualidade original/natural do rio, através de um processo de restauração da qualidade hídrica e da vida aquática.

É importante ressaltar que a falta de tratamento de esgoto, além de perda de qualidade dos rios, vai influenciar também no delicado aspecto das mudanças climáticas de origem antropogênica, pois contribui com a emissão de gás metano em rios onde o parâmetro de monitoramento OD (Oxigênio Dissolvido) esteja muito próximo as condições de anoxia (OD próximo perto de 0 ), portanto abaixo dos padrões de qualidade. Rios e reservatórios que servem de destino final para efluentes não tratados, tem processos anaeróbicos, emitindo gases de efeito estufa (metano) semelhantes a lagoas de tratamento e disposição de efluentes líquidos e sólidos mal operados.

Com isto, este projeto de doutorado estará de certa forma em consonância com as propostas das Metas do Milênio (MDGs- Millenium Development Goals), estabelecidas na Conferencia das Nações Unidas de Johanesburgo, e com a Década Internacional da Água (2005-2015) "A água, fonte de vida", cujo símbolo pode ser visto na figura 2, ambas para serem atingidas no até 2015. Dentre as 8 metas do Milênio a serem atingidas, destaca-se a meta 7 (Goal 7: Ensure Environmental Sustainability) que diz respeito a sustentabilidade e refere-se as condições de acesso a água potável e ao tratamento correto de efluentes. 
Figura 2 - Símbolo da Década da Água.

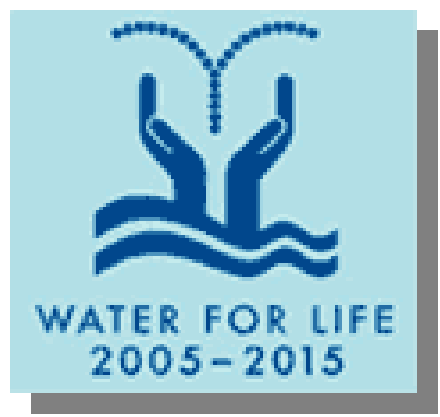

Fonte: ONU - Organização das Nações Unidas. Disponível em: <http://www.un.org/ waterforlifedecade/wdlogo.html>. Acesso em: 23 de setembro de 2009.

Dentro desse contexto dinâmico e de transformação permanente, é aconselhável contar com o uso de Geotecnologias. Para tanto, deve-se analisar a configuração geográfica das bacias hidrográficas e providenciar a geração de produtos, tais como: mapas com as médias anuais sobre a qualidade de águas referenciais das unidades de gerenciamento dos recursos hídricos; mapas de densidade populacional; mapas de densidade da rede de monitoramento, e mapas com o índice proposto neste estudo.

Nesse sentido, consultado-se especialistas e institutos internacionais em geoprocessamento com o intuito de adquirir conhecimento necessário para o desenvolvimento do tema proposto. Os produtos possíveis e gerados neste estudo, com o uso de um sistema de informação geográfico, com certeza irão nortear a aplicação de políticas públicas para a proteção e recuperação dos sistemas hídricos, bem como os investimentos da iniciativa privada, ao considerar a sustentabilidade do empreendimento em relação à qualidade da água disponível na região escolhida.

\section{2 - RECORTE ESPACIAL}

A área de estudo deste trabalho é o Estado de São Paulo, localizado na região Sudeste do Brasil. São Paulo e seus 645 municípios foram 
subdivididos em 22 UGRHIs (Fig. 3), que são utilizadas pelo governo paulista como as unidades de planejamento territorial e de recursos hídricos. A escolha de se realizar as análises e interpretações por meio de um SIG é em função da componente espacial estar atrelada a alguns indicadores usados neste estudo: a densidade de pontos de monitoramento e o crescimento populacional (densidade populacional) nas UGRHI's, juntamente com as outras variáveis definidas por este estudo.

\section{Figura 3 - Vista do Estado de São Paulo e a Divisão por UGRHIS.}

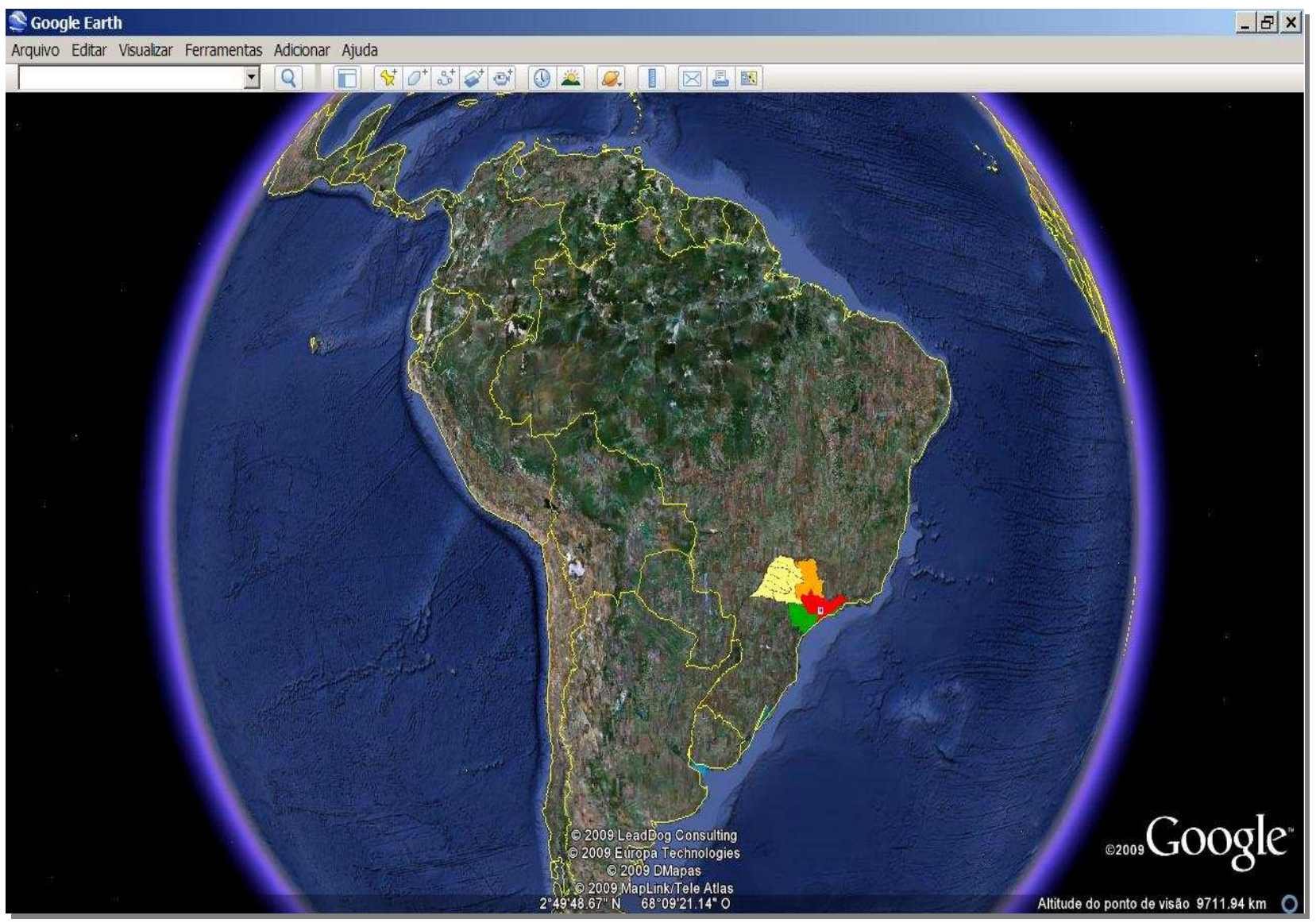

Fonte: GOOGLE EARTH, 2008.

\section{3 - RECORTE TEMPORAL}

O período definido para a avaliação da qualidade de água do Estado de São Paulo é de 30 anos. Tal intervalo de tempo permitirá que a 
avaliação reflita com segurança os objetivos elencados para este trabalho, bem como a confirmação ou não da hipótese sugerida. Isso somente é possível em virtude de se possuir uma base de dados consistente no órgão ambiental do Estado de São Paulo (CETESB), que, por meio de um índice de qualidade de água (IQA), avalia os rios deste Estado ao longo de todo o universo amostral escolhido.

\section{4 - ANÁLISE ESPACIAL}

A análise espacial consiste basicamente em maneiras de visualizar, analisar e modelar dados e/ou informações geográficas distribuídas no espaço. Pode ser feita de forma manual ou computadorizada. Procura associar seu padrão de distribuição aos fatos apresentados e relacionar e explicar padrões de distribuição em função de algum tipo relação, como por exemplo, de vizinhança, proximidade e a dependência espacial entre eles.

Segundo Câmara et al. (2002), é muito importante neste tipo de estudo "compreender a distribuição espacial de dados oriundos de fenômenos ocorridos no espaço constitui hoje grande desafio para a elucidação de questões centrais em diversas áreas do conhecimento, seja em saúde, em ambiente, em geologia, em agronomia, entre tantas outras".

Neste estudo, o interessante é perceber o estado da qualidade dos pontos de monitoramento de água, associado aos dados provenientes desses locais no espaço e delinear áreas que ofereçam conforto, saúde e respeito à natureza, ou seja, com completa qualidade ambiental e do mesmo modo, poder observar situações adversas. Segundo o autor opus cit. dentro da taxonomia por ele apresentada, este tipo de análise espacial é definida como sendo de superfície contínua, onde os problemas são analisados a partir de um conjunto de amostras de campo, regular ou 
irregularmente distribuídas, geralmente utilizadas para avaliação de recursos naturais.

A aplicação da geotecnologia, em constante desenvolvimento e aprimoramento, permite trabalhar simultaneamente com diversas áreas do conhecimento em suas questões centrais com as interfaces ambientais, em virtude do sistema de informação geográfica (SIG), que possibilita a visualização espacial em conjunto de variáveis como: índices de qualidade de água, crescimento populacional, recursos hídricos, uso e ocupação do solo e outros, por meio de mapas gerados por esse tipo de sistema. Para tanto, basta dispor-se de um banco de dados consistente com base geográfica que atenda as necessidades do projeto. O SIG transforma esses dados em informação geográfica, dando-Ihe um padrão espacial sobre o fenômeno escolhido, e este pode ser visualizado após operações de analise espacial, por meio de mapas temáticos.

A questão central da análise espacial é a de mensurar propriedades e relacionamentos, considerando a localização espacial do fato a ser estudado, ou seja, incorpora-se o espaço à análise que se deseja fazer. As análises espaciais de dados ambientais, associadas a dados sócioeconômicos, são compostas por um conjunto de procedimentos ligados entre si, cuja finalidade é a de escolher um modelo inferencial que considere explicitamente os relacionamentos espaciais presentes no objeto de estudo. Normalmente, o processo da modelagem é precedido por uma análise exploratória, juntamente com a apresentação visual dos dados em forma de gráficos e mapas individuais, e a identificação de padrões de dependência espacial do tema de estudo.

O termo Sistemas de Informação Geográfica é aplicado para sistemas que realizam o tratamento computacional de dados geográficos e que armazenam a geometria e os atributos dos dados georeferenciados, ou seja, localizados na superfície terrestre e representados em uma projeção cartográfica. Portanto, os procedimentos iniciais de análise espacial incluem um conjunto de métodos de análise e a visualização dos dados, em geral através de mapas temáticos. Tais técnicas permitem 
descrever a distribuição das variáveis do estudo, identificar observações atípicas não só em relação ao tipo de distribuição, mas também em relação aos pontos vizinhos e buscar a existência de padrões na configuração espacial. Por meio desses procedimentos é possível selecionar o modelo inferencial que melhor suporta os dados coletados.

\section{5 - FUNDAMENTOS TEÓRICO-METODOLÓGICOS}

\subsection{1 - Relacionamentos das Geotecnologias dentro da Moderna Geografia com outras ciências}

Procurando não entrar em periódicas e possíveis polêmicas que permeiam as discussões a respeito do objeto da Geografia, e como o assunto é considerado indispensável lhe será dado um breve enfoque.

O que é Geoinformação? É toda informação que tem um atributo de localização ligado a um sistema de referência espacial, isto é, georeferenciada. Significa colocar o fato em uma posição espacial com compromisso geométrico, latitude, longitude e altitude elipsóidal e, principalmente, amarrar tudo isso a um sistema plano retangular, após o mesmo ter passado por uma geocorreção. Isso significa atribuir ao fenômeno uma projeção cartográfica conhecida.

Segundo Burrough (1986), trabalhar com informação geográfica é mais complicado do que trabalhar com outros sistemas de informação de dados, pois ela tem que incluir obrigatoriamente a informação de posicionamento,

Geographical data are referenced to locations on the earth's surface by using a standard system of coordinates. The coordinates system may be purely local, as in the case of a study of a limited area, or it may be that of a national grid or 
an internationally accepted projection as the Universal Transverse Mercator Coordinate System (UTM). Geographical data are very often recognized and described in terms of well-establishes geographical "objects", or phenomena. All geographical studies have used phenomenological concepts such as town, rivers, floodplain, ecotope, soil association as fundamental building blocks or analyzing and synthesizing complex information. (BURROUGH, 1986, p.13)

\section{- O que é Geotecnologia?}

Embora possa ser considerado abrangente demais, qualquer tema é objeto de estudo da Geografia. Qualquer fenômeno existente ou por acontecer é e será sempre objeto de estudo da Geografia, uma vez que esteja posicionado em relação ao tempo e ao espaço geográfico e passe a produzir relações ambientais e comportamentos relacionados a outros fenômenos já existentes. Portanto, é necessário sempre formular o problema dentro de um enfoque geográfico. A multiplicidade de variáveis passíveis de serem analisadas através de cadeias de dados georeferenciados e informatizados, que aliada à velocidade de capacidade de sua análise, faz hoje com que os geógrafos fiquem cada vez mais atrelados às estas modernas ferramentas de trabalho. Apesar de muito utilizada quando relacionada à Geotecnologia, o termo ferramenta será evitado, pois em sentido lato é um objeto de ferro, e estamos a tratar de um programa de computador, então preferimos utilizar "instrumento" ou ainda "plataforma" utilizados no ramo da Cartografia Digital.

Mas as Geotecnologias não são nem mais nem menos importantes diante de tantas outras infinitas ramificações a que essa ciência geográfica já esteve sujeita. Em geral, a geotecnologia tende a auxiliar a compreender partes de um mesmo todo, e assim deve ser entendida. Pode ser utilizada em várias outras disciplinas. 
Tal qual acontece com outros fenômenos de abrangência espaciais, pesquisadores que se utilizam de Geotecnologias recorrem a contribuições de várias outras ciências de modo que tentam obter uma análise integradora dos aspectos principais enfocados em cada uma delas, obviamente de modo diferenciado. Destarte, baseando-se na riqueza da abrangência multidisciplinar, pode-se observar uma tendência dos estudiosos deste campo em não desprezar aspectos correlacionais.

Por isso, a Ciência Geográfica não deve prescindir em hipótese nenhuma do uso da Tecnologia na Geografia. O potencial da análise geográfica crítica em função da realidade espacializada pode alavancar o desenvolvimento de novas funcionalidades nesses programas, pois hoje, mais do que nunca, a informação vem acompanhada do binômio onde e quando.

As utilizações mais freqüentes das Geotecnologias na Geografia são feitas através de projetos de Ordenamento Territorial, Planejamento Espacial e Urbanismo, monitoramento e gerenciamento de espaços destinados às várias funcionalidades das cidades e também do campo. Com isto, visualizam-se áreas especialmente destinadas para preservação, áreas a serem reflorestadas, desenvolvidas informalmente para habitação, recuperação e conservação de espaços nas margens de rios e lagos, para o lazer, restauração e revitalização de rios, enfim com outros tantos usos que possibilitem a comparação da evolução temporal da paisagem.

Por fim, temos o uso dentro da cartografia temática que, em síntese, objetiva buscar o entendimento sobre as formas físicas espacializadas na natureza provenientes da organização territorial diferenciada dos elos humanos em sua totalidade, através de inúmeras maneiras de interação na superfície terrestre. Essa ciência utiliza-se cada vez mais de dados obtidos por sistemas de posicionamento de navegação por satélite, bancos de dados georeferenciados, cadastros multifinalitários, fotos aéreas e imagens de sensoriamento remoto. E O conjunto destes recursos de diversas origens forma hoje as geotecnologias. 


\section{3 - BASES CONCEITUAIS SOBRE O MONITORAMENTO DA QUALIDADE AMBIENTAL DAS ÁGUAS SUPERFICIAIS E REVISÃO BIBLIOGRAFICA}

\section{1 - QUALIDADE DA ÁGUA}

A quantidade de água na Terra é estável. Ela não diminui, mas pode sofrer mudança de estado em função do clima (vapor, gelo e liquida) e assim alterar a sua disponibilidade em termos de quantidade na superfície. A poluição das águas tem como origem diversas fontes. A alteração da qualidade das águas é um processo natural, pois está sujeita a ação das intempéries, variando conforme a estação climática do ano e a estação hídrica (seca ou chuvosa). Portanto, uma série de analises efetuada ao longo do ano constata oscilações em função dessas variações. A água enquanto recurso natural é o "melhor solvente que se conhece". Nela encontramos um sem número de substâncias e elementos dissolvidos. A Água pura, no ponto de vista químico, é um conceito limite. Pode-se dizer que sua existência é hipotética" (PHILIPPI JR., 1992, p.5).

Como o uso múltiplo desse recurso pelo homem não considera o ciclo de estações da natureza, os rios podem ressentir-se de ter águas retiradas para captação de abastecimento humano, pois o processo não é interrompido conforme as estações chuvosas ou não. Também são constantes os lançamento de resíduos domésticos e/ou industriais, as retiradas para irrigação e dessedentação de animais que ignoram a sazonalidade do rio. Estes usos antrópicos alteram a quantidade e a qualidade no ambiente aquático. Neste cenário, destaca-se a importância do monitoramento.

Pode-se dizer também que a qualidade da água é um reflexo dos cuidados da sociedade que vive em seu entorno, quer seja em regiões situadas à montante ou a jusante, que dela usufrui de várias formas. 
Water quality reflects the composition of water as affected by nature and human cultural activities, expressed in terms of both measurable quantities and narrative statements. In the United States the descriptive water quality parameters are related to intended water use. For each intended use and water quality parameters are related different parameters best expressing water quality. Both single compound (e.g., BOD5, ammonia, nitrate, dissolved oxygen, phenols, etc.) and multiple compound parameters (oil and grease, whole effluent toxicity, coliforms, etc.) are used. (NOVOTNY, 2003, p.25)

Essa gama de usos distintos deu origem a um sistema conhecido como "enquadramento dos corpos hídricos" que tenta classificá-los conforme seus usos múltiplos e será abordado mais adiante.

\section{2 - POR QUE MONITORAR?}

As redes de monitoramento de qualidade de águas superficiais têm como principal objetivo avaliar o estado de sua qualidade, dentro de unidade territorial quer seja esta natural, por exemplo, bacias hidrográficas, ou por unidades territoriais criadas pelo homem, que estão sujeitas a limites administrativos ou políticos, tal como municípios, estados ou países.

Water quality management may be defined as the effort by society to obtain quantitative information on the physical, chemical, and biological characteristics of water via statistical sampling." The type of information sought depends upon the objectives of the monitoring network. Objectives range from detecting stream standard violation to determining temporal water quality trends. (SANDERS, 1983, p.1)

Segundo o autor opus cit., dada a complexidade das idéias e verdades que consideramos quando imaginamos a tarefa de desenhar uma rede, ficaria fácil prever que 100 diferentes redes poderiam ser originadas de cem diferentes propositores de rede. Todavia, quando bem 
elaborada, é capaz de identificar quais seriam os locais prioritários para o controle de fontes de poluição e subsidiar ações de governo no planejamento. A figura 4 mostra um exemplo de rede de monitoramento de águas superficiais e subterrâneas para avaliações multi-finalitárias.

Figura 4 - Exemplo típico de rede de amostragem para monitoramento para múltiplos fins.

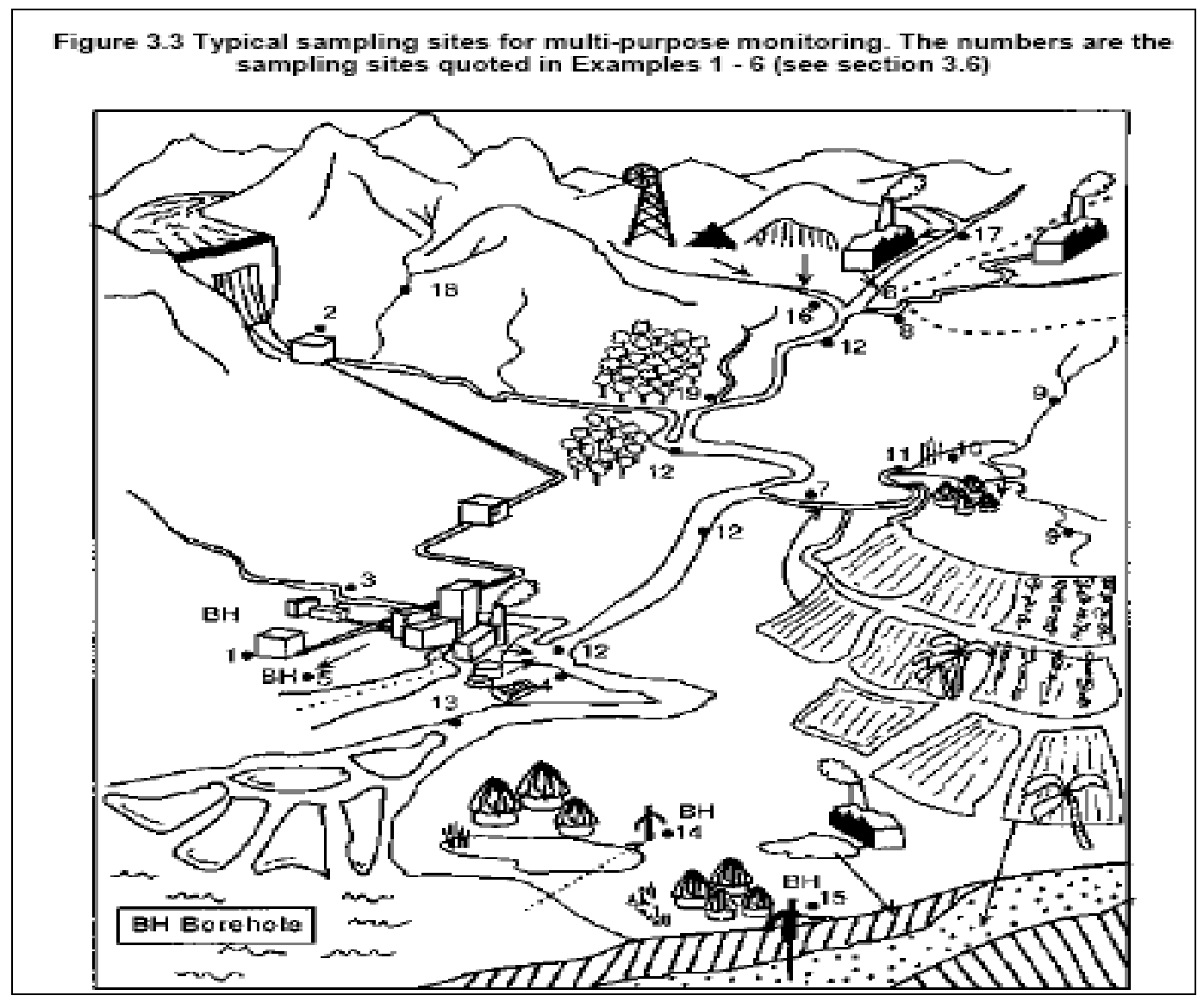

Fonte: UNEP/WHO, 1996.

Geralmente o monitoramento é executado por agências de governo, organismos mistos tais como comitês de bacias e organizações civis (ONGs). Pequenas redes de caráter investigatório podem ser encontradas em grandes complexos privados industriais, aterros e áreas de mineração. A dimensão e o foco principal dependem do propósito e uso dos rios e reservatórios de interesse. Podem ter abrangência local, regional, estadual ou federal. 
Além da importância de ter uma boa distribuição espacial, a rede de monitoramento também tem como outro aspecto importante a freqüência, que é expressa em termos de tempo de duração e intensidade das coletas das amostras, e demonstra aos interessados confiabilidade no conjunto de resultados apresentados.

Em 1996, o relatório da UNEP ("A Practical Guide to the Design and Implementation of Freshwater Quality Studies and Monitoring Programmes") destaca os tipos de monitoramento com relação ao tempo que devem durar:

\begin{abstract}
Monitoring is defined by the International Organization for Standardization (ISO) as: "the Programmed process of sampling, measurement and subsequent recording or signalling, or both, of various water characteristics, often with the aim of assessing conformity to specified objectives". This general definition can be differentiated into three types of monitoring activities that distinguish between long-term, short-term and continuous monitoring programmes" as follows: Monitoring is the long-term, standardized measurement and observation of the aquatic environment in order to define status and trends;

Surveys are finite duration, intensive programmes to measure and observe the quality of the aquatic environment for a specific purpose;

Surveillance is continuous, specific measurement and observation for the purpose of water quality management and operational activities. (UNEP/WHO, 1996, p.10)
\end{abstract}

O meio ecológico hídrico compreende as águas continentais (superficiais e subterrâneas) e águas costeiras. Os Rios e Reservatórios, conhecidos como águas doces, do ponto de vista da natureza enquanto águas de superfície, organizam-se, segundo Christofolletti (1974, p.81), por bacias hidrográficas, cuja drenagem fluvial é composta por um conjunto de canais de escoamento inter-relacionados, que definem a área drenada por determinado rio. Segundo o mesmo autor, classificam-se basicamente em exorréicas, quando o fluxo das águas se dá de modo contínuo até o mar, e em endorréicas, quando não possuem escoamento até o mar. 
Nesse contexto, as condições da Geomorfologia do terreno têm papel decisivo na formação de padrões de drenagem das águas, pois, além de dar forma ao modelado terrestre, determinam também a velocidade das águas correntes, quando em seu estado natural, isto é, sem interferência de barramentos. Assim, o tamanho do rio e sua declividade determinam sua velocidade e nesse percurso podem carrear toda sorte de material. É através do tipo e velocidade de escoamento das águas, e da força da gravidade, sempre dos pontos mais altos da bacia (área de montante) em direção a locais mais baixos (áreas de jusante) que a influência do transporte da carga difusa, e outras contribuições poderão ter maiores ou menores conseqüências no processo de sua autodepuração do mesmo.

Os rios cujas velocidades variam entre $0,1 \mathrm{~cm} / \mathrm{s}$ até $1 \mathrm{~m} / \mathrm{s}$, ou quando superam esse valor, são chamados de trechos lóticos (do latim lótus, que significa 'lavado'), portanto são trechos com mais energia, mais rápidos. Eles são classificados como lênticos (do latim lenis, que significa 'calmo') quando sua velocidade for menor que $0,5 \mathrm{~m} / \mathrm{s}$. Um rio pode ainda ser divido em zonas rápidas (leito) e lentas (próximo às margens). (Cf. ODUM, 1971, p.367)

E ratificando a importância desta componente,

[...] a velocidade é um importante fator ecológico, pois contribui para determinar os tipos de organismos (plantas e animais) que nele podem viver e que tipo de leito ele vai ter. (BRANCO, 1978, p.129)

Quanto maior a velocidade de um rio, tanto maior será sua capacidade de manter e transportar partículas em suspensão, visto que a água corrente possui a capacidade de manter em suspensão partículas sólidas graças à velocidade e, sobretudo, ao seu grau de turbulência; através do movimento das águas fluviais, verifica-se uma pressão horizontal sobre o leito do rio que pode movimentar rochas e seixos 
contidos no fundo do rio e o transporte deste material é, evidentemente, mais rápido na zona de maior velocidade.

Para poder avaliar essa influência dentro de um sistema GIS, devese proceder à construção de vários outros estudos como o DEM (Modelo Digital de Elevação), o que, no entanto, não é o objetivo neste estudo. Contudo, ressalta-se que a ocupação urbana e o progresso alteram as configurações naturais do relevo, aumentam a carga difusa nas bacias e podem desequilibrar o fluxo de água natural, ou, ao contrário, fazer com que muitas contribuições de efluentes em trechos extremamente meandrados do rio percam sua capacidade de auto-depuração. ROSSETTI, (2009) apresenta um exemplo desse fenômeno no estudo da influência de lançamento de cargas orgânicas entre as cidades paulistas de Caçapava e Taubaté, em um dos trechos considerado como críticos do Rio Paraíba do Sul, por influência do crescimento da urbanização nas áreas de várzea do rio, desacompanhada do devido tratamento de esgotos.

Já os reservatórios são tidos como massa de água natural ou artificial, usada para armazenar, regular e controlar os recursos hídricos, enfim é o "lugar onde a água é acumulada" (RIO DE JANEIRO, 1992, p.177). Os lagos, que são considerados ambientes lênticos, resultados de acumulações de água em depressões, tais como, falhas tectônicas, crateras vulcânicas, circos escavados por geleiras etc. De regra, são alimentados por rios e deságuam em outro rio que desemboca no mar. Comumente, possuem velocidades médias muito baixas, variando de 0,001 até $0,01 \mathrm{~m} / \mathrm{s}$, caracterizando-se por uma maior estabilidade de suas propriedades físicas. O tempo de residência da água em um lago pode variar de meses a centenas de anos. As correntes dentro dos lagos ocorrem em todas as direções e freqüentemente possuem variações de temperatura ao longo da coluna d'água (estratificação térmica), reguladas pelas variações climáticas. Em termos ecológicos, não há muita distinção entre lagos natural e artificial (reservatórios). Estes ambientes são propícios para o acúmulo de sedimentos que chegam em suspensão 
através de rios ou aportam por contribuições de carga difusa advindas de seu entorno.

\section{3 - OS RIOS DO ESTADO DE SÃO PAULO E A QUALIDADE DE ÁGUA}

O Estado de São Paulo possui uma boa rede de drenagem, sendo seus maiores representantes os Rio Tietê, Paranapanema,Turvo, Aguapeí, Peixe, Pardo, Mogi-Guaçu e Piracicaba, entre outros. O Estado tem a hidrografia desenhada nos limites de sua configuração geográfica, pois muitos rios são utilizados como divisa de estado: Paraná, Paranapanena e Rio Grande. Com isto, compartilha bacias nacionais também chamadas de bacias federais com outros estados, através de limites ou através da área de drenagem, tal como acontece no Rio Paraíba do Sul que banha também os Estados do Rio de Janeiro e Minas Gerais, ou mesmo com as nascentes formadoras do Rio Piracicaba, Jaguari, Camanducaia, Sapucaí entre tantos outros que vem de Minas Gerais.

Infelizmente, muitos deles, ao atravessarem áreas bastante urbanizadas, acabam tendo a sua qualidade hídrica modificada. Por estar localizado na região de maior crescimento econômico da América Latina. São Paulo conta com um dos principais e mais diversificados parques industriais, ao mesmo tempo em que apresenta setores de produção agroindustrial com tecnologias modernas e passíveis de ser referência no mundo. Com todo este destaque econômico, a contaminação de seus corpos d'água é objeto de muitos estudos sobre degradação ambiental.

Dentro do Estado, há três Regiões Metropolitanas ( $S$. Paulo, Campinas e Santos) e ao percorrerem esses conglomerados urbanos, alguns rios têm sua qualidade alterada mesmo logo após suas nascentes, tais como o rio Tietê e o rio Pinheiros, em São Paulo; o Córrego Piçarrão e o rio Anhumas, em Campinas; e o rio Moji, na Baixada Santista. Pode-se afirmar que na medida em que as cidades crescem, nas mesmas proporções teríamos o aumento de problemas ambientais em rios e 
reservatórios. Hoje estão com reflexos de intensa atividade antrópica rios como Tietê, Piracicaba, Mogi-Guaçu, Araras, Atibaia, Capivari, Paraíba do Sul e outros. Como resultado, temos, além da perda de qualidade pela queda dos níveis de OD (oxigênio dissolvido) por contribuição de matéria orgânica em decomposição, a possibilidade de eutrofização dos corpos hídricos. Este fenômeno é uma resposta natural ao excesso de nutrientes, tais como nitrogênio e fósforo que desempenham papel fundamental nesse processo em ambientes lênticos. A legislação federal CONAMA 357, de 2005, determina os limites do fósforo para rios, conforme tabela a seguir.

Tabela 1 - Limites para o Parâmetro fósforo.

\begin{tabular}{|l|c|c|c|}
\hline $\begin{array}{c}\text { CONAMA 357 } \\
\text { Parâmetro } \\
\text { Fósforo }\end{array}$ & $\begin{array}{c}\text { Ambiente } \\
\text { Lêntico }\end{array}$ & $\begin{array}{c}\text { Ambiente } \\
\text { Intermediário }\end{array}$ & Ambiente Lótico \\
\hline Classe 1 & 0,020 & 0,025 & 0,1 \\
\hline Classe 2 & 0,03 & 0,050 & 0,1 \\
\hline Classe 3 & 0,05 & 0,075 & 0,15 \\
\hline
\end{tabular}

Fonte: Resolução CONAMA no 357, de 17 de março de 2005 (Cf.: BRASIL, mar.2005).

O fósforo é um dos 9 parâmetros que compõem o IQA. A sua presença nos corpos d'água é indicador de poluição de origem antrópica. Sua origem nos corpos hídricos está associada tanto a dieta humana, como também a um componente aditivo muito utilizado na fabricação dos detergentes em pó, utilizados diariamente na lavagem de roupas. Já em áreas agrícolas, é geralmente usado na fabricação de fertilizantes (nutrientes), e chega aos rios e reservatórios através da contribuição da carga difusa e escoamento superficial.

A alta concentração de pessoas usando produtos com fósforo em sua composição química pode causar problemas semelhantes ao já visto na cidade de Pirapora do Bom Jesus, onde uma espuma produzida pela degradação incompleta de detergentes toma conta de todo o leito do rio Tietê e espalha-se na região de entorno. Estima-se que a RMSP gere um volume de 25 toneladas diárias de fósforo, o que favorece 0 
enriquecimento das águas, e propicia ambiente favorável ao crescimento de algas e macrófitas aquáticas, que alteram a qualidade de das águas. Segundo o Jornal da USP (07/05/2002):

\begin{abstract}
Em muitos mananciais e rios de São Paulo, esse número chega a $0,9 \mathrm{mg}$, o que torna o tratamento da água que consumimos mais caro, limita as possibilidades de lazer ou da prática de esportes náuticos, além de gerar problemas estéticos e mau cheiro. "Em $86 \%$ dos pontos de monitoramento da CETESB o fósforo foi encontrado em quantidades acima do ideal", informa José Eduardo Bevilacqua, gerente da Divisão de Qualidade de Águas da CETESB.
\end{abstract}

Com isto, resgata-se a correlação entre a concentração de pessoas em área urbanizadas, desprovidas de tratamento adequado de resíduos e a falta de qualidade da água. Já vimos que há muitas leis para o gerenciamento dos Recursos Hídricos e poucas providências para 0 "desgerenciamento" dos rejeitos hídricos: além dos já conhecidos rios repletos de esgotos conhecidos (Tietê, Tamanduateí, Pinheiros e etc.), muitos outros rios estão semimortos, anônimos, em várias cidades do interior paulista. As diferenças de afastamento (coleta), tratamento e eficiência de tratamento dentro do estado são muitas e existem poucas providências para reverter a situação.

Parece que passar ao lado de rios sem vida dentro de cidades grandes não comove a mais ninguém. Certamente que caso fossem montanhas de lixo ou entulho (Resíduo sólido) deixadas encima das diversas pontes que cruzam as principais vias de acesso da cidade de São Paulo, algumas delas muito modernas, o fato causaria muito mais indignação, pois as pessoas teriam que passar ao lado delas. Já passar sobre águas sujas (resíduo líquido) parece não ter o ter o mesmo impacto. 


\section{4 - EVOLUÇÃo dA LEGISLAÇÃo NO ESTADO DE SÃO PAULO NO GERENCIAMENTO DOS RECURSOS HÍDRICOS}

O DAEE (Departamento de Águas e Energia Elétrica) autarquia vinculada à Secretaria de Saneamento e Energia foi criado em 1951, e é hoje o principal responsável pela condução da gestão integrada, gerenciamento de outorgas e planejamento dos recursos hídricos no Estado de São Paulo. Mas, antes disto, existia o chamado "Código de Águas" publicado pelo governo federal através do Decreto no 24.643 , de 10 de julho de 1934:

O Chefe do Governo Provisório da República dos Estados Unidos do Brasil, usando das atribuições que lhe confere o 10 do decreto no 19.398 , de 11-11-1930, e:

Considerando que o uso das águas no Brasil tem-se regido até hoje por uma legislação obsoleta, em desacôrdo com as necessidades e interesse da coletividade nacional;

Considerando que se torna necessário modificar esse estado de coisas, dotando o país de uma legislação adequada que, de acôrdo com a tendência atual, permita ao poder público controlar e incentivar o aproveitamento industrial das águas; Considerando que, em particular, a energia hidráulica exige medidas que facilitem e garantam seu aproveitamento racional;

Considerando que, com a reforma porque passaram os serviços afetos ao Ministério da Agricultura, está o Governo aparelhado, por seus órgãos competentes, a ministrar assistência técnica e material, indispensável a consecução de tais objetivos;

Resolve decretar o seguinte Código de Águas, cuja execução compete ao Ministério da Agricultura e que vai assinado pelos ministros de Estado. (Cf.: DJI - ÍNDICE FUNDAMENTAL DO DIREITO, s/d)

O código das águas, livro III, dava à União a posse de todo o recurso hídrico, e tinha como ênfase o uso das águas como matéria-prima para o setor energético, e com isso relegava os outros usos a um segundo plano. Na prática, nada mudou até hoje, e essa lógica é usada em escala nacional, pois a matriz energética brasileira ficou muito tempo ancorada no modelo embasado na construção de usinas hidroelétricas, até certo 
ponto, justificado pela dependência externa do petróleo. Mas ainda hoje, com outras opções disponíveis, discuti-se o processo de construção de usinas no Rio Xingu e no Rio Madeira, onde não estão sequer vinculadas à existência de uma população em franco desenvolvimento econômico nas redondezas que seja capaz de utilizar esses recursos.

No Estado de São Paulo, a fartura de águas fez que esse uso do recurso hídrico também fosse muito utilizado para a finalidade de geração de energia. Isso implicou na alteração do fluxo natural de muitos rios. Em seus estudos no Brasil, o geógrafo francês Pierre Monbeig afirmou que a energia elétrica abundante e barata foi decisiva para o progresso de São Paulo, vislumbrando o que esse potencial poderia trazer como futuro para esta cidade:

Em maio de 1900 circularam pela primeira vez pelas ruas de Piratininga bondes elétricos. Data memorável, pois, com a energia elétrica, uma nova era começa em São Paulo, a qual já não será, apenas, a capital dos fazendeiros, mas uma metrópole com toda extensão da palavra. (MONBEIG, 1984)

Tal como já aconteceu durante a época de grande industrialização paulista (entre 1940 e 1970) ao longo do rio Tietê, com o intuito de se aproveitar o potencial hidrelétrico, foram construídas muitas usinas e barragens, mostradas na tabela 2. A primeira dessas usinas utilizou o desnível de 74 m da Cachoeira dos Freires, em Salesópolis, logo após as nascentes.

Tabela 2 - Barragens do Rio Tietê.

\begin{tabular}{|l|l|c|}
\hline \multicolumn{1}{|c|}{ Nome da Barragem / Usina } & \multicolumn{1}{|c|}{ Município } & $\begin{array}{c}\text { Ano de } \\
\text { Inaugu- } \\
\text { ração }\end{array}$ \\
\hline $\begin{array}{l}\text { Barragem da Usina Parque de Salesópolis } \\
\text { Empresa Força e Luz do Norte/EMAE }\end{array}$ & Salesópolis & 1914 \\
\hline Barragem da Ponte Nova (EMAE) & Salesópolis & 1972 \\
\hline $\begin{array}{l}\text { Barragem Edgard de Souza (EMAE) - Antiga } \\
\text { Usina de Parnaíba (LIGHT) }\end{array}$ & Santana de Parnaíba & $23 / 09 / 1901$ \\
\hline
\end{tabular}




\begin{tabular}{|l|l|c|}
\hline $\begin{array}{l}\text { Barragem de Pirapora do Bom Jesus } \\
\text { (EMAE) }\end{array}$ & Pirapora do Bom Jesus & $\begin{array}{c}\text { Década de } \\
1930\end{array}$ \\
\hline Barragem de Rasgão (EMAE) & $\begin{array}{l}\text { Pirapora do Bom } \\
\text { Jesus/Cabreúva }\end{array}$ & 1925 \\
\hline Barragem da Usina de Lavras (desativada) & Salto & 1906 \\
\hline Barragem de Porto Goés (EMAE) & Salto & 1928 \\
\hline Barragem de Barra Bonita- AES Tietê & Barra Bonita & $20 / 01 / 1963$ \\
\hline Barragem Bariri- AES Tietê & Bariri & 1965 \\
\hline Barragem Ibitinga- AES Tietê & Borborema / Iacanga & 1969 \\
\hline $\begin{array}{l}\text { Barragem de Promissão- Usina Hidrelétrica } \\
\text { Mário Lopes Leão - AES Tietê }\end{array}$ & Promissão/ Avanhandava & 1975 \\
\hline $\begin{array}{l}\text { Barragem Três Irmãos e } \\
\text { Usina de Ilha Solteira (Rio Paraná) - CESP } \\
\text { (desvio da água do Rio Tiete pelo canal de } \\
\text { Pereira Barreto que interliga os lagos das } \\
\text { duas barragens) }\end{array}$ & $\begin{array}{l}\text { Itapura/ } \\
\text { Ilha Solteira }\end{array}$ & 1999 \\
\hline
\end{tabular}

Org. MIDAGLIA, C. L. e MALAVOLTA, F., 2009. Fonte: Banco Interáguas, CETESB.

Como as usinas hidroelétricas precisam de grandes lagos que vertam sobre seus geradores, constroem-se grandes barragens que acabam por acumular também sedimentos e poluição, ocasionando a perda da qualidade da água e o desequilíbrio ecológico da vida aquática.

Mesmo hoje, quando o Estado de São Paulo já esta utilizando novas fontes de energia disponíveis, tal com o biogás e a biomassa, ainda se discute a implantação de novas PCHs - Pequenas Centrais Hidrelétricas, cujo potencial de geração de energia não pode ultrapassa $30 \mathrm{MW}$, como por exemplo, ao longo do Rio Paraíba do Sul.

Assim, novamente existe a correlação entre crescimento populacional, a demanda por mais energia e uso do recurso hídrico como provedor.

Mas, com o passar dos anos, a legislação referente ao uso da água torna-se mais abrangente e contempla um numero maior de usuários. Em 1991, foi aprovado pela Assembléia Legislativa de São Paulo, através da LEI no 7.663, de 30 de dezembro de 1991, o PERH (Plano Estadual de Recursos Hídricos), baseado em legislações existentes em países mais desenvolvidos, em relação à política de gestão de águas e esgotos. 
Segundo esta lei, em teoria, existiria um sistema integrado de gestão, com participação do estado, municípios e sociedade civil organizada, com direito a voz e voto, e por outro lado, os que não fossem suficientemente organizados ou esclarecidos para acompanhar os processos de administração/ gerenciamento de recursos hídricos, não têm direito a voto. Além disso, conta com três representantes de Universidades oficiais do Estado, um representante do Ministério Público, sete de entidades e órgãos estaduais e os presidentes dos CBHs (Comitês de Bacias hidrográficas) (SÃO PAULO, 1997, p.14). Obviamente que tudo isso ainda é insuficiente para uma população grande como a do Estado de São Paulo, pela importância que a água tem e pelo estado dos rios nos centros urbanos.

Essa mesma lei que instituiu o PERH (Política Estadual de Recursos Hídricos) e o SIGRHI (Sistema Integrado de Gerenciamento de Recursos Hídricos) estabeleceu entre seus princípios:

A Política Estadual de Recursos Hídricos tem como objetivo
assegurar que a água, recurso natural essencial à vida, ao
desenvolvimento econômico e ao bem-estar social, possa ser
controlada e utilizada, em padrões de qualidade
satisfatórios, por seus usuários atuais e pelas gerações
futuras, em todo território do Estado de São Paulo; e, a
adoção da bacia hidrográfica como unidade físico-territorial
de planejamento e gerenciamento; [...] (Art 30, inciso II).
(SÃO PAULO, set.1990)

Em 1994, a Lei 9.034 aprovou o 20 PERH (Plano Estadual de Recursos Hídricos) e dividiu o Estado de São Paulo em 22 UGRHIs (Unidades de Gerenciamento de Recursos Hídricos).

As UGRHIs constituem unidades territoriais "com dimensões e características que permitam e justifiquem 0 gerenciamento descentralizado dos recursos hídricos" (art.20 da Lei Estadual 7663 de 30/12/1991) e, em geral, são formadas por partes de bacias hidrográficas ou por um conjunto delas, que de forma alguma podem ser consideradas como bacias hidrográficas. (art.20 da Lei Estadual 7663, de 30/12/1991. (Cf.: SÃO PAULO, 2008a) 
As unidades de gerenciamento vão ser várias vezes citadas quer seja pelo nome ou pelo número e o quadro 1 , a seguir, funcionará como um dicionário.

\section{Quadro 1 - Estado de São Paulo dividido em 22 UGRHIs com atribuição e principais usos da Água.}

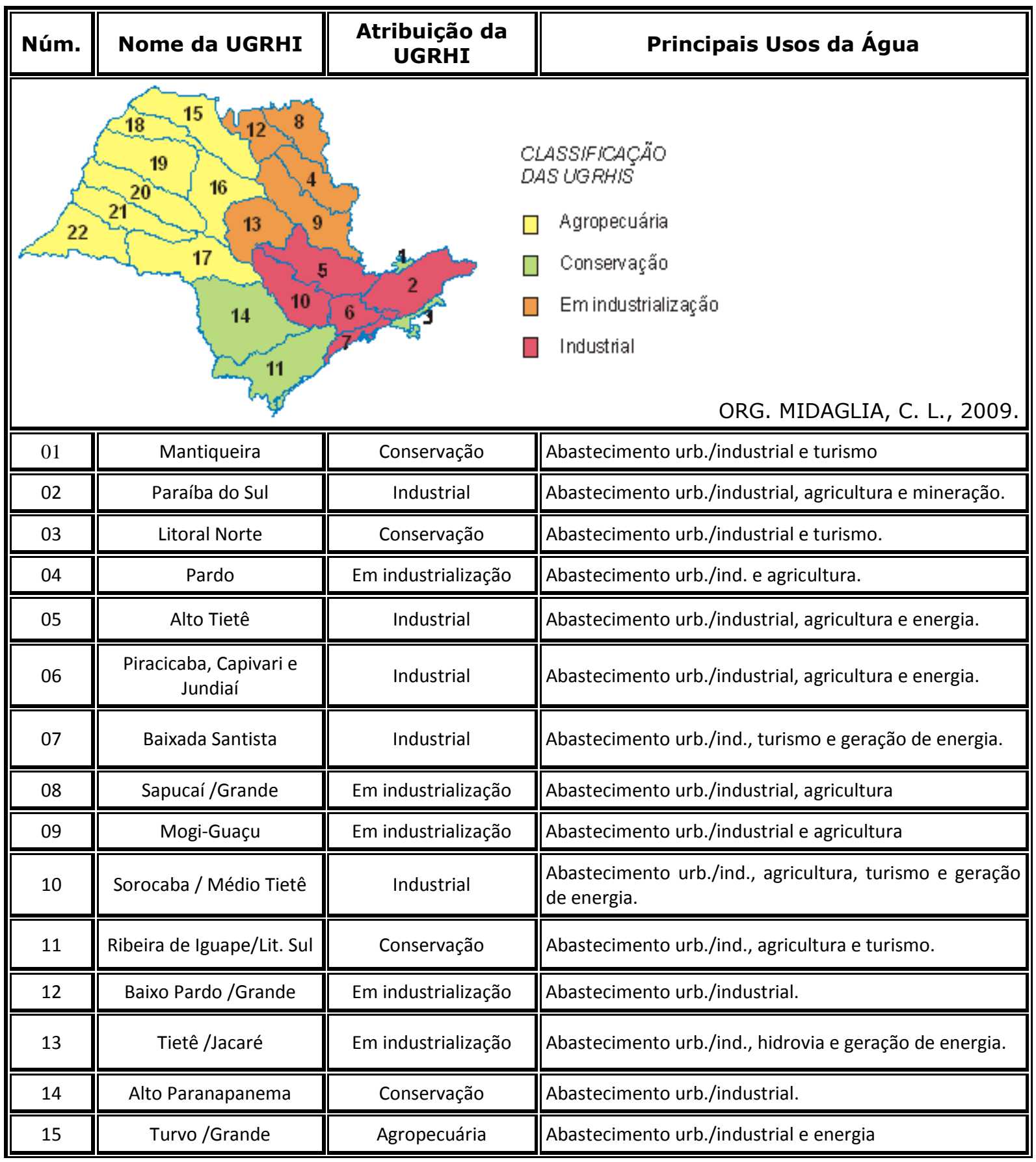




\begin{tabular}{|c||c||l|l||}
\hline 16 & Tietê /Batalha & Agropecuária & $\begin{array}{l}\text { Abastecimento urb./industrial, hidrovia, agroindústria, } \\
\text { turismo e geração de energia. }\end{array}$ \\
\hline \hline 17 & Médio Paranapanema & Agropecuária & Abastecimento urb./industrial e agroindústria \\
\hline \hline 18 & São José dos Dourados & Agropecuária & Abastecimento urb./ind. e geração de energia. \\
\hline \hline 19 & Baixo Tietê & Agropecuária & $\begin{array}{l}\text { Abastecimento urb./industrial, hidrovia, geração de } \\
\text { energia e agroindústria }\end{array}$ \\
\hline \hline 20 & Aguapeí & Agropecuária & Abastecimento urb./industrial e mineração \\
\hline \hline 21 & Peixe & Agropecuária & Abastecimento urb./industrial e agroindústria \\
\hline \hline 22 & Pontal do Paranapanema & Agropecuária & $\begin{array}{l}\text { Abastecimento urb./ind., agroindústria e geração de } \\
\text { energia. }\end{array}$ \\
\hline \hline
\end{tabular}

Org. MIDAGLIA, C. L., 2009. Fonte: CETESB, 2008.

Até então, os recursos hídricos do Estado eram organizados espacialmente em 8 zonas hidrográficas, com 18 sub-zonas. Com este novo desenho, alterou-se o tradicional modelo de gerenciamento por bacias hidrográficas e faz uma adaptação entre unidades administrativas e as bacias hidrográficas.

Cabe ressaltar que algumas das antigas grandes bacias foram divididas em várias UGRHIs, e só tem sentido pensar em termos de gerenciamento pleno de bacias, quando são vistas novamente de modo integrado. Por exemplo, o Rio Tietê, um rio 100\% paulista, atravessava 2 zonas hidrográficas ( $1^{\mathrm{a}}$. e $2^{\mathrm{a}}$. Zona) com seus $1100 \mathrm{~km}$, e passou a pertencer a 6 UGRHIs descritas no quadro 2:

\section{Quadro 2 - Rio Tietê através das UGRHIS no Estado de São Paulo.}

\begin{tabular}{|l|}
\hline UGRHI 05 - Piracicaba/Capivari/Jundiaí \\
\hline UGRHI 06 - Alto Tietê \\
\hline UGRHI 10 - Tietê/Sorocaba \\
\hline UGRHI 13 - Tietê/Jacaré \\
\hline UGRHI 16 - Tietê/Batalha \\
\hline UGRHI 19 - Baixo Tietê \\
\hline
\end{tabular}

Fonte: CETESB, 2002. 
Já a bacia do Rio Grande, que nasce em Minas Gerais, e é um rio federal (abrange mais de um estado), tem sua área de drenagem em dois estados e está também fragmentada em mais de uma UGRHI. O rio Grande, que é usado como divisa estadual tem nascentes formadoras também no território paulista, retorna a Minas Gerais e depois acompanha a divisa entre os dois estados até sua foz no rio Paraná. No território paulista, passa pelas seguintes UGRHIs, constantes do quadro 3 :

\section{Quadro 3 - Partes da Bacia Hidrográfica do Rio Grande no Território Paulista.}

\begin{tabular}{|l|}
\hline UGRHI 01 - Mantiqueira \\
\hline UGRHI 04 - Pardo \\
\hline UGRHI 08 - Sapucaí/Grande \\
\hline UGRHI 09 - Mogi-Guaçu \\
\hline UGRHI 12 - Baixo Pardo Grande \\
\hline UGRHI 15 - Turvo Grande \\
\hline \\
Fonte: CETESB, 2002.
\end{tabular}

Além do fato das UGRHIS não serem exatamente coincidentes com as bacias hidrográficas, existe também o problema de não se sobreporem completamente aos certos limites administrativos, tal como o Município de Marília, que possui seu território fracionado em 3 diferentes unidades, mas pertence oficialmente a UGRHI 21, como mostra a figura 5. Assim, o município pode captar água em uma unidade diferente de onde lança seus efluentes. Neste caso, pode inclusive participar de diferentes comitês de bacias, para opinar sobre decisões pertinentes. A divisão por atribuições também pode gerar dificuldade para desenvolver metodologias de comparação conjuntas, em termos de similaridade de atividades por vocação, uma vez que não são unidades necessariamente contíguas.

Alguns destes problemas envolvendo a gestão das UGRHIs, especialmente, a gestão de água são as demandas de investimentos, calculo da produção hídrica, risco de contaminação da água para a população, entre outros, que devem ser expressos para cada unidade 
dentro do território de cada UGRHI, conforme foi feito nos Relatórios R2 (Relatório de Metas do PERH 2004-2007) e Relatório R3 (Programa de Investimentos do PERH 2004-2007).

\section{Figura 5 - Município de Marília, com área fracionada em 3 UGRHIs.}

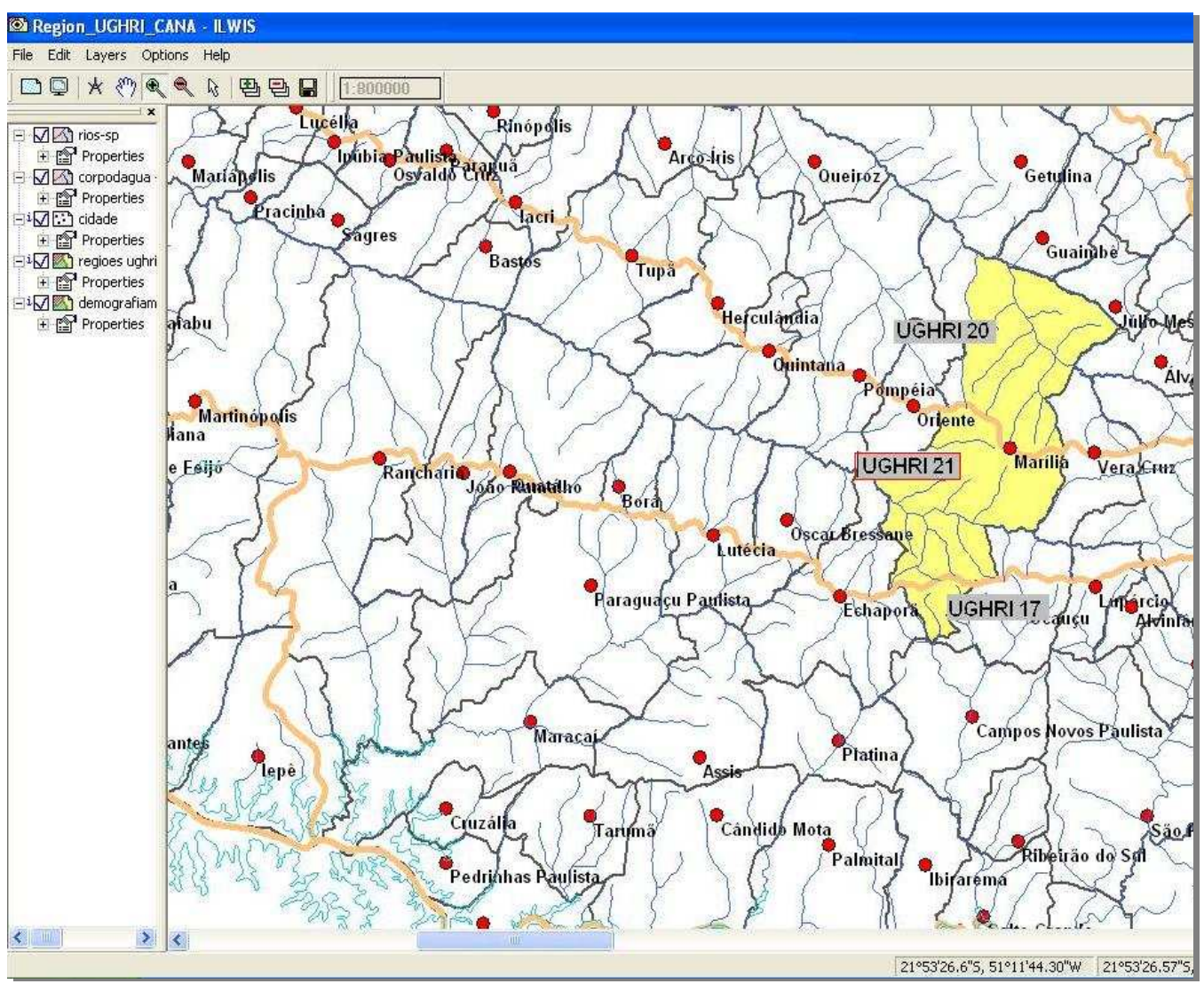

Elaborada por: MIDAGLIA, C. L., 2009. Fonte: SP_WATERNET, 2009.

Até mesmo para avaliar o monitoramento, considerando-se somente a distribuição interna de pontos, existem dificuldades, pois a qualidade de água registrada em cada um dos pontos sofre influencia de seu entorno. Um ponto a jusante de uma UGRHI pode ser igualmente importante para avaliação em outra unidade adjacente ou a montante. 
Figura 6 - Divisão geral das águas do estado de São Paulo em UGRHIS e Bacias Hidrográficas.

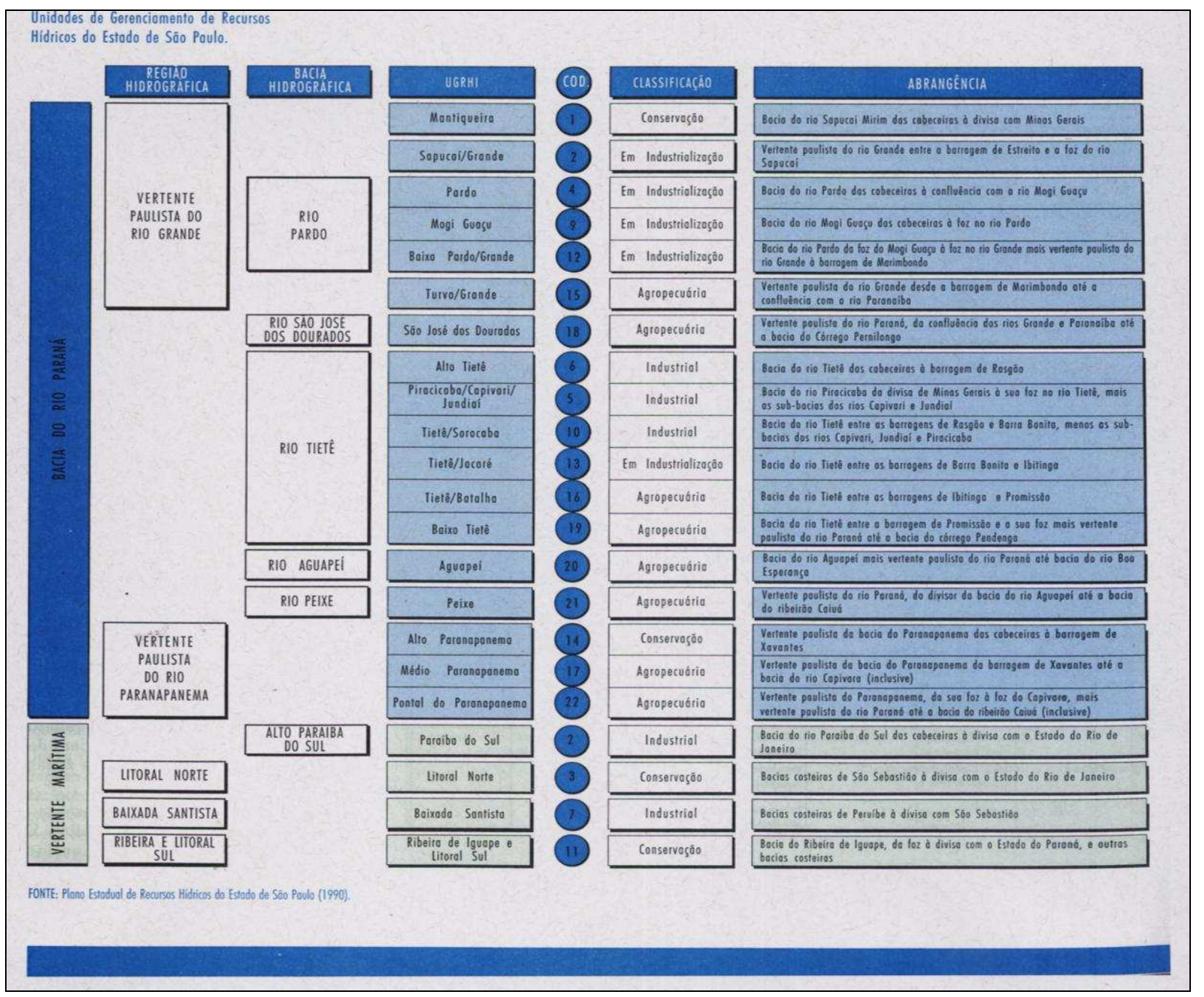

Fonte: PERH, 2004.

O último plano PERH correspondente ao período de 2008-2011 e prevê, em seu capítulo síntese, os seguintes objetivos:

(1) A quantificação das metas, mediante uma avaliação com os CBHs.

(2) A implementação dos indicadores e avaliação de sua sensibilidade e eficácia em traduzir a realidade.

(3) A ampliação e operacionalização do Sistema de Informações sobre Recursos Hídricos de modo a tornar mais rápida a apreensão da realidade e a elaboração do Diagnóstico do PERH 2008-2011. 
(4) O aumento do nível de articulação PERH-PPA (Plano Plurianual).

(5) Um mapeamento prévio dos recursos que poderão ser aplicados no $\mathrm{PERH}$, principalmente quanto às destinações regionais de recursos das empresas estatais e dos municipais (tanto a execução orçamentária quanto os dados de orçamentos e a consideração dos indicadores do PERH).

(6) maior precisão no enquadramento - pelos $\mathrm{CBHs}$ - das intervenções indicadas nos Planos de Bacia e nas metas do PERH, assim como nos quantitativos e custos associados, e indicação das fontes dos recursos. Nesse sentido, o preparo de um manual de enquadramento de intervenções nos PDCs- Programas de Duração Continuada seria bastante oportuno para uniformizar as escolhas.

(7) Ampliar e aperfeiçoar a participação pública. (SÃO PAULO, 2008b)

Portanto, a partir de tais demandas, verifica-se a confirmação da necessidade de desenvolver metodologias comparativas para essas novas unidades, classificadas inclusive por vocação do uso da terra, mas não ainda pelo uso da água. Poderíamos assim ter também UGRHIS classificadas segundo o uso da água para fins de geração de energia, irrigação, turismo, recebimento de esgoto e abastecimento, mas os usos são tantos que ficaria difícil de definir um uso preponderante.

Por fim, ressalta-se que a legislação brasileira que descreve a qualidade da água como própria para fins de consumo humano, ou seja, água potável é regulamentada portaria no 518 do Ministério da Saúde, de 25 de março de 2004, que estabelece os procedimentos e responsabilidades relativos ao controle e vigilância da qualidade da água para consumo humano e seu padrão de potabilidade. 


\section{1 - A CLASSIFICAÇÃO E ENQUADRAMENTO DOS CORPOS D'ÁGUA}

Como além da variação natural, a maioria das bacias hidrográficas superficiais localizadas em áreas urbanizadas pode sofrer interferência de processos antrópicos, amplia-se a possibilidade que essa interferência possa associar-se a variabilidade natural e causar a alteração ou perda da qualidade.

Alguns dos usos implicam na retirada de água das coleções hídricas, chamados usos consuntivos da água, como por exemplo, a agricultura, o processamento de alimentos para exportação (chamado uso virtual da água) enquanto outros, denominados de não-consuntivos, estão associados a atividades desenvolvidas no próprio ambiente aquático, tais como a recreação e o lazer, a preservação da flora e da fauna, a geração de energia, o transporte e a diluição de esgoto.

Portanto, quanto maior a gama de possibilidades de uso, maior será a pressão e o impacto. Para verificar possíveis alterações na variabilidade das águas, são monitoradas através de parâmetros amplamente usados e recomendados mundialmente pela CETESB, CONAMA, GEMS/Water (Global Enviromental Monitoring System) e EPA.

O estabelecimento de uma distinta ligação entre os diversos usos da água e seus requisitos de qualidade é fundamental. Determinados usos são considerados nobres, exigindo, portanto, um rigoroso controle da qualidade, no caso do abastecimento humano, enquanto outros usos são mais permissivos (lançamento de efluentes) e não estão vinculados a rígidos critérios de qualidade, tal como previsto para a classe 4 .

Ao longo de seu curso, um rio pode ser classificado em mais de uma classe, dependendo do seu uso no entorno. Por exemplo, o Rio Tietê tem suas nascentes no município de Salesópolis, com classe 2 e assim permanece a confluência com o Ribeirão Botujuru (localizado a montante de Mogi das Cruzes). A partir desse ponto, já em área metropolitana, é reclassificado como classe 3 , devido à intensa urbanização e industrialização. A partir da foz do Rio Itaquera, o rio Tiete é rebaixado 
novamente e passa a classe 4, por receber nesse trecho intensa carga de poluentes, seguindo nessa situação até a barragem de Pirapora. A jusante desta barragem, volta novamente a ser enquadrado na classe 2 e assim permanece até sua foz, no Rio Paraná, no município de Itapura.

Para definir estes diferentes vínculos entre a água e os usos do solo ao entorno, os rios foram classificados:

Na esfera federal, pela Portaria MINTER n. ${ }^{\circ}$ GM 0013, de 15/01/76, que inicialmente regulamentou a classificação dos corpos de água superficiais, com os respectivos padrões de qualidade e os padrões de emissão para efluentes.

No Estado de São Paulo estes padrões foram fixados pelo Decreto n. ${ }^{\circ} 8468$, de 08/09/76, que regulamentou a Lei $n .^{\circ} 997$, de 31/05/76, a qual subsidia a ação da prevenção e do controle da poluição no meio ambiente. Esse Decreto define a classificação das águas interiores situadas no território do Estado de São Paulo, segundo os usos preponderantes, variando da Classe 1 (mais nobre) até Classe 4 (menos nobre). Também são fixados, entre outros, padrões de qualidade das águas para as quatro classes e padrões de emissão para efluentes líquidos de qualquer natureza. O enquadramento dos corpos de água do Estado de São Paulo foi estabelecido pelo Decreto n. ${ }^{\circ} 10.755$ de 22/11/77. Em 1986, a Portaria GM 0013 foi substituída pela Resolução n. ${ }^{\circ} 20$ do Conselho Nacional do Meio Ambiente - CONAMA, qual estabelece uma nova classificação para as águas doces, bem como para as águas salobras e salinas do Território Nacional. Esta legislação foi atualizada pela resolução CONAMA 357/2005 (Disponível em: <http://www.mma.gov.br/ port/conama/res/res05/res35705.pdf>), onde são definidas nove classes, segundo os usos preponderantes a que as águas se destinam. As águas doces, em particular, são distribuídas nas cinco classes seguintes:

I - Classe Especial - águas destinadas:

a) ao abastecimento doméstico sem prévia ou com simples desinfecção;

b) à preservação do equilíbrio natural das comunidades aquáticas. 
II - Classe 1 - águas destinadas:

a) ao abastecimento doméstico após tratamento simplificado;

b) à proteção das comunidades aquáticas;

c) à recreação de contato primário (natação, esqui aquático e mergulho);

d) à irrigação de hortaliças que são consumidas cruas e de frutas que se desenvolvam rentes ao solo e que sejam ingeridas cruas sem remoção de película;

e) à criação natural e/ou intensiva (aqüicultura) de espécies destinadas à alimentação humana.

III - Classe 2 - águas destinadas:

a) ao abastecimento doméstico, após tratamento convencional;

b) à proteção das comunidades aquáticas;

c) à recreação de contato primário (esqui aquático, natação e mergulho);

d) à irrigação de hortaliças e plantas frutíferas;

e) à criação natural e/ou intensiva (aqüicultura) de espécies destinadas à alimentação humana.

IV - Classe 3 - águas destinadas:

a) ao abastecimento doméstico, após tratamento convencional;

b) à irrigação de culturas arbóreas, cerealíferas e forrageiras;

c) à dessedentação de animais.

V - Classe 4 - águas destinadas:

a) à navegação;

b) à harmonia paisagística;

c) aos usos menos exigentes. 
Destaca-se que o fato de um trecho de rio estar enquadrado em determinada classe não significa, necessariamente, que esse seja o nível de qualidade que ele realmente apresenta, mas sim aquele que se busca alcançar ou manter ao longo do tempo. Na prática, pode se frisar que existem rios de classe 2 que apresentam padrão de qualidade de classe 3, e assim por diante. Rios como o Tamanduateí, Pinheiros e Tietê (classificado como classe 4 no trecho urbano de São Paulo), inclusive apresentam valores inferiores aos limites para rios de classe 4, que tem padrão mínimo apenas para três parâmetros: OD (> 2,0 mg/L), Fenol ( 1,0 $\mathrm{mg} / \mathrm{L}$ ) e $\mathrm{pH}$ (entre 6 e 9), conforme demonstra a figura 7 :

\section{Figura 7 - Variação dos níveis de OD no Rio Pinheiros em 2008.}

\section{$\checkmark$ Microsoft Access - [Gráfico de Parâmetro Por Ponto : Formulário]}

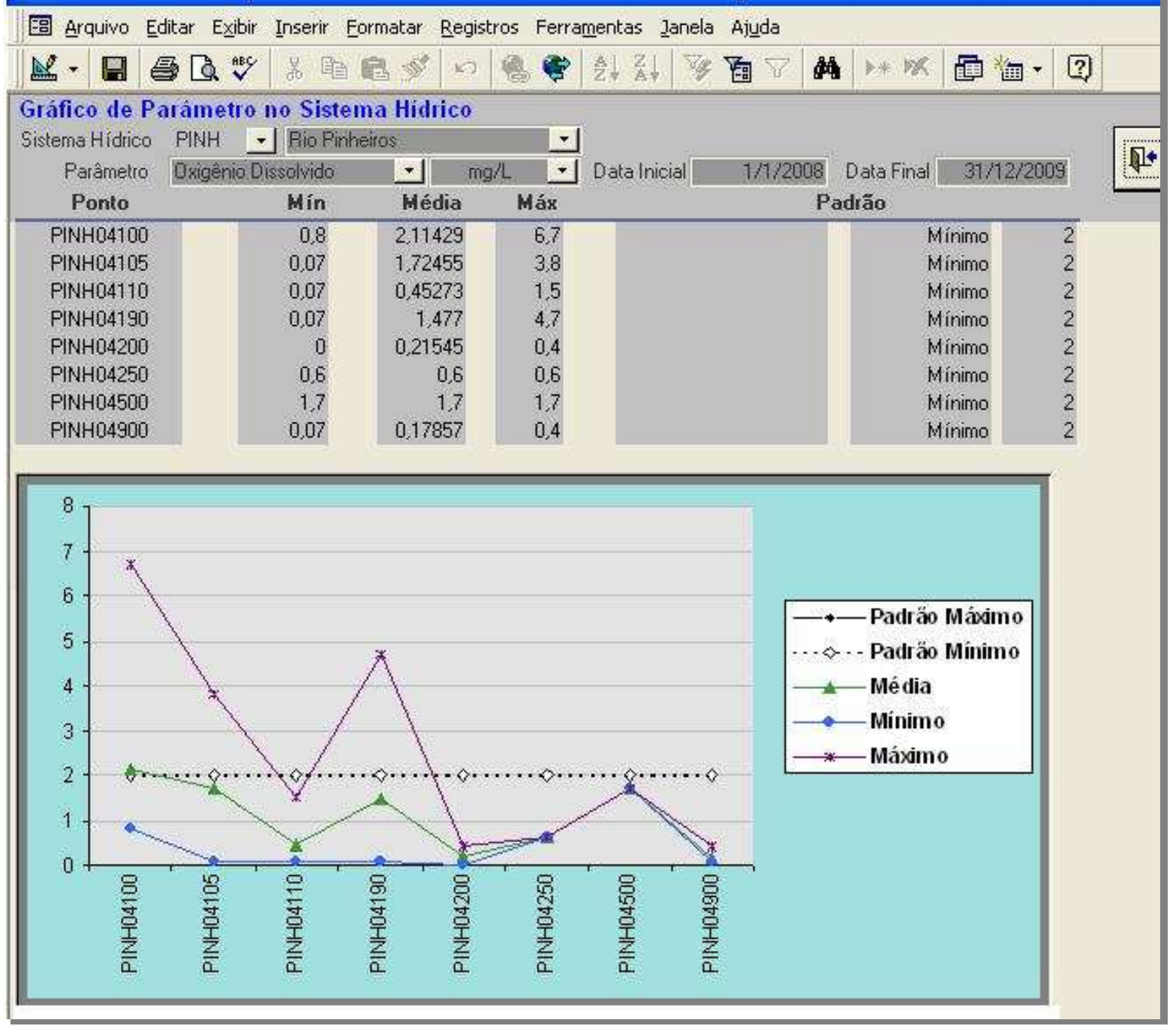

Fonte: Banco Interáguas, CETESB, 2008. 
Portanto, seria desejável que em intervalos regulares de tempo houvesse uma revisão do enquadramento dos rios de modo a ver se houve resultados caso medidas de interferência e controle ambiental tenham sido tomadas para tentar devolvê-los a sua classe original. Como sugere Carvalho a qualidade requerida depende do uso (apud RIO DE JANEIRO, 1992, p.169):
A qualidade da água é um conjunto de características químicas, físicas e biológicas, relacionadas com o se uso para determinado fim. A mesma água pode ser de boa qualidade para um determinado fim e de má qualidade para outro, dependendo de suas características e exigências requeridas pelo uso específico.

A avaliação da qualidade das águas interiores está atrelada às legislações estadual e federal, que fixam as classes de qualidade dos recursos hídricos, bem como os padrões de qualidade a serem respeitados. Os resultados obtidos no monitoramento de qualidade das águas interiores efetuado pela CETESB são comparados com os padrões estabelecidos pela Resolução CONAMA 357/05, por serem estes mais restritivos que os fixados pelo Decreto Estadual 8468/76. (Cf.: BRASIL, mar.2005).

Como pode ser visto na figura 8 , os laudos não trazem os índices prontos. Eles são calculados por programas auxiliares dentro do banco de dados "Interáguas", da CETESB, conforme os parâmetros selecionados e necessidades específicas para cada uso. 
Figura 8 - Exemplo de laudo CETESB do ponto BAGU 02700 na captação de Araçatuba.

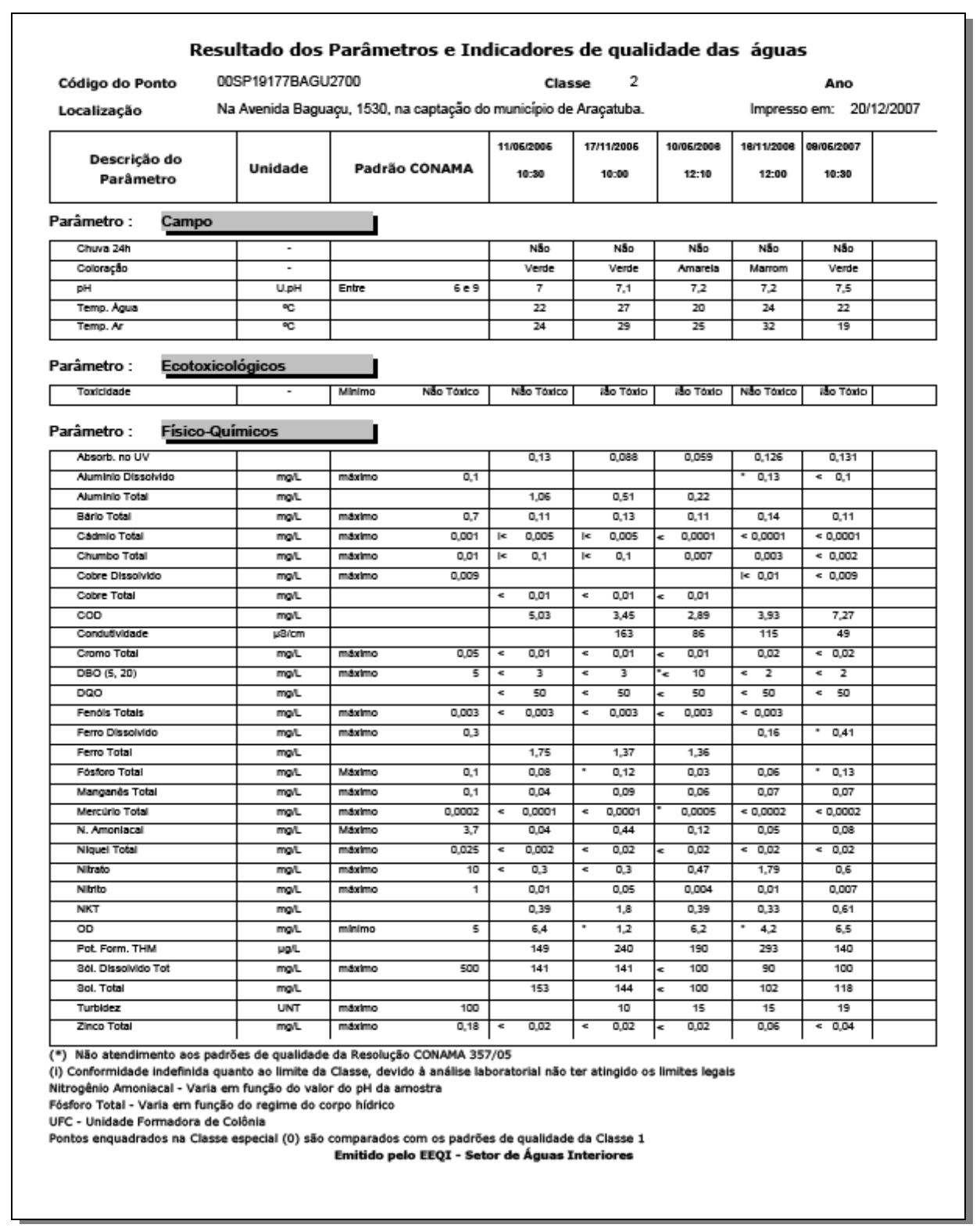

Fonte: Banco Interáguas, CETESB, 2008.

Depois de interpretados são disponibilizados na Internet, em forma de anexo dos relatórios. Normalmente, para cada um dos pontos, são programadas 6 coletas bimestrais, três coincidem com o período chuvoso e três com a estiagem. Em cada ponto são analisados cerca de 30 parâmetros, o que gera ao longo do ano cerca de 70.000 laudos. 
Os relatórios de qualidade das águas superficiais de São Paulo são publicados anualmente desde o ano de 1978, e a partir do ano 2000, podem ser obtidos na internet, no site da CETESB (http://www.cetesb. sp.gov.br/Agua/rios/publicacoes.asp).

Com base nesse amplo diagnóstico, planos regionais devem ser desenvolvidos, segundo as necessidades de recuperação, proteção e conservação dos recursos hídricos das bacias hidrográficas. A aprovação desses planos é de competência dos comitês de bacias hidrográficas, inclusive com o apoio de audiências públicas, conforme dispõe no seu artigo 26 a Lei Estadual 7.663, de 30/12/91, que estabelece normas de orientação à política Estadual de Recursos Hídricos, bem como ao Sistema Integrado de Gerenciamento de Recursos Hídricos.

Porém, a maioria da população desconhece a situação real da qualidade ambiental dos rios ou não acompanha esse diagnóstico com atenção, o que dificulta uma efetiva participação na tomada de decisões referentes ao uso das águas. 


\section{5 - A REDE DE QUALIDADE DE ÁGUAS SUPERFICIAIS PAULISTA - BREVE HISTÓRICO}

A Rede de Monitoramento da Qualidade das Águas Interiores do Estado de São Paulo foi criada em 1974, em atendimento à Lei Estadual no 118, promulgada em 29/06/73. A Portaria 1469, do Ministério da Saúde, de dezembro de 2000, também exigiu em seu Artigo 19, que os mananciais superficiais devessem conter um plano de monitoramento compatível com a legislação vigente.

A operação da Rede de Monitoramento da CETESB iniciou com a seleção de 47 pontos de amostragem e um primeiro conjunto de 29 parâmetros. Em dezembro de 1974, os coletores foram para campo e deram início ao monitoramento da qualidade das águas superficiais em São Paulo. Até então, o que havia eram levantamentos esporádicos, realizados aqui e ali, denominado de monitoramento investigatório, cujos dados não eram sistematizados e se perdiam.

Segundo contou o Eng. Rubens Monteiro de Abreu em seu depoimento quando a rede fez 25 anos (CETESB, 2000), na sua época o processamento das informações da rede contava com o Aquadata, banco de dados importado do Canadá, que ficava no computador IBM, centralizado na área de informática, cujo acesso para técnicos e públicos era muito complicado. Até 1977, não se publicavam os relatórios e utilizava-se gráficos de evolução para acompanhamento, que acabaram não sendo divulgados para o público externo devido ao grande volume que ocupavam. Para superar isso, nasceu, após muitas discussões, em 1978, o primeiro relatório anual de qualidade das águas superficiais da CETESB. Os resultados das análises dos pontos foram divididos em oito zonas hidrográficas, que agrupavam as 29 principais bacias dos grandes rios paulistas, com seus respectivos pontos cartografados em mapas parciais das bacias (zonas), uma tabela de resultados com parâmetros analisados e o gráfico de evolução. Nos mapas, a preocupação com o tamanho das cidades era representado pela equivalência proporcional em 
5 tamanhos diferentes atribuídos ao símbolo das cidades, cujas classes de densidades populacionais eram: 0-20, 20-50, 50-100, 100-500 e mais de 500 hab./km2, provavelmente segundo o censo do IBGE de 1970.

Tabela 3 - Evolução da distribuição dos pontos quando divididos por zonas hidrográficas (1978 e 1993).

\begin{tabular}{|c|c|c|c|c|c|}
\hline $\begin{array}{c}\text { Zonas } \\
\text { Hidrográficas e } \\
\text { Núm. de Bacias }\end{array}$ & Bacias & $\begin{array}{c}\text { Área } \\
\text { (km2) }\end{array}$ & $\begin{array}{c}74 \\
\text { pontos } \\
\text { em } \\
1978 \\
\end{array}$ & $\begin{array}{c}93 \\
\text { pontos } \\
\text { em } \\
1988 \\
\end{array}$ & $\begin{array}{c}105 \\
\text { pontos } \\
\text { em } \\
1993 \\
\end{array}$ \\
\hline $\begin{array}{l}\text { 1a. Zona: } \\
\text { Abrange desde as } \\
\text { cabeceiras do rio } \\
\text { Tietê até à } \\
\text { Barragem de Barra } \\
\text { Bonita, incluindo o } \\
\text { Sistema Billings. }\end{array}$ & $\begin{array}{l}\text { 01-Tietê Alto Cabeceiras } \\
\text { 02-Tietê Alto Zona } \\
\text { Metropolitana } \\
\text { 03-Billings } \\
\text { 04-Cotia } \\
\text { 05-Guarapiranga } \\
\text { 11-Tietê Médio Superior } \\
\text { 12-Capivari } \\
\text { 13-Jundiaí } \\
\text { 14-Piracicaba } \\
\text { 15-Sorocaba } \\
\text { TOTAL (10 Bacias) }\end{array}$ & 32.170 & $\begin{array}{c}4 \\
12 \\
3 \\
2 \\
3 \\
3 \\
1 \\
2 \\
6 \\
2 \\
39\end{array}$ & $\begin{array}{c}5 \\
11 \\
\\
5 \\
3 \\
3 \\
4 \\
1 \\
2 \\
9 \\
3 \\
46\end{array}$ & $\begin{array}{c}5 \\
11 \\
\\
5 \\
3 \\
3 \\
7 \\
1 \\
3 \\
10 \\
3 \\
\mathbf{5 1}\end{array}$ \\
\hline $\begin{array}{l}\text { 2a. Zona: } \\
\text { Desde a barragem } \\
\text { de Barra Bonita até } \\
\text { a foz do rio Tietê no } \\
\text { rio Paraná. }\end{array}$ & $\begin{array}{l}\text { 21-Tietê Médio Inferior } \\
\text { 22-Tietê Baixo } \\
\text { 92-Paraná Vertentes } \\
\text { Parciais } \\
\text { TOTAL (3 Bacias) }\end{array}$ & 41.460 & $\begin{array}{l}6 \\
2 \\
1 \\
9\end{array}$ & $\begin{array}{l}6 \\
2 \\
1 \\
9\end{array}$ & $\begin{array}{l}6 \\
3 \\
1 \\
10\end{array}$ \\
\hline $\begin{array}{l}\text { 3a. Zona: } \\
\text { É composta pelos } \\
\text { rios Aguapeí, Peixe } \\
\text { e das vertentes do } \\
\text { rio Paraná situadas } \\
\text { na porção ocidental } \\
\text { do Estado de São } \\
\text { Paulo. }\end{array}$ & $\begin{array}{l}\text { 31-Peixe } \\
\text { 32-Aguapeí ou Feio } \\
\text { 92-Paraná Vertentes } \\
\text { Parciais } \\
\text { TOTAL ( } 3 \text { Bacias) }\end{array}$ & 26.050 & $\begin{array}{l}1 \\
1 \\
- \\
2\end{array}$ & $\begin{array}{l}2 \\
3 \\
- \\
5\end{array}$ & $\begin{array}{l}2 \\
3 \\
- \\
5\end{array}$ \\
\hline $\begin{array}{l}\text { 4a. Zona: } \\
\text { É formada pelo rio } \\
\text { Santo Anastácio, e os } \\
\text { pequenos corpos } \\
\text { d'água que drenam } \\
\text { em direção ao rio } \\
\text { Paraná e toda a bacia } \\
\text { hidrográfica do rio } \\
\text { Paranapanema. }\end{array}$ & $\begin{array}{l}\text { 41-Santo Anastácio } \\
\text { 42-Paranapanema Alto } \\
\text { 43-Paranapanema Baixo } \\
\text { 92-Paraná Vertentes } \\
\text { Parciais } \\
\text { TOTAL (4 Bacias) }\end{array}$ & 57.614 & $\begin{array}{l}1 \\
1 \\
1 \\
- \\
3\end{array}$ & $\begin{array}{l}1 \\
3 \\
2 \\
- \\
6\end{array}$ & $\begin{array}{l}1 \\
3 \\
2 \\
- \\
6\end{array}$ \\
\hline
\end{tabular}




\begin{tabular}{|c|c|c|c|c|c|}
\hline $\begin{array}{l}\text { 5a. Zona: } \\
\text { Abrange todos os } \\
\text { corpos d'água que } \\
\text { drenam para o mar } \\
\text { nos limites do } \\
\text { Estado, ou seja, } \\
\text { toda a faixa } \\
\text { litorânea do Estado } \\
\text { de São Paulo. }\end{array}$ & $\begin{array}{l}\text { 51-Baixada Santista } \\
\text { 52-Litoral Norte } \\
\text { 53-Litoral Sul } \\
\text { 54-Ribeira do Iguape } \\
\text { TOTAL (4 Bacias) }\end{array}$ & 27.000 & $\begin{array}{l}5 \\
- \\
1 \\
2 \\
8\end{array}$ & $\begin{array}{l}5 \\
- \\
1 \\
3 \\
9\end{array}$ & $\begin{array}{l}5 \\
- \\
1 \\
3 \\
9\end{array}$ \\
\hline $\begin{array}{l}\text { 6a. Zona: } \\
\text { Trecho paulista da } \\
\text { bacia hidrográfica } \\
\text { do rio Paraíba do } \\
\text { Sul. }\end{array}$ & $\begin{array}{l}\text { 61-Paraíba do Sul } \\
\text { 62-Serra da Mantiqueira } \\
\text { TOTAL ( } 2 \text { Bacias) }\end{array}$ & 15.061 & $\begin{array}{l}4 \\
- \\
4\end{array}$ & $\begin{array}{l}6 \\
- \\
6\end{array}$ & $\begin{array}{l}6 \\
- \\
6\end{array}$ \\
\hline $\begin{array}{l}\text { 7a. Zona: } \\
\text { É integrada pelas } \\
\text { bacias hidrográficas } \\
\text { dos rios Pardo, } \\
\text { Sapucaí, Carmo e } \\
\text { Canoas, incluindo } \\
\text { os tributários do rio } \\
\text { Grande. }\end{array}$ & $\begin{array}{l}\text { 71-Sapucaí-Mirim } \\
\text { 72-Pardo } \\
\text { 73-Mogi-Guaçu } \\
\text { 91-Rio Grande Vertente } \\
\text { Parcial } \\
\text { TOTAL (4 Bacias) }\end{array}$ & 40.600 & $\begin{array}{l}1 \\
2 \\
3 \\
-\end{array}$ & $\begin{array}{l}2 \\
4 \\
4 \\
- \\
10\end{array}$ & $\begin{array}{r}2 \\
4 \\
4 \\
- \\
10\end{array}$ \\
\hline $\begin{array}{l}\text { 8a. Zona: } \\
\text { Compreende as } \\
\text { bacias hidrográficas } \\
\text { do rio Turvo, São } \\
\text { José dos Dourados } \\
\text { e as vertentes do } \\
\text { curso inferior do rio } \\
\text { Grande a montante } \\
\text { de Ilha Solteira. }\end{array}$ & $\begin{array}{l}\text { 81-Turvo } \\
\text { 82-São José dos } \\
\text { Dourados } \\
\text { 91-Rio Grande Vertente } \\
\text { Parcial } \\
\text { TOTAL (3 Bacias) }\end{array}$ & 22.900 & $\begin{array}{l}1 \\
4\end{array}$ & $\begin{array}{l}6 \\
1 \\
1 \\
8\end{array}$ & $\begin{array}{r}2 \\
4 \\
4 \\
10\end{array}$ \\
\hline
\end{tabular}

Elaborada por: MIDAGLIA, C. L., 2009. Fonte: Relatórios CETESB, 1978-1993.

Desde o início da operação da rede de monitoramento, nota-se que já existia uma forte concentração do conjunto de pontos de amostragem na $1^{\mathrm{a}}$ e na $2^{\mathrm{a}}$ zonas hidrográficas, que corresponderiam hoje às UGRHIs 05- Piracicaba/ Capivari / Jundiaí, 06-Alto Tietê e 13-Tietê / Jacaré. O registro de tal fato pode ver visualizado no Mapa 1 - Pontos da Rede de monitoramento da qualidade das águas de 1983, que constava do relatório de Caracterização dos Recursos Hídricos de São Paulo de 1984, elaborado pelo DAEE, para descrever com detalhes as águas do Estado. Esta concentração de pontos provavelmente ocorreu devido à já visível perda de qualidade das águas no entorno da 
Mapa 1- Pontos da Rede de Monitoramento da Qualidade das Águas - Ano 1983

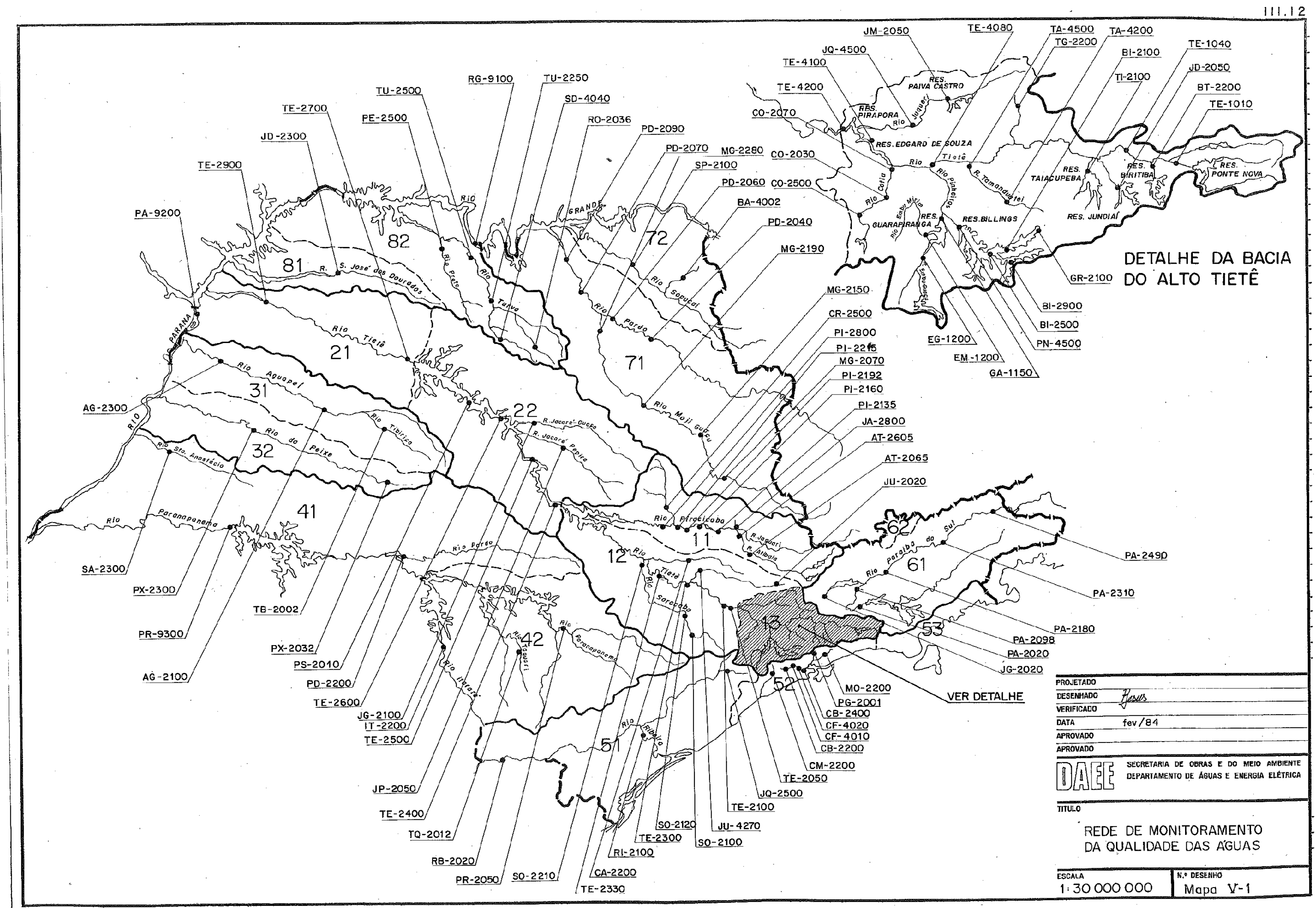


capital paulista, bem como às dificuldades variadas de logística existentes desde o momento da coleta, com prazo de validade de 24 horas até o transporte para processamento laboratorial das amostras.

Durante estes mais de 30 anos de existência, a rede manteve, de certa forma, uma distribuição proporcional bem semelhante no que se refere a número de corpos hídricos avaliados por classes, conforme o tipo de enquadramento definido no Decreto $n .^{\circ} 8468$, já citado anteriormente. No início em 1978, nota-se uma maior ênfase na colocação de pontos em áreas de mananciais da região metropolitana, cuja proporção era o dobro da que existente em 2008. O número de pontos e a média do IQA por classe é demonstrado no quadro 4:

Quadro 4 - Classes dos rios e reservatórios amostrados por ano.

\begin{tabular}{|c|c|c|c|c|c|}
\hline $\begin{array}{l}\text { Total de Pontos } \\
\text { por Classes }\end{array}$ & $\begin{array}{c}0 \text { ou } \\
1\end{array}$ & 2 & 3 & 4 & Proporção \\
\hline $\begin{array}{c}\text { Total de pontos em } \\
1978(74) \\
\\
\text { Média Anual IQA=> } \\
59,56\end{array}$ & $\begin{array}{c}11 \\
77,48\end{array}$ & $\begin{array}{c}50 \\
61,89\end{array}$ & $\begin{array}{c}5 \\
55,21\end{array}$ & $\begin{array}{c}8 \\
23,10\end{array}$ & $\begin{array}{l}\text { Monit.Classes } 1978 \\
=1 \quad 2=3 \quad=4 \\
11 \% \\
7 \%\end{array}$ \\
\hline $\begin{array}{c}\text { Pontos em } 1991 \\
(101) \\
\text { Média Anual IQA=> } \\
55,85\end{array}$ & $\begin{array}{c}9 \\
74,43\end{array}$ & $\begin{array}{c}75 \\
58,43\end{array}$ & $\begin{array}{c}7 \\
50,63\end{array}$ & $\begin{array}{c}10 \\
21,03\end{array}$ & 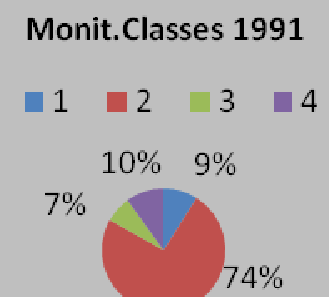 \\
\hline $\begin{array}{c}\text { Pontos em } 1996 \\
(122) \\
\text { Média Anual IQA=> } \\
56,75\end{array}$ & 76,42 & $\begin{array}{c}94 \\
58,90\end{array}$ & 51,23 & $\begin{array}{c}11 \\
24,04\end{array}$ & $\begin{array}{l}\text { Monit.Classes } 1996 \\
\begin{array}{c|ccc}1 & =3 & \square & \\
& 9 \% & 8 \% & \end{array} \\
6 \%\end{array}$ \\
\hline
\end{tabular}




\begin{tabular}{|c|c|c|c|c|c|}
\hline $\begin{array}{c}\text { Pontos em } 2004 \\
(189) \\
\text { Média Anual IQA=> } \\
55,69\end{array}$ & $\begin{array}{c}15 \\
73,59\end{array}$ & $\begin{array}{c}142 \\
59,38\end{array}$ & $\begin{array}{c}15 \\
42,27\end{array}$ & $\begin{array}{c}17 \\
20,91\end{array}$ & $\begin{array}{c}\text { Monit.Classes } 2004 \\
\square 1=2=3=4 \\
8 \% 9 \% \quad 8 \%\end{array}$ \\
\hline $\begin{array}{c}\text { Pontos em } 2008 \\
(289) \\
\text { Média Anual IQA => } \\
56,05\end{array}$ & $\begin{array}{c}19 \\
77,64\end{array}$ & $\begin{array}{c}220 \\
59,24\end{array}$ & $\begin{array}{c}21 \\
45,15\end{array}$ & $\begin{array}{c}29 \\
25,06\end{array}$ & $\begin{array}{l}\text { Monit.Classes } 2008 \\
\begin{array}{c}1 \square 2 \square 3 \\
10 \% 7 \% \\
7 \%\end{array}\end{array}$ \\
\hline
\end{tabular}

Elaborado por: MIDAGLIA, C. L. Fonte: Relatórios CETESB, 1978-2008.

O pleno crescimento da rede para o interior só será possível quando for acompanhado do aumento da descentralização dos laboratórios. Além disto, existem os altos custos para aparelhamento, capacitação e credenciamento dos laboratórios de análises fisico-químicas, microbiológicas e hidrobiológicas. O quadro 5 mostra quando estes foram inaugurados no interior do Estado:

\section{Quadro 5 - Fundação de Laboratórios no Interior do Estado de São Paulo.}

\begin{tabular}{|l|c|}
\hline Laboratórios de Análises de Água CETESB & Ano de Inauguração \\
\hline Laboratório da Sede (São Paulo) & 1969 \\
\hline Setor de Laboratório de Cubatão & 1971 \\
\hline Setor de Laboratório de Campinas & 1972 \\
\hline Setor de Laboratório de Taubaté & 1972 \\
\hline Setor de Laboratório de Ribeirão Preto & 1975 \\
\hline Setor de Laboratório de Sorocaba & 1978 \\
\hline Setor de Laboratório de Marília & 1979 \\
\hline Setor de Laboratório de Piracicaba & 1990 a 2004 \\
\hline Setor de Laboratório de Limeira & 2005 \\
\hline
\end{tabular}

Fonte: CETESB - Divisão de Laboratórios, 2009. Fotos: Acervo Interáguas 
Com a conseqüente ampliação da rede, aumentou o volume de dados gerados e necessidade de interpretação dos laudos. Os pontos foram ganhando nome e sobrenome para ser associados aos números das amostras. Passaram a ser codificados primeiramente em função da sua localização no corpo hídrico. Nos primeiros relatórios os nomes aparecem em forma de 2 letras e 4 números: PA 2490 (Ponte na cidade de Queluz), e informava somente o código do nome do recurso hídrico, no caso PA correspondia ao corpo hídrico Rio Paraíba do Sul, $\mathbf{2}$ era referente à sua classe e $\mathbf{4 0 0}$ a localização em termos de jusante (999 corresponde a foz) ou montante (000 corresponde a nascente). Nesta época, a codificação do rio correspondia ao curso todo (até a foz no Estado do Rio de Janeiro). Com o passar do tempo e a sofisticação do armazenamento dos dados em um novo banco relacional, chamado INTERÁGUAS (Access 98), os pontos passaram a ter seus códigos revisados. Ficaram mais elaborados, sendo possível identificá-los geograficamente, pois, descrevem, através da chamada codificação completa, o seu endereço geográfico no espaço compreendido pelo território paulista. Assim, após a implementação do banco em 1998, o ponto PA 2490 foi recodificado para 18 dígitos, passando para 00SP02567PARB02900, ou apenas PARB 02900, em sua forma simplificada. Pelo código, descobre-se o tipo de monitoramento (Ex. o dígito $\mathbf{0}$ equivale à rede de águas superficiais, $\mathbf{1}$ a sedimento, etc). Segue com o tipo de sistema hídrico: 0 para rios e $\mathbf{1}$ para reservatórios, classificando o tipo de ambiente do ponto como descrito anteriormente, pois alguns parâmetros (fósforo) variam em função desta condição. Depois, nos próximos dois campos, coloca-se a sigla do estado onde esta localizada o ponto de coleta, preenchido pelas letras SP. A posição geográfica dentro do Estado de São Paulo, pode ser descoberta pelo $4^{\circ}$. campo, composto por 2 dígitos, referente às 22 UGRHIS. No $5^{\circ}$ campo, são colocados os três dígitos do código numérico correspondente ao número do município onde está situado o ponto. O nome do corpo hídrico, composto por 4 letras, vem em seguida, por exemplo, Rio Paraíba, PARB. 
Depois do código do sistema hídrico, seguem-se mais 2 dígitos correspondente, a classe do rio no local do ponto, e por fim mais três dígitos referentes a sua localização ao longo do percurso do mesmo, distancia relativa entre a nascente e a foz, como mostrado na figura 9:

\section{Figura 9 - Procedimento para codificação de Pontos de Monitoramento da CETESB.}

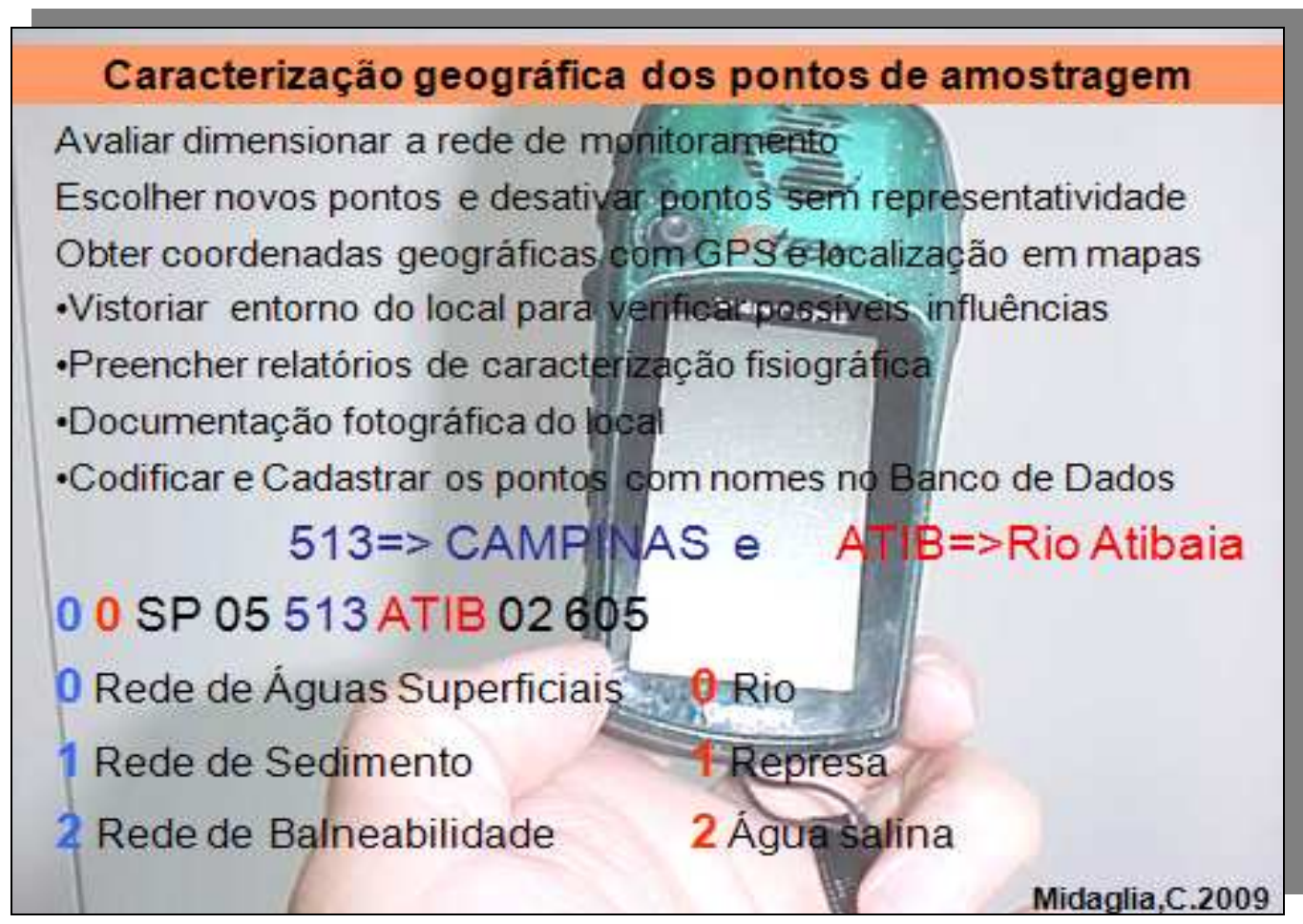

Fonte: CETESB, 2005.

Deve-se ressaltar que todos os pontos monitorados estão padronizados por esta codificação.

Em 2008, dos 333 pontos existentes na rede básica da CETESB, 59 $(17,4 \%)$ já tinham 30 anos de monitoramento. Isso é um acervo precioso que merece ser melhor estudado geograficamente, pois registra um histórico que poucos estados ou mesmo países tem. Por outro lado, isto mostra também que a ampliação, adequação e a necessidade de constante de renovação da rede é necessária para manter a capacidade dinâmica de diagnóstico frente a novos problemas ambientais que resultam em contaminação da água. 
Tabela 4 - Resultados das Médias do IQA de pontos

com 30 anos de existência.

\begin{tabular}{|c|c|c|c|c|c|c|c|c|c|}
\hline $\begin{array}{c}\text { Data } \\
\text { de } \\
\text { iní- } \\
\text { cio }\end{array}$ & $\begin{array}{c}\text { UGR } \\
\text { HI }\end{array}$ & $\begin{array}{c}\text { Clas- } \\
\text { se }\end{array}$ & $\begin{array}{c}\text { Nome } \\
\text { Antigo } \\
\text { do } \\
\text { Ponto }\end{array}$ & $\begin{array}{c}\text { Nome Atual } \\
\text { (simplifi- } \\
\text { cado) }\end{array}$ & Corpo Hídrico & $\begin{array}{c}\text { IQA } \\
1978\end{array}$ & $\begin{array}{c}\text { IQA } \\
1988\end{array}$ & $\begin{array}{c}\text { IQA } \\
1998\end{array}$ & $\begin{array}{l}\text { IQA } \\
2008\end{array}$ \\
\hline 1974 & - & 2 & PA 2310 & PARB 02600 & Rio Paraíba do Sul & 59,83 & 59,00 & 51,93 & 45,99 \\
\hline 1974 & 2 & 2 & 2490 & ARB 02900 & Rio Paraíba do Sul & 5,08 & 57,50 & 57,14 & 55,89 \\
\hline 1974 & 4 & 2 & PD 2040 & PARD 02500 & $\begin{array}{l}\text { Rio Pardo- } \\
\text { UGRHIs } 4 \text { e } 12\end{array}$ & 65,50 & 69,16 & 57,37 & 66,21 \\
\hline 1974 & 5 & 2 & CA 2200 & CPIV 02200 & Rio Capivari & 34,33 & 27,20 & 31,40 & 31,93 \\
\hline 1974 & 5 & 2 & CR 2500 & CRUM 02500 & Rio Corumba & 51,75 & 45,00 & 52,28 & 54,25 \\
\hline 1974 & 5 & 2 & JA 2800 & JAGR 02800 & $\begin{array}{l}\text { Rio Jaguari- } \\
\text { UGRHI } 05\end{array}$ & 53,25 & 52,40 & 60,25 & 55,76 \\
\hline 1977 & 5 & 2 & JU 2020 & 2020 & $\begin{array}{l}\text { Rio Jundiaí- } \\
\text { UGRHI } 05\end{array}$ & 48,50 & 46,66 & 45,87 & 37,28 \\
\hline 1974 & 5 & 4 & $\mathrm{JU} 4270$ & JUNA 04270 & $\begin{array}{l}\text { Rio Ju } \\
\text { UGRH }\end{array}$ & 35,16 & 32,83 & 38,95 & 40,61 \\
\hline 1974 & 5 & 2 & PI 2100 & РСAB 02100 & Rio Piracicaba & & IC & 56,47 & 53,73 \\
\hline 1977 & 5 & 2 & & РСAB 02192 & Rio Pirac & & & 36,45 & 35,54 \\
\hline 1974 & 5 & 2 & & PCAB 02800 & Rio Piracicaba & & & 45,67 & 42,04 \\
\hline 1974 & 6 & 2 & BI 2100 & RGDE 02900 & Res. do Rio Gra & 64,33 & 81,00 & 82,85 & 82,03 \\
\hline 1976 & 6 & 2 & 2500 & BILL 02500 & Res. Billings & 36,69 & 31,66 & 69,08 & 80,30 \\
\hline 1976 & 6 & 2 & 2900 & ILL 02900 & Res. Billings & 48,72 & 51,50 & 76,93 & 82,18 \\
\hline 1977 & 6 & 2 & BT 2200 & BMIR 02800 & Rio Biritiba-Mirim & 71,16 & 70,33 & 66,15 & 73,55 \\
\hline 1977 & 6 & 0 & CO 2500 & COGR 00900 & Res. das Graças & 82,00 & 68,66 & 83,48 & 75,49 \\
\hline 1978 & 6 & 2 & CO 2030 & COTI 03800 & Rio Cotia & 48,25 & 40,40 & 46,19 & 34,95 \\
\hline 1977 & 6 & 0 & EG 1200 & EMGU 00800 & Rio Embu-Guaçu & 69,00 & 61,83 & 64,22 & 69,36 \\
\hline 1974 & 6 & 0 & GA 1150 & GUAR 00900 & Res. do Guarapiranga & 80,08 & 84,00 & 84,43 & 76,61 \\
\hline 1977 & 6 & 0 & JM 2050 & JQJU 00900 & $\begin{array}{l}\text { Res. do J } \\
\text { Paiva Cas }\end{array}$ & 89,00 & 76,90 & 80,69 & 82,08 \\
\hline 1974 & 6 & 3 & JQ 4500 & JQRI 03800 & Rio Juqueri & 28,33 & 39,33 & 30,76 & 23,61 \\
\hline 1977 & 6 & 4 & PN 4500 & PINH 04100 & Rio Pinheiros & 17,08 & 15,50 & 26,75 & 31,52 \\
\hline 1977 & 6 & 2 & TI 2100 & TAIA 02800 & Rio Taiaçupeba-Aç & 79,16 & 80,00 & 76,42 & NC \\
\hline 1977 & 6 & 4 & TA 4200 & TAMT 04500 & Rio Tamanduateí & 14,50 & 13,66 & 13,90 & 15,72 \\
\hline 1977 & 6 & 4 & TA 4500 & TAMT 04900 & Rio Tamanduateí & 12,25 & 12,83 & 13,04 & 13,70 \\
\hline 1977 & 6 & 0 & TG 2200 & TGDE 00900 & $\begin{array}{l}\text { Res. do Tanque } \\
\text { Grande }\end{array}$ & 86,33 & 83,00 & 81,93 & 76,68 \\
\hline 1976 & 6 & 4 & TE 4100 & TIES 04900 & Res. Edgard de Souza & 33,08 & 15,33 & 16,50 & 18,76 \\
\hline 1977 & 6 & 2 & TE 1010 & TIET 02050 & Rio Tietê & 69,18 & 63,16 & 63,62 & 68,09 \\
\hline 1976 & 6 & 4 & TE 4020 & TIET 04150 & Rio Tietê & 18,16 & 27,16 & 20,09 & 15,99 \\
\hline 1976 & 6 & 4 & TE 4080 & TIET 04200 & Rio Tietê & 16,33 & 15,83 & 14,52 & 16,40 \\
\hline
\end{tabular}




\begin{tabular}{|c|c|c|c|c|c|c|c|c|c|}
\hline 1974 & 6 & 4 & TE 4200 & TIPI 04900 & Res. de Pirapora & 38,25 & 21,80 & 16,84 & 21,88 \\
\hline 1977 & 7 & 0 & CM 2200 & CAMO 00900 & Res. Capivari-Monos & 70,33 & 70,50 & 69,83 & 71,05 \\
\hline 1977 & 7 & 2 & \begin{tabular}{|l|} 
CF 4020 \\
CF 2020 \\
\end{tabular} & CFUG 02900 & $\begin{array}{l}\text { Canal de Fug } \\
\text { UHE Henry B }\end{array}$ & 69,91 & 58,83 & 71,47 & 3,03 \\
\hline 1977 & 7 & 0 & CB 2200 & CUBA 02700 & Rio Cubatão & 60,25 & 73,66 & 65,84 & 65,17 \\
\hline 1977 & 7 & 3 & CB 2400 & CUBA 03900 & Rio Cub & 53,91 & 45,33 & 54,71 & 55,93 \\
\hline 1977 & 7 & 3 & MO 2200 & MOJI 02800 & $\begin{array}{l}\text { Rio Moji- } \\
\text { UGRHI } 07\end{array}$ & 31,75 & 39,50 & 46,14 & 46,60 \\
\hline 1974 & 8 & 2 & SP 2100 & SAPU 02400 & $\begin{array}{l}\text { Rio Sapucaí- } \\
\text { UGRHI } 08\end{array}$ & 57,30 & 60,66 & 62,19 & 65,18 \\
\hline 1976 & 9 & 2 & MG 2070 & MOGU 02200 & Rio Mogi-Guaçu & 56,66 & 50,83 & 55,93 & 55,44 \\
\hline 1977 & 9 & 2 & MG 2280 & MOGU 02900 & Rio Mogi-Guaçu & 60,80 & 66,40 & 62,10 & 62,56 \\
\hline 1976 & 10 & 2 & So 2100 & SORO 02100 & Rio Sorocaba & 40,66 & 30,60 & 44,88 & 46,70 \\
\hline 1974 & 10 & 2 & 02210 & SORO 02900 & Rio Sorocaba & 58,10 & 59,00 & 50,49 & 55,90 \\
\hline 1978 & 10 & 2 & E 2300 & TIET 02350 & Rio Tietê & 31,83 & 42,00 & 39,55 & 34,14 \\
\hline 1977 & 10 & 2 & E 2330 & TIET 02400 & Rio Tietê & 52,41 & 42,40 & 29,84 & 31,89 \\
\hline 1977 & 11 & 0 & 2500 & JUQI 00800 & Rio Juquiá & 74,50 & 72,00 & 65,50 & 63,33 \\
\hline 1974 & 11 & 2 & RI 2100 & RIIG 02500 & Rio Ribeira de Iguape & 65,66 & 63,00 & 61,23 & 60,81 \\
\hline 1974 & 12 & 2 & PD 2090 & PARD 02800 & $\begin{array}{l}\text { Rio Pardo- UGRHIs } 4 \\
\text { e } 12\end{array}$ & 63,10 & 66,16 & 65,70 & 65,56 \\
\hline 1974 & 13 & 3 & JG 2100 & JCGU 03900 & Rio Jacaré-Guaçu & 68,33 & 65,16 & 55,70 & 61,95 \\
\hline 1974 & 13 & 2 & TE 2400 & TIET 02500 & Rio Tietê & 84,25 & 76,83 & 69,06 & 70,32 \\
\hline 1978 & 14 & 2 & PR 2010 & PARP 02100 & Rio Paranapanema & 64,76 & 57,60 & 69,00 & 69,00 \\
\hline 1974 & 15 & 2 & PE 2500 & PRET 02800 & Rio Preto- UGRHI 15 & 68,10 & 57,16 & 55,15 & 53,99 \\
\hline 1974 & 15 & 2 & TU 2500 & TURV 02800 & Rio Turvo & 66,90 & 64,83 & 65,35 & 56,60 \\
\hline 1974 & 16 & 2 & TE 2600 & TIET 02600 & Rio Tietê & 85,00 & 71,66 & 78,14 & 83,74 \\
\hline 1974 & 18 & 2 & JD 2300 & SJDO 02500 & $\begin{array}{l}\text { Rio São José dos } \\
\text { Dourados }\end{array}$ & 73,27 & 65,50 & 67,28 & 68,67 \\
\hline 1974 & 19 & 2 & PA 9200 & PARN 02100 & Rio Paraná & 85,08 & 80,33 & 82,34 & 88,42 \\
\hline 1974 & 19 & 2 & TE 2700 & TIET 02700 & Rio Tietê & 86,63 & 82,33 & 82,80 & 85,63 \\
\hline 1974 & 19 & 2 & TE 2900 & TITR 02800 & Res. de Três Irmãos & 81,33 & 74,83 & 84,25 & 88,96 \\
\hline 1974 & 20 & 2 & AG 2300 & AGUA 02800 & Rio Aguapeí & 70,36 & 64,33 & 62,54 & 70,37 \\
\hline 1974 & 22 & 2 & PR 9300 & PARP 02750 & Rio Paranapanema & 79,75 & 77,66 & 79,15 & 84,42 \\
\hline 1978 & 22 & 2 & SA 2300 & STAN 02700 & Rio Santo Anastácio & 57,16 & 41,66 & 48,78 & 58,59 \\
\hline
\end{tabular}

NC - Não calculado por falta de dados.

Elaborada por: MIDAGLIA, C. L., 2009. Fonte: Relatórios CETESB, 1978-2008. 
Desde então, a rede de monitoramento, em busca de melhor representatividade $\mathrm{e}$, em atendimento às necessidades de crescimento populacional e devido a maior espacialização das indústrias no interior do Estado, introduziu várias modificações. Com isso, foram alterados o número de pontos de amostragem, a freqüência das coletas e o conjunto de parâmetros de qualidade avaliados por ponto, que possibilitaram a geração de outros índices de avaliação da qualidade de água.

A rede de qualidade das águas interiores passou a ter vários programas de monitoramento, que complementam o diagnóstico feito pela rede básica. O Programa de balneabilidade das praias interiores, realizado desde 1994, faz amostragens em algumas praias de rios e reservatórios utilizadas para recreação e lazer, tal como a Represa de Guarapiranga. Para estes, calcula-se o IB (Índice de Balneabilidade), para qual existe outra legislação específica. (CONAMA 274/2000).

Dentre outros tipos, tem-se o monitoramento automático, realizado por meio de estações telemétricas instaladas na região do Alto e Médio Tietê, que transmitem em tempo real dados de qualidade como $O D, p H$, temperatura, turbidez e condutividade elétrica. Existe também, desde 2002, uma rede de sedimentos de freqüência anual que objetiva fazer um aperfeiçoamento do diagnóstico, dentro da coluna d'água, mostrando a condição de qualidade do sedimento no leito de rios e reservatórios, em um compartimento que sofre menos alterações de suas características químicas e biológicas ao longo do tempo. A evolução dos programas de monitoramento por número de pontos pode ser visto na figura 10 . Todos estes últimos tipos de monitoramentos citados não serão incluídos neste estudo, e nem seus pontos serão contados para efeitos de densidade espacial da rede de monitoramento. 
Atualmente, os instrumentos oficiais de medida da qualidade das Águas Superficiais no Estado de São Paulo são os Índices de Qualidade de Água divulgados pela CETESB: IQA, IVA, IAP, IB e IET.

Figura 10 - Evolução Geral dos Tipos de Monitoramento de Qualidade de água operados pela CETESB.

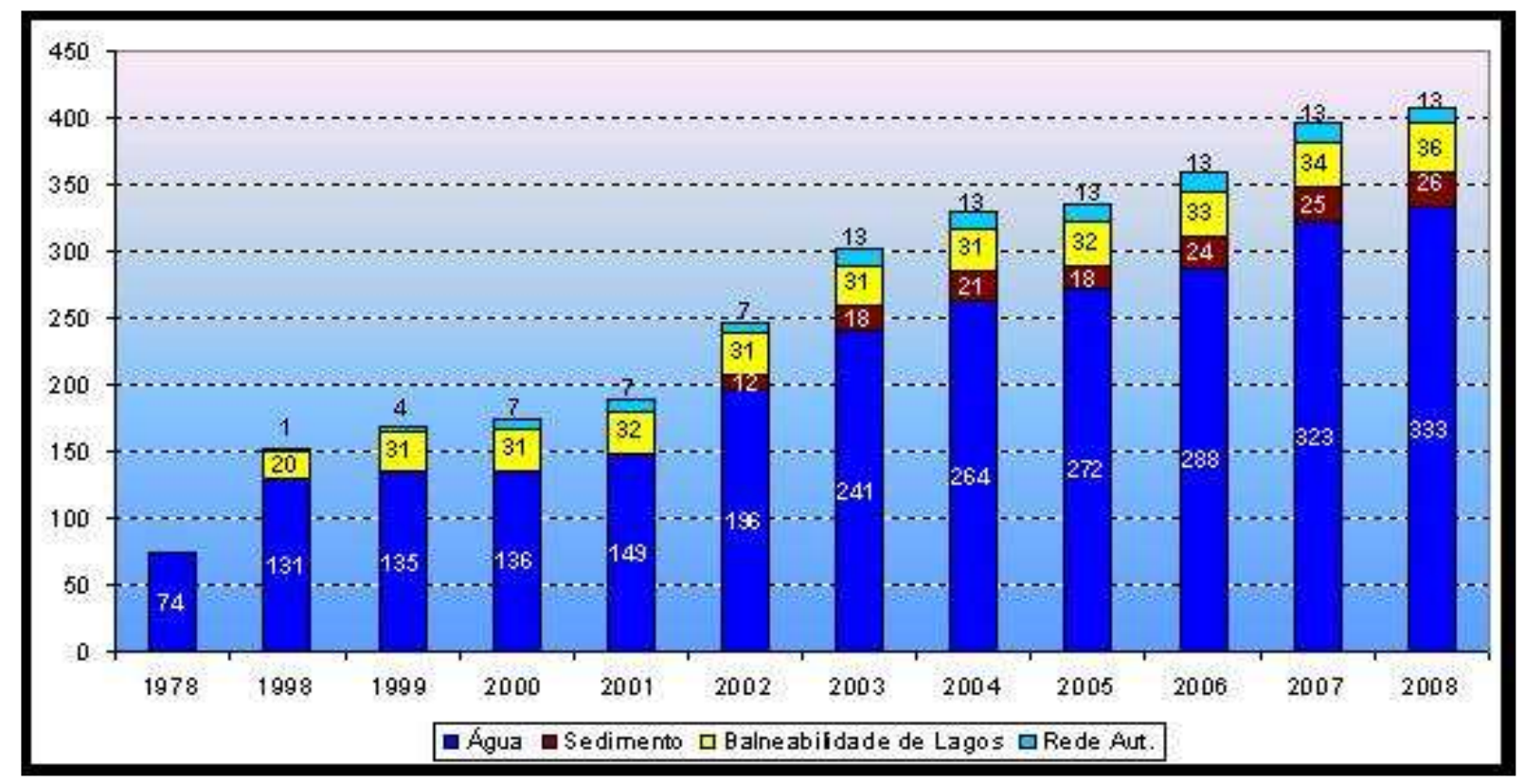

Fonte: CETESB, 2008.

Em seqüência, colocamos aqui um mosaico com fotos dos pontos da rede de monitoramento da CETESB que já possuem 30 anos de amostragem, que podem ser visualizadas na Figura 11. 
Figura 11: Fotos da Rede de Monitoramento da CETESB com 30 anos de amostragem.

PONTOS DA REDE DE

AGUAS SUPERFICIAIS

DA CETESB COM 30

ANOS DE

MONITORAMENTO
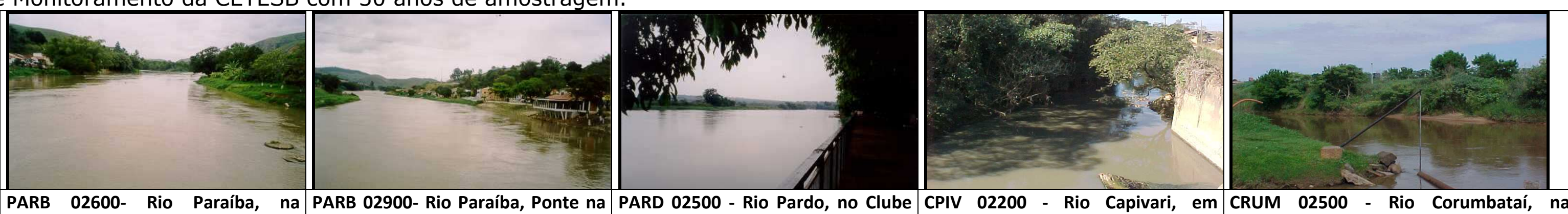
captação de Aparecida cidade de Queluz.

de Regatas de Ribeirão Preto.

CPIV 02200
Monte Mor

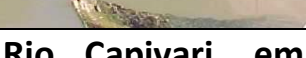
captação de Piracicaba.
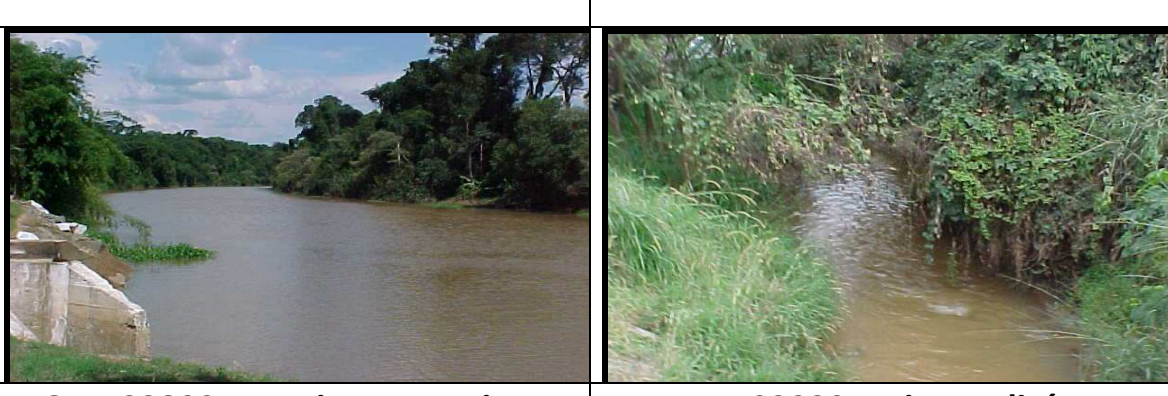

captação de Limeira.

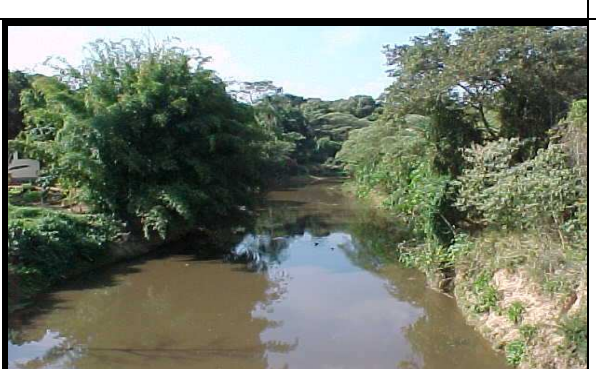

JUNA 02020 - Rio Jundiaí, em

JUNA 04270- Rio Jundiaí, em Itaici,
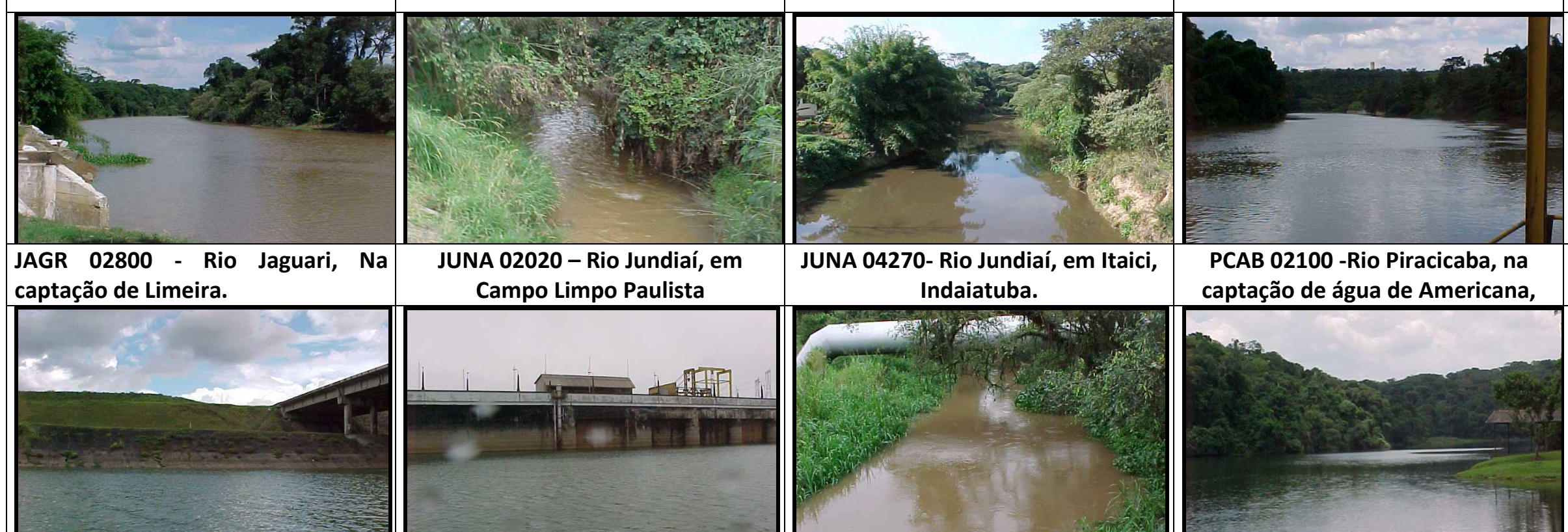

Campo Limpo Paulista

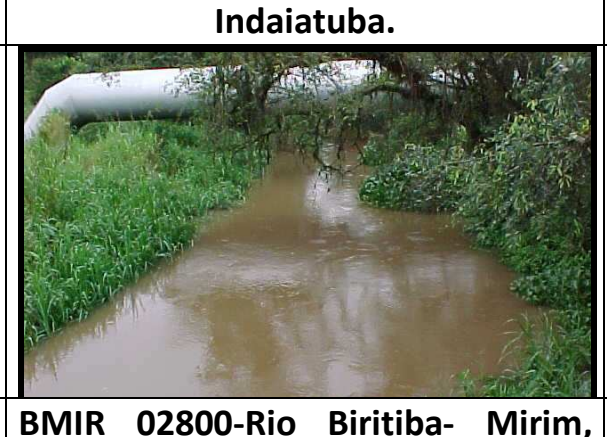

PCAB 02100 -Rio Piracicaba, na

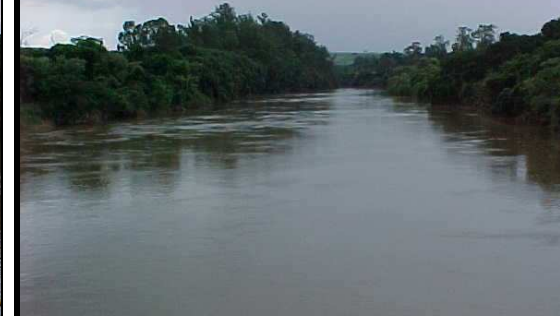

captação de água de Americana

PCAB 02192 - Rio Piracicaba, próximo à Usina Monte Alegre

PCAB 02800- Rio Piracicaba, na localidade

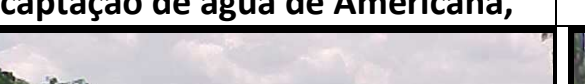

6.

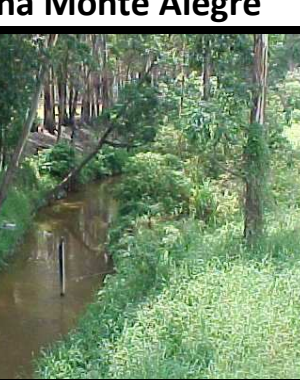

de Artemis.

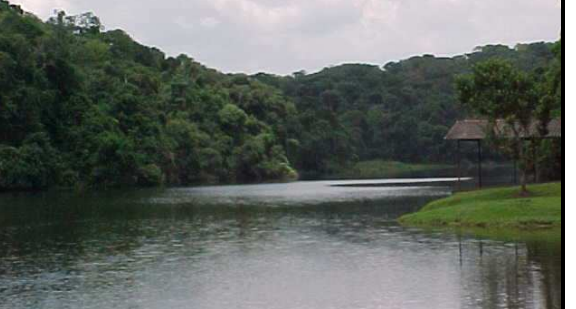

BILL 02500-Res. Billings, sob a ponte BILL 02900-Res. Billings, da Imigrantes. barragem do Summit Control.

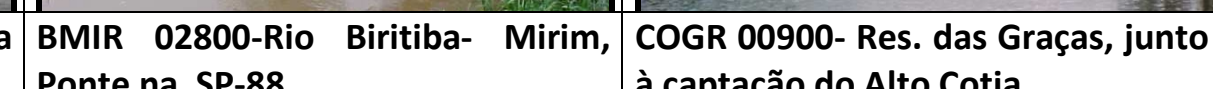

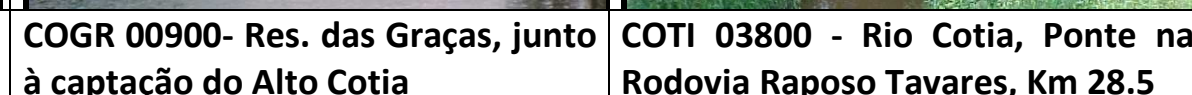

COTI 03800 - Rio Colla, Ponte na EMGU 00800 - Rio Embu-Guaçu, estrada
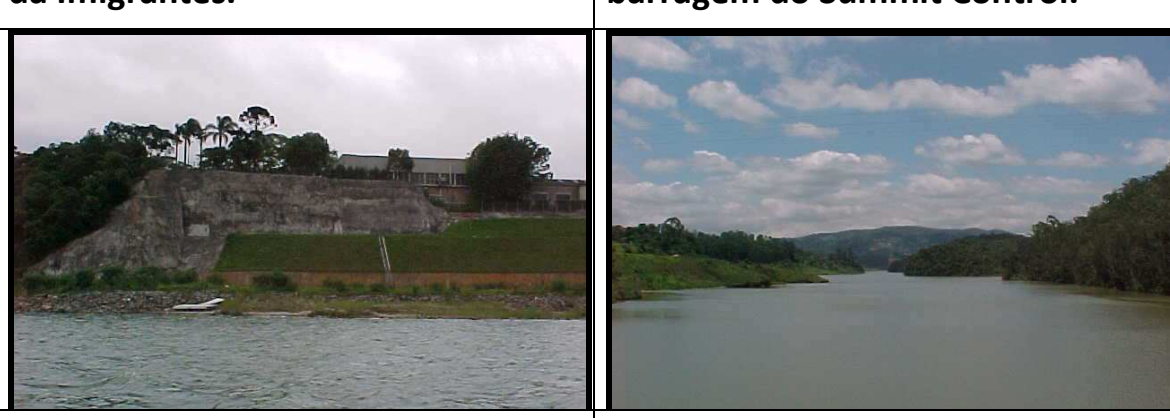

GUAR 00900 - Res. Gu
na Captação da SABESP Ponte na SP-88.
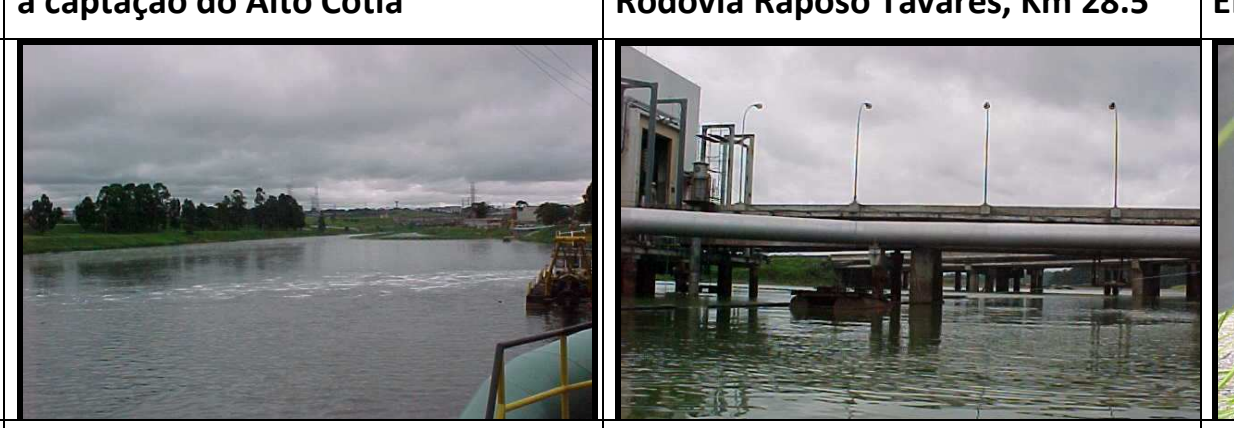

Embu-Guaçu /Fazenda llha.

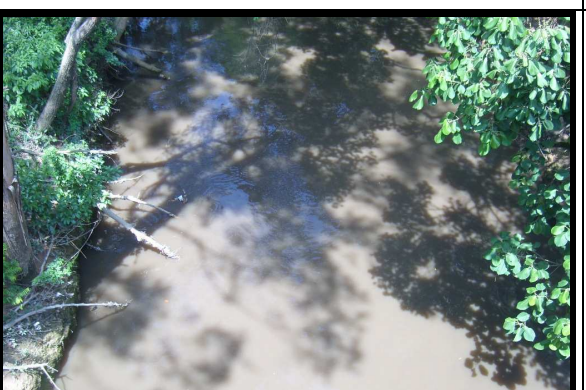
\begin{tabular}{l}
$\begin{array}{l}\text { JQJU 00900- Res. do Juqueri, na } \\
\text { Ponte Santa Inês, }\end{array}$ \\
\begin{tabular}{|l|l} 
JQRI 03800- Rio Juqueri, Po \\
rodovia Anhangüera (SP-330)
\end{tabular} \\
\hline
\end{tabular}

PINH 04100- Rio Pinheiros,
Elevatória de Pedreira.
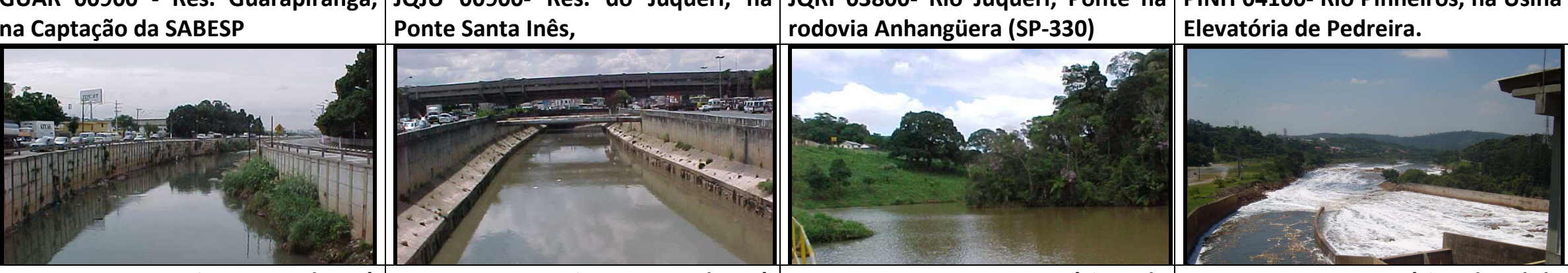
\begin{tabular}{l|l}
$\begin{array}{l}\text { RGDE 02900- Reservatório do Rio } \\
\text { Grande, captação da SABESP }\end{array}$ & $\begin{array}{l}\text { TAIA } 02800-\text { Rio } \\
\text { jusante do vertedouro }\end{array}$ \\
\hline
\end{tabular}
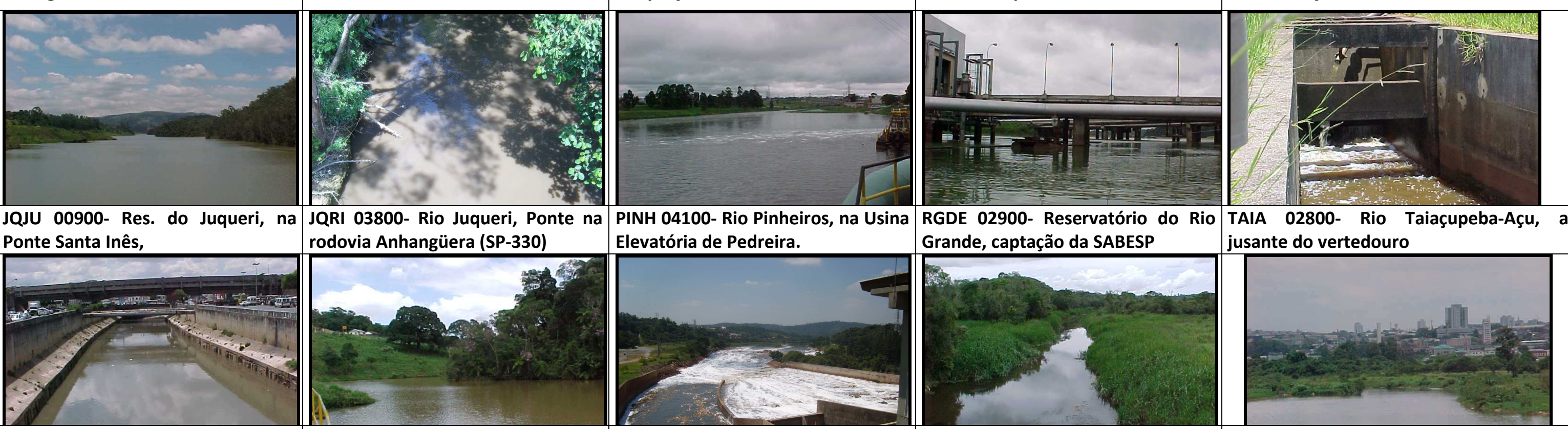

divisa de S. Caetano e Sto. André

TAMT 04900-Rio Tamanduatei,
Ponte na Av. Santos Dumont, SP

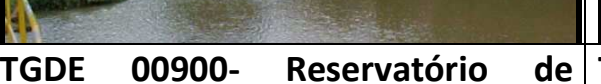

TIES 04900- Reservatório Edgard de

Souza, Próximo às comportas

TIET 02050- Rio Tietê, Ponte na SP- TIET 04150-Rio Tietê, Ponte na Rod 88 entre Mogi das Cruzes a Ayrton Senna.

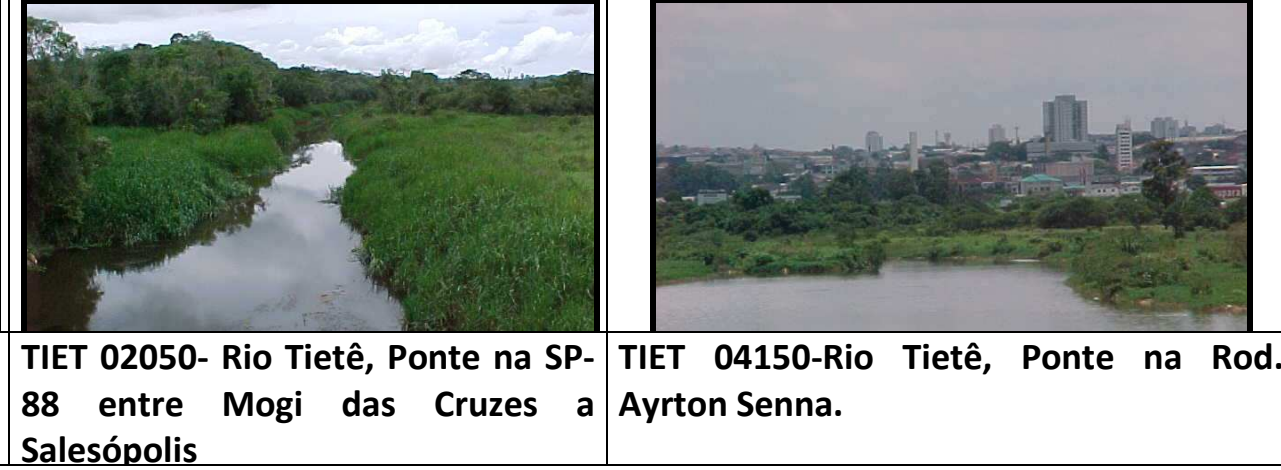




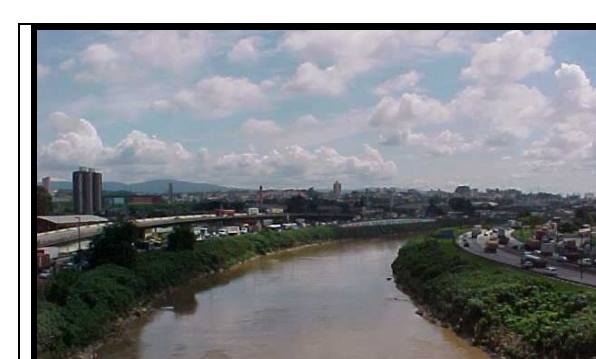

TIET 04200 Rio Tietê, Ponte dos Remédios, SP.

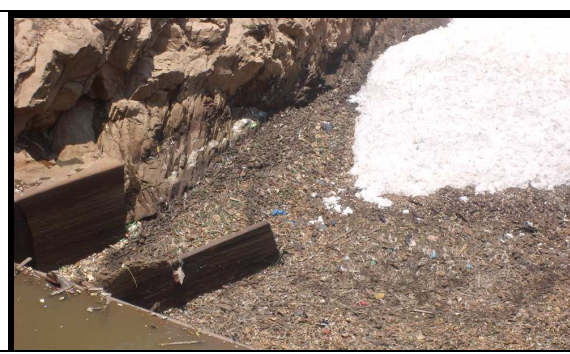

TIPI 04900- Reservatório de Pirapora, perto da comporta.

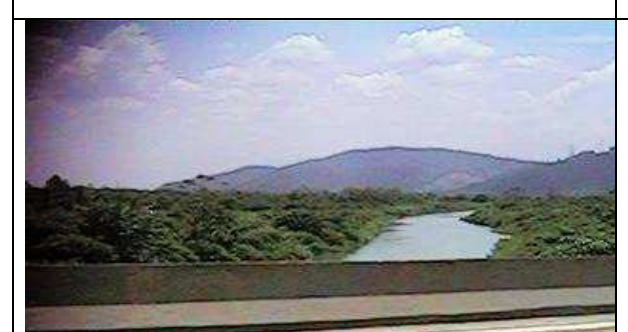

MOJI 02800- Rio Moji- Ponte na Piaçaguera.

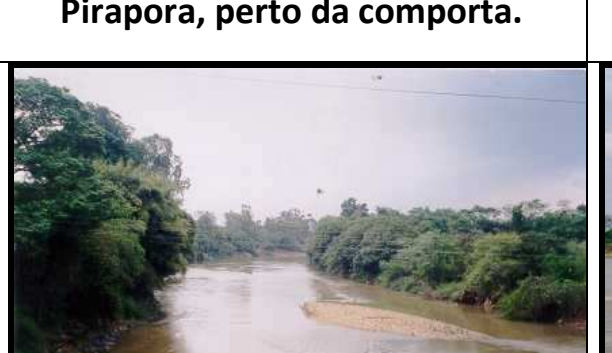

MOGU 02200- Rio Mogi-Guaçu, em

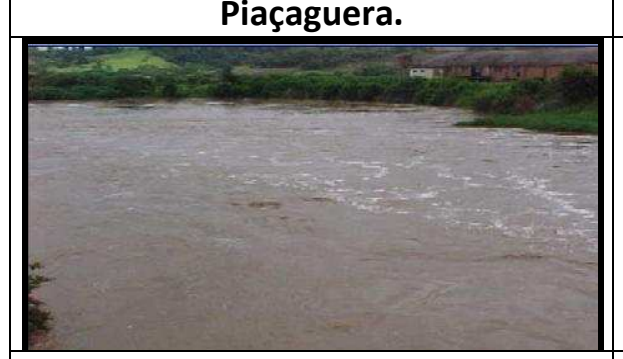

TIET 02400- Rio Tietê, Ponte rodovia SP-113, em Tietê.

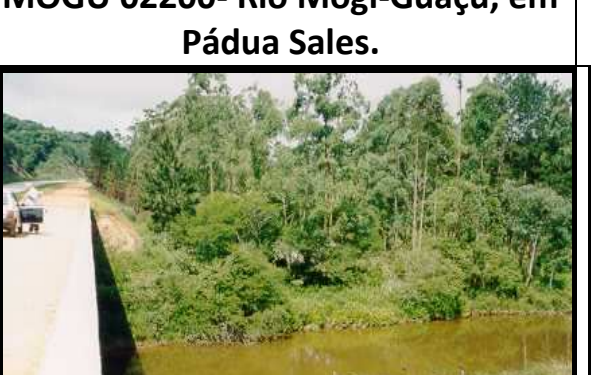

JUOI 00800- Rio Juquiá, Ponte na

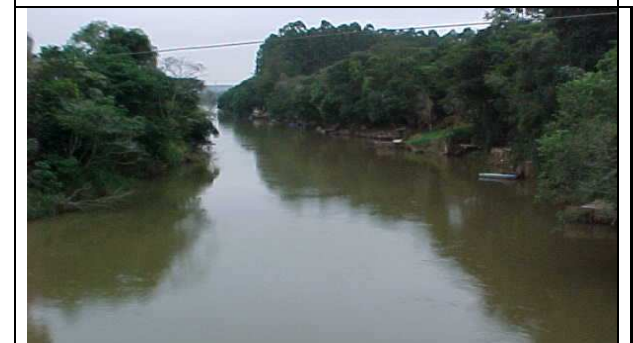

PARP 02100- Ponte na rod. que liga Campina do Monte Alegre a Buri.

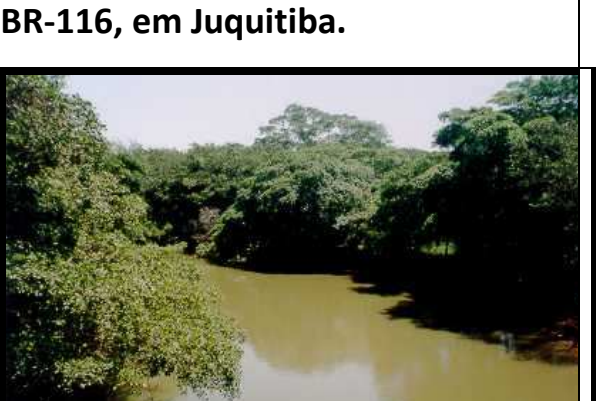

Américo de Campos Palestina.

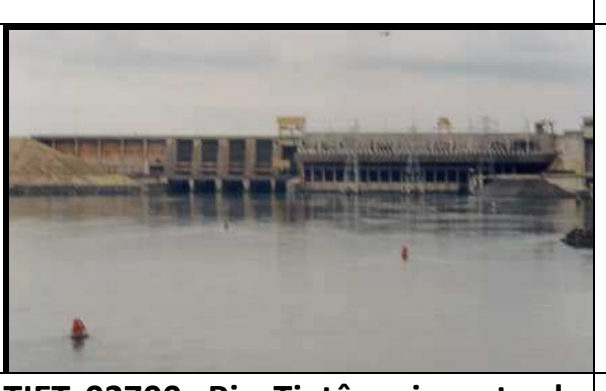

TIET 02700- Rio Tietê, a jusante da TITR 02800- Reservatório de Três barragem de Promissão. Irmãos, Ponte na rodovia SP-563

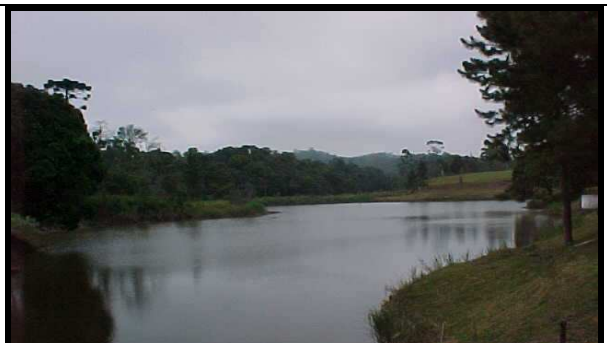

CAMO 00900- Res. Capivari-Monos, Junto à Est.de Recalque da SABESP.

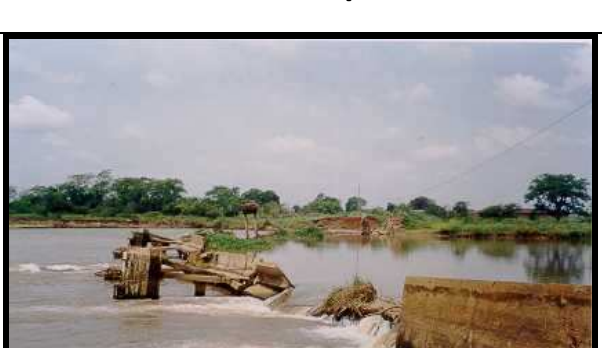

MOGU 02900- Rio Mogi-Guaçu, em Pitangueiras

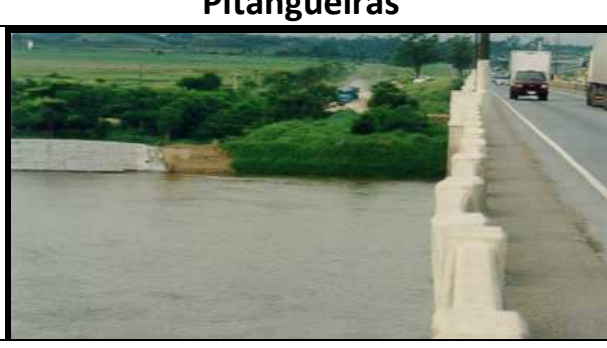

G2500- Rio Ribeira de Iguape,
rodovia BR-116, em Registro.

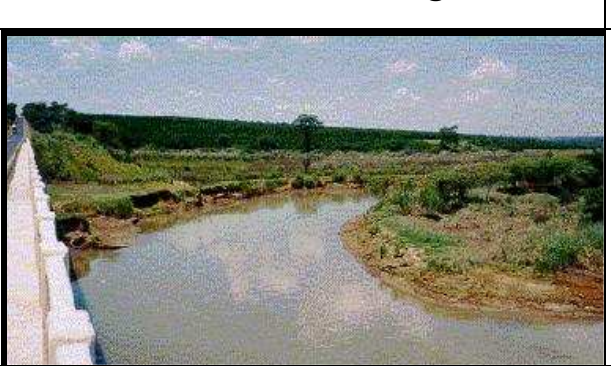

TURV 02800- Rio Turvo, na BR-153,

na divisa de Nova Granada e Icém,

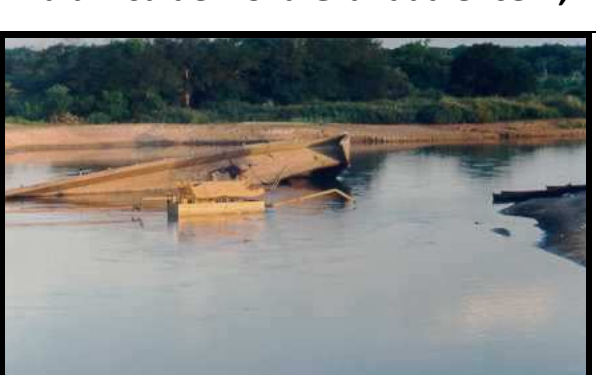

AGUA 02800- Rio Aguapeí, Ponte que liga Tupi Paulista a Andradina.

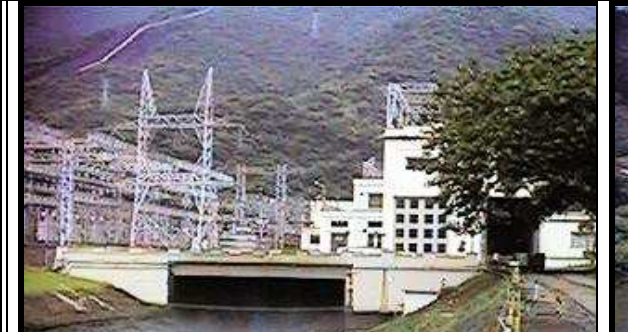

CFUG 02900- Canal de Fuga II da UHE Henry Borden

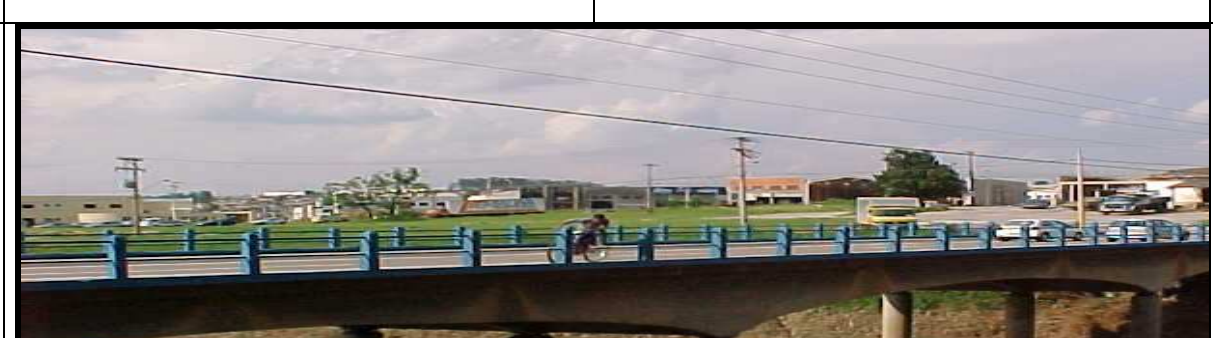

SORO 02100- Rio Sorocaba, Ponte Pinga-Pinga, em Sorocaba.

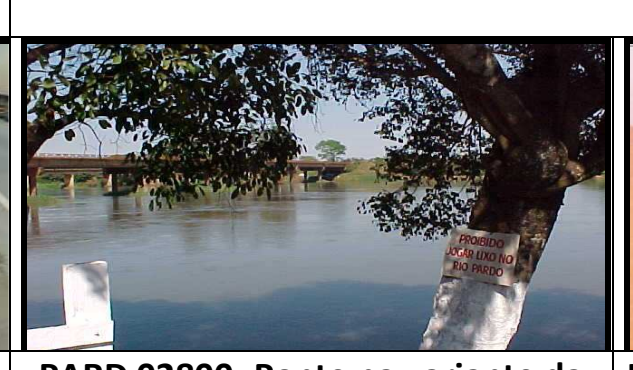

PARD 02800- Ponte na variante rodovia SP-425, em Guaíra

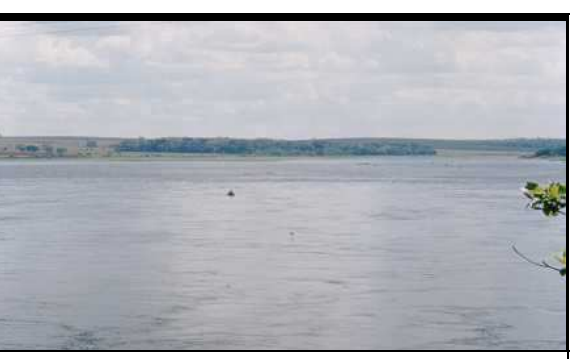

TIET 02600- Rio Tietê, jusante do canal Usina Hidrelétrica de Ibitinga. na
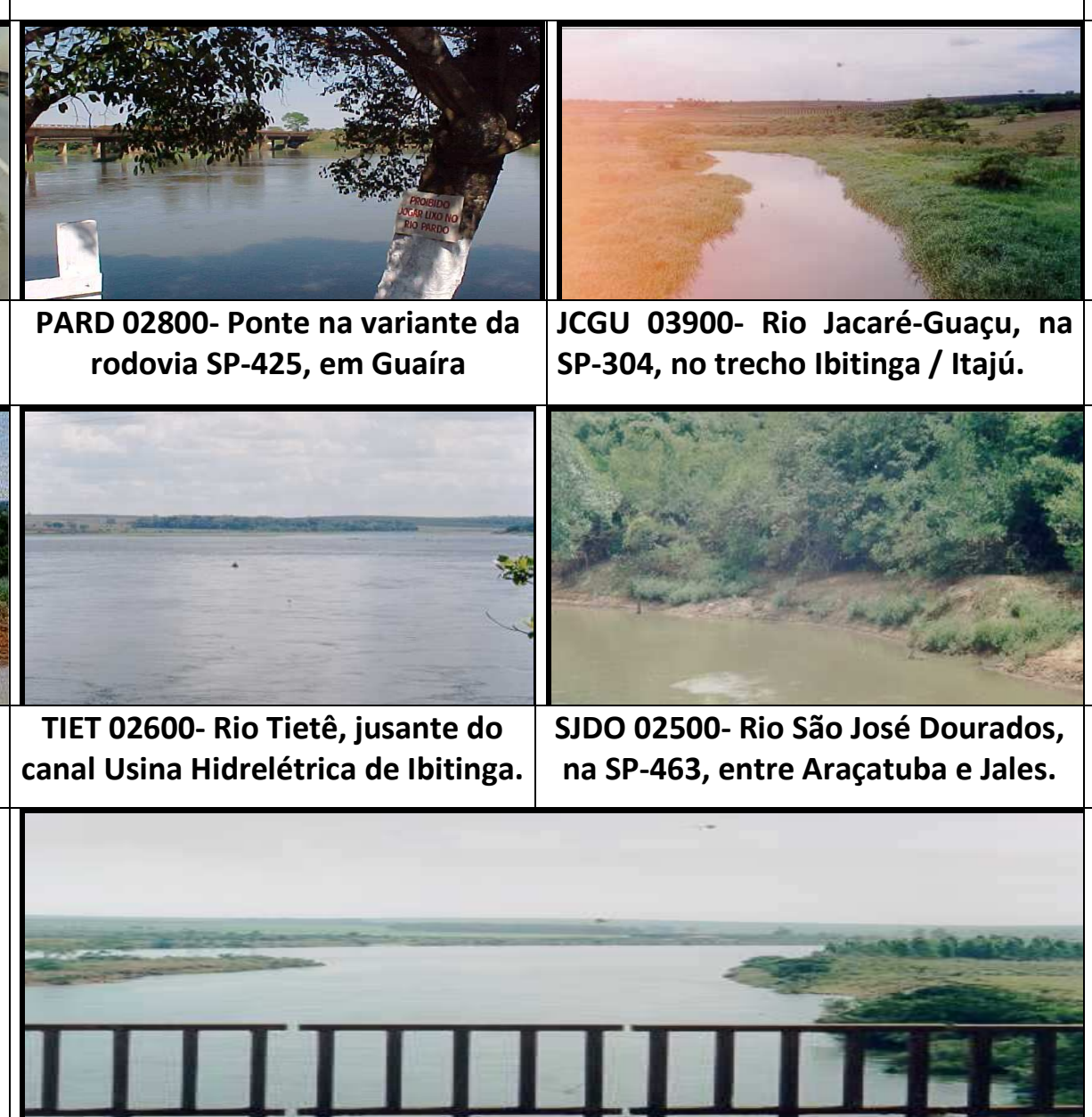

03900- Rio Jacaré-Guaçu, SP-304, no trecho Ibitinga / Itajú.

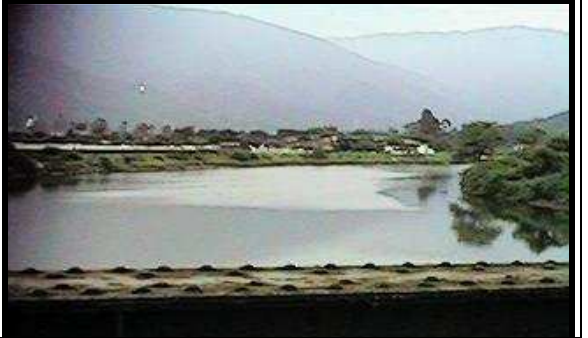

CUBA 03900- Rio Cubatão, Ponte da estrada de

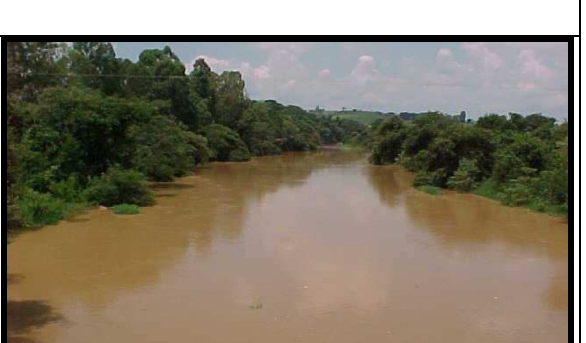

SORO 02900-Rio Sorocaba, em Laranjal Paulista.

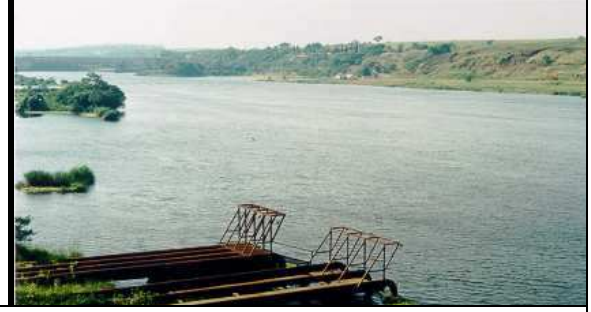

TIET 02500-Rio Tietê a jusante da Usina Hidroelétrica de Bariri

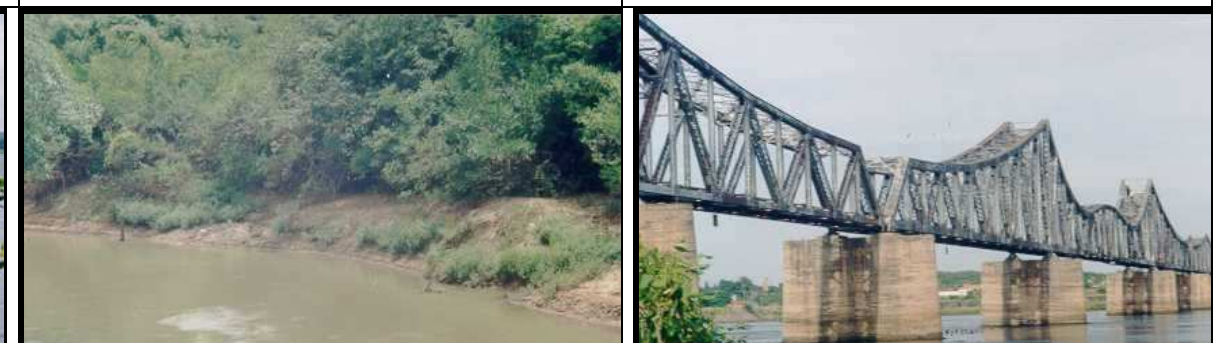

PARN 02100- Rio Paraná, sobre a barragem do Reservatório de Jupia

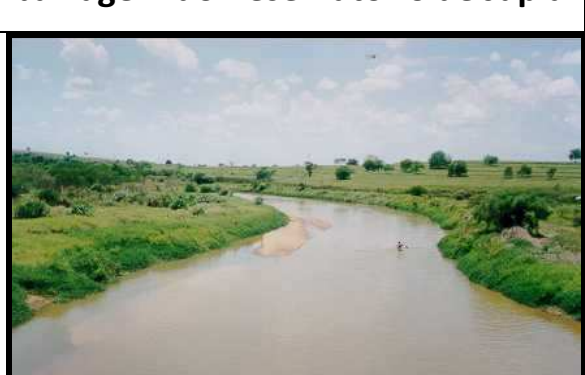

PARP 02750- Rio Paranapanema, $800 \mathrm{~m}$ a jusante da barragem de STAN 02700- Rio Sto Anastácio, SP Capivara.

563 entre Pres.Venceslau e Teodoro Sampaio.

Fonte: Acervo de fotos do Banco InterÁguas da Cetesb. 


\section{6 - ÍNDICE DE QUALIDADE DAS ÁGUAS - IQA}

A partir de um estudo realizado em 1970 pela "National Sanitation Foundation-NSF" dos Estados Unidos, o WQI- Water Quality Index, O IQA (Índice de Qualidade de Água) foi criado. A CETESB o adaptou e o IQA é composto por 9 parâmetros (temperatura da água, $\mathrm{pH}$, oxigênio dissolvido, demanda bioquímica de oxigênio, coliformes termotolerantes, nitrogênio total, fósforo total, resíduo total e turbidez) considerados relevantes para a avaliação da qualidade das águas, tendo como determinante principal a sua utilização para abastecimento público, mas com condições de indicar a presença de lançamentos de efluentes domésticos.

A criação do IQA baseou-se numa pesquisa de opinião junto a especialistas em qualidade de águas, que indicaram os parâmetros a serem avaliados, o seu peso relativo dos mesmos e a condição com que se apresentam cada parâmetro; exercia um papel semelhante à uma nota de 0 a 100 para a qualidade das águas, conforme tabela 5 .

Tabela 5 - Tabela dos pesos dos parâmetros para cálculo do IQA.

\begin{tabular}{|c|l|c|c|}
\hline \multicolumn{4}{|c|}{ Tabela de Parâmetros do IQA (pesos) } \\
\hline Ranking & Variável de Qualidade & Unidade & Peso (weight) \\
\hline 1 & Oxigênio Dissolvido & $\%$ saturação & 0,17 \\
\hline 2 & Coliformes Fecais & $\mathrm{NMP} / 100 \mathrm{~mL}$ & 0,15 \\
\hline 3 & $\mathrm{pH}$ & - & 0,12 \\
\hline 4 & $\mathrm{DBO}_{5}$ & $\mathrm{mg} \mathrm{O} / \mathrm{L}$ & 0,10 \\
\hline 5 & Nitrogênio Total & $\mathrm{mg} \mathrm{N} / \mathrm{L}$ & 0,10 \\
\hline 6 & Fósforo Total & $\mathrm{mg} \mathrm{P} / \mathrm{L}$ & 0,10 \\
\hline 7 & Temperatura de & ${ }^{\circ} \mathrm{C}$ & 0,10 \\
\hline 8 & Desvio & $\mathrm{uT}$ & 0,08 \\
\hline 9 & Turbidez & $\mathrm{mg} / \mathrm{L}$ & 0,08 \\
\hline & \multicolumn{2}{|l|}{ Somatos Totais } & 1 \\
\hline
\end{tabular}

Elaborada por: MIDAGLIA, C. L., 2009. Fonte: CETESB, disponível em: <http://www. cetesb.sp.gov.br/Agua/rios/indice_iap_iqa.asp>, acesso em: 23 de setembro de 2009. 
O índice sofreu adaptações para atender os limites dos parâmetros, em função do decreto 8468, de 1976. Depois disso, desde 1975, suas notas passaram a ser usadas pela CETESB com vistas a servir de informação básica de qualidade de água para o público em geral, bem como para o gerenciamento das águas superficiais.

A geração do índice dá-se por meio de uma série de coleta de amostras de água, realizadas sistematicamente ao longo dos anos, sendo que normalmente três correspondem aos períodos de chuva (setembro a março) e em períodos secos (março a setembro). Hoje, a rede de monitoramento obtém amostras em rios e reservatórios, em todas as UGRHIs, com a mesma intensidade (freqüência), mas não com a mesma densidade espacial (número de pontos de coleta por unidade de gerenciamento/1.000 $\mathrm{km}^{2}$ ).

Os resultados dos parâmetros analisados devem estar em conformidade com os padrões de qualidade especificados nas respectivas classes da Resolução CONAMA, 357/05 de 17 de março de 2005.

\section{1 - A RAZÃO DA EXISTÊNCIA DOS ÍNDICES DE QUALIDADE DE ÁGUA E SUA EVOLUÇÃO. TENDÊNCIAS DE CIÊNCIAS DA INTERPRETAÇÃO.}

Como pode ser entendido, para visualizar a condição do estado de um corpo hídrico, precisa-se recorrer a uma série muito grande de resultados, por períodos consecutivos de tempo. A existência de índices de qualidade reflete a necessidade de sintetizar dados em uma informação que precisa afirmar se a água esta boa ou não, própria ou imprópria para um determinado uso. Este índice representa uma média ponderada de vários parâmetros, em um valor que passa ter maior facilidade de comunicação com o público especializado ou não. Técnicos que trabalham com gestão e planejamento de grandes áreas recorrem aos índices, pois representam uma média ponderada, feita a partir de variáveis selecionadas por grupo de especialistas, que depois são resumidas num 
número simples, que varia geralmente de 0 a 1 , mas que no caso do IQA aqui estudado, a variação é de 0 a 100, e classificado em faixas já descritas.

Em geral, o índice tem maior status que os parâmetros individuais; pois já agregaram estes dados em sua composição. Suas principais vantagens são: a facilidade de comunicação com o público não técnico, o status maior do que os parâmetros individuais e o fato de representar uma média de diversas variáveis em um único número, combinando unidades de medidas diferentes em uma única medida, num número que varia de 0 a 1 . No entanto, sua principal desvantagem consiste na perda de informação das variáveis individuais e da interação entre elas. O índice, apesar de fornecer uma avaliação integrada, jamais substituirá uma avaliação detalhada da qualidade das águas. O IQA é utilizado em vários países e Estados do Brasil, porém existe variação tanto na sua composição como nos intervalos adotados. A figura 12 a seguir mostra a diferença de faixas de valores para alguns Estados:

Figura 12 - Faixas de classificação do IQA nos Estados Brasileiros.

\begin{tabular}{|c|c|c|c|}
\hline \multicolumn{4}{|c|}{ Tabela 3 - Classificaçāo dos valores do Indice de Qualidade das Águas nos estados brasileiro } \\
\hline $\begin{array}{l}\text { VALOR DO IOA } \\
\text { (Estados: AP, MG, MT, PR, RS) }\end{array}$ & $\begin{array}{l}\text { VAL OR DO IQA } \\
\text { (Estiod BA GO, ES, MS, SP) }\end{array}$ & QUALIDADE DA ÁGUA & COR \\
\hline $91-100$ & $80-1000$ & otnit & \\
\hline 7190 & $52-79$ & $\mathrm{BCed}$ & \\
\hline $51-70$ & 37- 51 & Acstanel & \\
\hline 2650 & $20-36$ & Rulm & \\
\hline 0.25 & $0-19$ & Prssimas & \\
\hline
\end{tabular}

Fonte: Panorama da Qualidade das Águas Superficiais no Brasil (BRASIL, 2005, p.18).

Os parâmetros de qualidade que fazem parte do cálculo do IQA, foram escolhidos em função do potencial de refletir principalmente a contaminação dos corpos hídricos ocasionada pelo lançamento de esgotos domésticos. É importante lembrar que, na época em que esse índice foi desenvolvido, predominava uma visão mais sanitarista, para avaliar a 
qualidade das águas, tendo como determinante principal a sua utilização para a possibilidade potencial para abastecimento público, considerando muito mais os aspectos relativos ao seu tratamento. Hoje em dia, existem preocupações ambientais mais amplas. A revisão e criação de novos indicadores podem favorecer uma visão mais precisa sob vários outros aspectos. Entretanto, diante do fato do saneamento ser ainda um dos principais problemas de depreciação dos corpos hídricos no Brasil, esse índice continua com importância relevante.

Sabe-se que a crescente urbanização e industrialização de algumas regiões do Estado de São Paulo têm reflexos negativos e, como conseqüência, houve um maior comprometimento da qualidade das águas dos rios e reservatórios devidos, principalmente, à maior complexidade dos poluentes que estão sendo lançados no meio ambiente, e à deficiência do sistema de coleta e tratamento dos esgotos gerados pela população e indústria. Os sedimentos dos rios e reservatórios guardam registros destes eventos.

Tanto na Legislação Estadual (Decreto Estadual no 8468/76) quanto na Federal (Resolução CONAMA no 20/86), estabeleceu-se que os usos preponderantes do recurso hídrico eram, dentre outros: abastecimento público e a preservação do equilíbrio das comunidades aquáticas.

Diante dos resultados referentes à qualidade da água obtidos através do IQA, que apresentam algumas limitações restritas ao seu enfoque sanitário, entre elas a de considerar apenas a sua utilização para o abastecimento público, ele começou a sofrer algumas críticas. Entre elas, o fato do índice não contemplar outros parâmetros, tais como: metais pesados, compostos orgânicos com potencial mutagênico, substâncias que afetam as propriedades organolépticas da água e o potencial de formação de trihalometanos das águas de um manancial.

Em 13 de agosto de 1998, para atender esta demanda, foi aprovado pela Resolução SMA/65, o Índice de Qualidade de Águas Brutas para Fins de Abastecimento Público (IAP) e o Índice de Proteção da Vida Aquática (IVA). Em função dessa Resolução criou-se um Grupo de Trabalho multi- 
institucional que contou com a participação de técnicos da CETESB, da SMA, da SABESP e da USP, para a revisão dos índices de qualidade da água.

Em 1999, os dois novos índices, IAP (monitoramento de captações) e IVA (com ênfase no monitoramento biológico) foram validados por meio de sua aplicação aos dados da Rede de Monitoramento. Desde 2002, passaram a ser divulgados nos relatórios anuais de qualidade de água superficiais da CETESB. No IAP, os parâmetros específicos para captações são o Teste de Ames para avaliação da mutagenicidade, o Potencial de formação de trihalometanos, Carbono orgânico dissolvido e absorbância do ultravioleta.

Além disso, o IAP, assim como o IQA, pode ser calculado para todos os corpos de água, inclusive os de classe 4, mesmo que não utilizados para abastecimento público. E como o IAP é o resultado da ponderação dos resultados do IQA (Índice de Qualidade das águas) e do ISTO (Índice das substâncias tóxicas e organolépticas), existe uma forte correlação entre eles. Sua classificação varia de 0 a 100, conforme TABELA 6.

Tabela 6 - Faixas de classificação do IAP.

\begin{tabular}{|l|c|}
\hline Classificação do IAP & $\begin{array}{c}\text { Faixas de Variação } \\
\text { do IAP }\end{array}$ \\
\hline Qualidade Ótima & $79<$ IAP $<100$ \\
\hline Qualidade Boa & $51<$ IAP $<79$ \\
\hline Qualidade Regular & $36<$ IAP $<51$ \\
\hline Qualidade Ruim & $19<$ IAP $<36$ \\
\hline Qualidade Péssima & IAP $<19$ \\
\hline
\end{tabular}

Fonte: CETESB, 2008.

Já o IVA, de acordo com a legislação estadual (Regulamento da Lei 997/76, aprovada pelo Decreto Estadual 8468/76) e federal (Resolução CONAMA 20/86), entende que a proteção das comunidades aquáticas está prevista somente para corpos d'água enquadrados nas classes 1, 2 e 3, 
sendo, portanto, pertinente a aplicação do IVA somente para esses ambientes. Assim sendo, para os corpos d'água enquadrados na classe 4 não é calculado o IVA. Nesse caso, assume-se que não há vida aquática relevante nesses ambientes e admite-se que as condições de criticidade do rio são irreversíveis, ou seja, está teoricamente "morto". Mas se isto não for totalmente verdade e os rios melhorarem, ou seja, adquirirem um status de qualidade melhor, esta mudança não será detectada por este índice. Já o IQA, que é calculado para todas as classes, pode detectar eventuais melhoras. A avaliação por ambos os índices valorizaram a analise da qualidade e mostram um escopo mais próximo da realidade.

Por fim, o IET -Índice do Estado Trófico- que faz parte do cálculo do IVA, é composto pelo Índice do Estado Trófico para o fósforo - IET (PT) e o Índice do Estado Trófico para a clorofila a - IET (Cl), modificados por Lamparelli (2004), que tem por finalidade classificar corpos d'água em diferentes graus de trofia, ou seja, avalia a qualidade da água quanto ao enriquecimento por nutrientes e seu efeito relacionado ao crescimento excessivo de algas ou ao aumento da infestação de macrófitas aquáticas. Foi testado na rede de monitoramento no período de 1996 a 2001 e passou a ser divulgado nos relatórios da CETESB desde 1998. O Mapa 2IET- Índice do Estado Trófico da Água- Níveis em 2008, mostra a situação de trofia nos principais rios e reservatórios de São Paulo.

O IET é recomendado para detectar contribuições antrópicas, porém, segundo Lamparelli (2004), pode ser influenciado pelas estações do ano, que causam maior ou menor aumento da temperatura da água, maior disponibilidade de nutrientes e condições propícias de penetração de luz na água, sendo comum observar-se um incremento do processo na época da primavera, após o período de inverno, em que se mostrava menos intenso. Nesse sentido, a determinação do grau de eutrofização médio anual de um corpo hídrico pode não identificar, de forma explícita, as variações que ocorreram ao longo do período anual. 
Mapa 2: IET- Índice do Estado Trófico da Água- Níveis em 2008

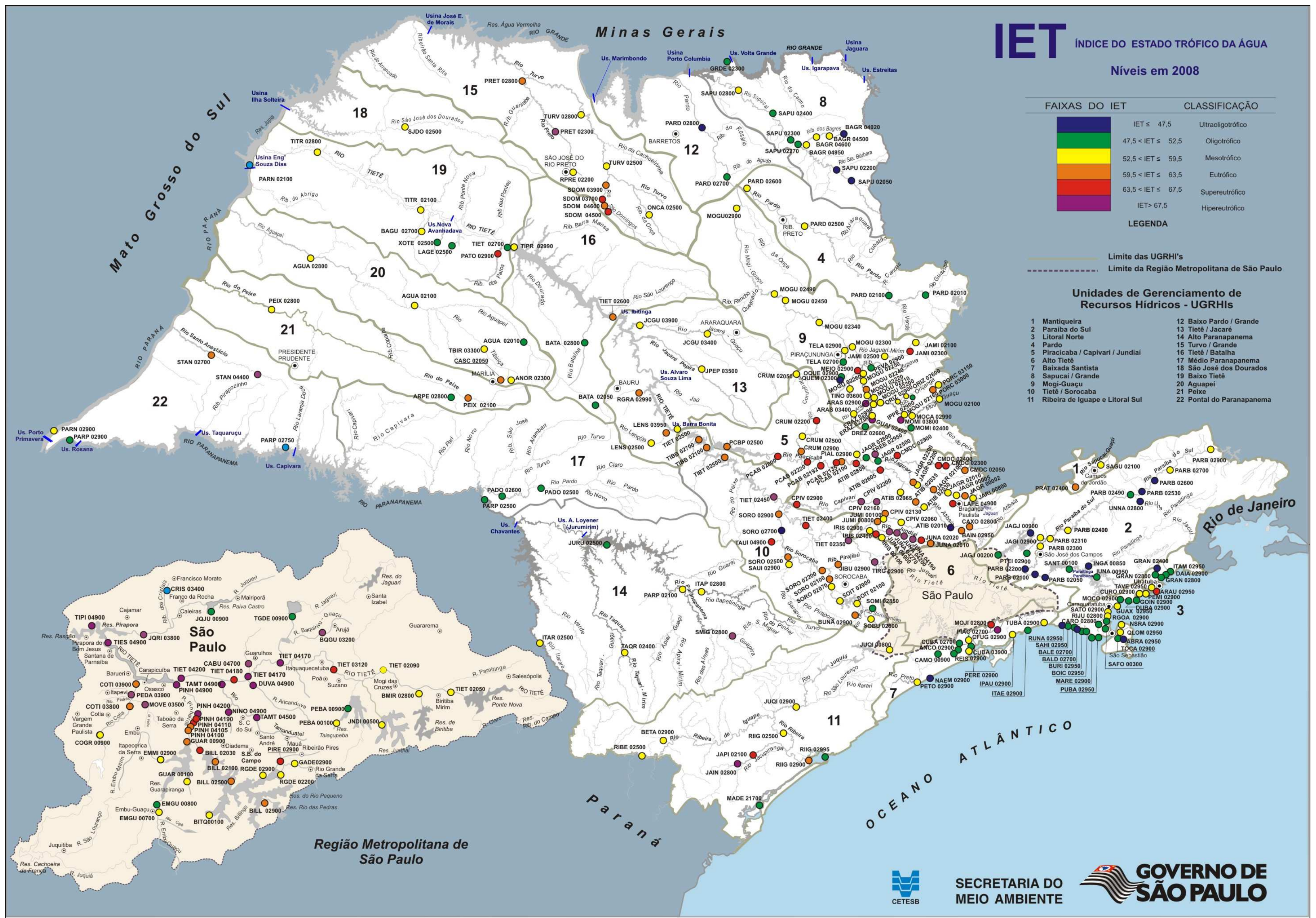


A tabela 7 mostra as faixas que definem os ambientes variando em oligotróficos (Corpos de água limpos, de baixa produtividade, em que não ocorrem interferências indesejáveis sobre os usos da água) a hipereutróficos, onde os corpos de água são afetados significativamente.

Tabela 7 - Faixas de classificação do IET.

\begin{tabular}{|c|c|c|}
\hline & Ultraoligotrófico & IET $=47,5$ \\
\hline & Oligotrófico & $45,5<$ IET $=52,5$ \\
\hline & Mesotrófico & $52,5<$ IET $=59,5$ \\
\hline & Eutrófico & $59,5<$ IET $=63,5$ \\
\hline & Supereutrófico & $63,5<$ IET $=67,5$ \\
\hline & Hipereutrófico & IET $>67,5$ \\
\hline
\end{tabular}

Fonte: CETESB, 2008.

Para o cálculo do índice de monitoramento IAEM que está sendo proposto neste estudo, foi cogitada também a inclusão da média do IET, pois tem potencial e sensibilidade para detectar ambientes influenciados pela ação antrópica. Porém, como o IET não tem um histórico que contemple o período deste estudo, nem todos os pontos ele não pode ser incluído. Portanto, dentre tantas alternativas de analise ambiental para qualidade de água, ressalta-se que ainda hoje o IQA é um índice de grande potencial de análise comparativa da qualidade de recurso hídrico superficial, em termos de múltiplo uso. Sua história dentro da rede de amostragem tem período razoável de existência para ser analisado sob o ponto de vista temporal, com freqüência consolidada e resultados fornecidos dentro dos critérios atuais de certificação laboratorial. A figura 13 mostra a evolução total do número de pontos da rede paulista operada pela CETESB, cujos resultados propiciaram a geração do calculo do IQA desde 1975 até 2008. O número de pontos desta síntese foi distribuído segundo os limites das atuais UGRHIS. Para se visualizar a situação do Estado é preciso consultar o gráfico que consta desta mesma figura. 
FIGURA 13 - Evolução do Número de pontos com IQA calculado no Estado de São Paulo.

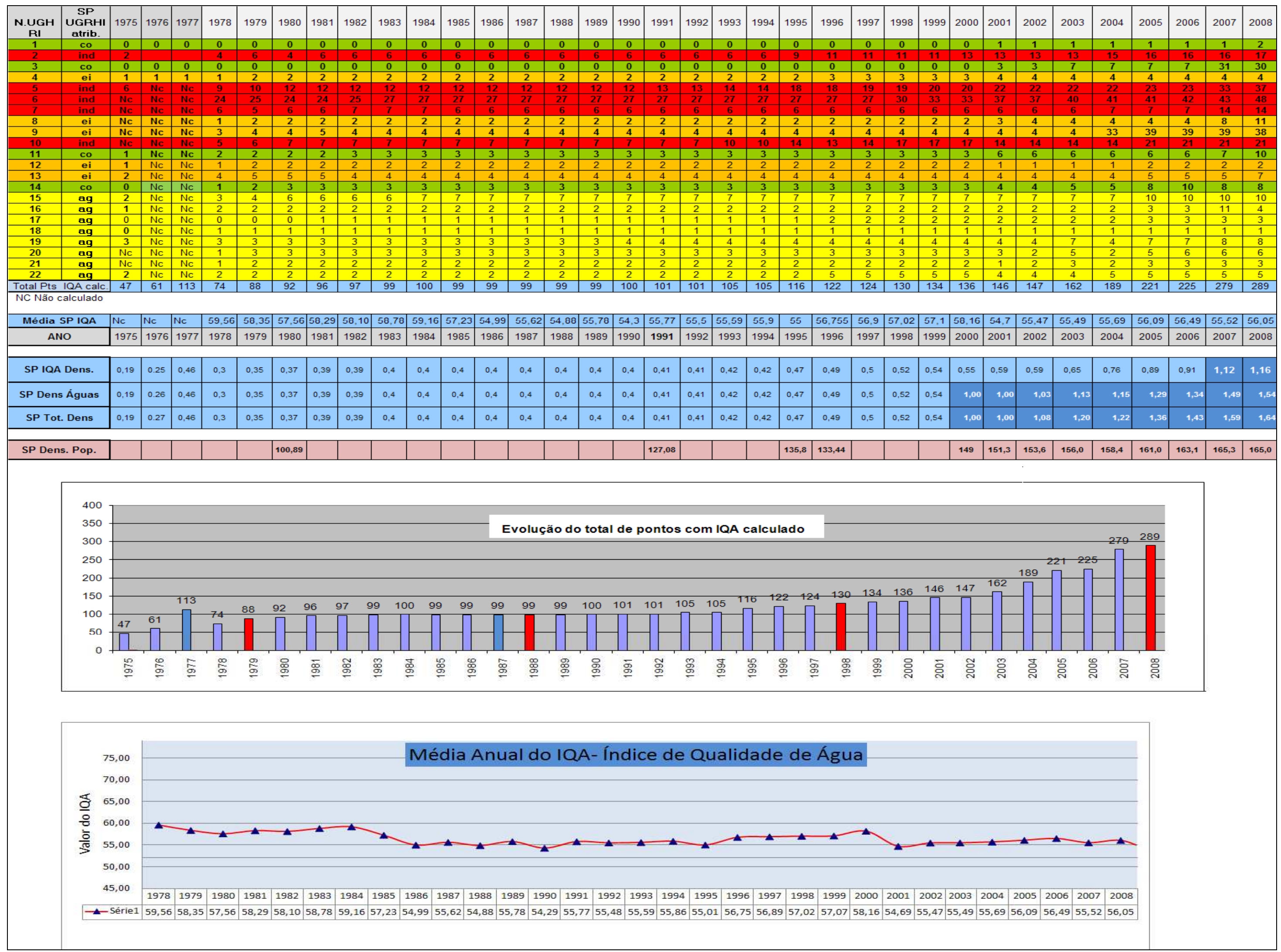

Org. MIDAGLIA,C.L. 2009

Fonte: CETESB- Relatórios de Qualidade de Água 1978-2008 


\section{2 - A RELAÇÃO DE PONTOS POR ÁREA: DENSIDADE ESPACIAL DA REDE DE MONITORAMENTO SUPERFICIAL DA CETESB}

Conforme já visto no mapa 1 e na figura 13 sobre a evolução dos pontos com IQA calculado, deve-se ressaltar que o fato da distribuição espacial dos pontos não ter apresentado a mesma proporção em todo Estado durante estes anos, nenhum dos principais rios do território paulista ficaram completamente privados de análise de qualidade da água.

Para fins de estudo da densidade da rede de água, tanto quanto para fins de estudo da densidade populacional, adotou-se a Área Territorial Oficial do Estado de São Paulo, estabelecida pela resolução n०5 do IBGE 10/10/2002, de $248.209 \mathrm{~km}^{2}$, apesar das bases digitais adquiridas informarem uma área é de $248.625,794 \mathrm{Km}^{2}$. Além disto, nos relatórios da CETESB utilizam-se como áreas das UGRHIs aquelas que constam do PERH- Plano Estadual de Recursos Hídricos. Aqui, do mesmo modo, adotara-se para cada UGRHI o mesmo procedimento, ou seja, utiliza-se a área $\mathrm{PERH}$, ainda que as bases digitais indiquem ligeira diferença entre ambos os números.

Portanto, foram recalculadas as densidades que constavam em relatórios da CETESB anteriores ao ano de 2005, quando ainda se adotava a área divulgada nos chamados "Relatórios Zero de Plano de Bacias". Assim as tabelas tiveram sua relação de densidade de pontos igualada sob - aspecto de áreas territorial, usada para cálculo neste estudo, padronizando as comparações temporais até o primeiro ano estudado, ainda que seja antes da divisão do estado por UGRHIs. E, em ambos os casos (densidade da rede de monitoramento ou densidade populacional) serão consideradas as áreas totais, quer sejam porção de terra ou água, pois a exclusão de áreas não habitáveis tais como represas, parques, aterros sanitários e outros não caberiam nesta escala de trabalho, que privilegia a macro-visão. 
Desde o ano 2002, a CETESB tem adotado como referência de representatividade espacial da rede de monitoramento o padrão mínimo de 1 ponto por $1.000 \mathrm{~km}^{2}$. Este índice foi adotado pela Comunidade européia por orientação da Diretiva Quadro da Água - Water Framework Directive (disponível em: <http://ec.europa.eu/environment/water/waterframework/index_en.html>, (Cf.: EUROPEAN COMMISSION, 19/08/2009) para atender as metas previstas para serem atingidas até 2015.

No documento EUROWATERNET - The European Environment Agency's Monitoring and Information Network for Inland Water Resources, publicado em 1998 pela Agência Européia de Meio Ambiente (EEAEuropean Environment Agency), entidade supranacional designada para assuntos de meio ambiente (disponível em: <www.eea.europa.eu/ publications/TECH07/tech07.pdf>, existem orientações básicas para prover os agentes com informações básicas para implementar redes de monitoramento de qualidade de águas superficiais, inclusive para selecionar lugares relevantes a nível nacional e também local, com espalhamento geográfico ao longo de todo país. (Cf.: EEA, jun.1998), conforme figura 14 : 
Figura 14 - Critérios para distribuição da Rede de Monitoramento EUROWATERNET.

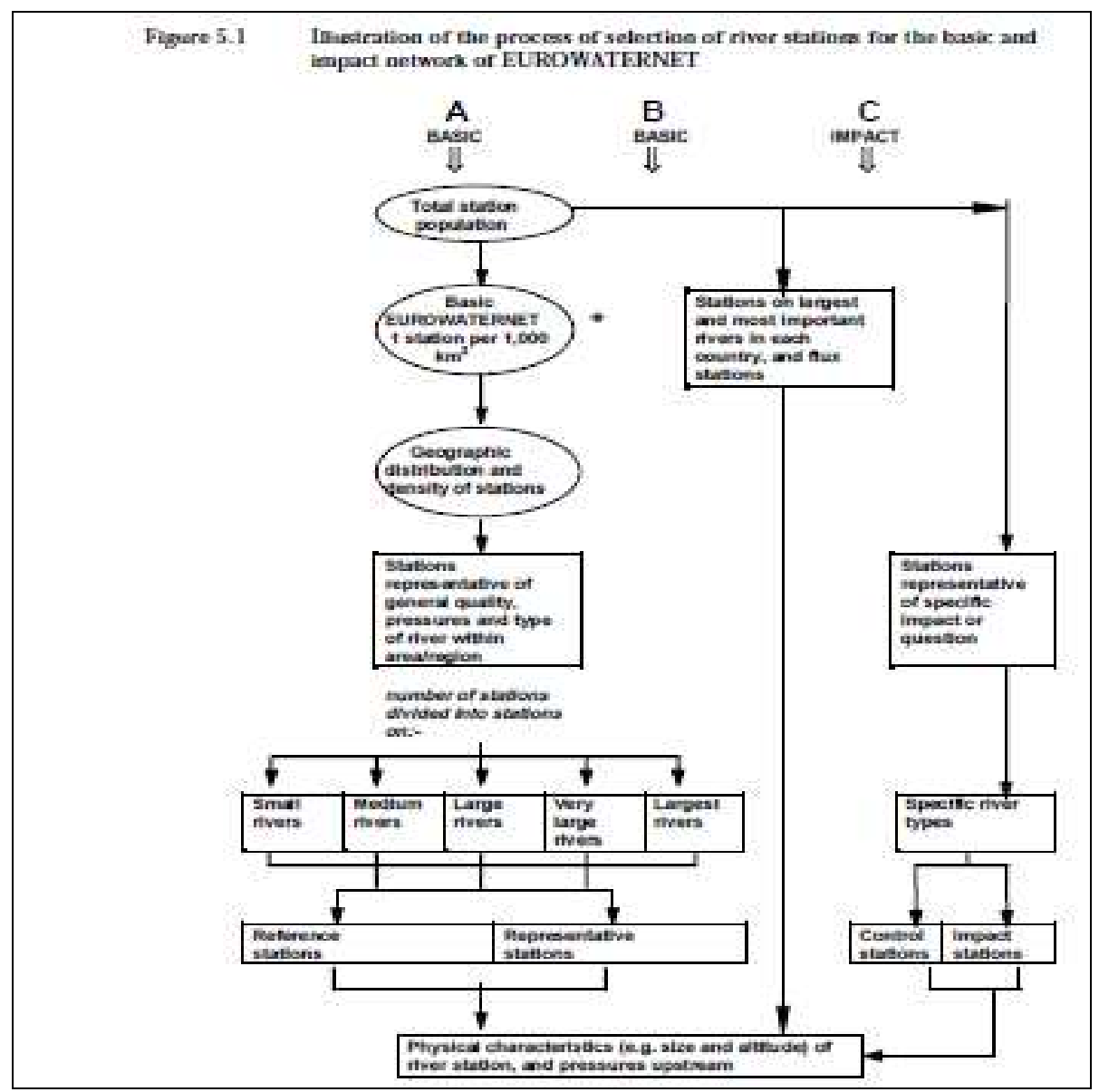

Fonte: EEA, jun.1998, p.12.

O documento também aponta a necessidade de se estabelecer critérios para a representatividade, a nível nacional, destas redes de qualidade e de quantidade, que devem estar espalhadas por todo o país, e que devem também incluir lagos. As diretrizes as EUROWATERNET são aplicáveis para todos os países europeus membros dentro da área de atuação da Agencia Ambiental Européia. No caso dos lagos, ela prevê uma diferenciação entre as taxas de densidade de rios e densidade de lagos, estes últimos equivalentes aos nossos reservatórios:

- Densidade Recomendada de pontos de Rios $=$ No de pontos de água superficial $1.000 \mathrm{~km}^{2}$,

- Densidade Recomendada de pontos de Lagos (cuja área é $>0,1 \mathrm{~km}^{2}$ ) = No de pontos de água superficial/ $1.750 \mathrm{~km}^{2}$. 
The required number of stations for the basic network should be selected as described in following paragraphs. The process of selection of river stations for the basic network is illustrated in Figure 5.1.

The starting point is the number of river monitoring stations in national and/or regional monitoring networks that is the 'total station population'. The total number of river stations selected by the Member Country from the total station population will initially be based on total land area at a density of 1 river station per $1,000 \mathrm{~km} 2$ (Line $A$ in Figure 5.1). Guidance on how many river stations this equates to for each country is given in Table 5.1. Member Countries will also be able to report what they consider to be representative of the issue/pressure being assessed, and results from regional surveys will be acceptable. Thus lower (from those recommended in Table 5.1) river station numbers (densities) will be acceptable if representativeness can be demonstrated. In this case an indication of how 'representative' the information is should be given, for example, the removal of bias by weighting. (EEA, jun.1998, p.13)

Já no caso das águas superficiais, de acordo com os critérios da EUROWATERNET, é exigido aos estados-membros a caracterização geográfica das bacias, prevista no Annex 2 ENV/98/105 de 30 de abril de 1998. Esta caracterização devera ser capaz de descrever fisiograficamente os corpos hídricos, com identificadores de tamanho (área das bacias e altitude) e também verificar os níveis de pressão ambiental a que são submetidas, através de levantamentos em campo.

Dentre as principais pressões antrópicas, relacionadas por este documento que devem estar associadas aos pontos/estações a serem monitorados estão: a densidade populacional presentes nas bacias situadas a montante, porcentagem de área agrícola, de área cultivada, de pastagens, de florestas, de urbanização, e avaliações de contribuições por fontes pontuais e uso de fertilizantes em bacias a montante. 
No que se refere à densidade da rede amostral básica, é proposto 1 ponto/estação de monitoramento por $1.000 \mathrm{~km}^{2}$. Portanto, com base nesta relação, no momento a única disponível, a CETESB começou a expressar a densidade de sua rede de monitoramento dentro das mesmas recomendações da EUROWATERNET, para fins de comparação temporal e espacial. Entretanto, a CETESB não adota densidades diferentes para rios e reservatórios, nem para áreas com maior ou menor impacto, assumindo a relação recomendada de 1 ponto por $1.000 \mathrm{~km}^{2}$, por inferir que no caso do Estado de São Paulo, já se tratava de área mais impactadas ou vulneráveis. Assim, conforme esta relação de proporção, a necessidade de pontos de água superficial para a área total do estado de São Paulo seria de 248 pontos, distribuídos conforme figura 15, dentro das respectivas UGHRIs.

\section{Figura 15 - Mapa de São Paulo - Número de Pontos necessários por UGRHI para atender a Densidade Recomendada pelo critério (CEE/EEA).}

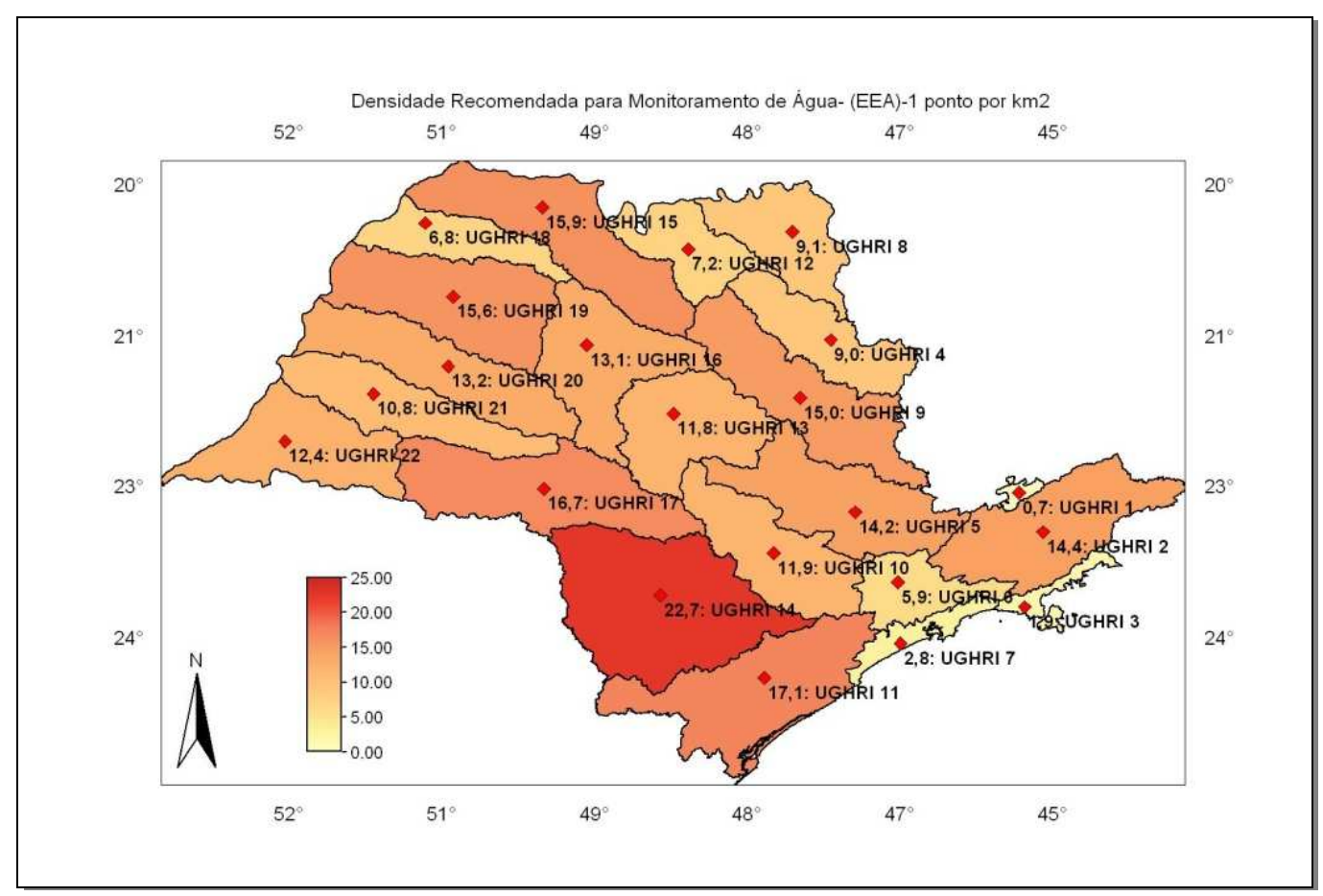

Elaborada por: MIDAGLIA, C. L., 2009. Fonte: SP_WATERNET. 
Contudo, argumentos baseados somente na densidade espacial da rede, mesmo para áreas mais impactadas, não são completamente coerentes em um país de grandes proporções como o Brasil, ou ainda em um Estado como São Paulo, e em pleno desenvolvimento de atividades quer seja no setor de prestação de serviços, quer atividades industriais e agroindustriais. Considerando-se somente a variável área, em termos de Brasil, ter-se-ia muitos pontos em áreas remotas, tais como no interior da Amazônia, ou em mesmo em áreas secas, de caatinga, no nordeste, etc. Além disto, questões tais como a acessibilidade aos locais para serem monitoramento e proximidade de laboratórios para analise das amostras, traria ao gerenciador de qualidade de água mais dificuldades do que propriamente informação. Embora devam existir alguns pontos em áreas fronteiriças, de estados ou países.

O mesmo caso, em menores proporções, dá-se para o Estado de São Paulo, com tamanho semelhante à de alguns países da Europa, mas com uma desigualdade de distribuição da população muito mais irregular. A densidade proposta analisada somente pela variável área coloca a necessidade de se monitorar igualmente áreas habitadas e desabitadas. Outro fato peculiar de São Paulo, ou ainda do Brasil, que nos diferem da Europa, é que lá já não existem tantos rios recebendo efluentes sem tratamento de esgotos e captando estas mesmas águas para abastecimento. Portanto, a relação de densidade espacial para densidade de monitoramento pode ser revista e adaptada para as necessidades brasileiras ou estaduais.

A tabela 8 mostra a situação para o ano de 2008, segundo os diversos tipos de monitoramento executados pela CETESB, e a situação de déficit ou superávit por UGRHI em relação ao critério numérico adotado pela CEE. 


\section{Tabela 8 - Densidade Ideal de pontos de monitoramento da rede de Monitoramento Paulista segundo critério da CEE e sua situação de déficit ou superávit em 2008.}

\begin{tabular}{|c|c|c|c|c|c|c|c|c|c|c|c|c|c|c|}
\hline $\begin{array}{l}\text { Núm. } \\
\text { UGRHI }\end{array}$ & UGRH / Tipo & $\begin{array}{c}\text { Area em } \\
\mathrm{Km}^{2} \\
\text { (PERH) }\end{array}$ & $\begin{array}{l}\text { População } \\
\text { Estimada } \\
\text { IBGE-2008 }\end{array}$ & $\begin{array}{c}\text { Dens. Pop. } \\
2008\end{array}$ & $\begin{array}{l}\text { Rede } \\
\text { Básica }\end{array}$ & $\begin{array}{l}\text { Monit. } \\
\text { Aut. }\end{array}$ & $\begin{array}{l}\text { Baln. } \\
\text { Águas } \\
\text { Doces } \\
\end{array}$ & $\begin{array}{l}\text { Mon. } \\
\text { Total } \\
\text { Água } \\
\end{array}$ & $\begin{array}{l}\text { Rede } \\
\text { Sedim. }\end{array}$ & $\begin{array}{l}\text { Monit. } \\
\text { Total }\end{array}$ & $\begin{array}{c}\text { Dens. } \\
\text { Pontos } \\
\text { Água } \\
\end{array}$ & $\begin{array}{l}\text { Dens. } \\
\text { Pontos } \\
\text { Total }\end{array}$ & $\begin{array}{l}\text { Dens. } \\
\text { IDEAL } \\
\text { CEE } \\
\end{array}$ & $\begin{array}{c}\text { Déficit/ } \\
\text { Superavit }\end{array}$ \\
\hline 1 & Mantiqueira & 675 & 64.099 & 94,96 & 2 & 0 & 0 & 2 & 0 & 2 & 2,96 & 2,96 & 0,675 & 1,33 \\
\hline 3 & Litoral Norte & 1.948 & 272.218 & 139,74 & 30 & 0 & 0 & 30 & 0 & 30 & 15,40 & 15,40 & 1,948 & 28,05 \\
\hline 11 & Ribeira de Iguape/Litoral Sul & 17.068 & 378.309 & 22,16 & 10 & 0 & 0 & 10 & 3 & 13 & 0,59 & 0,76 & 17,068 & 7,07 \\
\hline 14 & Alto Paranapanema & 22.689 & 736.443 & 32,46 & 8 & 0 & 0 & 8 & 1 & 9 & 0,35 & 0,40 & 22,689 & 14,69 \\
\hline \multicolumn{2}{|c|}{ UGHRIs Conservação (04) } & 42.380 & 1.451 .069 & 34,24 & 50 & 0 & 0 & 50 & 4 & 54 & 1,18 & 1,27 & 42,38 & 7,62 \\
\hline 15 & Turvo / Grande & 15.925 & 1.287 .950 & 80,88 & 10 & 0 & 0 & 10 & 0 & 10 & 0,63 & 0,63 & 15,93 & 5,93 \\
\hline 16 & Tietê / Batalha & 13.149 & 513.892 & 39,08 & 4 & 0 & 1 & 5 & 0 & 5 & 0,38 & 0,38 & 13,15 & 8,15 \\
\hline 17 & Médio Paranapanema & 16.749 & 675.951 & 40,36 & 3 & 0 & 0 & 3 & 1 & 4 & 0,18 & 0,24 & 16,75 & 13,75 \\
\hline 18 & São José dos Dourado & 6.783 & 226.833 & 33,44 & 1 & 0 & 0 & 1 & 0 & 1 & 0,15 & 0,15 & 6,78 & 5,78 \\
\hline 19 & Baixo Tietê & 15.588 & 752.698 & 48,29 & 8 & 0 & 0 & 8 & 2 & 10 & 0,51 & 0,64 & 15,59 & 7,59 \\
\hline 20 & Aguapeí & 13.196 & 364.862 & 27,65 & 6 & 0 & 0 & 6 & 0 & 6 & 0,45 & 0,45 & 13,20 & 7,20 \\
\hline 21 & Peixe & 10.769 & 461.396 & 42,84 & 3 & 0 & 0 & 3 & 0 & 3 & 0,28 & 0,28 & 10,77 & 7,77 \\
\hline 22 & Pontal do Paranapanema & 12.395 & 480.626 & 38,78 & 5 & 0 & 0 & 5 & 2 & 7 & 0,40 & 0,56 & 12,40 & 7,40 \\
\hline \multicolumn{2}{|c|}{ UGHRIs Agropecuárias (08) } & 104.554 & 4.764.208 & 45,57 & 40 & 0 & 1 & 41 & 5 & 46 & 0,39 & 0,44 & 104,55 & 63,55 \\
\hline 4 & Pardo & 8.993 & 1.059 .828 & 117,85 & 4 & 0 & 0 & 4 & 0 & 4 & 0,44 & 0,44 & 8,99 & 4,99 \\
\hline 8 & Sapucaí / Grande & 9.125 & 682.200 & 74,76 & 12 & 0 & 0 & 12 & 0 & 12 & 1,32 & 1,32 & 9,13 & 2,88 \\
\hline 9 & Mogi-Guaçu & 15.004 & 1.384 .031 & 92,24 & 39 & 0 & 2 & 41 & 0 & 41 & 2,73 & 2,73 & 15,00 & 26,00 \\
\hline 12 & Baixo Pardo / Grande & 7.239 & 330.310 & 45,63 & 2 & 0 & 0 & 2 & 0 & 2 & 0,28 & 0,28 & 7,24 & 5,24 \\
\hline 13 & Tietê / Jacaré & 11.779 & 1.489 .153 & 126,42 & 7 & 0 & 1 & 8 & 1 & 9 & 0,68 & 0,76 & 11,78 & 3,78 \\
\hline \multicolumn{2}{|c|}{ UGHRIs em Industrialização (05) } & 52.140 & 4.945 .522 & 94,85 & 64 & 0 & 3 & 67 & 1 & 68 & 1,29 & 1,30 & 52,14 & 14,86 \\
\hline 2 & Paraíba do Sul & 14.444 & 1.972 .745 & 136,58 & 19 & 0 & 2 & 21 & 1 & 22 & 1,45 & 1,52 & 14,44 & 6,56 \\
\hline 5 & Piracicaba, Capivari e Jundiaí & 14.178 & 4.975 .692 & 350,94 & 80 & 1 & 6 & 87 & 5 & 92 & 6,14 & 6,49 & 14,18 & 72,82 \\
\hline 6 & Alto Tietê & 5.868 & 19.452 .375 & 3314,99 & 45 & 10 & 22 & 77 & 7 & 84 & 13,12 & 14,31 & 5,87 & 71,13 \\
\hline 7 & Baixada Santista & 2.818 & 1.651 .906 & 586,20 & 14 & 0 & 0 & 14 & 1 & 15 & 4,97 & 5,32 & 2,82 & 11,18 \\
\hline 10 & Sorocaba / Médio Tietê & 11.829 & 1.798 .118 & 152,01 & 21 & 2 & 2 & 25 & 2 & 27 & 2,11 & 2,28 & 11,83 & 13,17 \\
\hline \multicolumn{2}{|r|}{ UGHRIs Industriais (05) } & 49.137 & 29.850 .836 & 607,50 & 179 & 13 & 32 & 224 & 16 & 240 & 4,56 & 4,88 & 49,14 & 174,86 \\
\hline \multicolumn{2}{|r|}{22 UGRHIs } & 248.209 & $41,011.635$ & 165,23 & 333 & 13 & 36 & 382 & 26 & 408 & 1,54 & 1,64 & 248,21 & 133,79 \\
\hline
\end{tabular}

Elaborada por: MIDAGLIA,C. L. 2009. Fonte: CETESB, 2008.

Percebe-se que desde o início da rede até 2008, as áreas onde existe maior carência de pontos, segundo este critério (CEE), corresponde às unidades de gerenciamento hídrico com vocação agropecuária, cuja densidade de pontos ainda esta muito abaixo do recomendado, necessitando um acréscimo de 60 novos pontos para atender a um espalhamento geográfico menos desigual.

Segundo Midaglia, Ramirez e Nader (2008), em um estudo sobre proposta de novos pontos em UGRHIS agropecuárias, esta região poderia ter mais pontos localizados em rios situados a jusante de cerca de 40 cidades, cuja população seja superior a 50.000 habitantes, e o tratamento 
de efluentes domésticos não seja satisfatório, ou ainda próximo de desemboques de rios de classe 4 em rios de classe 2 .

Estas UGRHI's Agropecuarias totalizan un área de 104,554 $\mathrm{km} 2$ que representa un $42 \%$ del territorio del Estado. En 2007, de los 395 puntos de muestreo en todo el Estado de Sao Paulo, sólo 48 de estos pertenecieron a las UGRHI's Agropecuarias: 26 en la Red Básica de Monitoreo, 14 puntos en Monitoreo Regional, 7 puntos en la Red de Sedimentos, 1 en Balneabilidade en aguas dulces; constituyendo apenas el $12 \%$ del total de puntos de muestreo a lo largo del Estado de Sao Paulo. (http://egal2009.easyplanners.info/ programaExtendido.php?sala_ $=\mathrm{C} \% 20-\% 2007 \&$ dia $_{-}=$ DOMINGO_AREAS_6_7_8\#)

No conjunto das UGRHIS para conservação e em industrialização, a densidade recomendada já foi obtida. Contudo, nas áreas industriais, existe teoricamente um excesso de pontos, mas que nem sempre é suficiente para registrar todos os acontecimentos. Portanto, é preciso adequar à rede as necessidades de cada lugar, pois nem os rios, e as pessoas, nem os pontos estão distribuídos de maneira igual, o que é perfeitamente normal no mundo real. A proposta de um índice que correlacione alguns destes fatos pode auxiliar nesta análise, mostrando onde estão as áreas mais vulneráveis.

A figura 16 mostra a evolução da densidade da rede de monitoramento da CETESB para os anos de 1978, 1988, 1998 e 2008 segundo o critério CEE. 
Fig. 16- Evolução da Densidade de Pontos da Rede de Monitoramento de Águas Superficiais da CETESB 1978/1988/1998/2008 (Critério CEE)
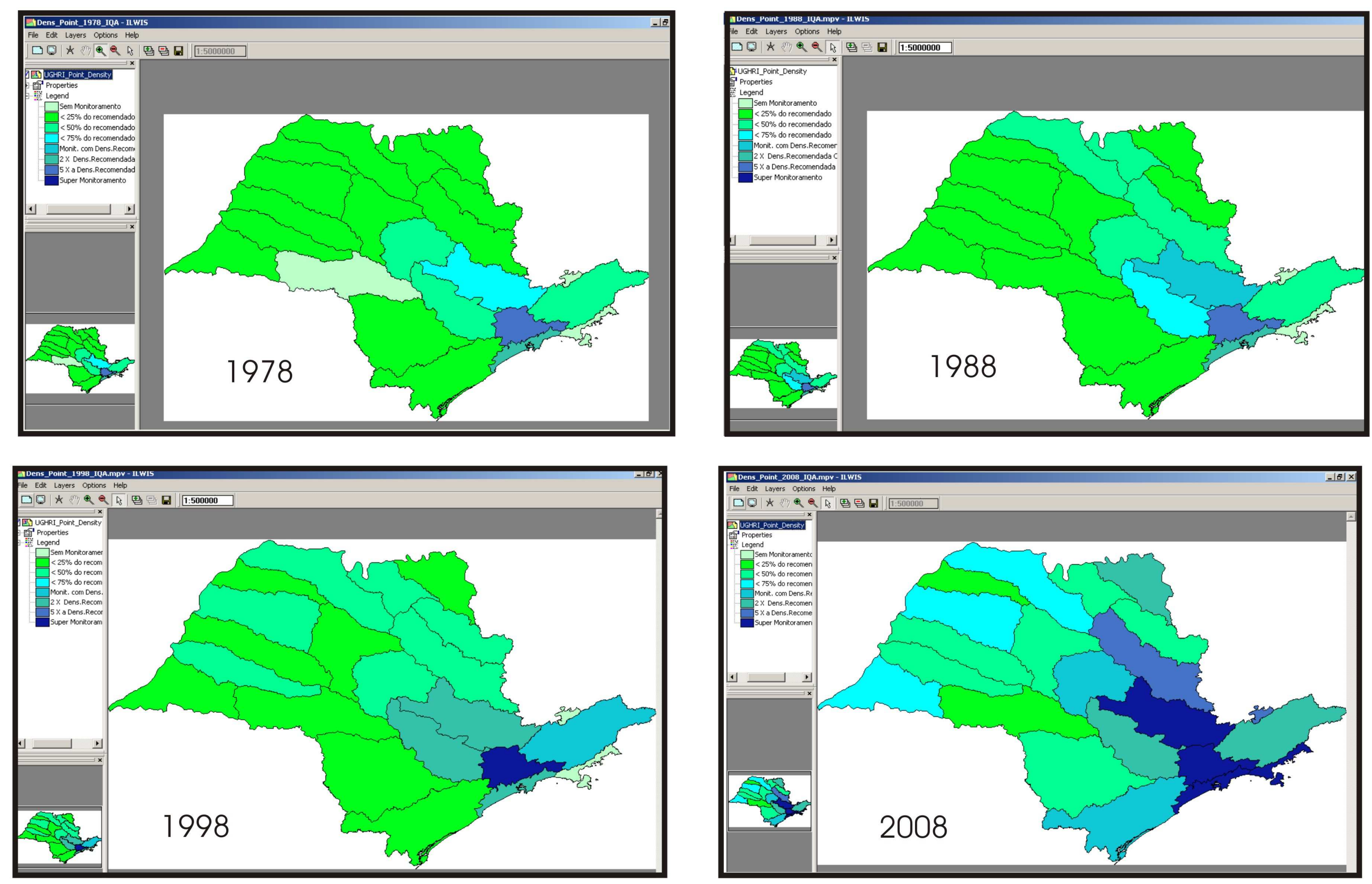

Org. MIDAGLLA,C.L. 2009 


\section{3 - EXEMPLOS DE REDES E DENSIDADE DE MONITORAMENTO EM OUTROS PAÍSES}

A Estônia, país europeu situado na costa do mar Báltico, tem área equivalente a um quinto do território paulista, é dividida em três bacias, e tem uma população de 1.342 .409 (2007), com uma densidade populacional de $28,7 \mathrm{hab} . / \mathrm{km}^{2}$. O início da operação de sua rede de monitoramento para rios e lagos deu-se em 1992. Segundo a Diretiva da Água da EEA, o país deveria ter uma densidade recomendada de 45 pontos, pois possui uma área de $45.226 \mathrm{~km}^{2}$. Mas como o governo estoniano entendeu que o país apresentava uma densidade populacional reduzida, portanto de baixo impacto antrópico, considerou como 27 o número de estações/pontos mínimos para operar sua rede que possuía em 2005, com a seguinte configuração:

- 60 estações de avaliação química de água, o que equivale 1 est./ 750 $\mathrm{km}^{2}$.

- 37 estações hidrológicas: 1 estação por 1.200 km²

- 270 estações de avaliação em rios para Monitoramento Biológico, em Sistemas de Rotação (hydrobiology complex monitoring)

The requirements of the monitoring and information network EUROWATERNET, established by the European Environment Agency, should be taken account of; according to these requirements the density of river monitoring stations in the areas with high human impact must be 1 station per 1000 $\mathrm{km} 2$ and in the areas with low human impact, 1 station per $1700 \mathrm{~km} 2$. Thus minimal number of stations is 27. (ESTONIA, 2005, p.16)

No caso de Portugal, país cuja área total é de $92.3919 \mathrm{~km}^{2}$, e cerca de 10 milhões de habitantes em 2007, em um estudo sobre a reestruturação das redes de monitoramento (denominada de 
monitorização) de qualidade da água, ao sul do Rio Tejo, feito pelos pesquisadores F. Quadrado, F. Gomes e A. Carmona Rodrigues do INAGInstituto Nacional da Água, verificavam a necessidade de reestruturação da rede de qualidade da água, e como metodologia principal, reuniram no seu sistema de monitorização, um conjunto de elementos necessários, para efetuar uma avaliação da qualidade dos recursos hídricos nacionais:

\begin{abstract}
A metodologia desenvolvida e, já apresentada noutra comunicação, começou por ser aplicada a Sul do Tejo. Para tal, caracterizou-se, o mais detalhadamente possível, as bacias hidrográficas, nomeadamente, as fontes de poluição, a ocupação do solo, a pressão demográfica, os usos actuais e potenciais, a definição das zonas sensíveis e o estado da qualidade da água nos rios e albufeiras. Da avaliação da rede actual de qualidade da água, para a zona em estudo, verificou-se que existem 46 estações, o que corresponde a uma densidade de 1,3 estações/ $1.000 \mathrm{~km} 2$ (745 km2/estação), das quais 35 são coincidentes com a rede hidrométrica e apenas uma é automática com teletransmissão. (QUADRADO, GOMES, CARMONA RODRIGUES, 1998)
\end{abstract}

Segundo o tal estudo supra citado, na nova proposta da rede de monitoramento para as várias bacias existentes ao sul do Tejo, o número total de pontos/estações passaria de 46 para 95, ou seja, iria duplicar (Figura 17), conduzindo evidentemente a uma densidade superior, com 2,8 estações/ 1.000 km², (361 km² /estação). Destas estações, 92 seriam coincidentes com estações hidrométricas, o que corresponde a uma maior (quase completa) integração das redes de quantidade e qualidade, atendendo dessa forma aos requisitos da Diretiva da Água. Assim, novamente o argumento de se identificar os impactos antrópicos foi utilizado como justificativa para aumentar a rede acima do recomendado. 
Figura 17 - Densidade da rede de Monitoramento

de Portugal por bacias.

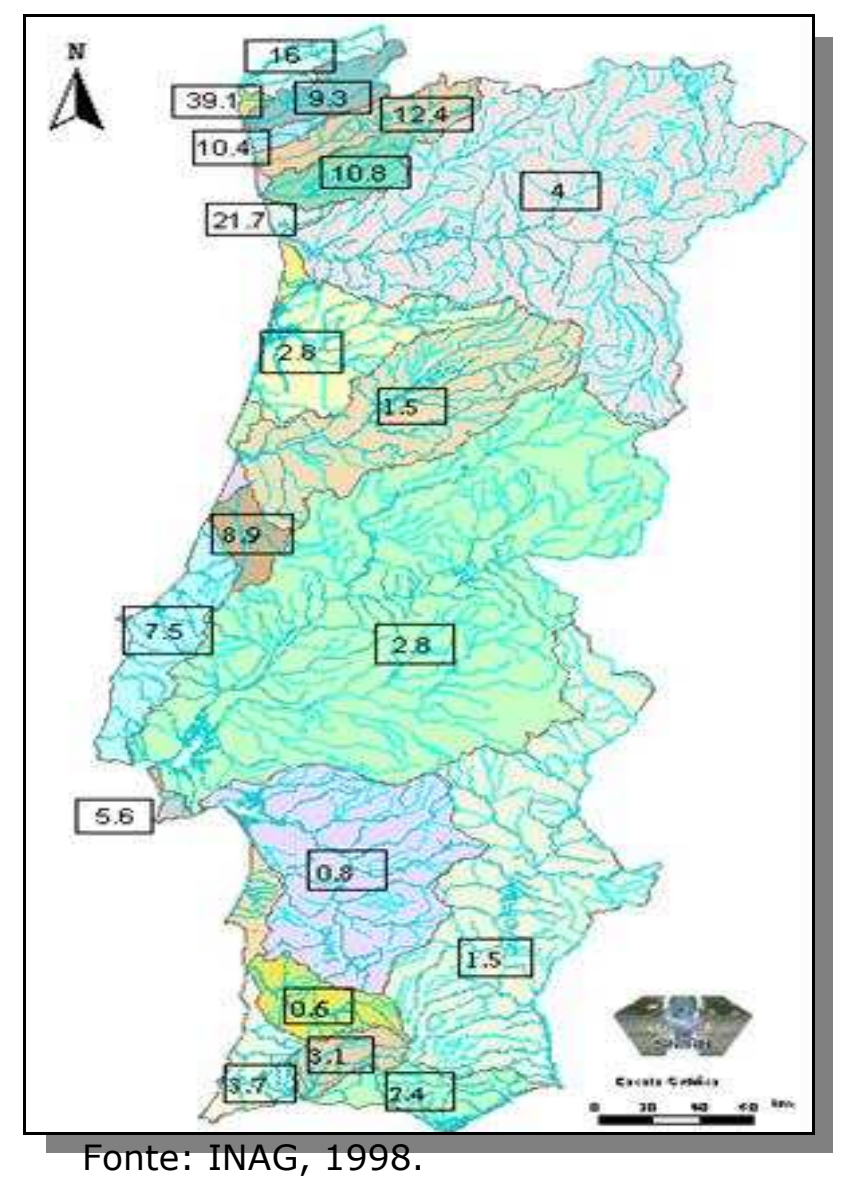

O Relatório de Qualidade de Água Interiores da CETESB- 2004 fez referência ao sistema de gerenciamento de água da França, cujo monitoramento teve início em 1971. Com uma área de $551.100 \mathrm{~km}^{2}$, (cerca de duas vezes o tamanho do Estado de São Paulo) deveria ter uma densidade recomendada equivalente a 551 pontos. Entretanto, o país possui uma boa Rede de Monitoramento Nacional de Bacias (RNB- Réseau National des Données sur l'Eau -SEQ-Eau, 2004), contendo 1.700 pontos de observação, o que corresponde a uma densidade de 3,08 pontos para cada $1.000 \mathrm{~km}^{2}$, bem superior ao recomendado. Esta rede de monitoramento tem como vocação o conhecimento geral da qualidade das águas superficiais, considerando a escala de tempo. Além desta, possuem outras redes de apoio: 
- Redes Complementares de Bacias (RCB): com a mesma vocação geral da RNB, mas realizada em parceria com os departamentos dos rios localmente mais importantes;

- Redes de Uso: trata-se do monitoramento da qualidade de água dos mananciais destinados a produção de água potável (a água superficial representa $40 \%$ do volume destinado ao consumo humano na França);

- Redes Locais: organizadas por iniciativas locais, quando rios ou situações geográficas necessitem de monitoramento especial (água para recreação); e

- Redes Dedicadas: específicas para algumas variáveis, seguindo as circunstâncias locais, como por exemplo, as amostragens de sedimento, especializadas em avaliar micropoluentes orgânicos, pesticidas e metais. O monitoramento da qualidade da água é obrigatório a montante e a jusante das centrais nucleares.

Com tantos esforços em monitoramento e também em revitalização e recuperação de rios, a qualidade das águas francesas já apresenta melhores resultados conforme mostra figura 18, apresentada pelo representante da agência francesa Eau Seine Normandie, CASTEROT, Baptiste na palestra "River revitalization- French Experience on Seine, durante o I Seminário Internacional sobre Revitalização de Rios, realizado em Belo Horizonte, em 9 de setembro de 2008. Graças a esta melhoria, o número de espécies de peixes passou de 14 para 29, entre 1990 e 2007, na bacia do rio Sena, uma das mais pressionadas em termos de ocupação populacional (17,5 milhões de habitantes), com cerca de 5.000 indústrias e responsável por $25 \%$ da agricultura francesa. Ou seja, uma pressão antrópica muito comparável em termos de semelhança do impacto com a situação do Rio Tiete quando atravessa a RMSP. 
Figura 18 - Evolução dos resultados do monitoramento na Bacia do Sena (1985-2007) para 15 parâmetros

\section{The results Inland water quality evolution}

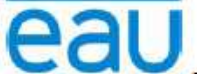

SeINe Evolution of the measurement points' distribution according to 5 classes NORMANDIE

- 15 conbined physical and chemical parameters -

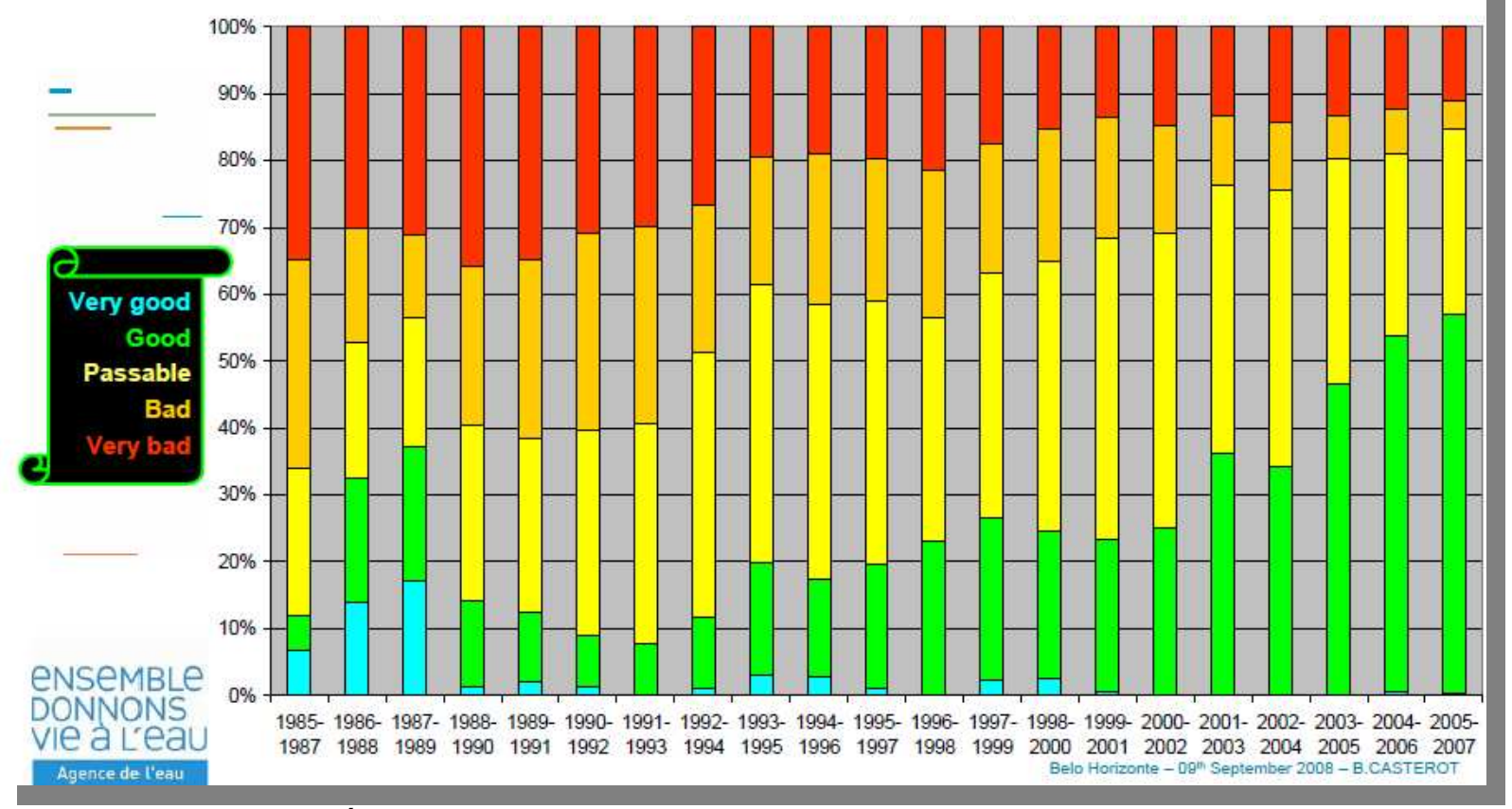

Fonte: Agência de Águas Seine Normandie, 2008.

Deve-se destacar que, tal como França, a Holanda também tem grande tradição e know-how em gerenciamento dos recursos hídricos. Para a Holanda, o conhecimento foi resultado da necessidade de adaptarse a viver literalmente dentro da água, pois $26 \%$ de seu território esta abaixo do nível do mar. As unidades de gerenciamento da Holanda (waterschappen), semelhantes às UGRHIs do Estado de São Paulo, surgiram no século XII, e eram dirigidas por duques (de dijkgraaf), cuja tradução poderia ser "o duque dos diques", nomeados pela rainha. O mapa da figura 19 mostra a divisão atual destas províncias de água. Em 1950, existiam cerca de 2500 delas no território holandês, mas após alguns processos de reestruturação, passou a ter a seguinte configuração: 
Além da divisão em municípios, a Holanda possui uma divisão chamada de Associações das Águas. Essas associações são uma das mais antigas formas democrática de administração territorial. Trata-se de organismos de direito público, encarregados da administração das águas dentro de determinada zona e da defesa do solo contra a água. Relatam os holandeses que os "waterschappen" são as estruturas democráticas mais antigas que surgiram na Holanda. A primeira delas surgiu no século XIII. No ano de 2006, 27 associações recobriam todo o país, algumas delas localizadas em imponentes prédios históricos. (MIDAGLIA, jan.-jun./2007, p.31)

A Holanda, com seu pequeno território, de $41.526 \mathrm{~km}^{2}$, situada na área de desembocadura de importantes rios europeus: Reno, Ijssel, Waal, e Mosela e alta densidade populacional, por volta de 485 habitantes por $\mathrm{km}^{2}$, apenas 41 pontos de monitoramento seriam insuficientes para verificar a qualidade da água superficial. Mas, existem muito mais. E como existem tantos organismos que cuidam da água, fica praticamente impossível tentar descobrir quantos pontos de monitoramento existem. Mas verifica-se que, a maioria deles, destina-se a principalmente a mensurar o nível das águas para prevenção de alagamentos e enchentes, ou seja, com ênfase maior na questão da segurança. Esta medida pode ser entendida pelo fato do país ter um alto grau de controle sobre o manejo dos esgotos domésticos e industriais que passam inclusive por tratamento terciário. Outro fator complementar é que, estando situada em área de deltas, sujeitas a forte influencia de mares, as águas dos rios holandeses são pouco utilizadas para abastecimento humano. 
Figura 19 - Divisão da Holanda pelas 27 Províncias de Água.

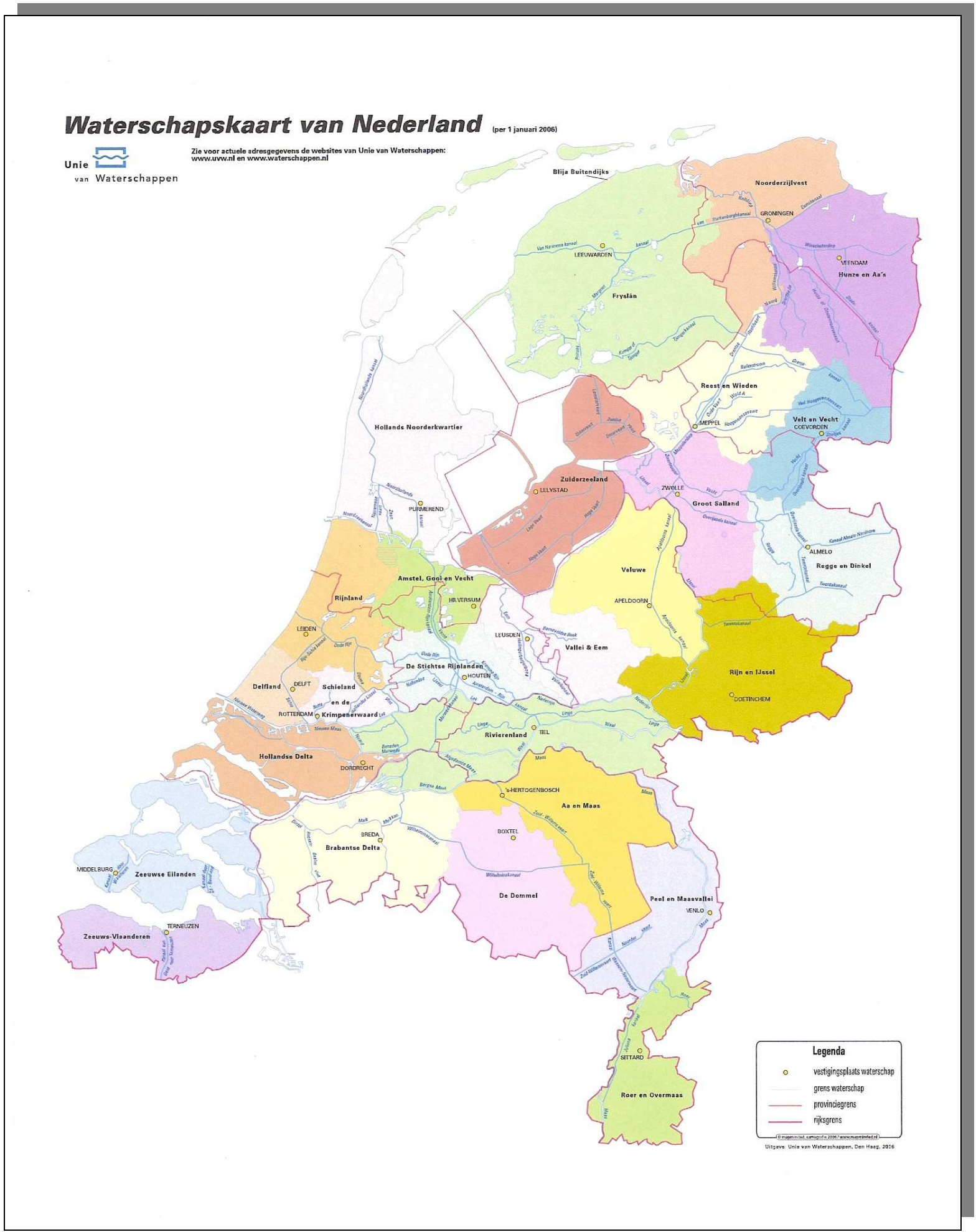

Fonte: Unnie Van Waterschappen, 2006.

Portanto, conclui-se que a relação entre densidade de pontos de monitoramento de qualidade de águas superficiais deve ser flexível para corresponder as necessidades de cada uso local. No caso do Estado de 
São Paulo, a densidade da população deve ser considerada em termos de correlação, uma vez que existe uma grande deficiência de tratamento de esgoto, que apenas é recolhido e afastado das áreas urbanas e geralmente é devolvido aos rios sem que nem a metade dele tenha sido tratada adequadamente.

Um dos objetivos aqui propostos é contribuir com uma proposta de índice de densidades de monitoramento de águas superficiais que se aproxime mais da realidade paulista/brasileira. A figura 20 apresenta um quadro resumo de estados brasileiros com a situação do monitoramento nacional em 2005.

Figura 20 - Quadro Comparativo Nacional de Monitoramento.

\begin{tabular}{|c|c|c|c|c|}
\hline \multicolumn{5}{|c|}{ Tabela 1-Redes de monitoramento da qualidade da água nas unidades da Federaçāo } \\
\hline $\begin{array}{l}\text { UNIDADE DA } \\
\text { FEDERAÇĀAO }\end{array}$ & $\begin{array}{c}\text { ENTIDADE } \\
\text { RESPONSÁVEL }\end{array}$ & $\begin{array}{l}N^{2} \text { DE PONTOS } \\
\text { DE COLETA }\end{array}$ & $\begin{array}{c}N^{N} D E \\
\text { PARÂMETROS }\end{array}$ & $\begin{array}{l}\text { Ne DE COLETAS } \\
\text { POR ANO }\end{array}$ \\
\hline MINAS GERAIS & Igam, Fean, Cetec & 242 & 50 & 4 \\
\hline SAOO PAULO & Cetesb & 241 & 50 & 6 \\
\hline BAHIA & CRA & 232 & 43 & $1-3$ \\
\hline RIO DE JANEIRO & Feema & 143 & 21 & 6 \\
\hline PARANA & Suderhsa, IAP & 127 & 14 & $1-4$ \\
\hline CEARA & Cogerh/Semace & 115 & 3 & 4 \\
\hline RIO GRANDE DO SUL & Fepan, Corsan, Dmae & 88 & 32 & $1-4$ \\
\hline ESPIRITO SANTO & Seama & 75 & 15 & 3 \\
\hline MATO GROSSO DO SUL & Imap & 74 & 20 & 3 \\
\hline PERNAMBUCO & CPPH & 69 & 10 & 6 \\
\hline DISTRITO FEDERAL & Caesb & 56 & 15 & 12 \\
\hline PARAIBA & Sudema & 39 & 16 & 2 \\
\hline GOIAS & $\begin{array}{c}\text { Agência Ambiental } \\
\text { De Golás }\end{array}$ & 26 & 10 & 4 \\
\hline AMAPA & Sema & 25 & 16 & 2 \\
\hline MATO GROSSO & Fema & 14 & 19 & 4 \\
\hline TOTAL & & 1.506 & - & - \\
\hline
\end{tabular}

Fonte: BRASIL, 2005, p.13. 


\section{7 - DESENVOLVIMENTO DO PROJETO GIS SP_WATERNET}

\section{1 - OS PRINCIPAIS MÉTODOS DE ABORDAGEM DA CARTOGRAFIA MODERNA}

Os geógrafos procuram expressar-se através da cartografia. Nos últimos anos, constata-se uma mudança gradativa da cartografia analógica para a cartografia digital. Estas mudanças instrumentais são compatíveis com o mundo tecnológico moderno e apresentam novas formas de enxergar a Geografia. Neste momento, outras ciências também recorrem às Geotecnologias e às vezes utilizam os mapas como um enfeite ou como um grosseiro localizador. A cartografia digital deve sempre que possível seguir as orientações da cartografia temática tradicional em suas representações. As novas geotecnologias em desenvolvimento baseiam-se na constante evolução das técnicas de análise do Sensoriamento Remoto, da entrada de dados terrestres via GPS (Global Positional System), e da arquitetura dos GIS (Geograhic Information System) disponíveis em vários programas e com grau variado de dificuldade.

Conforme revisto por Morato, Kawakubo e Luchiari (2008, p.154): "A disponibilidade de recursos tecnológicos representa um importante instrumento para os mais diversos campos da ciência e da sociedade". Para a Geografia em especial, como demonstra Maguire (1989, apud MORATO, KAWAKUBO, LUCHIARI, 2008), a partir da apresentação de numerosos exemplos, a informática abriu possibilidades muito amplas e impossíveis de serem enumeradas adequadamente, apesar de vários campos da ciência ainda não terem se apropriado substancialmente destes recursos. "Esse conjunto de tecnologias é conhecido como Geoprocessamento, que pode ser aplicado também a outras ciências, além da Geografia." 
A modelagem de dados através de Sistemas de Suporte a Decisão (DSSs- Decision Suport Sistems) também pode ajudar nas técnicas de estruturação de problemas, pois permite melhores possibilidades para executar análises mais completas de bacias para fins de gerenciamento dos Recursos Hídricos. Entretanto, devido a alta complexidade destes modelos e a grande dificuldade de construção de cenários, muitos deles ainda não conseguem expressar adequadamente a realidade geográfica. Mas conseguem calcular a relação entre muitos valores adimensionais envolvidos na análise e auxiliar na interpretação de índices de qualidade de água e/ou previsão de dispersão de poluentes.

Em alguns estudos, foram adicionados componentes espaciais a modelos computacionais e estes assim passam a ser denominados de SDSS (Spatial Decision Support System) Sistemas Espaciais de Suporte a Decisão. Sua arquitetura foi aperfeiçoada para a tomada de decisão em relação a qualidade e quantidade de água e oferecem grande contribuição ao gerenciamento integrado de recursos hídricos de bacias, no enriquecimento de bases para bancos de GIS e no estudo de prevenção de enchentes, eventos hidrológicos e transporte de sedimentos.

As imagens de sensoriamento remoto são muito utilizadas para obtenção de dados espaciais que geram informação sobre o comportamento hidrológico em bacias hidrográficas. As coleções de imageamento do sensoriamento remoto podem também ser utilizadas para observar mudanças espaciais do comportamento do uso do solo em bacias hidrográficas. A plena integração de todos estes dispositivos geotecnológicos ainda não foi alcançada. Neste estudo, o uso da tecnologia do sensoriamento remoto não será incluído, pois exigiria uma capacidade de processamento muito grande, em função do tamanho da área estudada e escala do trabalho.

Sintetizando, nesta fase do estudo, aborda-se a necessidade de integração destas novas tecnologias- o desenvolvimento de banco de dados relacionais, a modelagem e a contribuição das geotecnologias 
aplicadas ao gerenciamento integrado de recursos hídricos, planejamento de bacias e aos estudos sobre o crescimento desordenado das cidades.

Assim, tentar-se-á desenvolver um projeto de GIS que contemple múltiplas variáveis, com possibilidades de avaliar a evolução da qualidade das águas dos rios e reservatórios do Estado de São Paulo. Através desse projeto será possível evidenciar o levantamento de áreas prioritárias para o controle da poluição das águas, avaliar as condições de qualidade das águas brutas captadas para abastecimento público; identificar trechos de rios degradados, verificar a situação dos Recursos Hídricos e subsidiar as tomadas de decisões apresentadas pelos Comitês de Bacias Hidrográficas. Também pode ações preventivas e de controle por parte do órgão ambiental, tais como a construção de Estações de Tratamento de Esgoto (ETEs) pelos municípios ou a adequação de lançamentos industriais. Como a falta de tratamento dos esgotos nos rios paulistas é ainda um componente negativo muito presente, é preciso dar ênfase na parte de análise espacial da qualidade das águas.

\section{2 - CONSIDERAÇÕES SOBRE A ESCOLHA DA PLATAFORMA DE GEOPROCESSAMENTO}

A escolha do software é um dos passos decisivos para a realização de projetos de pesquisa em geotecnologias de Sensoriamento Remoto (SR) ou de sistemas de informações geográficas (SIG). Cabe ao usuário pesquisar qual o software adequado para o seu propósito específico. Há no mercado inúmeros produtos, desde os mais simples até os mais sofisticados, geralmente com valores inacessíveis para estudantes e pesquisadores. Assim, a questão da facilidade de sua obtenção deve ser considerada como essencial e a com a escolha de um software livre, o usuário terá ainda muito mais tranqüilidade para desenvolver o projeto, sem se preocupar com custos de aquisição e licenças de atualização. No caso, o software escolhido foi o ILWIS, versão 3.3. Desenvolvido pelo 
International Institute for Geo-Information Science and Earth Observation, instituição com reconhecimento indubitável, conhecido internacionalmente como ITC, o software ILWIS- Integrated Land and Water Information System (Cf.: ITC, 20/08/2009) é um programa com funções de SIG/GIS e de sensoriamento remoto para desktop, com um conjunto de funções de processamento de imagem e análise espacial. Considerado de aprendizagem rápida, mas na prática, é preciso descobrir muitos detalhes. Possui documentação e tutoriais em inglês on-line completo, sendo reconhecido pela sua funcionalidade e interface amigável. A inexistência de versão em língua portuguesa acredita-se que o conhecimento de termos em inglês é indispensável para o domínio de plataformas tão modernas, em rápido desenvolvimento e de uso global.

Em 2007, o ILWIS 3.4 evoluiu para o sistema open-source, (aberto e gratuito) disponível na versão conhecida por "ILWIS 3.6 Open", hospedada no site da $52^{\circ}$ North (http://52north.org/index.php?option=com_content\&task=view\&id=131\&I temid=155) e faz parte da "Initiative for Geospatial Open Source Software $G m b H^{\prime \prime}$, uma companhia internacional de pesquisa e desenvolvimento, cuja missão é promover a concepção, desenvolvimento e aplicação de geo-softwares livres para educação, treinamento e pesquisa.

Entre outros recursos, apresenta a possibilidade de análise espacial conhecido como Spatial Multiple Criteria Evaluation (SMCE), que é a Avaliação Espacial Multi-Critério. Este item permite a combinação de critérios espaciais com não espaciais, através de funções interativas. Possui habilidades de processar operações hidrológicas com o DEM (Digital Elevation Model), que dá noção de tri-dimensionalidade do relevo através da altitude, geomorfologia e fragilidade de estruturas, etc. Além disto, gera análises de proximidade linear ao longo dos rios (buffer área). Porém, infelizmente por limitações de tempo e pelo fato da necessidade de conversão de praticamente todos os mapas para adequar-se a exigência de processamento de entrada na árvore de decisão optou-se por executá-la de forma manual (planilhas Excel). Mas, deve-se entender que 
a fase manual da SMCE, a MCE, multi-criteria evaluation, (AMC- avaliação multi-critério) é quase uma pré-condição para o passo futuro, ou seja, a análise dentro do software, através da SCME.

Dentre as principais características do ILWIS estão as seguintes funcionalidades:

- Integração entre ambientes Raster e Vetoriais;

- Funções de importação e exportação (para alguns formatos de dados);

- Recursos para conversão dos dados; Processamento de estruturas de dados vetoriais (mapas) e matriciais (imagens);

- Capacidade de produção de saídas diversas (mapas, gráficos, relatórios, etc.);

- Segurança e integridade dos dados;

- Digitalização na tela ou por meio de mesa digitalizadora;

- Conjunto de ferramentas de processamento de imagens de ortofotos, georeferenciamento de imagens com até 8 pontos fiduciais e mosaicagem (com precisão de sub-pixel, 3D e transformação de coordenadas usando de 7 a 10 datum);

- Modelos avançados de análise espacial de dados;

- Visualização 3D com edição interativa para melhor visão (distancia ângulo, orientação e exagero vertical);

- Ampla biblioteca de projeções e sistemas de coordenadas (obs. funciona melhor com sistema UTM);

- Análises Geo-estatísticas, tais como Krigagem para melhorias de interpolação;

- Avaliação de análise SMCE Espacial Multi-criterial. O aplicativo SMCE funciona com um overlay sobre os mapas de referencia, através de combinação de mapas, com funções interativas de gráficos e padronização;

- Conjunto de operações com modelos digitais do terreno - DEM e Processamento Hidrológico com otimização topológica, extrator de rede de drenagem, etc. 
A partir desses critérios e, considerando-se o fato de que a autora deste trabalho, além de ex-aluna deste instituto, gostaria de usar um programa livre e que possa ser desenvolvido em computador pessoal, optou-se, portanto, pelo software ILWIS.

\section{3 - METODOLOGIA DE CONSTRUÇÃO DO GIS WATERNET}

$\mathrm{Na}$ estruturação da pesquisa dentro de bases metodológicas prédefinidas, deve-se esclarecer o aparecimento de vários termos técnicos empregados na linguagem cotidiana de usuários de geoprocessamento. Como a maior parte do desenvolvimento da técnica da geo-informação se dá fora do país, a adaptação dos termos para a língua portuguesa é um pouco mais lenta e por certo período de tempo pode existir confusão de terminologia. Dentro do universo do geoprocessamento, as nomenclaturas novas surgem a cada dia e quando usadas dentro de um programa onde todos os comandos estão em inglês, certas vezes é melhor manter-los no original. Quando houver necessidade serão explicados, e outros que já acabaram sendo incorporados ao nosso vocabulário ficarão em inglês.

Para poder modelar o volume de informação referente aos dados históricos do IQA tem-se que ser definido um protótipo de como o banco vai armazenar estes dados e definir quais regras de comportamento para os objetos inseridos, para que se possa alcançar os objetivos. Assim, o passo inicial foi organizar as variáveis básicas de onde poderiam ser derivadas todas as demais, que seriam usadas para acompanhar a evolução da rede de monitoramento do Estado de São Paulo. Portanto, a análise de processamento neste projeto dá-se em termos regionais, pois a área de abrangência é muito grande. Ao longo dos anos estudados passase a perceber uma maior riqueza das informações pontuais que permitem um panorama mais factível. A escala de trabalho para visualização do Estado de São Paulo dentro do ambiente ILWIS foi de 1: 4.000.000, conforme figura 21. 
Figura 21 - Visualização plena do Layer redeagua (pontos inseridos no ILWIS) na tela em escala 1: 4.000.000.

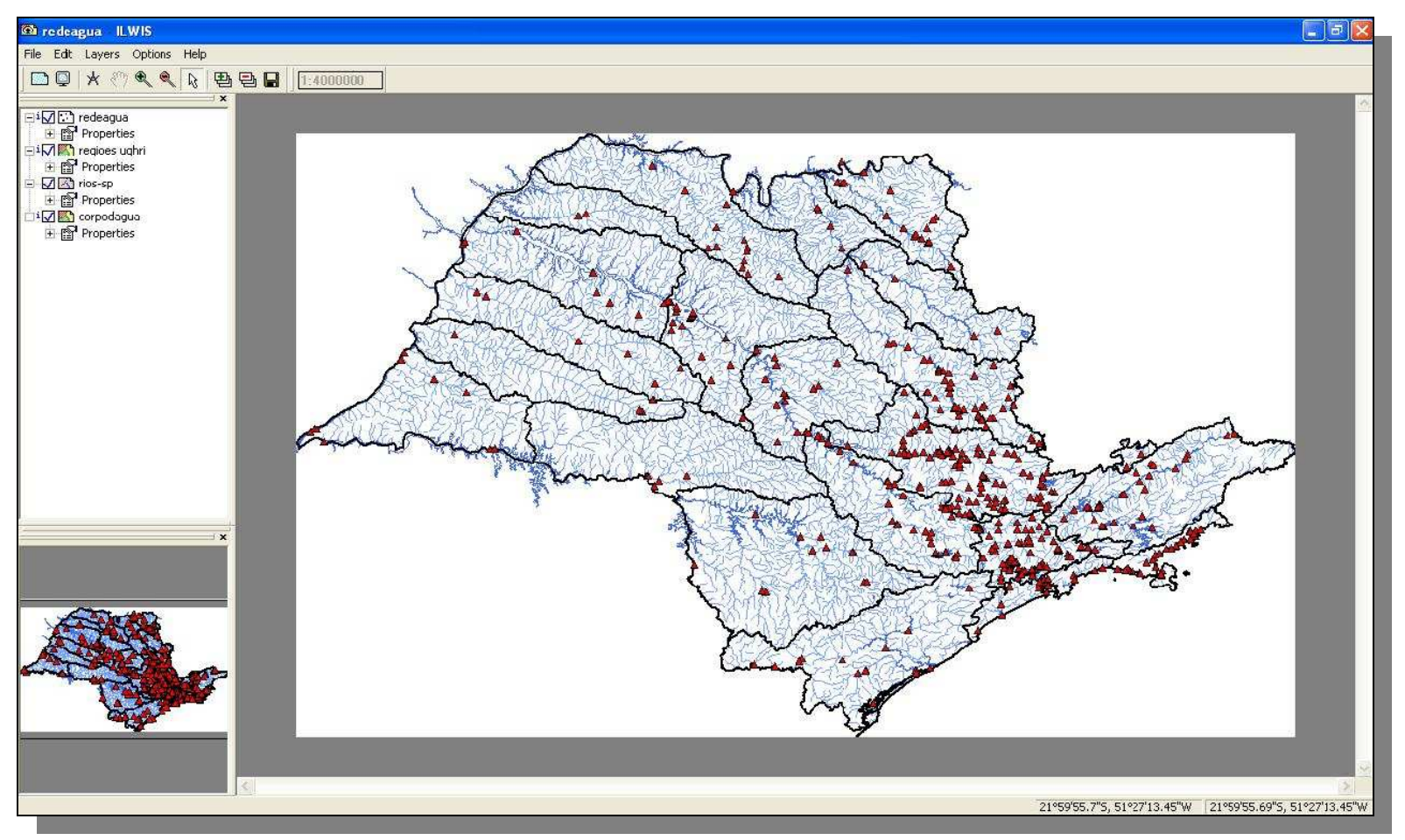

Elaborada por: MIDAGLIA, C. L e KAWAKUBO, F., 2009. Fonte: SP_WATERNET.

A fonte de dados do IQA foram antigos relatórios e planilhas com resultados, de onde foram compilados os resultados dos pontos de monitoramento. As informações geográficas utilizadas como base foram aquelas requeridas para uma análise convencional deste porte tais como o mapa do Estado de São Paulo, com divisão em unidades de gerenciamento de recurso hídrico, a base digital com rios e reservatórios, a localização de cidades e os limites municipais. Estes arquivos bases são de estruturas vetoriais, nas quais foram adicionadas informações de caráter pontual, para constituírem as camadas/layers com informações para análise.

Os Dados essenciais: Os tópicos descrevem o desenvolvimento da etapa de levantamento de obtenção de dados ou bases essenciais, que podem ser entendidos como instrumentais e os dados e bases secundárias ou temáticas. De maneira geral, estes dados têm como unidade de análises as UGRHIs, os municípios e os corpos hídricos. O objetivo é 
oferecer possibilidade de análise espacial e proporcionar simulações regionais.

A menor unidade territorial de análise considerada neste estudo foi o município, uma vez que os dados sobre população encontravam-se organizados por municípios e sua sede municipal. Porém, quando se referem aos dados de qualidade de água, as informações foram reagrupadas para as unidades de gerenciamento de recurso hídrico.

O desenvolvimento deste projeto SIG está apoiado na necessidade de avaliar múltiplos componentes da realidade ambiental que interagem no gerenciamento dos recursos hídricos. Como mencionado no início deste trabalho, a natureza é a soma de um grande número de variáveis ambientais e, na tentativa de representá-la fielmente, inúmeros dados são gerados todos os dias. Assim, é necessário selecionar e trabalhar vários deles praticamente ao mesmo tempo, para que seja possível entender a dinâmica de respostas dos rios e reservatórios ao ambiente em sua volta, identificando as interações locais e regionais aos usos da água e seus reflexos para a sociedade.

A análise dessas variáveis, índices e densidades espaciais possibilitará o entendimento da evolução da rede de amostragem, e possivelmente poderá embasar o desenho de novas redes que, em conjunto com a aplicação de políticas públicas mais vigorosas, possa contribuir para a recuperação dos recursos hídricos, utilizando tecnologias de sistema de informação geográfica e análise espacial como suporte para as tomadas de decisão por parte do poder público e da iniciativa privada, quando assim for necessário.

Durante o intervalo de tempo de 30 anos, correspondentes à existência da rede de monitoramento das águas superficiais, aconteceram modificações no numero de municípios, limitando um pouco a comparação espacial entre eles. Em 1984, haviam 572 municípios no Estado de São Paulo. Após a lei complementar n. 651 de 31 de julho de 1990, o Estado de São Paulo passou por algumas divisões municipais. Em 1991, havia 625 Municípios. Em 1996, aumentou para 636 municípios e mais tarde 
com a de Lei no 9330 de 27 de dezembro de 1995, foram criados mais nove. $O$ número passou para 645 (disponível em: <http://www.igc.sp.gov.br/novmunicip.htm>) que permanece até hoje.

Também neste intervalo de tempo, o próprio conceito de UGRHIs só aparece em 1991, quando foi regulamentado pela Lei Estadual $n^{\circ}$ 9034/94, de 27/12/1994, que estabelecia em 22 as Unidades de Gerenciamento de Recursos Hídricos - UGRHIs, reunidas em 11 Grupos. E são estas ultimas divisões, as UGRHIs, e a base com 645 municípios que serão utilizadas em todas as análises, até pelo fato de não se encontrar muitas bases digitais de períodos anteriores.

\section{4 - AQUISIÇÃO DE BASES PARA ANALISE ESPACIAL}

A construção do banco foi um processo trabalhoso, lento e difícil. Foi preciso comprar bases e adaptá-las para integrar um conjunto mínimo de informações dispostas em layers que deveriam ser relacionados. Os demais dados vieram de fontes variadas, conforme apresentado no Quadro 6. As principais etapas estão assim relacionadas:

- A compra de bases digitais do Estado de São Paulo referentes a drenagem, divisão administrativas e sistemas viários.

- Seleção dos dados essenciais: Os dados essenciais são os que comporão as bases de análise do GIS. Foram obtidos de várias maneiras: construídos ou importados de bases já existentes, com algumas adaptações.

- Obtenção junto ao Banco de Dados Interáguas da CETESB da atual relação de Pontos de Monitoramento de Água Interiores com as respectivas coordenadas geográficas. Migração para planilhas do (MS Excel) dos pontos e dados referentes a toponímia do local, a partir do cadastro existente: 
- Pesquisa para identificação dos antigos locais de monitoramento, geração aproximada de sua latitude e longitude baseada em descrições e, por fim, a recuperação da informação dos índices do IQA através de compilação de resultados de Relatórios publicados a partir de 1978 ate 1989, quando passaram a ter os resultados cadastrados no banco Interáguas da CETESB.

- Resgate da relação de códigos antigos e correlação com nomes atuais.

- Adoção das bases cartográficas do Estado de São Paulo, que é dividido em dois fusos: 22 e, 23, pois a área do Estado é muito grande.

- Definição da área/retângulo envolvente de trabalho, e do sistema de projeção policônica.

- Importação dos arquivos advindos de CAD (Computer Aided Design) em DXF (Drawing Interchange File Format) para ambiente de SIG.

- Conversão das coordenadas geográficas obtidas em Latitude e Longitude dos pontos de monitoramento georeferenciados (disponíveis nos Relatórios da CETESB de Qualidade de água) para o formato Graus, Minutos e Segundos, para coordenadas geográficas no formato de Graus decimais, conforme requisito de entrada do software ILWIS.

- Transformação dos arquivos DXFs em formato SHPs (Shape file, padrão dos arquivos do Software Arc View), utilizando o softer ArcView 3.2 existente no LASERE- Laboratório de Aerofotogeografia e Sensoriamento Remoto da USP. Posteriormente, o mesmo processo foi feito para migração e inserção dentro dos formatos do ILWIS, que foram acomodados no recorte espacial mostrado pela figura 22: 
Figura 22 - Recorte Espacial dentro do SIG SP_WATERNET - Lat: $-20^{\circ} 00^{\prime} /-25^{\circ} 00^{\prime} \mathrm{S} X$ Long: $-45^{\circ} 00^{\prime} /-53^{\circ} 00^{\prime} \mathrm{W}$.

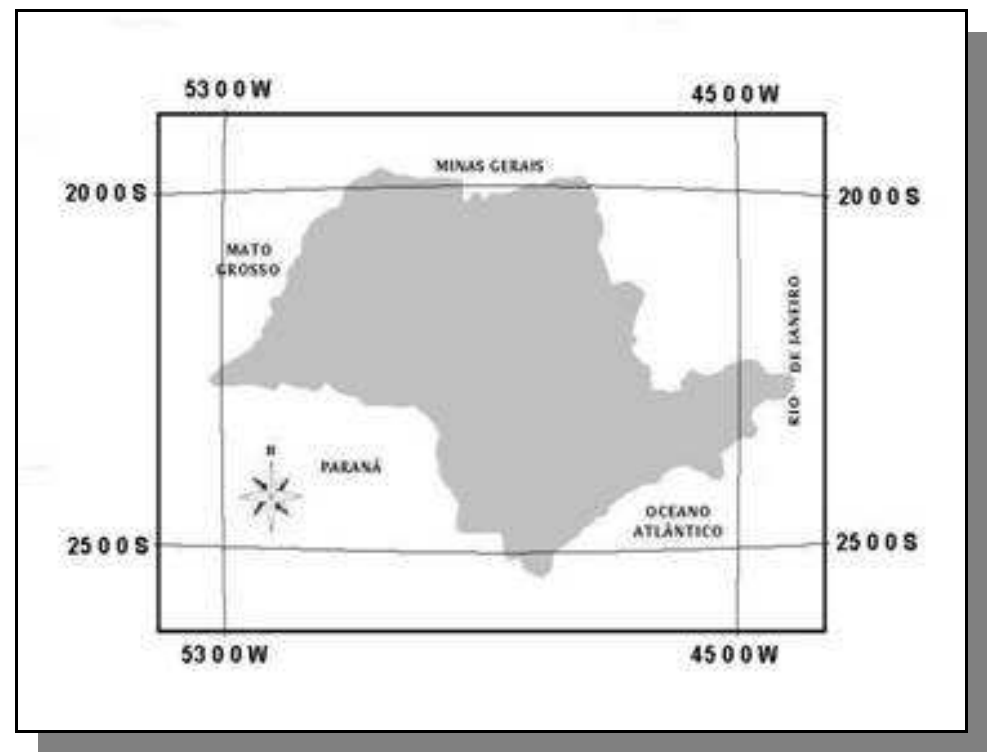

Elaborada por: MIDAGIA, C. L. e MALAVOLTA, F., 2009.

A maioria das coordenadas dos pontos foi obtida usando-se o datum Córrego Alegre, pois a princípio destinavam-se para serem colocadas em cartas topográficas do IBGE, em escala 1: 50.000. Como as bases digitais adquiridas possuíam o datum WGS 84 (World Geodetic System, revisado em 1984), foi necessário fazer a conversão para uma referencia em comum.

Segundo o IBGE/COCAR, o datum a ser utilizado na cartografia brasileira é, desde 1969 o SAD 69 (South American Datum), mas futuramente deverá ser empregado o SIRGAS - Sistema de Referência Geocêntrico, para as Américas. Mas dentro do ambiente ILWIS, o sistema adotado foi o WGS 84, conforme mostra a figura 23 . 
Figura 23 - Sistema de coordenadas adotadas para georeferenciamento das bases.

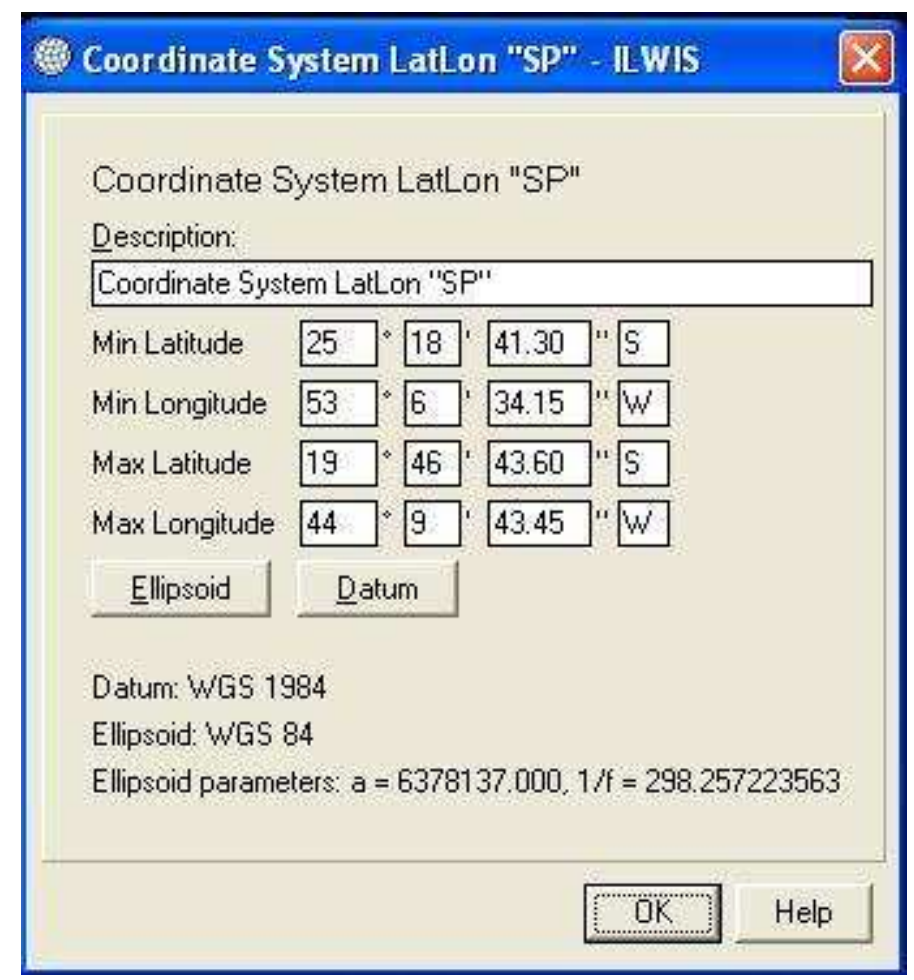

Fonte: SP_WATERNET.

\section{5 - PRODUTOS ESPERADOS}

A partir da montagem do banco de dados SP_GIS Waternet, contendo os pontos/tipo de monitoramento e macro uso do solo os produtos esperados para a análise espacial são:

- Mapas de visualização entre os resultados dos pontos e correlação com os usos vocacionais das UGRHIs.

- Confecção dos Layers com resultados de Índices de Qualidade da Água de anos diversos, na escala aproximada de 1: 4.000.000, para formar cada Map View.

- Analise espacial da distribuição da população e da densidade populacional.

- Classificação ponderada dos diferentes tipos de usos da água, considerando o macro uso do solo, na análise multi-criterio. 
- Definição dos mapas que poderão representar os critérios na proposta MCE (Multi-Criteria Evaluation)

- Obtenção do novo índice de densidade de monitoramento vinculado a densidade demográfica, mostrando a influencia antrópica sobre a qualidade

- Definição da escala de saída dos mapas do Estado de São Paulo, que quando no formato A3 estarão na escala aproximada de 1: 2,500.000 e quando no formato $A 4$, terão a escala aproximada de 1:4.000.000. O ILWIS quando trabalha em coordenadas geográficas apresenta dificuldades para representar a escala em seus layouts.

\section{Quadro 6 - Origem dos Layers do Banco SP_WATERNET.}

\begin{tabular}{|c|c|c|c|c|}
\hline $\begin{array}{c}\text { Conjunto } \\
\text { de Layers/ } \\
\text { camadas } \\
\text { com } \\
\text { elementos } \\
\text { da } \\
\text { realidade }\end{array}$ & $\begin{array}{l}\text { Tipo de dado } \\
\text { (geometria } \\
\text { das bases) } \\
\text { Elipsóide: } \\
\text { WGS } 84 \\
\text { World } \\
\text { Geodesic } \\
\text { system }\end{array}$ & $\begin{array}{l}\text { Atributos/ } \\
\text { comporta- } \\
\text { mento } \\
\text { topológico }\end{array}$ & $\begin{array}{l}\text { Maneira/ } \\
\text { Formato } \\
\text { de entrada }\end{array}$ & Fonte/ Metadado \\
\hline $\begin{array}{l}\text { Hidrografia - } \\
\text { Rios }\end{array}$ & $\begin{array}{l}\text { Vetorial } \\
\text { (linhas) } \\
\text { Segment map }\end{array}$ & $\begin{array}{l}\text { Parcialmente } \\
\text { (rudimentar) }\end{array}$ & Importação & $\begin{array}{l}\text { CAD (DXF) - Shape-file } \\
\text { (SHP) } \\
\text { Empresa Multispectral - } \\
\text { Mapas Digitais } \\
\text { Formato: MapInfo WGS } \\
84 \\
2 \text { de maio de } 2006\end{array}$ \\
\hline $\begin{array}{l}\text { Hidrografia- } \\
\text { Represas }\end{array}$ & $\begin{array}{l}\text { Vetorial } \\
\text { (polígono) e } \\
\text { raster }\end{array}$ & $\begin{array}{l}\text { Parcialmente } \\
\text { (rudimentar) }\end{array}$ & Importação & $\begin{array}{l}\text { CAD (DXF) - Shape-file } \\
\text { (SHP) } \\
\text { Empresa Multispectral - } \\
\text { Mapas Digitais } \\
\text { Formato: MapInfo WGS } \\
84 \\
2 \text { de maio de } 2006\end{array}$ \\
\hline
\end{tabular}




\begin{tabular}{|c|c|c|c|c|}
\hline $\begin{array}{l}\text { Pontos da rede } \\
\text { monitoramento } \\
\text { de água }\end{array}$ & $\begin{array}{l}\text { Vetorial } \\
\text { (pontos) }\end{array}$ & $\begin{array}{l}\text { Parcialmente } \\
\text { (rudimentar) }\end{array}$ & $\begin{array}{l}\text { Manual, } \\
\text { Um a um, } \\
\text { inserir novo } \\
\text { ponto }\end{array}$ & $\begin{array}{l}\text { Relação de pontos } \\
\text { obtidos em campo } \\
\text { durante a caracteriza- } \\
\text { ção geográfica no } \\
\text { processo de inclusão/ } \\
\text { atualização da rede de } \\
\text { monitoramento da } \\
\text { CETESB }\end{array}$ \\
\hline $\begin{array}{l}\text { Agencias } \\
\text { Regionais da } \\
\text { CETESB }\end{array}$ & $\begin{array}{l}\text { Polígonos/veto } \\
\text { rial }\end{array}$ & Parcialmente & Importado & $\begin{array}{l}\text { Adaptado- CAD (DXF) } \\
=>\text { Shape-file (SHP) }\end{array}$ \\
\hline Cidades Sedes & $\begin{array}{l}\text { Vetorial } \\
\text { (pontos) }\end{array}$ & $\begin{array}{l}\text { Parcialmente } \\
\text { rudimentar }\end{array}$ & Importado & $\begin{array}{l}\text { CAD }(D X F)=>\text { Shape- } \\
\text { file }(S H P)\end{array}$ \\
\hline Município & $\begin{array}{l}\text { Polígonos/veto } \\
\text { rial }\end{array}$ & Parcialmente & Importado & $\begin{array}{l}\text { CAD }(D X F)=>\text { Shape- } \\
\text { file }(S H P)\end{array}$ \\
\hline UGRHI & $\begin{array}{l}\text { Vetorial } \\
\text { (polígono) e } \\
\text { raster }\end{array}$ & $\begin{array}{l}\text { Parcialmente } \\
\text { rudimentar }\end{array}$ & Importado & $\begin{array}{l}\text { Shape-file (SHP) - } \\
\text { Fonte: DAEE- } \\
\text { Departamento de } \\
\text { Águas e Esgoto- Secr. } \\
\text { Recursos Hídricos-SP }\end{array}$ \\
\hline $\begin{array}{l}\text { UGRHI } \\
\text { (centróides) }\end{array}$ & $\begin{array}{l}\text { Point map } \\
\text { (vetorial) }\end{array}$ & $\begin{array}{l}\text { Parcialmente } \\
\text { rudimentar }\end{array}$ & Derivado & $\begin{array}{l}\text { Shape-file (SHP) - } \\
\text { Fonte: DAEE- } \\
\text { Departamento de } \\
\text { Águas e Esgoto- Secr. } \\
\text { Recursos Hídricos-SP }\end{array}$ \\
\hline $\begin{array}{l}\text { Topografia em } \\
\text { intervalos de } \\
200 \mathrm{~m}\end{array}$ & $\begin{array}{l}\text { Vetorial } \\
\text { (linhas e } \\
\text { ponto } \\
\text { cotados) } \\
\end{array}$ & Parcial & Importado & $\begin{array}{l}\text { IBGE- Shape-file } \\
\text { (SHP) site do IBGE- } \\
\text { Escala } 1: 1.000 .000\end{array}$ \\
\hline Tabelas & $\begin{array}{l}\text { Colunas: são } \\
\text { informações } \\
\text { tabuladas que } \\
\text { se referem a } \\
\text { informação } \\
\text { geográfica } \\
\text { armazenada } \\
\text { nos mapas } \\
\text { tabular. }\end{array}$ & & $\begin{array}{l}\text { Importado } \\
\text { Ou criada }\end{array}$ & $\begin{array}{l}\text { Estão associadas aos } \\
\text { objetos }\end{array}$ \\
\hline Estado & $\begin{array}{l}\text { Vetorial } \\
\text { (polígono) } \\
\text { Raster }\end{array}$ & Parcial & Importado & $\begin{array}{l}\text { CAD (DXF) - Shape- } \\
\text { file (SHP) } \\
\text { Área do estado } \\
\text { segundo resolução n5 } \\
\text { do IBGE } 10 / 10 / 2002 \text { é } \\
248.209 \mathrm{~km} 2 \text {. No } \\
\text { entanto, nesta base a } \\
\text { área indicada é } \\
248.625 .794\end{array}$ \\
\hline
\end{tabular}




\begin{tabular}{|l|l|l|l|l|}
\hline $\begin{array}{l}\text { Imagem } \\
\text { Modis Terra }\end{array}$ & Raster & - & Importado & $\begin{array}{l}\text { Sensor MODIS - } \\
\text { Satélite Terra } \\
\text { Fonte: Universidade } \\
\text { de Maryland (2004) }\end{array}$ \\
\hline
\end{tabular}

\section{6 - PRINCIPAIS FORMATOS DO ILWIS}

Os mapas quando utilizadas em forma de layers possuem diferentes feições e funções dentro do banco de dados ILWIS (Quadro 7). Estas referem-se a sua posição e ao tipo de registro geográfico (informação espacial) que contem:

Quadro 7 - Formatos do ILWIS.

\begin{tabular}{|c|c|c|}
\hline Símbolo & Nomenclatura & Uso \\
\hline & $\begin{array}{l}\text { Point maps: Mapas de } \\
\text { pontos }\end{array}$ & $\begin{array}{l}\text { Tem como feições pontos. Ex. cidades e } \\
\text { pontos de amostragem. }\end{array}$ \\
\hline & $\begin{array}{l}\text { Polygon maps: Mapas } \\
\text { poligonais }\end{array}$ & $\begin{array}{l}\text { Tem como feições áreas fechada. } \\
\text { Ex. municípios, UGRHIs e Estado. }\end{array}$ \\
\hline & $\begin{array}{l}\text { Segment maps: Mapas de } \\
\text { vetores }\end{array}$ & $\begin{array}{l}\text { Tem como feições linhas, por exemplo, } \\
\text { estradas e rios. }\end{array}$ \\
\hline & $\begin{array}{l}\text { Raster Maps: mapas } \\
\text { rasters contem pixels } \\
\text { (picture element) }\end{array}$ & $\begin{array}{l}\text { No ILWIS, a maioria das operações } \\
\text { espaciais é realizada por estas feições. } \\
\text { Guardam a informação espacial. }\end{array}$ \\
\hline
\end{tabular}

Dentro dos layers, as feições são identificadas por um ID (identificador único), na qual a informação fica associada e, que ocorre de modo geral, uma única vez no mapa que corresponde a um número 
relacionado a como cada uma desta unidade é conhecida. Por exemplo, não podem existir dois municípios com o mesmo ID. Eles também têm domínios que podem ser do tipo classe, onde as feições são identificadas pelo nome de classe (ex. uso do solo) e que podem ocorrer em várias áreas dentro do mesmo mapa, como por exemplo, neste caso, a atribuição das UGRHIS. Podem ter domínio de valores, com representações referentes aos resultados dos valores medidos dos índices do IQA. 


\section{DO DADO DO PONTO A INFORMAÇÃO: A CARACTERIZAÇÃO GEOGRÁFICA DOS PONTOS DE MONITORAMENTO DA REDE DE QUALIDAde de Água - A CONSTRUÇÃo dA bASE PARA ANÁLISE ESPACIAL}

Em todo mundo as informações sobre recursos hídricos estão sendo sistematizadas, e vários bancos de dados estão em desenvolvimento por organismos nacionais ou supra-nacionais diversos. O motivo é a possível escassez de água de boa qualidade. Uma questão maior é com a falta de codificação e qualificação dos rios e represas. No Brasil, ainda não existe uma padronização nacional devido aos diferentes graus de gerenciamento do recurso hídrico, em todo o território nacional. A hierarquização de bacias não é um critério suficiente pra designar os pontos amostrados dada a extensão do país e diversos tipos de densidade de drenagem.

No que refere-se a codificação dos corpos hídricos, a CETESB adota um sistema próprio e, como este estudo utiliza estes pontos, usa-se o mesmo nome. O georeferenciamento de pontos amostrados é feito com aparelhos receptores GPSs do tipo de navegação (modelo GPS ETREX Venture e ETHEX Vista). Cada ponto proposto para integrar a rede é avaliado geograficamente e, são registradas suas coordenadas, em graus, minutos e segundos assim como a altitude em metros, com possível margem de erro de 10 a $15 \mathrm{~m}$. Cada um destes pontos é uma informação discreta, com geometria $X, Y$ que foram transpostos para um layer vetorial denominado "redeagua", dentro deste projeto GIS.

Portanto, com este conjunto de registros de coordenadas geográficas obtidas através de visitas em campo e publicadas nos relatórios da CETESB, obteve-se a relação anual dos locais avaliados. No processo de sua plotagem no layer "Redeagua", como sempre, apareceram alguns problemas de precisão na rotina de inserções de pontos. Mas, como foram plotados um a um, pode-se eventualmente verificar o grau de sua confiabilidade/accuracy dos mesmos. 
Para acompanhar espacialmente a evolução da rede e seus resultados foi preciso resgatar os dados históricos mensais em seus relatórios originais, verificar os locais dos pontos, e partir daí iniciar a construção do banco de dados georeferenciados, SP_WATERNET, onde constam as médias anuais dos IQAs gerados por cada ponto monitorado no período entre 1978 e 2008. Assim, foi construída uma tabela onde esta a serie das médias anuais do IQA, principal variável ambiental vinculada ao tema deste projeto. Este layer produz como resultado um conjunto de mapas temáticos gerados dentro do ambiente SIG, que resgatam e retratam o panorama da situação real do estado da qualidade de água. Este data set é a base fundamental para a obtenção da visão da evolução da distribuição espacial dos pontos. A figura 24 mostra parte da construção deste procedimento com a plotagem dos pontos da rede de monitoramento no layer "redeagua":

Figura 24 - Inserção de pontos no Layer "redeagua".

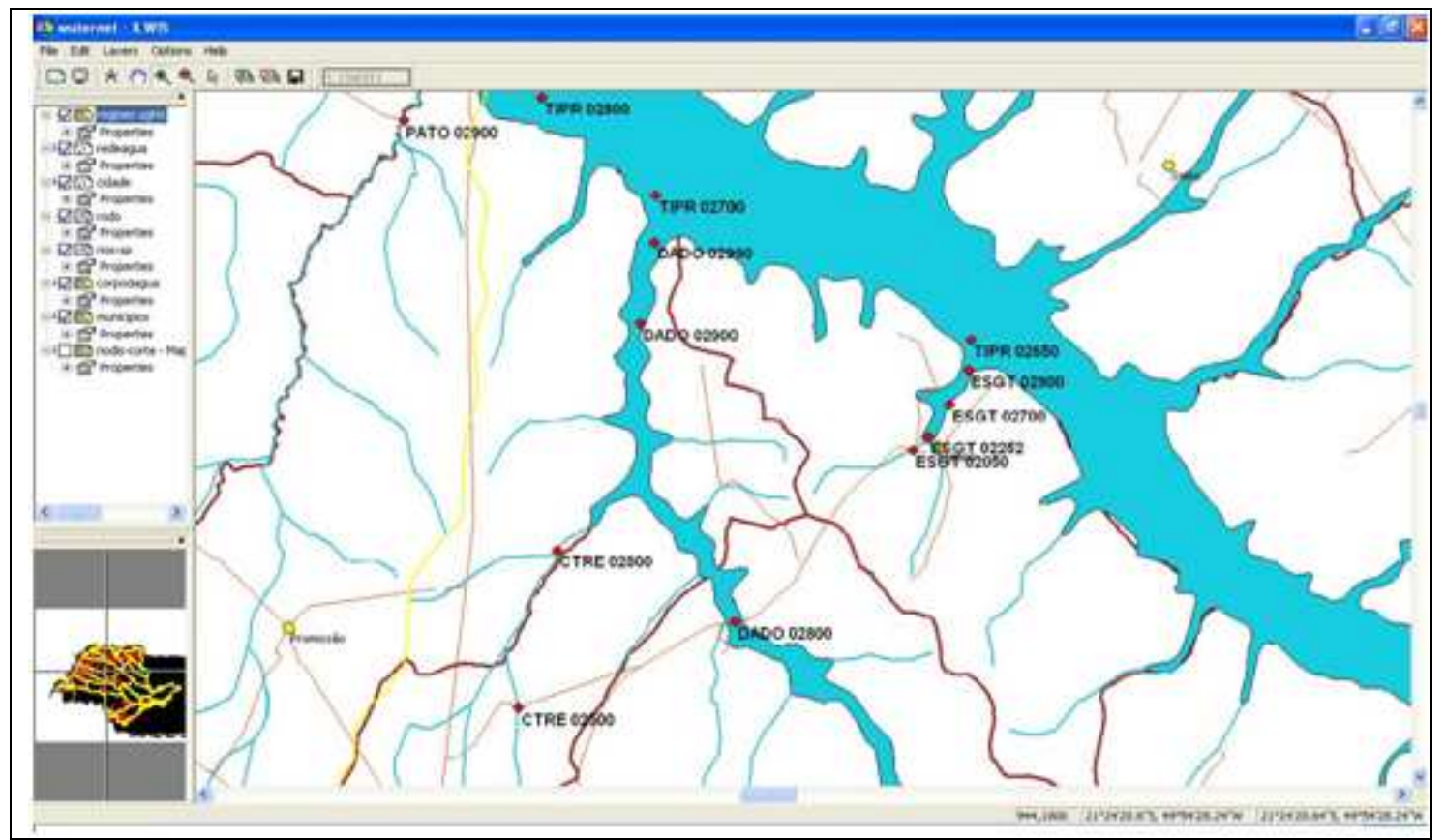

Elaborada por: MIDAGLIA, C. L., 2009. Fonte: SP_WATERNET.

As eventuais dúvidas de localização foram solucionadas através da comparação paralela feita no sistema online "Google Earth" (versão 4.3 
beta), bastante útil para este fim (figura 25). Assim, após as conferências, confirma-se se a coordenada correspondente ao ponto visitado foi plotada corretamente e/ou se necessário faz-se um ajuste manual do local selecionado em razão dos pontos caírem em terra (próximo as margens) quando sabidamente estavam em rios. Neste processo, varias vezes foi necessário fazer o ajuste

\section{Figura 25 - Pontos de amostragem verificados no Google Earth.}

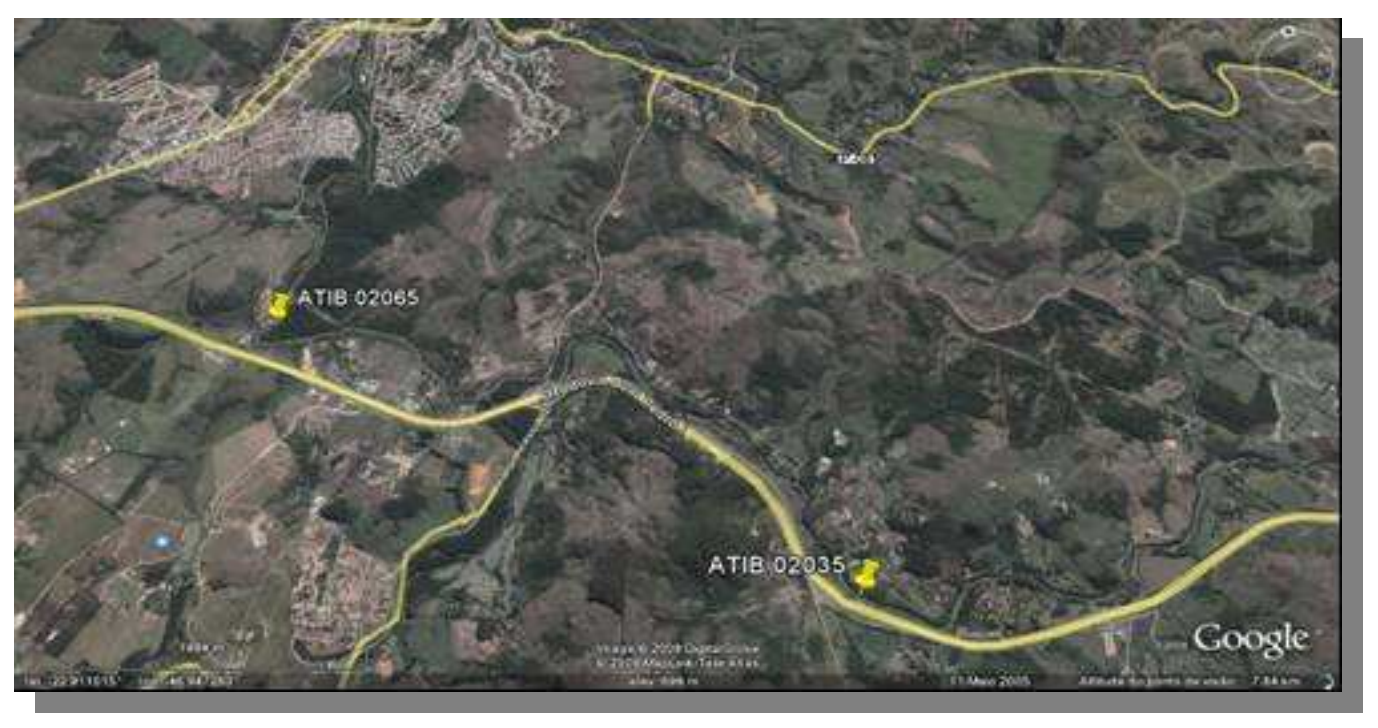

Em razão do Estado de São Paulo possuir mais de um fuso (22 e 23) na projeção UTM, foram usadas as coordenadas geográficas em formato latitude e longitude que conforme a exigência do programa ILWIS. Foi necessário fazer a sua transformação para décimos de minutos, para possibilitar a inserção dos pontos sobre as bases de rios e represas. Estes foram feitos através de calculadoras de conversão existentes na Internet (tais como as que estão disponíveis gratuitamente nos sites <http://www.rdtec.com.br/ rdgeomg/localmaster.htm> e $<$ http://www.stevemorse.org/jcal/dms.html siteb >).

Assim, indiretamente, pode-se verificar se existia correlação entre as diferentes bases adquiridas para este estudo e os registros obtidos em campo no mapa, que estava sendo gerado com os próprios pontos de monitoramento. Neste processo, os pontos de coleta assumem o papel de 
controle do terreno (GCP-Ground Control Points), pois como normalmente são colocados em cima de pontes. Dentro do banco de dados, as pontes são equivalentes a coincidências dos cruzamentos da base digital de rios com a base digital de estradas. Naturalmente, alguns conflitos são esperados, pois as bases digitais têm origens diversas e são digitalizadas por entidades/pessoas diferentes, e como, além disto, muitos rios são também divisa de estado ou município isto faz surgirem outras inconsistências. A figura 26 apresenta o caso do ponto SDOM 03990, situado na extrema foz do Ribeirão São Domingos com o Rio Turvo, local de encontro de três limites municipais e dois rios. A solução aqui se deveu ao fato da autora ter estado no local e ter recolhido as coordenadas pessoalmente, pois sabia-se de qual município o ponto estava mais próximo da margem, e com isto define-se a qual deles pertence, para fins de cadastramento e codificação. Embora, enquanto ponto, poderá fornecer informação espacial e ambiental útil para os três municípios.

Figura 26 - Exemplo de conflito típico de limites de bases.

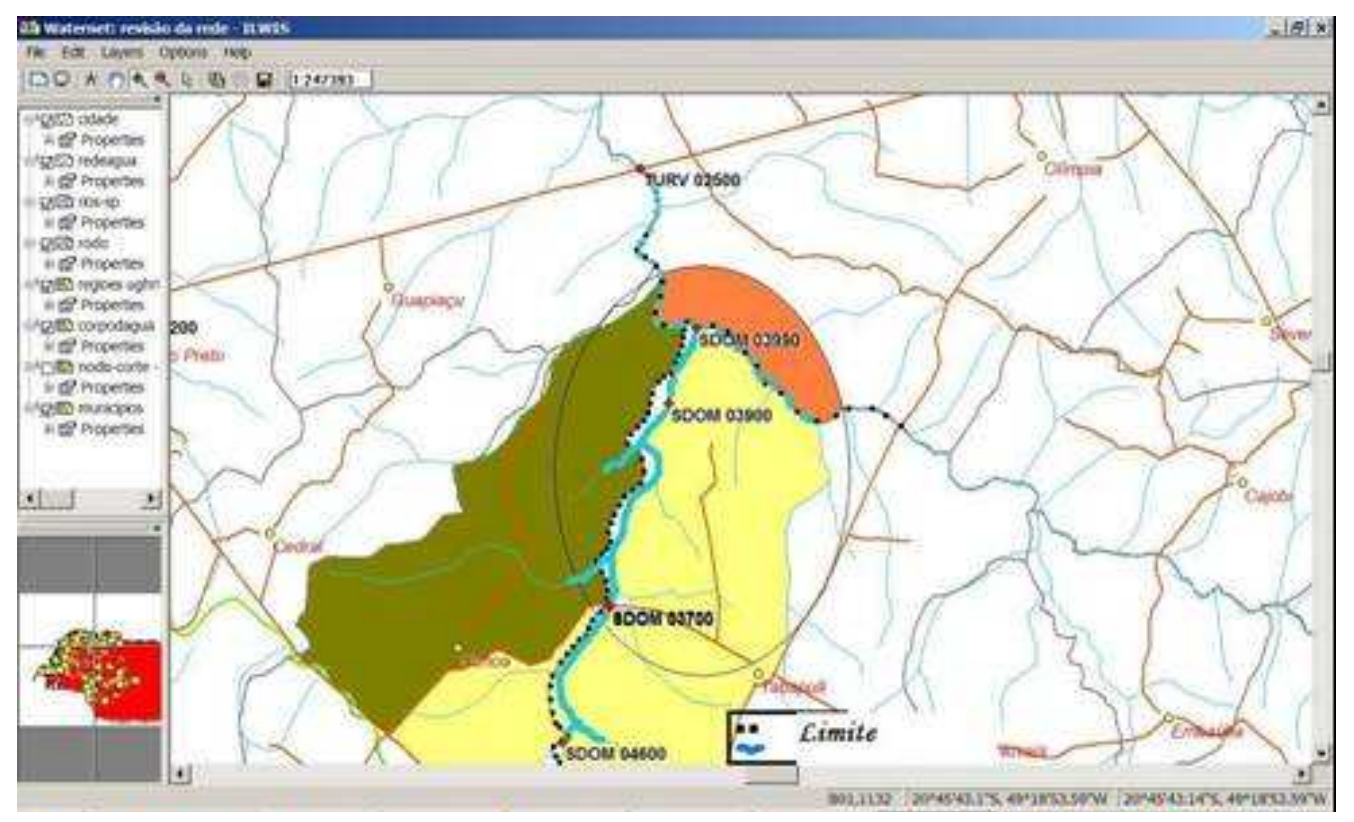

Elaborada por: MIDAGLIA, C. L., 2009. Fonte: SP_WATERNET. 


\section{1 - ALGUNS TIPOS DE ANÁLISE ESPACIAL UTILIZADAS EM GEOTECNOLOGIAS}

Como tudo acontece em algum lugar no espaço ou não acontece, cresce muito o interesse por estudos de correlações de fenômenos na dimensão tempo/espaço. Os eventos tendem a ser quantificados e georeferenciados para buscar a presença ou não de relações entre os fenômenos, através de verificação de tendências e coincidências de comportamento espaciais.

Uma vez colocados todos os pontos no layer redeagua, procedeu-se a sua alimentação com a informação desejada, a média anual do IQA, principal variável ambiental vinculada ao tema deste projeto, no período de 1978 a 2008 para todos os pontos. Os dados foram inseridos em colunas da tabela correspondente ao layer, por ano e por classificação. Ou seja, na coluna valor por um domínio de valor, onde é colocado exatamente o resultado da média, e em outra coluna ao lado, um domínio de classe, associado a uma representação pré-estabelecida, que classifica permanentemente os valores conforme a categoria convencionada. Este layer produz um conjunto de mapas temáticos gerados dentro do ambiente SIG, que resgatam e retratam o panorama da situação real do estado da qualidade de água. Este data set é a base será fundamental para as operações de análise espaciais visando a obtenção da distribuição temporo-espacial dos pontos.

Para verificar a existência de correlação espacial dos pontos da rede em função de seus resultados, utilizou-se uma função estatística do ILWIS que executa a operação de correlação espacial, gerando uma tabela composta pelos índices estatísticos de Correlação Espacial: Índice de Moran e de variância: Índice de Geary. Basicamente estas funções avaliam o grau de dependência espacial entre os valores dos pontos, aqui representados com as médias dos valores anuais, sugerindo que possam ser afetados por processos semelhantes. 
A dependência espacial pode ser compreendida como uma leitura para veriicar se os resultados dos pontos têm comportamento espacial isotrópico (não variam em função de sua localização, ou seja, os valores são semelhantes, mesmo em lugares diferentes) ou anisotrópico (não tem padrão espacial vinculado ao local). Naturalmente, este índice também varia em função do ano que se escolhe para executar a operação, pois quando mais recente o ano, maior é o número de pontos (pares) existente na rede, e assim, esta correlação par a par entre eles é alterada, pois está vinculada á distancia existente entre eles. O algoritmo gerado por Geary (C) compara a diferença ao quadrado de um par de pontos com as médias gerais, e o índice de Moran (I), compara a diferença ao quadrado dos desvios dos pares de pontos em relação à média entre todos os valores, sintetizando a relação de dependência espacial de todo universo de pontos. (Cf.: WESTEN, FARIFTEH, 1997)

\section{Figura 27 - Análise de correlação espacial em 2008 com distância de 25 km.}

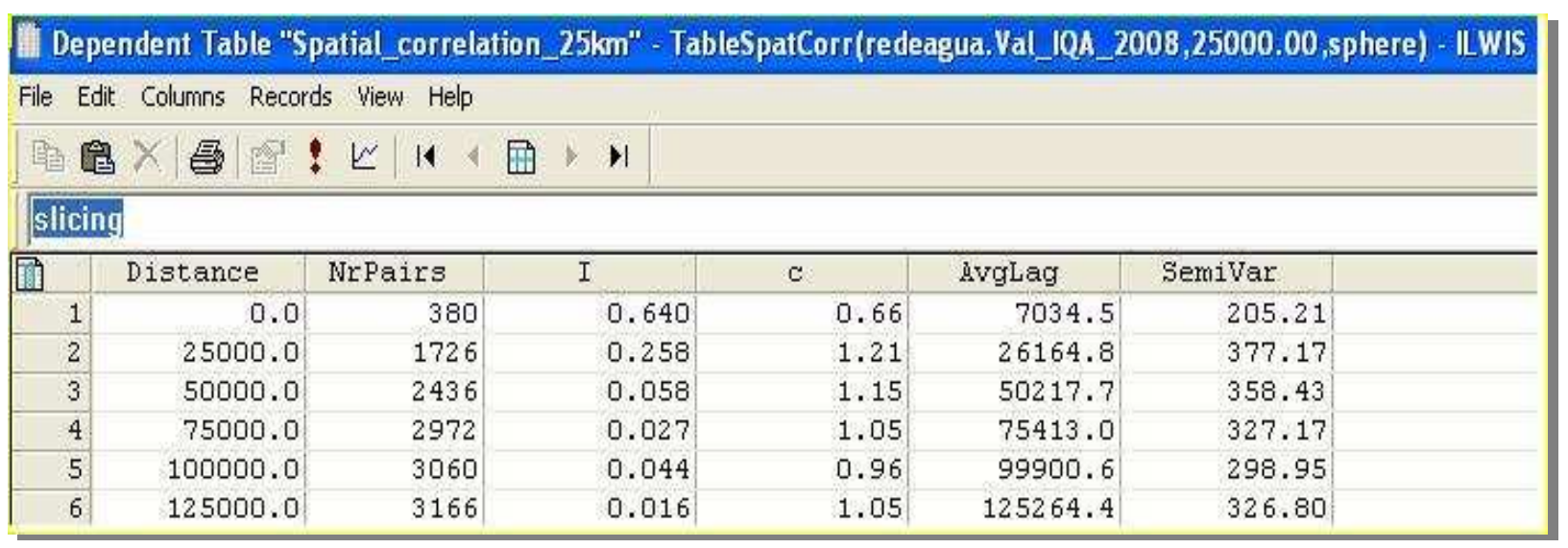

Fonte: SP_WATERNET.

Os cálculos foram feitos para os anos de 1978, 1988, 1998 e 2008, que identificaram de 40 (1978) a 380 (2008) pares, que apresentaram forte correlação espacial positiva quando têm, entre eles, uma distancia em todas as direções (omnidirectional distance) que varia de 12,5 a 25 Km. A interpretação geral das estatísticas está resumida na tabela 9. 


\section{Tabela 9 - Comparação da Análise de correlação espacial}

1978 e 2008 com distância de 25 km.

\begin{tabular}{|c|c|c|c|c|c|}
\hline $\begin{array}{c}\text { Ano/ } \\
\text { Índice }\end{array}$ & $\begin{array}{c}\text { Índice de } \\
\text { Moran (média } \\
\text { IQA com raio } \\
\text { de } 25 \mathrm{~km} \text { ) }\end{array}$ & $\begin{array}{l}\text { MORAN } \\
\text { (I) }\end{array}$ & $\begin{array}{c}\text { Índice de } \\
\text { GEARY } \\
\text { (média } \\
\text { IQA com } \\
\text { raio de } 25 \\
\text { km) }\end{array}$ & $\begin{array}{l}\text { GEARY } \\
\text { (C) }\end{array}$ & Classificação \\
\hline 2008 & $I=0,64$ & $I>0$ & 0,66 & $0<C<1$ & $\begin{array}{l}\text { Forte auto-correlação } \\
\text { positiva }\end{array}$ \\
\hline 1998 & $I=0,65$ & $\mathrm{I}>0$ & 0,92 & $0<C<1$ & $\begin{array}{l}\text { Forte auto-correlação } \\
\text { positiva }\end{array}$ \\
\hline 1988 & $I=0,65$ & I $>0$ & 0,95 & $0<C<1$ & $\begin{array}{l}\text { Forte auto-correlação } \\
\text { positiva }\end{array}$ \\
\hline \multirow[t]{3}{*}{1978} & $I=0,55$ & $\mathrm{I}>0$ & 0,88 & $0<C<1$ & $\begin{array}{l}\text { Forte auto-correlação } \\
\text { positiva }\end{array}$ \\
\hline & & $\mathrm{I}<0$ & & $C>1$ & $\begin{array}{l}\text { Forte auto-correlação } \\
\text { negativa }\end{array}$ \\
\hline & & $I=0$ & & $C=1$ & $\begin{array}{l}\text { Distribuição aleatória ou } \\
\text { randômica dos valores. }\end{array}$ \\
\hline
\end{tabular}

Elaborado por MIDAGLIA, C. Fonte: SP_WATERNET.

Portanto, quando mais próximos do intervalo de $25 \mathrm{~km}$ os resultados de qualidade de água estiverem, maior correlação espacial apresentaram, sendo este um comportamento isotrópico. Mas quanto mais fora desta distancia estiverem, a auto-correlação tende a ficar negativa e a superfície espacial então se comporta de forma anisotrópica, o que é perfeitamente factível com o mundo real, que é desigual por natureza, mas que tende ao equilíbrio.

\section{2 - ANÁLISE ESPACIAL COM A OPERAÇÃO PONTO MAIS PRÓXIMO (NEAREST POINT) DO ILWIS}

Nos mapas síntese dos Relatórios de Qualidade de água CETESB, a informação da qualidade dos rios é feita através de atribuição de cores com valores convencionados para cada faixa de valores índices obtidos.

Conforme a metodologia de preenchimento, quando a qualidade entre dois pontos tem faixas de classificação diferentes, divide-se o trecho pela metade e cada parte recebe a cor equivalente ao valor gerado no 
próprio ponto amostrado. Em um processo de análise espacial computadorizado, esta mesma metodologia poderia ser feita usando-se o método de interpolação estudado nos diagramas de Voronoi, também conhecido com triângulos de Thiessen, ou de Direchlet. O método consiste na decomposição da área, tesselação, por método de divisão linear entre os pontos. É uma metodologia de análise espacial com representação existente em vários software de GIS e que pode sugerir áreas de influência ou cobertura. A figura 28 mostra um exemplo desta divisão.

\section{Figura 28 - Exemplo de representação utilizando divisão de Voronoi.}

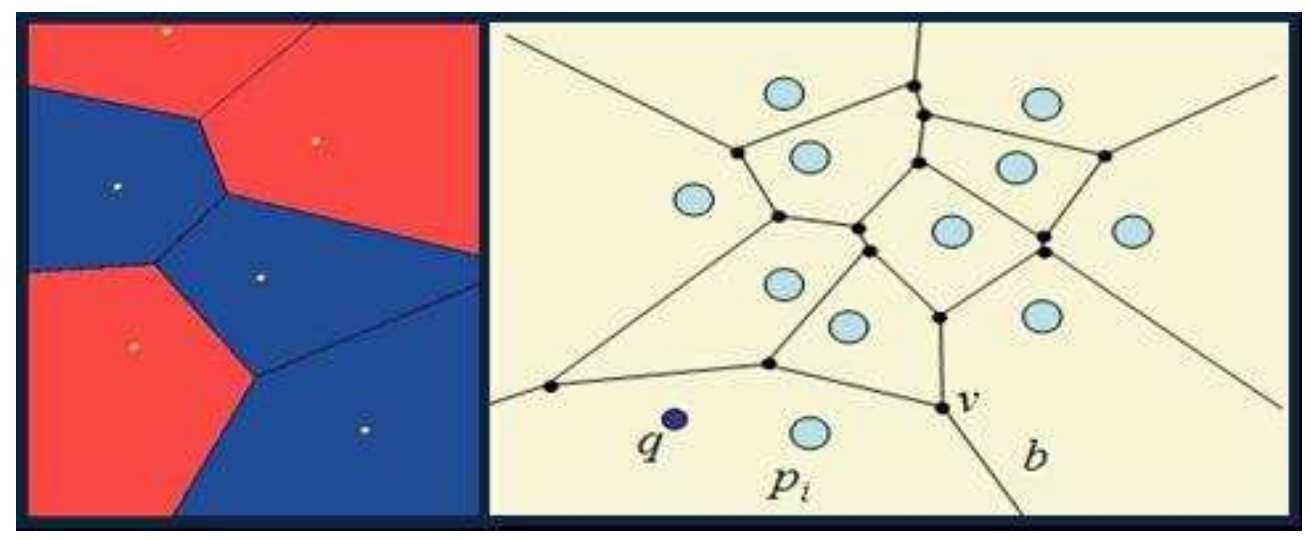

Fonte: http://www.voronoigame.com

Os polígonos de Voronoi têm sido muito utilizados por sua versatilidade em termos de estrutura de dados na Geometria computacional, com aplicações em diversas áreas da ciência. Assim, os pontos de amostragem de água adjacentes são interligados invisivelmente por retas que se subdividem na altura de sua mediatriz (a mediatriz $\mathrm{m}$ de um segmento $A B$ é, por definição, o conjunto de todos os pontos do plano que eqüidistam das extremidades $A$ e $B$ do segmento distancia), formando vários polígonos, que indicam as áreas de domínio de cada interseção do ponto de monitoramento ao longo do rio ou reservatório. E, assim abstraise para a realidade que aquela área contida no interior do segmento é representada pelo mesmo valor. 
Nesta primeira tentativa de análise espacial, os Polígonos de Thiessen seriam as áreas de "domínio" de cada ponto de monitoramento de água superficial. Poder-se-ia assumir que no interior dessas áreas, o valor do IQA ou de qualquer outro parâmetro monitorado, seria igual ao do respectivo ponto amostrado. Os polígonos são traçados da seguinte forma: dois pontos de monitoramento adjacentes são ligados por um segmento de reta e traça-se a mediatriz deste segmento de reta. Esta mediatriz divide para um lado e para outro as regiões de "domínio".

Este método de análise espacial dentro do software ILWIS obtém-se a partir da função Interpolação, seguida da opção "ponto vizinho mais próximo" (Nearest neighbour or Thiessen). Esta operação de determinação de ponto mais próximo requer um mapa de pontos como entrada ("redeagua") e o transforma em um mapa raster como saída dos pontos interpolados. Cada pixel do mapa de saída terá tamanho de aproximadamente meio décimo de segundo de grau (1,700 metros) e estará identificado por um valor do ponto mais próximo a que se refere, ou com sua classe temática, se posteriormente sua imagem for submetida a uma operação de fatiamento.

A figura 29 mostra o mapa do Estado de São Paulo com valores interpolados por vizinhança a partir das médias do IQA, dos 74 pontos referente a 1978, para obtenção de áreas de domínios de pontos da rede de água superficial. 
Figura 29 - Exemplo de divisão para obtenção de áreas de domínios de pontos da rede de água superficial.

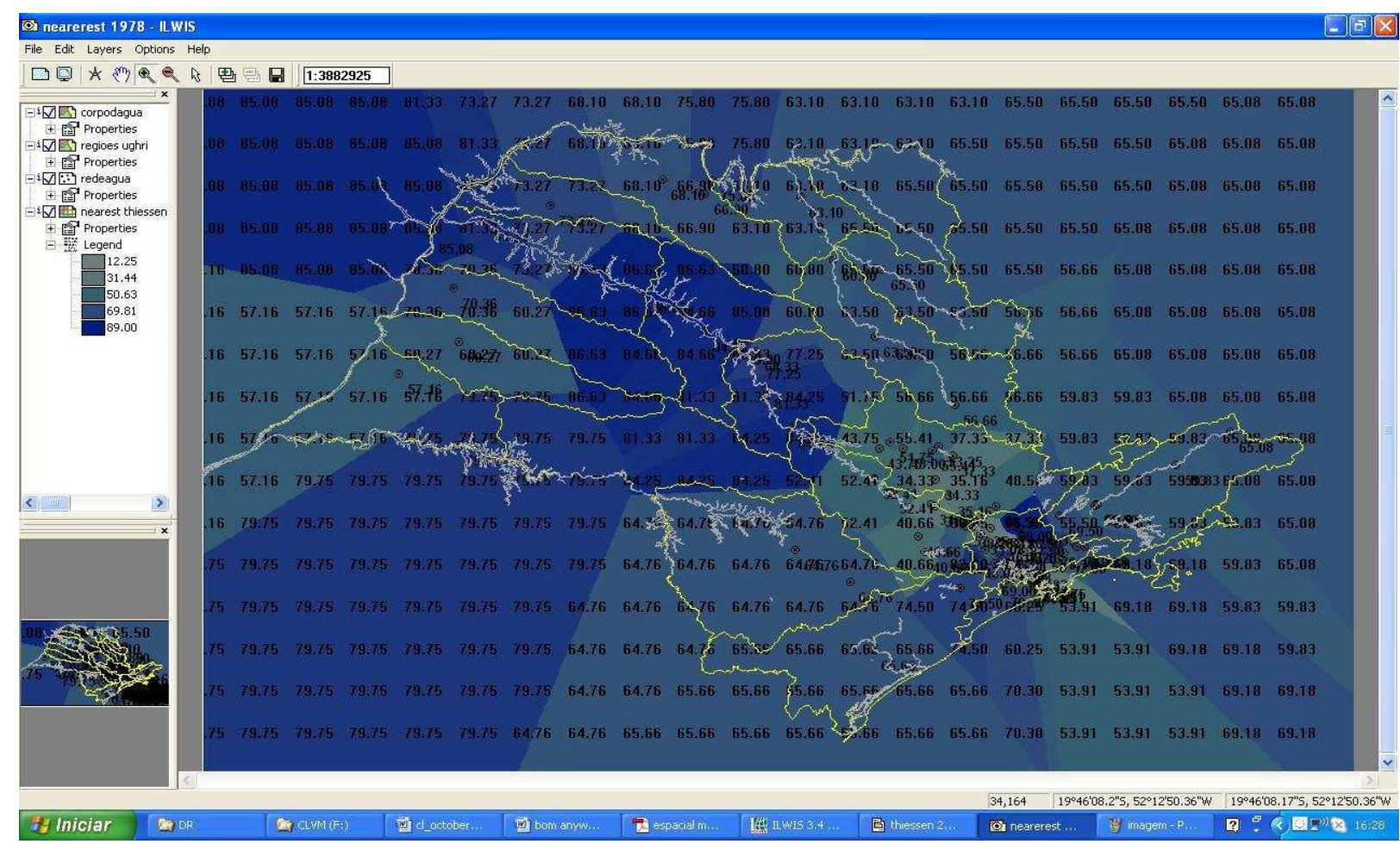

Elaborado Por MIDAGLIA, C. Fonte: SP_WATERNET.

8.3 - ANÁLISE ESPACIAL COM A MÉDIA MÓVEL - MOVING AVERAGE DO ILWIS

Segundo o manual do ILWIS versão 3.3, a função de análise espacial feita através da média móvel é também um método de interpolação de pontos que exige como entrada um mapas dos pontos, por exemplo, o layer cidades, e retorna um mapa de polígonos como a saída. Os valores dos pixels da saída são as médias ponderadas dos valores dos pontos do mapa de entrada. O cálculo da média é feito através da soma dos produtos dos pesos e dos valores do ponto, divididos pela soma dos pesos. Os fatores de ponderação dos pontos da entrada são calculados por uma função de peso especificada pelo usuário. Há dois métodos: distância inversa e diminuição linear. Em ambos os métodos, assegura-se que os pontos que são próximos a um pixel da saída 
obtenham grandes pesos e que os pontos que são mais distante longe de um pixel da saída obtenham pesos menores. Os valores dos pontos que são próximos a um pixel da saída são assim da maior importância a este valor do pixel da saída, do que os valores dos pontos que estão mais distante ausentes. Neste caso, foi utilizado o método da distancia inversa.

A partir do layer de pontos foram feitas varias tentativas para definir qual seria a melhor distância de raio, cuja área de influência, seria suficiente para recobrir o Estado de São Paulo, sem deixar espaços vazios inclusive no ano de 1978, quando havia poucos pontos. A figura 30 mostra um exemplo destas tentativas, utilizando-se a distancia de $250 \mathrm{Km}$ como raio de abrangência.

\section{Figura 30 - Análise Espacial por Interpolação com Média}

Móvel - Médias do IQA referente ao ano de 1998 com distância de $250 \mathrm{~km}$ de raio.

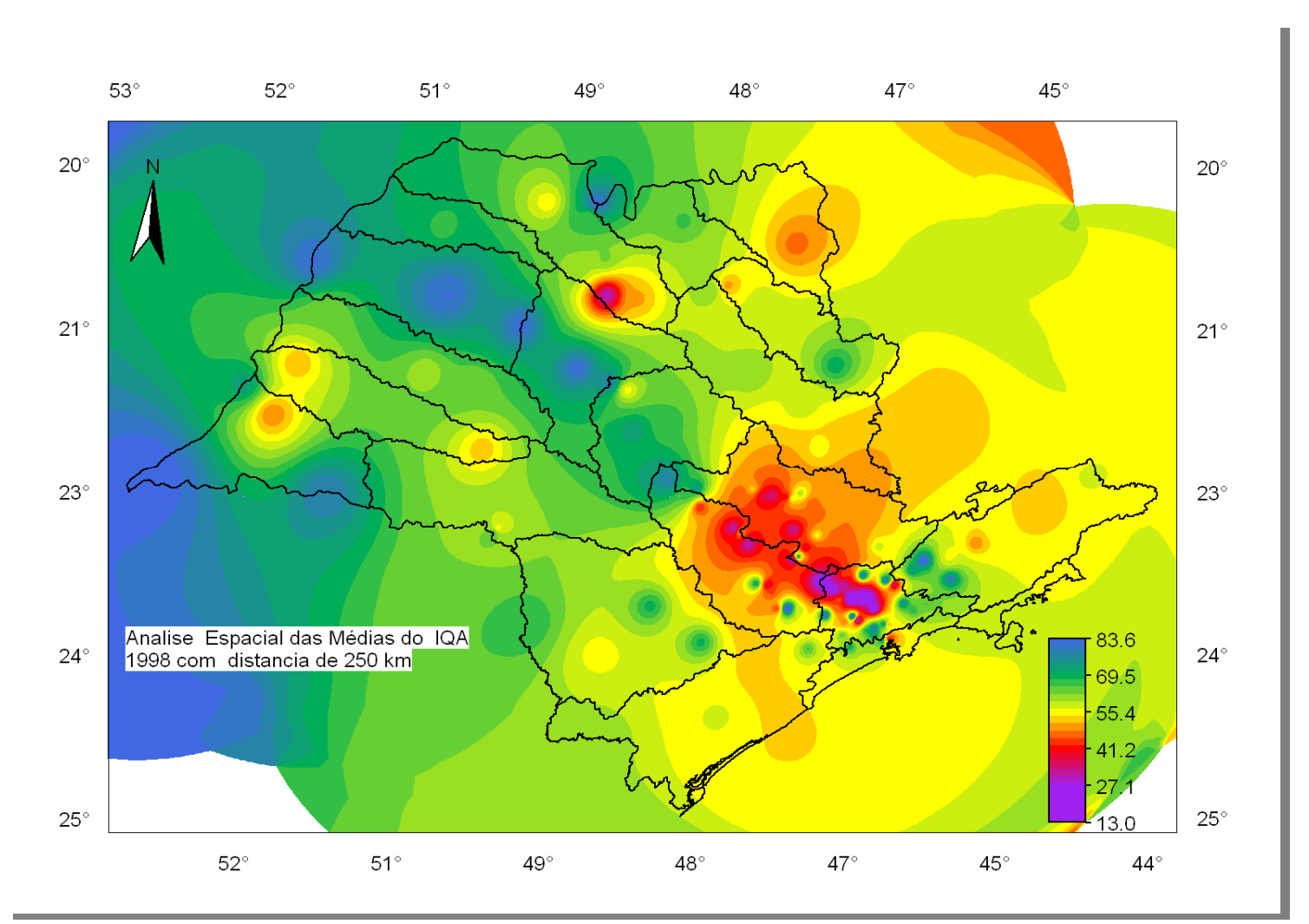

Elaborada por: MIDAGLIA, C. L., 2009. Fonte: SP_WATERNET. 
No caso das médias anuais do IQA, após alguns testes para se determinar qual seria a melhor distância, conclui-se que o raio de $150 \mathrm{~km}$ era adequado com vistas a obter bons resultados. Com o passar dos anos, com mais pontos poder-se-ia usar distancias menores. Quando se define esta distância de limitação ou abrangência, influencia-se até qual distância os pontos, dentro do mapa, seja levada em consideração para o cálculo do valor do pixel na saída; e, somente os valores dos pontos que caem dentro da distância de limitação a este pixel da saída serão usados. Os valores dos pontos que estão mais distante de um pixel da saída do que a distância de limitação especifica, obtêm o peso zero pelo cálculo do peso, e estes valores não serão usados assim no cálculo do pixel da saída. Para futuras operações entre mapas raster é melhor não ter espaços sem valores. A figura 31 mostra a tela de entrada desta função, com definições para que o programa faça o cálculo.

\section{Figura 31 - Tela de entrada para a função de análise de cálculo de Médias Móveis.}

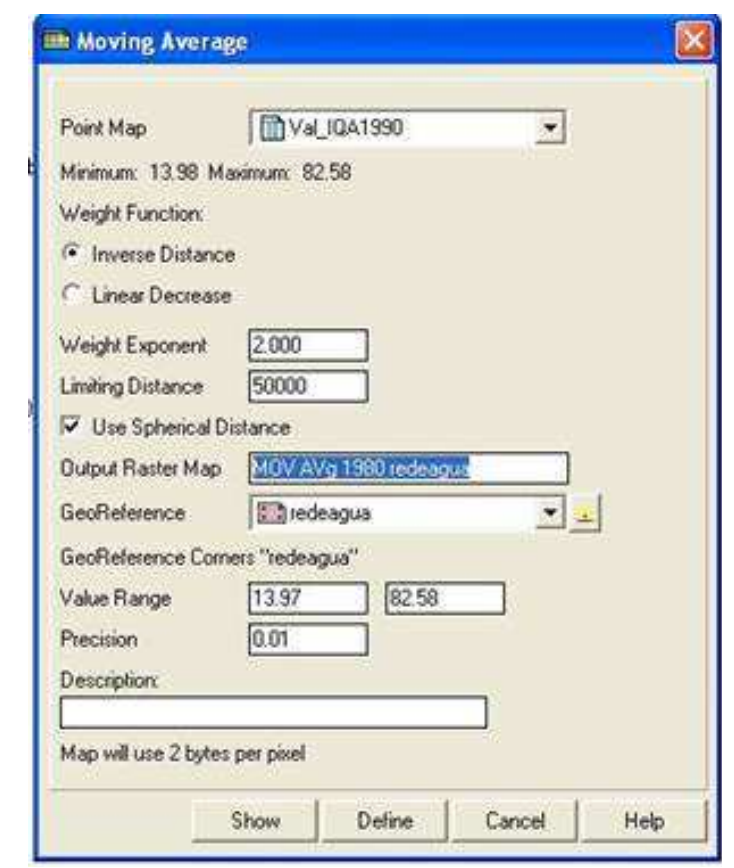

Fonte: SP_WATERNET.

Ressaltar-se que no caso de grandes áreas de estudo como é o caso do Estado de São Paulo, não se deve usar a distância euclidiana, que não 
considera a curvatura da Terra, mas sim a distância esférica, que considera a forma do planeta, conforme explicação constante no manual de usuário do ILWIS, 3.3. Além disto, com o sistema de coordenadas geográficas expressas em latitude e longitude, é recomendável marcar também a opção referente a distância esférica.

Esta análise exige como entrada o layer de pontos relacionados a um valor que está armazenado em uma tabela de atributo, que pode estar ligado também a uma classe ou domínio da identificação. Uma vez definido os raios de abrangência, e preenchida a tabela, aciona-se a função interpolation, moving average. A operação de análise é então processada, gerando um mapa de formato raster, onde aparecem áreas/zonas calculadas pela média móvel. Cada pixel tem um valor, pois os números são espacializados de forma homogênea. Lembrando-se também que, quanto maior for o do raio escolhido, mais suaves ficam as linhas de contorno, embora demore mais tempo para ser processada. Novamente, assim como no método anterior, este mapa poderá ser ainda submetido a função slicing, ou seja, fatiamento e ser reclassificado para outras classes definidas conforme o domínio de interesse.

Os resultados da operação de interpolação dos pontos elaboradas a partir das médias anuais dos diversos anos do IQA mostraram que esta distância poderia sim variar em função do crescimento da rede; mas para fins de padronização, foi adotado a distância de $150 \mathrm{~km}$ para todos os anos, suficiente para que haja recobrimento total do território paulista.

O panorama com os mapas gerados pela operação de análise espacial com os métodos acima descritos (Mapa 3, em anexo) sugerem que estas análises são bastante interessantes como forma de representação e podem ser utilizadas para informar de forma espacializada e sintética os resultados os dados de qualidade das águas. Podem inclusive gerar seqüências de imagens tais como as utilizadas na previsão do tempo, através do recurso Map List, ou lista de mapas que arrola seqüências de séries, com variação espacial ou temporal. 
A mesma metodologia foi repetida nos mapas de que interpolam as densidades populacionais, mas que neste critério, utilizou-se valores de raio de $15 \mathrm{~km}$, a partir do centro das cidades. Os mapas de variação temporal da densidade populacional paulista estão no Mapa 4 (anexo).

A análise espacial é, portanto, valiosa para diagnósticos, de forma a se verificar se o recurso hídrico tem capacidade de suportar novos empreendimentos urbanos ou industriais, com potencial poluidor conhecido. Atualmente, como as licenças industriais para funcionamento são renováveis, é necessária a integração de resultados de campo com bancos de dados e plataforma de trabalho GIS. O conjunto das representações geradas neste processo podem ser visualizadas nos cartogramas de números $3,4,5,6,7$ e 8 , no anexo do trabalho, de forma sintetizada segundo alguns anos selecionados deste estudo.

Estas informações poderiam fomentar estudos de correlação entre incidências de doenças de veiculação hídrica, taxa de mortalidade por falta de saneamento básico, riscos de contaminação da água para a população em geral, entre muitas outras possibilidades.

\section{9 - A URBANIZAÇÃO E QUALIDADE AMBIENTAL DOS RECURSOS HÍDRICOS}

Por que se preocupar com a urbanização no Estado de São Paulo?

Simples, nos últimos 20 anos, a cidade de S. Paulo está sempre relacionada entre as 10 maiores cidades do planeta (figura 32). A densidade mundial, baseada na população de 6,5 bilhões de pessoas apresenta-se em torno de 43 hab. por km². No Estado de São Paulo já habitam $1 / 5$ da população brasileira e só na RMSP, metade da população do Estado. A densidade nestas áreas é bastante alta, semelhante a de países com área territorial pequena, tal como Mônaco, Singapura e Malta, acima de 3.000 habitantes por $\mathrm{Km}^{2}$. Dentro do Estado, existem outras duas áreas que já receberam a condição de áreas metropolitana, ou seja, 
áreas de grande conurbação, com alta densidade populacional e com elevada complexidade de problemas sociais e ambientais.

Figura 32 - Cenário para grandes cidades do Mundo.

\section{Largest Cities, Worldwide}

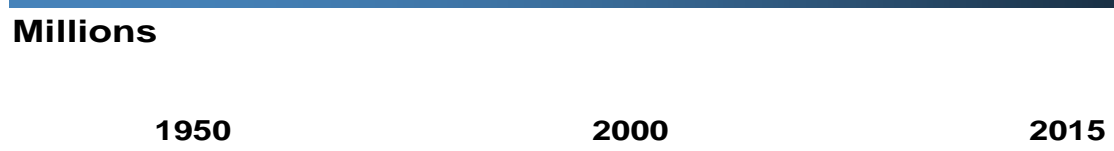

1950

2000

2015

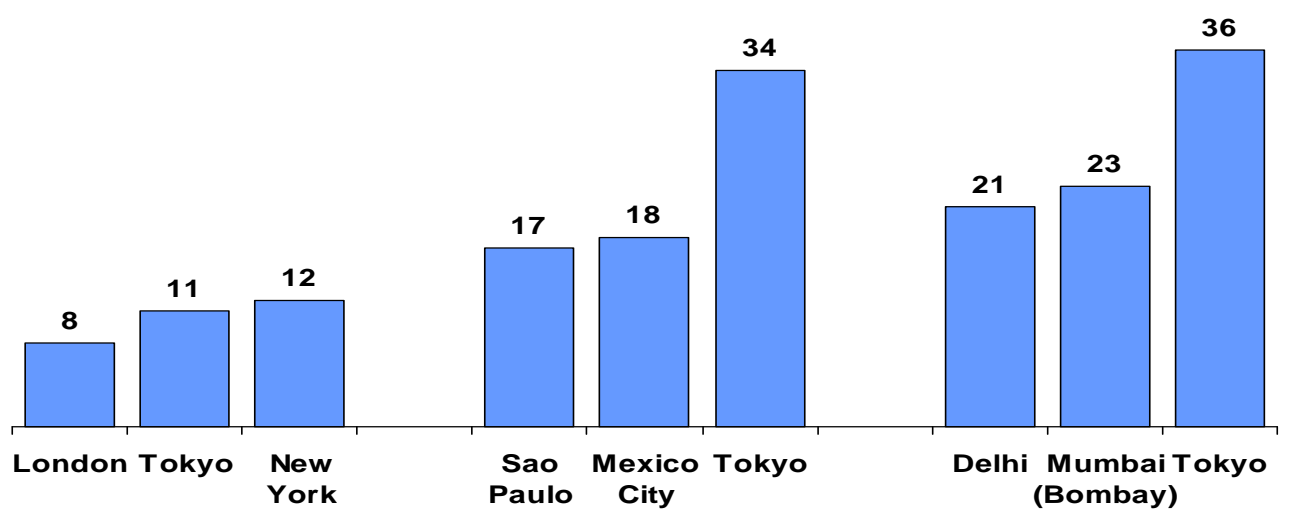

Source: United Nations, World Urbanization Prospects: The 2003 Revision (medium scenario), 2004.

Fonte: UN, World Urbanization Prospects: the 2003 revision (medium scenario), 2004.

\section{1 - A URBANIZAÇÃO DO ESTADO DE SÃO PAULO}

Conforme histórico obtido no Atlas da População do Estado de São Paulo (SÃO PAULO, 1991), verifica-se que o extraordinário dinamismo populacional do Estado de São Paulo fez com que, em oitenta anos, a sua densidade demográfica aumentasse de 9,2 hab./km² em 1900 para 101,2 hab./km² em 1980. Segundo os autores opus cit., as mudanças nos padrões da distribuição espacial do Estado mostram basicamente dois momentos bem nítidos na estruturação da população paulista: 
O primeiro momento situa-se entre 1900 e 1950, quando a economia paulista era predominantemente agrícola, sustentada principalmente pelo complexo cafeeiro iniciado na segunda metade do século passado e cuja expansão redundou na ocupação do Estado pelas frentes pioneiras que avançavam em direção ao oeste do planalto ocidental.

Depois, o quadro populacional de São Paulo foi influenciado pelo desenvolvimento ligado ao plantio e comercio do café. No segundo momento, entre 1960 e 1980, o Estado urbanizou-se, apoiado na forte industrialização desencadeada a partir dos anos 50, quando se dá o adensamento da população nas frentes agrícolas do extremo oeste, ao mesmo tempo, que explode a urbanização e se estrutura a Região Metropolitana de São Paulo.

O quadro populacional de São Paulo acompanha a evolução com complexo cafeeiro, que se iniciou no Vale do Paraíba e se deslocou para as regiões de Campinas, Sorocaba e Ribeirão Preto, apresentando densidades próximas a 60 hab./km². Com a propagação do café, em 1920, o leste do Estado já se encontrava consideravelmente povoado, sendo que a maior concentração populacional encontrava-se nos municípios das encostas ocidentais da Mantiqueira. Este atlas da população faz uma correlação com o prolongamento da malha ferroviária, que surgira para transportar o café, em direção ao oeste paulista, surgindo novos municípios, com o povoamento adensando-se na medida em que as novas áreas eram desbravadas.

Continuando a análise, aponta que em 1940, a densidade do Estado alcançava 29 hab./ $\mathrm{km}^{2}$ e que novas cidades estavam a surgir:

Já em 1940, a densidade do Estado alcançava 29 hab $/ \mathrm{km}^{2}$. Nesse tempo era notável o avanço das frentes pioneiras nos espigões dos diversos afluentes do Rio Paraná, no planalto ocidental, sendo que a Noroeste o povoamento chegou até as barrancas do Paraná. Em contrapartida, com o apogeu do café já tendo passado, alguns pólos de esvaziamento surgiram, principalmente no Vale do Paraíba. Ainda em 1940, observa-se uma grande estruturação da Grande São Paulo, com um grande aumento na densidade populacional 
da Capital e de municípios periféricos, como Santo André, São Bernardo do Campo e Santos. Municípios agrícolas também apresentaram grande crescimento populacional, evidenciando a importância da agricultura mercantil diversificada, que já abastecia os centros industriais que surgiam próximos a Capital. Esses novos pólos populacionais justificaram a criação de 56 novos municípios.

O fortalecimento das funções comerciais e de serviços nos centros regionais e sub-regionais, bem como o processo de expansão da industrialização, fez com que, entre 1940-1950, o crescimento absoluto da população do Estado de São Paulo fosse superior a 2 milhões. Esse crescimento não fora igual no campo a na cidade: a mecanização da agricultura provocou um êxodo rural. Nessa década, da ordem de 1,3 milhões de pessoas, vieram em direção as cidades, principalmente da área limítrofe a Minas Gerais, ao Norte e a Leste do Estado, até quase as margens do Paraná.

Na década de 1960, a Região Metropolitana da São Paulo já se encontrava estruturada, sendo institucionalizada em 1967, contando com 29 municípios além da capital, com 4,8 milhões de habitantes, cerca de, então, 39\% da população do Estado. Em 1970, a população de São Paulo já chegava a 17,9 milhões de habitantes, com uma densidade demográfica de 72 hab./ $\mathrm{km}^{2}$. Desse total, cerca de $80 \%$ já se concentravam em aglomerações urbanas. Esse período revela um intenso esvaziamento das áreas rurais do Estado. Apenas alguns municípios da Alta Araraquarense (região de Jales), da Alta Paulista (região de Adamantina), e da Alta Sorocabana (Região de Presidente Prudente) registravam mais de 30 hab. $/ \mathrm{km}^{2}$ na área rural. Como um todo, a Alta Paulista, já em meados de 1980, apresentava uma diminuição de povoamento na ordem de $8 \mathrm{hab} . / \mathrm{km}^{2}$.

Segundo o IBGE, já no censo de 1980, o índice de urbanização do Estado era de $88 \%$ e a densidade populacional de 100 hab./km2. Em 1991, a população segundo IBGE era de 31.588 .925 e a densidade 127,27 hab./km². Em 2000 o índice de urbanização atinge 93\% com a densidade 
populacional entorno de $149 \mathrm{hab} . / \mathrm{km} 2$. A estimativa de 2008 apontava uma população de 41.011 .635 e densidade de 165,23 hab./ km². Segundo o IBGE, já no censo de 1980, o índice de urbanização do Estado era de $88 \%$, com uma densidade populacional de $100 \mathrm{hab} . / \mathrm{km}^{2}$. O desenvolvimento desigual alcançado pelas diversas regiões do país foi colocando São Paulo sempre na vanguarda da economia e industrialização e, atraía para o Estado cada vez mais pessoas.

Na década de 1990, a cidade de São Paulo rompeu o marco de 10 milhões de habitantes, número comparável ao das maiores cidades do mundo. Embora em ritmo inferior ao da década de 1970-80, período em que mais cresceu demograficamente, a cidade - e o Estado - continuam a crescer. Seguindo a linha histórica, atualmente a população do Estado continua em ascensão. Segundo a Estimativa das Populações residentes, divulgada pelo IBGE em $1^{\circ}$ de Julho de 2009 , a cidade conta com cerca de 11 milhões de pessoas, o que the rende uma média de 7.216 hab./ $\mathrm{km}^{2}$, densidade considerada muito alta, enquanto que no Estado todo vivem mais de 41 milhões de pessoas, ou seja, 165 hab./km².

As pessoas vieram para as cidades em busca do progresso e, como uma das conseqüências, os rios pioraram, pois não tinham como prover água para tanta gente nem como absorver todos os resíduos gerados. As pessoas dificilmente vão deixar as cidades, pois se trata de uma tendência mundial. Querem estar próximas dos serviços de todos os tipos que as cidades oferecem e principalmente do consumo e da sensação de modernidade. Por isto, a solução é que os rios têm que melhorar ambientalmente, ter um nível de tratamento dos esgotos gerados com maior eficiência e evitar a entrada de lixo por todo seu percurso. Até hoje esta tendência de crescimento persiste em São Paulo, embora de forma menos acentuada, mais ainda exercendo atração nacional, além de países latinos vizinhos e de migrantes orientais em busca de negócios.

Desde os primeiros relatórios de estudos sobre Recursos Hídricos Estado do São Paulo, a urbanização e a população aparecem como considerações importantes no diagnóstico de situação destes recursos. 
Em 1984, no relatório publicado pelo DAEE "Caracterização dos recursos hídricos no Estado de São Paulo" o tema da crescente demanda de água para regiões em desenvolvimento é abordado:

O acelerado desenvolvimento industrial e populacional que vem ocorrendo no Estado de São Paulo, tem concorrido para a crescente utilização dos recursos hídricos, resultando daí, a necessidade de se reorganizar o espaço hidrográfico de forma a aperfeiçoar a política de uso e preservação dos mananciais superficiais e subterrâneos"...A organização em zonas hidrográficas e sua divisão em sub-zona oferece facilidade para o planejamento dos recursos hídricos, já que permite a caracterização de regiões que exibem diferenças acentuadas de densidade demográfica e atividades socioeconômicas. (DAEE, 1984, p.7)

Dentro do Estado existem três Regiões Metropolitanas (São Paulo, Campinas e Santos) e ao percorrem estes conglomerados urbanos, alguns rios tem sua qualidade alterada mesmo logo após suas nascentes, tais como os rios Tietê e Pinheiros em São Paulo, o Piçarrão e Anhumas em Campinas, o Moji na Baixada Santista, e Ribeirão dos Bagres em Franca. Poder-se-ia afirmar que a medida que as cidades crescem, nas mesmas proporções, ter-se-ia impactos de problemas ambientais manifestados em rios e reservatórios. No Mapa 3 (anexo), é possível ver os reflexos de intensa atividade antrópica em trechos de rios como Tietê, Piracicaba, Mogi-Guaçu, Atibaia, Capivari, Sorocaba, Paraíba do Sul, entre outros.

Para assegurar que a qualidade da água que será utilizada para abastecimento humano, seja preservada, são construídos muitos reservatórios, que apresentam um uso limitado do recurso hídrico, restritos de outros usos. Como o Reservatório Jaguari, que faz parte do Sistema Cantareira, usado exclusivamente para abastecimento urbano da cidade de São Paulo. Mas a água deveria ter múltiplo uso.

Visando orientar a ocupação das bacias hidrográficas entorno da região de mananciais de abastecimento da RMSP, foram promulgadas as Leis 898, de 18 de dezembro de 1975 (disponível em: <www.ana.gov.br/ institucional/aspar/.../LEI898-75-SP.doc>) e Lei 1172, de 17 de novembro 
de 1976 (disponível em: <http://www.vitaecivilis.org.br/anexos/Lei_ Estadual_1172.pdf), onde entre os parâmetros de uso e ocupação de solo incluíam-se referencias ao adensamento populacional, conforme as categorias das áreas:

- de primeira categoria, ou de maior restrição, que correspondem aquelas situadas as margens das represas, rios e córregos, cobertas por mata, ou próximas das áreas inundáveis ou em áreas de grande declividade;

- de segunda categoria, que se dividem em três subdivisões: Classe A, áreas urbanas com densidade máxima de 50 hab./ha.; Classe $B$, áreas destinadas a expansão urbana, cuja densidade podia variar entre 25 a 34 hab./ha.; Classe C, as demais áreas, com densidade de 6 a 2434 hab./ha.

Entretanto, mesmo com os cuidados previstos para a preservação, a ocupação foi bastante intensa na região sul da cidade de São Paulo, e entre 1970 a 1990, a região da Billings e da Guarapiranga tornou-se residência para mais de 1 milhão de pessoas. Desde então, a situação não melhorou e a pressão antrópica causada pela expansão da urbanização já esta sufocando os braços dos reservatórios, que estão eutrofizados. Os problemas de qualidade da água são causados por lançamentos in natura de esgotos gerados na região.

De modo geral, a poluição dos rios é originada por contribuições diversas, que venham causar alteração deixando-as impuras ou menos potáveis para consumo humano. Mas, além do fato de serem impróprias para consumo humano, deve-se considerar que a água serve a inúmeras espécies na natureza, que não podem, tal como os humanos, depender de um tratamento convencional, distribuído através de uma rede de água municipal ou estatal. Portanto é preciso que ela esteja limpa para todos. Segundo Menegon Jr. (2005):

A poluição hídrica pode ser definida como a introdução num corpo d'água de qualquer matéria ou energia que venha a alterar as propriedades dessa água, afetando, ou podendo afetar, por isso, a saúde das espécies animais ou vegetais que dependem dessas águas ou com elas tenham contato. 
Portanto, fica nítido que à medida que as cidades crescem sem infra-estrutura, seus rios que outrora já foram atrativos tão importantes no momento de sua fundação, tornam-se, por falta de saneamento, canais de esgoto in natura, com aspecto de falta de vida, sem beleza, semelhantes aos vitimados cursos dos rios da cidade de São Paulo, dentro outros exemplos em grandes cidades do mundo. Para tentar resolver o problema, muitos rios e pequenos córregos foram canalizados, como se assim, enterrados, deixassem de causar mau cheiro, enchentes e outros fatos que, certamente, não são de origem natural. Em nome da urbanização, as margens são aniquiladas por ruas e, muitos trechos são retificados em nome de projetos urbanização, quando na verdade, deveriam ser hidro-morfologicamente restaurados e reintegrados a paisagem urbana. Existe sim a perspectiva que as bacias hidrográficas deixem cada vez mais de ter o aspecto de formação natural, condicionado ao longo do tempo pelas condições geomorfológicas, e passem a ter cada vez mais seus trechos fracionados, em função dos usos urbanos, ou ainda designados por lei, conforme as suas classes, perdendo assim a sua integridade e dissolvendo-se do sistema natural onde foram gerados.

Constata-se hoje em dia que rios que foram enquadrados como classe 3 ou classe 4, sem que pudessem ter outro destino mais nobre, de uso múltiplo, terão pouquíssimas chances de recuperação e provavelmente vão ser de pouca valia dentro das cidades que atravessam, não servindo sequer para contribuir com a harmonia da paisagem. Se a situação não for revertida, existe a perspectiva que bacias hidrográficas deixem cada vez mais de ter o aspecto de formação natural.

São muitas as intervenções artificiais em grande ou pequena escala, tais como retificações, barragens, canalizações e transposições, que extirpam as feições hidro-morfológicas dos rios de modo brutal. No campo, em áreas de monoculturas, a situação não é muito diferente, pois onde existem, precisam ter as APPs (Área de Preservação Permanente) resguardadas e assim, em alguns casos, opta-se por sumir com os pequenos afluentes, aumentando a área cultivada; são aterrados e planta- 
se em cima, nivelando-se o terreno e facilitando o uso de máquinas na agroindústria ou agropecuária.

Para justificar uma convivência mais pacífica entre homem e natureza e os limites para esta integração, Ross (1994, p.64) defende os pressupostos do desenvolvimento sustentável quando apresenta a metodologia para elaboração de cartogramas de fragilidade ambiental. Justifica a importância dessa análise, colocando que, em decorrência de práticas econômicas predatórias e que acarretam implicações para a sociedade a curto e médio prazos, seja pelo desperdício de recursos naturais, seja pela degradação generalizada, torna-se necessário um planejamento físico-territorial que contemple não só à questão sócio- econômica como também a ambiental.

Jurandyr Ross coloca ainda que as sociedades humanas não devem ser tratadas como elementos estranhos à natureza. Mas que pelo contrário, devem ser vistas como parte fundamental da...

[...] Dinâmica representada através dos fluxos energéticos que fazem o sistema como uni todo funcionar. Entretanto, as progressivas alterações até então inseridas pelas sociedades humanas nos diferentes componentes naturais afetam cada vez mais a funcionalidade do sistema e com freqüência induzem à graves processos degenerativos ao ambiente natural em um primeiro momento e á própria sociedade em prazos mais longos. Por isso é cada vez mais urgente que se faça inserções antrópicas absolutamente compatíveis com a potencialidade dos recursos de um lado e com a fragilidade dos ecossistemas ou ambientes naturais de outro. (ROSS apud VILAS-BOAS, 2001, p.65)

\section{2 - OS RIOS DAS GRANDES CIDADES: FUTUROS CANAIS DE ESGOTO SEMELHANTES À CIDADE DE SÃO PAULO?}

Existe a perspectiva que face à urbanização intensa, muitas das bacias naturais passem a ser cada vez mais forjadas e manejadas para 
beneficio do homem. Este não é um fenômeno que ocorre somente no Brasil, mas que é sentido e estudado em várias partes do mundo.

Sabe-se que existe uma forte correlação entre o uso do Solo e a qualidade da água, e, verificando-se os laudos do índice de qualidade das Águas, pode-se correlacionar a presença de vários parâmetros, caso do já citado fósforo, em excesso nos corpos hídricos, como reflexos de uso do solo urbano e rural. Também constata-se altos índices de metais tais como, Al, Mn, K, Fe, Na, Sil, e Ca - principais componentes da litosfera e principais macro-constituintes do solo brasileiro, nos resultados do monitoramento da CETESB. Apontam uma possível desconformidade destes elementos, associada a uma resposta natural do meio a uma ação/ocupação antrópica mais intensa, causada por um maior aporte da chamada carga difusa. Esta evidência fica plausível quando interpreta-se laudos em pontos localizados em áreas protegidas (pouco impactadas pela expansão urbana) com pontos desprotegidos (alterados pela urbanização).

Conforme afirma Menegon Jr. (2005, p.15), é preciso dar ênfase a recuperação e a melhoria das águas superficiais.

[...] a crescente expansão demográfica e industrial observada nas últimas décadas trouxe como conseqüência $o$ comprometimento da qualidade e da quantidade das águas dos rios e lagos. A falta de recursos financeiros nos países em desenvolvimento tem agravado esse problema, pela impossibilidade da aplicação de medidas corretivas para reverter a situação. A disponibilidade de água doce na natureza é limitada pelo alto custo da sua obtenção nas formas menos convencionais, como é o caso da água do mar e das águas subterrâneas. Deve ser, portanto, da maior prioridade, a preservação, o controle e a utilização racional das águas doces superficiais.

O Estado de São Paulo, contem três das 27 Regiões Metropolitanas existente em todo o Brasil. São elas: RMSP, RMC e RMBS, que ocupam as seguintes posições (Quadro 8 ), em termos de população total entre as demais regiões metropolitanas brasileiras: 
Quadro 8 - Posição em termos de tamanho da população

das Regiões Metropolitanas existentes no estado de

São Paulo em relação às demais Brasileiras.

\begin{tabular}{|c|l|c|c|}
\hline Posição & \multicolumn{1}{|c|}{ Nome } & População & Densidade \\
\hline $1 a$. & $\begin{array}{l}\text { RMSP- Região } \\
\text { Metropolitana de } \\
\text { São Paulo }\end{array}$ & 19.223 .897 & $\begin{array}{c}2.420,0 \\
\text { hab./km² }\end{array}$ \\
\hline 9a. & $\begin{array}{l}\text { RMC- Região } \\
\text { Metropolitana de } \\
\text { Campinas }\end{array}$ & 2.633 .523 & $\begin{array}{c}722,1 \\
\text { hab./km² }\end{array}$ \\
\hline $14 a$. & $\begin{array}{l}\text { RMBS- Região } \\
\text { Metropolitana da } \\
\text { Baixada Santista }\end{array}$ & 1.606 .863 & $\begin{array}{c}\text { 663,2 } \\
\text { hab./km² }\end{array}$ \\
\hline
\end{tabular}

Fonte: www.stm.sp.gov.br/rmc/htm, acesso em 23 de setembro de 2009.

A RMSP - Região Metropolitana de São Paulo foi criada pela Lei Complementar n 14 do Brasil, em 08/06/1973. É a maior do Estado de São Paulo e do Brasil. Possui população total de 19.223.897 habitantes, e densidade populacional de $\mathbf{2 . 4 2 0} \mathbf{h a b} . / \mathbf{k m}^{\mathbf{2}}$. É formada por 39 municípios: Arujá, Barueri, Biritiba- Mirim, Caieiras, Cajamar, Carapicuíba, Cotia, Diadema, Embu, Embu-Guaçu, Ferraz de Vasconcelos, Francisco Morato, Franco da Rocha, Guararema, Guarulhos, Itapevi, Itapecerica da Serra, Itaquaquecetuba, Jandira, Juquitiba, Mairiporã, Mauá, Mogi das Cruzes, Osasco, Pirapora do Bom Jesus, Poá, Ribeirão Pires, Grande da Serra, Salesópolis, Santa Isabel, Santana de Parnaíba, Santo Andre, São Bernardo do Campo, São Caetano do Sul, São Lourenço da Serra, São Paulo, Suzano, Taboão da Serra, Vargem Grande Paulista.

A RMC - Região Metropolitana de Campinas foi criada pela Lei Complementar n 870, de 19/06/2000. É a mais nova do Estado de São Paulo e ocupa a $9^{a}$ posição em termos nacionais. Possui população total de $\mathbf{2 . 6 3 3 . 5 2 3}$ habitantes e densidade populacional de $\mathbf{7 2 2 , 1}$ hab./km². Os 19 municípios integrantes são: Americana, Artur Nogueira, Campinas, Cosmópolis, Engenheiro Coelho, Holambra, Hortolândia, Indaiatuba, Itatiba, Jaguariúna, Monte-Mor, Nova Odessa, Paulínia, 
Pedreira, Santa Bárbara d'Oeste, Santo Antônio da Posse, Sumaré, Valinhos e Vinhedo.

A RMBS - Região Metropolitana da Baixada Santista foi Lei Complementar Estadual 815, em 30 de julho de 1996. Possui população total de $\mathbf{1 . 6 0 6 . 8 6 3}$ habitantes e densidade populacional de $\mathbf{6 6 3 , 2}$ hab./km². É formada por 9 municípios: Bertioga, Cubatão, Guarujá, Itanhaém, Mongaguá, Peruíbe, Praia Grande, Santos e São Vicente. (IBGE, 2007)

Infelizmente, em termos de desenvolvimento urbano e econômico isto significa grande pressão sobre o recurso água e crescimento dos usos múltiplos da água, ou seja, demanda de todos os tipos de uso: abastecimento humano e industrial, agricultura e pecuária, energia, recreação e afastamento de efluentes.

Segundo Scarlato (in ROSS, 1996, p.432).

Antes de qualquer análise de metropolização no Brasil, é importante uma reflexão a respeito do termo metrópole, em virtude da complexidade que ele envolve. Segundo a etimologia, metrópole significa cidade-mãe; a maioria das pessoas usam-na como sinônimo de cidade grande. Mas em Geografia a palavra tem significado preciso e só deve ser aplicada a cidades grandes, dotadas das seguintes características específicas:

1.um crescimento que expande a cidade, prolongando-a para fora do seu perímetro, e absorve aglomerados rurais e outras cidades. Estas, até então com vida autônoma, acabam comportando-se como parte integrante da metrópole. Com a expansão da integração, desaparecem os limites físicos entre os diferentes núcleos urbanos fenômeno chamado conurbação;

2. a existência de um centro histórico onde se concentram atividades de serviços e a partir do qual surgem subcentros; 3. a dicotomia entre a existência da cidade enquanto espaço edificado e a estrutura político administrativa. Em outros termos: um único espaço edificado resultante da conurbação, porém com várias administrações políticoadministrativas autônomas, como, por exemplo, São Paulo e ABCD (Santo André, São Bernardo, São Caetano e Diadema). Cada uma dessas cidades tem seu centro administrativo municipal autônomo e juntas formam um conurbação. 
4. fluxos de circulação de veículos com dois picos de maior intensidade, normalmente no período da manhã e no final da tarde, formando o chamado fluxo pendular, atravessando mais de uma cidade.

As regiões metropolitanas geralmente propiciam o aparecimento em seu entorno, de anéis de moradias precárias, onde os serviços básicos não existem ou demoram muito para chegar, e, quando estão presentes não funcionam de forma adequada, pois não conseguem acompanhar o ritmo de crescimento populacional desordenado, causado pelo déficit habitacional.

Segundo o organismo da ONU que cuida de Habitação, o United Nations - Habitat (http://ww2.unhabitat.org/mediacentre/documents/ sowcr2006/SOWCR\%205.pdf, estas moradias precárias são conhecidas como slum, termo que se refere a um grupo de indivíduos que vivem sob o mesmo teto em áreas urbanizadas, às quais não tenha um ou mais dos requisitos descritos a seguir:

Moradia durável e permanente que proteja contra condições extremas do clima;

- Apresente espaço suficiente, de modo que não mais do que três pessoas dividindo o mesmo quarto;

- Fácil acesso a água segura (potável) e com preços razoáveis;

- Acesso ao saneamento adequado, de forma que o banheiro seja uso privativo ou compartilhado com um número razoável de pessoas; e

- Posse segura da moradia de modo a evitar ou e impedir expulsões forçadas.

Portanto, este termo pode ser traduzido como habitação ou moradia semelhante a cortiços e favelas, que tanto pode estar em bairros pobres ou distantes, como em áreas urbanas centrais abandonadas. Se por acaso apresentem uma destas condições, poderão ser entendidas como slums. Este tipo de moradia é muito comum em países em desenvolvimento, onde são registrados crescimentos não planejados de cidades, com este 
tipo de habitações, sem infra-estrutura, tal como observa Scarlato (in ROSS, 1996, p.456).

\begin{abstract}
A rapidez do crescimento da RMSP não gerou somente problemas de circulação viária e de habitação. A forma desordenada dos loteamentos, nos quais primeiramente se constroem as habitações para depois se improvisarem as condições de infra-estrutura criaram um espaço urbano com precárias condições de saneamento. Na medida em que os loteamentos sempre foram feitos de forma indiscriminada, sem ajustar previamente os arruamentos e as instalações dos sistemas de esgoto e de água a céu aberto, poluindo rios e córregos da região com resíduos dificilmente tratados, de outro, a necessidade de buscar água em locais cada vez mais distantes da região metropolitana.
\end{abstract}

Dentro das áreas metropolitanas paulistas, a falta de saneamento ambiental se caracteriza principalmente pela falta de tratamento de esgoto, e não de coleta. Mesmo bairros localizados em áreas já consolidadas, são servidos por todo tipo de serviço, exceto o de tratamento adequado de esgoto. Os bairros tradicionais, situados na bacia do rio Pinheiros, drenam suas águas desde o espigão da Av. Paulista, e que tem no seu curso principal, um retrato desta lamentável situação. Moradores e cidadãos que por ali transitam, são obrigados a conviver, com a triste figura de um rio moribundo, que de forma nenhuma, pode ser associada às clássicas imagens de crianças pobres da periferia brincando ao lado de córregos poluídos com esgoto in natura, ignorando o seu potencial poluidor. Mas, como as crianças destes bairros tradicionais não brincam fora e nem convivem diretamente com os rios Pinheiros e Tietê, talvez cresçam sem saber opinar positivamente sobre a importância deles.

Segundo Zee (2001) já foram feitas algumas tentativas para dimensionar a capacidade de suporte entre população e meio ambiente, e comenta estudos feitos na China com ênfase na potencialidade dos recursos naturais. Isto é:

The relation between population and environment is a complex one. Many approaches are used in trying to gain an 
understanding of this relation. One of these is the design of models to determine the population carrying capacity of a country or region. (ZEE, 2001, p.287)

Prosseguindo e citando Zonneveld, apresenta um destes modelos, a equação do problema mundial da miséria, onde $\mathbf{M}$ significa a Miséria, não somente no que se refere às pessoas, mas também ao ambiente. Portanto, talvez quisesse dizer algo além da miséria social, algo que incluísse a idéia de degeneração, ou deteriorização ambiental, que remete principalmente, à perda da qualidade dos recursos naturais. Nas letras da equação $\mathbf{N}$, expressaria o número de habitantes, $\mathbf{A}$, significaria a força destrutiva do homem, $\mathbf{C}$, a capacidade ambiental de suporte e $\mathbf{S}$, se refere ao tamanho da área habitada.

$$
\begin{array}{r}
\text { Misery }=>\mathbf{N} \text { (Number of people) X A (man's destructive activity) } \\
\hline \mathbf{C} \text { (Environment Capacity) X } \mathbf{S} \text { (Size of the living area) }
\end{array}
$$

The imbalance between the ever-growing population and the environment with its natural resources had already been observed and discussed by many scientists before it was identified as a major landscape ecological problem. In 1798more than 200 years ago-Thomas Malthus put forward a theory on the relation between population growth and economic development, which still survive today. (ZEE, 2001, p.287)

A verdade é que mesmo sendo às vezes sendo julgada de forma crítica, a idéia de que o crescimento populacional pode propagar-se indefinitamente, só aumenta a pobreza em áreas já debilitadas pela falta de todo tipo de infra-estrutura, e acarretam condições de vida indigna para estes habitantes. Surgem e agravam-se problemas de saúde e de sobrevivência básica, tal como o acesso a água potável. Diz-se que a cada ano, nasce no planeta uma nova Mumbai. Isto significa que o mundo cresce justamente em áreas já saturadas, com altos índices de densidade demográfica, e em regiões subdesenvolvidas ou em desenvolvimento. 
Oliveira (2001, apud BORTOLUZZI, HOCHHEIM, 2004), fazendo uma comparação entre as densidades populacionais existentes no centro de Florianópolis, e as densidades propostas pelo Plano Diretor, estudou a caracterização dos padrões de ocupação do solo para fins urbanos. Ressalta que dificilmente pode-se afirmar qual seria o valor mais adequado para o adensamento urbano, pois fatores culturais, estrutura familiar, formas de edificação, aptidão econômica e estrutura etária descrevem condições onde as densidades ideais permanecem incógnitas. Rodrigues (1986, apud BORTOLUZZI, HOCHHEIM, 2004) lembra que, a partir de pesquisas específicas, a ONU recomenda 450 hab./ha para a densidade bruta; a Associação Americana de Saúde Pública limita em 680 hab./ha; de acordo com experiências mais próximas pode-se arriscar em dizer que 100 hab./ha é pouco e não viabilizaria a presença de muitos serviços e que entre 1.500 a 2.000 hab./ha é excessiva. Portanto, quando comparados com os valores da UGRHI 6 em 2008, com mais de 3.300 habitantes por km2, percebe-se o quanto este número é alto.

Comparando-se as UGRHIs, verifica-se que algumas delas são muito povoadas, já que sua densidade demográfica é bem superior a do Brasil, que, segundo a última divulgação IBGE sobre a estimativa da população residente no Brasil, o número era de 191.480 .630 habitantes, o que resulta numa densidade nacional de $22 \mathrm{hab} / \mathrm{km}^{2}$. É também superior a densidade média do Estado, que ficou perto de 166 pessoas por $\mathrm{km}^{2}$.

Em 2002, L. Fagundes, citando o CEPAM (2001), explica que densidade populacional, densidade demográfica ou População Relativa é a medida que expressa a relação entre a população que habita uma determinada superfície do território, expressa em habitantes $/ \mathrm{Km}^{2}$. Pode ser expressa em: PR - População Relativa ou PA - População Absoluta. Em seu estudo ela verifica os efeitos nocivos que urbanização com ênfase na impermeabilização dos solos em centros urbanos, provoca em áreas sujeitas a enchentes. Em seu estudo, optou por utilizar a densidade populacional relativa, que retira da área total de um município ou cidade, parques, reservatórios, aterros e etc, ou seja, espaços não habitados. 
Como no presente estudo não existe necessidade de distinção desta taxa, aplicável em estudos em centros urbanos, portanto com áreas menores, ela não será utilizada, e sim a densidade absoluta.

Estima-se que para atender mundialmente ao crescimento populacional seria necessário criar todos os dias, ETEs com capacidade para tratar esgotos de cerca de 500.000 pessoas, o que é impossível, pois a cada ano o mundo esta produzindo uma nova Mumbai (Bombaim), com referencia a maior cidade indiana, super populosa (densidade de 21.700 $\mathrm{hab} / \mathrm{km}^{2}$ ), que passou por rápido crescimento e tem vários problemas de infra-estrutura e saneamento.

O Brasil, segundo a Organização Mundial de Saúde - OMS (2006) tem 46 milhões de pessoas sem acesso a saneamento básico. As metas do Milênio, assumidas em 2000, enfatizam o compromisso de reduzir até 2015 o número de pessoas sem acesso a água potável e a saneamento básico. No que se refere ao acesso à água, o Brasil conseguiu atingir esta meta antes do prazo, pois em 1990, 83\% da população brasileira já tinham este beneficio. Em 2004, a taxa foi de 90\%. Mas em relação ao Saneamento a evolução dos índices não foi tão satisfatória. Em 1990, $71 \%$ da população tinham acesso a este serviço e em 2005 chega a 75\%. Provavelmente conseguirá chegar à meta dos $80 \%$ em 2015, mas isto não significara tratamento dos esgotos, e sim afastamento.

Em São Paulo, localiza-se o maior número de problemas ambientais urbanos do país. A maioria da população do Estado, cerca de $85 \%$, está concentrada no lado leste do estado, onde se originam as nascentes dos muitos rios endorréícos, entre eles o Tiête, que percorre um longo caminho, por onde recebe poluição por esgotos, que deterioram a qualidade de suas águas. A proporção de esgotos tratados pode ser visualizada na figura a seguir: 


\section{Figura 33 - Evolução do Tratamento de esgotos no Estado de São Paulo.}

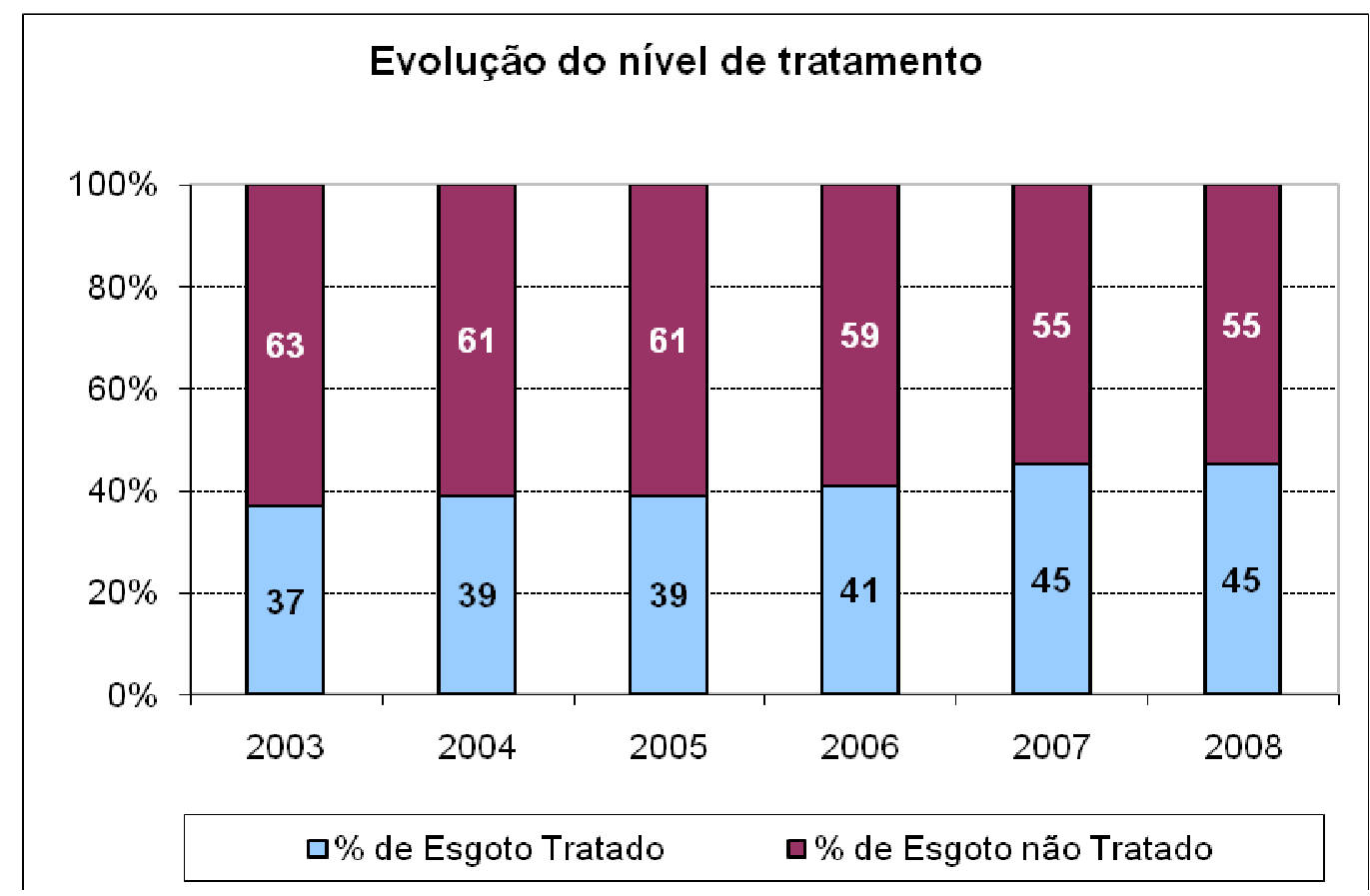

Fonte: CETESB, 2009.

Portanto, o Estado de São Paulo trata apenas cerca de $45 \%$ dos esgotos gerados pelos seus 41 milhões de habitantes. $E$, apenas neste estado da federação, já são mais de 24 milhões de pessoas sem acesso ao saneamento básico. Caso o Estado de São Paulo fosse um país, será que teria condições de alcançar esta meta de $80 \%$ ? E o resto do Brasil?

A pressão humana, alavancada pelo crescimento populacional e pela forte tendência de urbanização verificada no estado de São Paulo (85\% de urbanização) induz a ocupação desordenada e a falta de preservação de áreas de nascentes e mananciais. Portanto, áreas altamente urbanizadas acarretam uma interferência antrópica de maior relevância no ambiente. Com isto pretende-se dizer que além da área recomendada de 1 ponto por 1.000 por $\mathrm{Km}^{2}$, em monitoramento de bacias hidrográficas, dever-se-ia considerar também a densidade populacional da UGRHI. A importância da qualidade da água está bem conceituada na Política Nacional de Recursos Hídricos, que define, dentre seus objetivos, "assegurar à atual e às futuras gerações a necessária disponibilidade de água, em padrões de qualidade adequados aos respectivos usos" (Art. 20, Cap. II, Tit. I, Lei no..9.433). A 
Política Nacional de Recursos Hídricos também determina, como uma das diretrizes de ação do Sistema Nacional de Gerenciamento de Recursos Hídricos, "a gestão sistemática dos recursos hídricos, sem dissociação dos aspectos de quantidade e qualidade e a integração da gestão dos recursos hídricos com a gestão ambiental" (Art. 3o, Cap. III, Tit. I, Lei no. 9.433).

A densidade do monitoramento está citada também no art. $4^{\circ}$ da resolução no 22, de 24 de maio de 2002 :

$[\ldots]$

Os Planos de Recursos Hídricos, elaborados por bacia, devem contemplar o monitoramento da quantidade e qualidade dos recursos dos aqüíferos, com os resultados devidamente apresentados em mapa e a definição mínima da:

I - rede de monitoramento dos níveis d'água dos aqüíferos e sua qualidade;

II - densidade dos pontos de monitoramento; e,

III - freqüência de monitoramento dos parâmetros. (BRASIL, mai.2002)

É preciso desenvolver um novo meio de interpretar a informação espacial governamental gerada sobre recursos hídricos, um modelo ou ainda um índice acessível ao cidadão comum, pois a água não deve ser simplesmente tratada como uma mercadoria comum, e os esgotos como um resíduo importante. A ANA -Agência Nacional de Águas, tem atribuições conferidas pela sua lei de criação, para elaborar Planos de Recursos Hídricos, subsidiar a aplicação de recursos financeiros da União em obras e serviços de regularização de cursos d'água, de alocação e distribuição de água e de controle da poluição hídrica.

\section{3 - DADOS DE POPULAÇÃO}

Os dados de população utilizados para o cálculo do índice proposto tiveram preferencialmente como fonte o IBGE, que investiga as características das pessoas e dos domicílios nos municípios, distritos e subdistritos, através dos Censos Demográficos, que, por sua 
complexidade e abrangência, possui uma periodicidade de 10 anos, sendo que o último realizado foi em 2000 e anterior a este, houve o Censo de 1991. Neste intervalo foi feita a Contagem da População nos anos de 1996 e 2007. Esta pesquisa é realizada no intervalo entre dois Censos e tem menos informações que um Censo. Sendo assim, os dados populacionais utilizados que tiveram como base o IBGE foram:

- 1980 - Censo Demográfico:

- 1991 - Censo Demográfico;

-1992, 1993, 1994 e 1995 - Estimativa;

Em 1996 foi feita a Contagem da População de 1996, que teve como data de referência o dia 01/08/96. Assim, todos os resultados apresentados, preliminarmente e definitivos, têm por base esta data. De acordo com a divisão político-administrativa vigente à época, existiam no país 4.974 municípios. São Paulo contava com uma população total de 34.119.110 habitantes.

- 2000 - "Censo Demográfico 2000 - Primeiros Resultados da Amostra". Estes e outros dados também podem ser consultados na página da internet do IBGE, pelo seguinte caminho: www.ibge.gov.br> População> Censos Demográficos> Resultados da Amostra> Tabelas ou Publicação completa (em formato pdf).

- 2003 a 2006 - Estimativas populacionais SEADE;

- 2007 - Contagem da População. A Contagem de População 2007 foi realizada nos municípios com menos de 170.000 habitantes, o correspondente a $97 \%$ dos municípios brasileiros. Nos municípios onde não houve contagem, foi divulgada a Estimativa de População. Os dados divulgados em 21 de dezembro de 2007 contemplam população urbana e rural, cortes por sexo e idade, além de média de moradores por domićlio e estão disponíveis no site do IBGE, pelo seguinte caminho: www.ibge.gov.br> Download> Estatística> Contagem da População 2007. 
- 2008 - Estimativa de População é um cálculo baseado na taxa de crescimento, entre dois períodos, da população de todos os municípios brasileiros. É publicada em Diário Oficial da União no último dia do mês de agosto do ano em curso e divulga apenas a população total do município, ou seja, para este ano, a Estimativa terá como data de referência o dia $1^{\circ}$ de julho (assim como as anteriores), porém a data de divulgação, como sempre, será em 31/08/2009.

A partir de 2010 foram utilizados os dados da Fundação SEADE Projeções para o Estado de São Paulo, que é resultado de uma pesquisa realizada em parceria com a SABESP para orientar a implementação de serviço de abastecimento de água no período de 2000 a 2025. 


\section{0 - A ANÁLISE MULTI-CRITÉRIO E A GERAÇÃO DO ÍNDICE DE ABRANGÊNCIA ESPACIAL DO MONITORAMENTO}

Como atualmente estamos vivendo em um ambiente de fácil acesso à comunicação, o problema que se apresenta, não é exatamente o de falta de dados ou de informação, mas sim, o contrário, uma grande profusão deles, vindo de várias fontes e em diversos formatos. Em função dos usos múltiplos da água e de seus distintos usuários aparecem alguns conflitos de interesse sobre o seu real status de qualidade. Muitos julgam que para esclarecer tais questões, necessita-se ter uma rede de monitoramento mais abrangente, mais completa, e isto quer dizer com mais pontos. Surge então a discussão sobre onde e quantos pontos deveriam existir, onde devem ser incluídos, e qual o custo envolvido na ampliação para coletar, analisar as amostras, processar os dados, organizar a informação de forma cada vez objetiva e divulgá-la rapidamente em forma de índices. Sabe-se que, quanto mais informação apresentada de forma isolada, maior a dificuldade de escolher as possibilidades de encontrar respostas para os problemas.

\footnotetext{
A large amount of spatial data can only be handled by presenting a reduced amount of data to a decision maker. Options to do this are: selection, aggregation and visualization.

In selection, only a part of the data is offered to a decision maker. Aggregation reduces the amount of information by combining parts of it. Then the data can be presented not only numerically, but also graphically. Visualization techniques are used to present the data in an accessible way. The techniques to handle a large amount of spatial data are described in Chapter 4 and applied in Chapters 6, 7 and 8. (HERWIJNEN, 1999)
}

Para oferecer melhor possibilidade de compressão do estado da qualidade ambiental frente aos tomadores de decisão em relação ao gerenciamento de água, às vezes basta tomar ações com as informações já existentes. Se o excesso de informação confunde e impossibilita a 
compreensão dos gestores e técnicos em geral, imagine como é difícil para o publico compreender o que esta sendo feito, e ter confiança para opinar quando acionado para participar de comitês ou para fazer escolhas sobre prioridades para um determinado uso da água.

T. Sanders (1983, p.12) comenta este problema quando se refere aos dados de qualidade de água após o processo de armazenamento e consistência, quando estes precisavam ser convertidos em informação que atendesse as necessidades e expectativas dos tomadores de decisão:

The small number of past studies in the area of data utilization for regulatory water quality management purposes is indicative of the difficulty in dealing with subjective nature of management decision making. In the data utilization portion of a monitoring system, objectives pieces of data are converted into information which is then used in a rather subjective manner to assist decision making.

Portanto, além da comparação espacial obtida através dos mapas gerados pelo GIS SP_WATERNET, na plataforma ILWIS, que registrou e mapeou correlações importantes entre os efeitos do avanço da urbanização e a possibilidade de queda da qualidade de água, que remetem a hipótese, recorreu-se também a uma avaliação manual Multicritério, AMC, ou ainda Multi-criteria evaluation. O recurso esta disponível no programa ILWIS na função análise espacial denominada SCME (Spatial Multi-Criteria Evaluation) onde se elabora uma a árvore de decisão com critérios (criteria-tree) para fins de análise. Infelizmente por limitações de tempo e pelo fato da necessidade de conversão de praticamente todos os mapas para adequar-se a exigência de processamento de entrada na árvore de decisão optou-se por executá-la de forma manual. Porém, entende-se que a fase manual da SMCE, a MCE, multi-criteria evaluation, (AMC- avaliação multi-critério) é quase pré-condição para o passo futuro, ou seja, a análise dentro do software, através da SCME. A fase manual corresponde a fase racional da equalização do problema, a forma de como se proceder a hierarquização analítica (AHP), e como se estabelecer a 
combinação das diferentes informações, que vão pertencer a série de critérios selecionados para compor o novo indicador, que deve ser capaz de sintetizar e subsidiar a resposta do problema estudado.

As fases de construção da análise multi-critério foram adaptadas de exercícios do material do curso "Distance Education Course on Spatial Decision Support Systems", desenvolvido por Boerboom,L./Sharifi,A. e Zucca, A.,2008, oferecido pelo ITC em 2008. Cabe-se ressaltar que o modelo da AMC foi adaptado para comparar alternativas, que aqui seriam as UGRHIS, com maior abrangência e eficiência da rede, onde não se tem que necessariamente escolher qual foi a melhor solução (nota mais alta) ou qual a pior UGRHI, tal como proposta do curso original para a tomada de decisão.

Para iniciar-se o processo de análise, deve-se ter em mente que, esta avaliação precisa sempre responder a uma pergunta, colocada no início do estudo, em forma de hipótese. A finalidade é medir ou avaliar a performance da Rede de Monitoramento da CETESB, em termos de abrangência espacial ao longo dos 30 anos de estudo, por meio de um índice. Então a pergunta é: Como a rede de monitoramento se desenvolveu em termos de abrangência espacial nas diferentes UGRHIS frente ao crescimento populacional?

Durante o processo de avaliação Shariffi et al. (2004) defendem a importância de analisar os fatos de forma racional para poder estabelecer comparações:

But what is "rational"? The dictionary defines it as, based on or derived from reasoning. It implies the ability to reason logically. We define it as selection of a choice that best meets the objectives. The fundamental concept of various models of individual or organizational decision making behavior is rationality, which affirms the superiority of intellect over empirical experience. A rational or effective decision can be made through a systematic approach to the method and practice of decision-making. In this context, we define decision making as a "process of generating and evaluating alternatives and choosing a course of action in order to solve a decision-problem". (ITC, 2008) 
Como primeiro passo, estabelece-se o ambiente operacional onde se dará deste estudo, que reduz o universo de analise para dentro de um sistema menor, onde constam apenas os temas que serão abordados, demonstrados na figura 34 .

Figura 34 - Estruturação Racional da Análise Multi-critério.

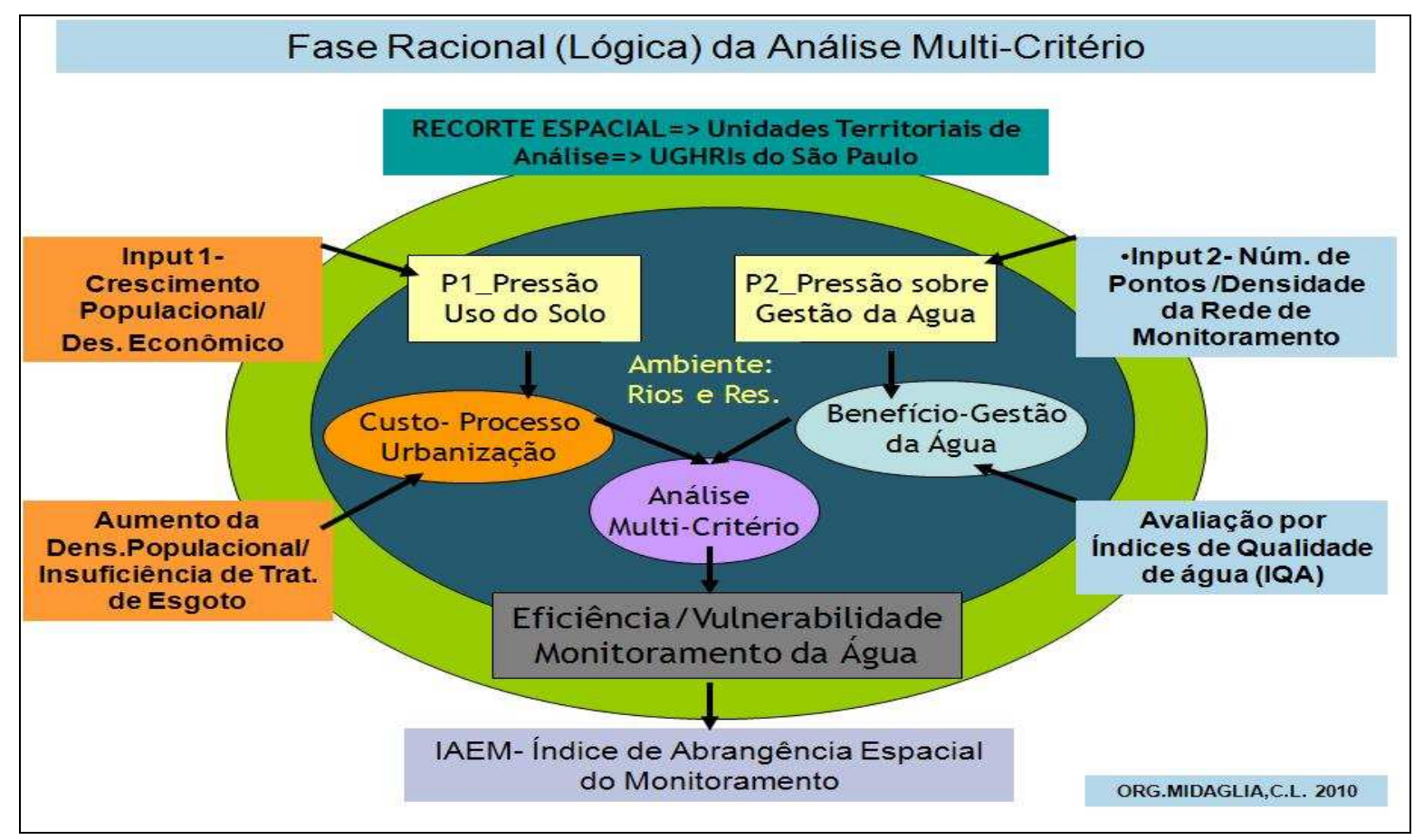

Figura elaborada por MIDAGLIA,C. (Exercício do curso ITC-DESDSS, 2008).

Definido o ambiente operacional (recorte espacial), deve-se estudar e estabelecer por quais medidas este universo será avaliado. Nesta fase identificam-se as variáveis (ou critérios) consideradas importantes para atender ao objetivo proposto. A seleção é um passo muito importante do processo. Para a determinação desses critérios (por exemplo, média do IQA por UGRHI, densidade CEE, geologia, hidrologia, fator socioeconômico, etc. é fundamental fazer uma discussão de como eles podem se comportar. É sempre aconselhável ouvir diversas opiniões de técnicos que poderiam a vir utilizar o índice, conhecer bem o ambiente operacional (rios e reservatórios do estado e principais concentrações urbanas) e saber como cada critério pode influenciar esta análise. 
Observa-se que, Boerboom, L. 2008 recomenda que não se deve mesmo elencar um número muito grande de grupos de análise de critérios (5 no máximo) e, que quando estes precisarem ser sub-divididos, não devem passar de três. Assim, neste estudo definiu-se 5 (cinco) variáveis, divididas em dois grupos, considerados no processo de avaliação multicritério (MCE).

Ao final do processo de análise gera-se um índice que pode criar um "ranking" de UGRHIS, que serão classificadas segundo legenda a ser definida pelo o elaborador da análise, que devera dar resposta a pergunta inicial, isto é, áreas onde o monitoramento esteve presente de modo mais apropriado. Aos conjuntos, pode-se ainda adicionar funções de valor (caso dos pesos na atribuição das UGRHIS), ou restrições (constrains). Se a análise estivesse sendo feita dentro do ambiente ILWIS poder-se-ia incluir limitações (constrains) espaciais, associadas a distancia dos laboratórios, proximidade de vias de acesso, estradas e pontes, entre outras possibilidades. As limitações não podem ser compensadas e, portanto não entram aqui nesta fase manual. Assim, foram adotados como critérios para serem compor a matriz de análise os seguintes temas:

- Densidade Populacional: indicador estatístico obtido através da divisão da população total estimada levantada pelo IBGE- Instituto Brasileiro de Geografia e Estatística pela área de cada UGHRI (segundo o PERH- Plano Estadual de Recursos Hídricos) expresso em hab./km²;

- Macro Uso do Solo- Atribuição da UGRHI, segundo o anexo III da Lei 9034 de 1994 (PERH);

- Número de Pontos operados por ano pela CETESB- Companhia Ambiental do Estado de São Paulo com IQA calculado por UGRHI

- Densidade da Rede de Monitoramento- No de pontos de água superficial/1.000 km². Segundo recomendação da Agencia EEA- Agência Ambiental Européia para a CEE- Comunidade Econômica Européia equivale a 1 ponto por $1000 \mathrm{~km}^{2}$.

- Resultado das Médias Anuais dos resultados do IQA por UGRHI divulgados pela CETESB- Companhia Ambiental do Estado de São Paulo. 
Pensou-se em incluir um critério que apresentasse a porcentagem de esgoto coletado e tratado. Mas como estes números são ainda bastante controversos, pois dependem da informação da porcentagem de coleta correta, isto é, se a rede coletora estaria realmente acompanhando o crescimento da cidade em sua região de periférica. E depende da informação correta sobre a porcentagem de tratamento de esgoto coletado. Por fim, dependeria do sistema e sua eficiência operacional. Com isto, havia possibilidade do dado trazer mais incerteza do que contribuição de análise na avaliação multi-critério e por isto não foi incluído. Ainda que a informação fosse bastante interessante recomenda-se que em caso de incertezas que elas não sejam incluídas, pois quando na próxima fase, onde se atribuem os pesos, podem induzir a erros e causar danos no resultado geral. Assim, a presença ou não de esgoto vai ser inferida pelo critério da qualidade de água, ou seja, pelo índice do IQA, que será apresentado pela média. Outro índice que foi cogitado para integrar esta análise foi o IET, pois reflete a condição de eutrofização dos corpos hídricos por influencia de nutrientes presentes nos esgotos, dieta humana, entre outros já explicados anteriormente. Mas para este caso o fator limitante foi a série histórica, pois como é um índice mais recente, e que não é calculado para todos os pontos, não atenderia as exigências de estar presente em todos os anos escolhidos para compor o estudo da AMC. Por isso, após algumas ponderações o grupo ficou restrito a estas 5 variáveis já acima listados.

Portanto, as 22 unidades de gerenciamento hídricos de São Paulo serão submetidas ao método da AMC, por meio de 5 critérios, que após processados, vão gerar um índice que englobe os assuntos selecionados (humanos e ambientais) e que podem sintetizar o panorama da abrangência espacial da rede de qualidade e sua vulnerabilidade diante das pressões antrópicas com o passar do tempo.

A fase seguinte consiste em definir como cada critério vai influenciar a análise muti-critério. E isto é feito basicamente verificando-se qual a importância e significado de cada um deles. Vale lembrar que, é uma 
análise subjetiva, e pode variar conforme o analista e seus interesses. Mas é fundamental dividi-los de maneira que eles possam ser entendidos como um custo, ou como um benefício, para o avaliador.

Para este tipo de análise, o critério é entendido como um custo quando seu potencial de impacto vai influenciar negativamente na sua escolha. Por exemplo, quando se compra uma passagem aérea provavelmente leva-se o preço em consideração. Quanto maior for este preço, pior para o passageiro. No mesmo exemplo, o critério tipo benefício, pode ser entendido pela variável tempo. Esta mesma viagem pode ter muitas escalas em função do menor preço, o que vai aumentar o seu tempo de deslocamento. Portanto, neste caso, quanto menor for o tempo gasto, melhor. Isto é um critério do tipo benefício.

$\mathrm{Na}$ análise selecionada definiu-se como custos os critérios da densidade demográfica e do uso do solo predominante na unidade analisada. Quanto maior a densidade demográfica, maior o impacto ela causa sobre os rios, portanto, entendido como custo. Já no caso do uso do solo, usou-se as 4 classificações vocacionais que generalizam o uso preponderante de cada UGRHI. Este critério também é um custo, pois quanto mais agressivo for o uso do solo, pior o pode ser o impacto ambiental causado. Neste caso usau-se um valor de ponderação (valuefunction) associado a cada classe para fazer esta potenciação dos usos. As UGRHIS industriais receberam o valor 4, as em industrialização, 3, agropecuárias 2 e as de conservação peso 1 .

\section{1 - A IMPORTÂNCIA DA PADRONIZAÇÃO}

Segundo Shariffi et al., a análise multi-critério é composta por várias fases, mostradas na figura 35 (ITC, 2008).

Para o cálculo de cada um dos indicadores foi necessário padronizar as variáveis de forma a torná-las comparáveis entre si e permitir sua agregação. Como os critérios escolhidos apresentam-se através de valores 
expressos em diferentes unidades de medidas elas não são comparáveis entre si, portanto não existe a menor possibilidade de fazer uma comparação obvia entre elas, sendo necessário realizar a padronização entre eles, para que possam ser somados, multiplicados ou comparados entre si. Para apreender a importância relativa de cada fator no contexto da avaliação, a ponderação considera a técnica de avaliação aos pares (Analytical Hierarchy Process), desenvolvida por Saaty (1980), que orienta os seres humanos a desmembrar os problemas para poder solucioná-los.

Figura 35 - Fases da Análise Multi-critério.

\section{Multi-criteria analysis (MCA) phases}

\begin{tabular}{|c|c|c|c|c|c|}
\hline $\begin{array}{l}\text { Area of } \\
\text { concern }\end{array}$ & $\begin{array}{l}\text { hidvidual } \\
\text { concerral }\end{array}$ & Descriptors & $\begin{array}{l}\text { high } \\
\text { way }\end{array}$ & $\begin{array}{c}2 \\
\text { tane } \\
\text { road }\end{array}$ & trath \\
\hline \multirow{3}{*}{$\begin{array}{l}\text { Economic } \\
\text { effects }\end{array}$} & $\cos t$ & Total cost (min. 5) & 200 & 250 & 500 \\
\hline & $\begin{array}{l}\text { Accessibeti } \\
\text { ty }\end{array}$ & $\begin{array}{l}\text { Travel time } \\
(-, 1+*++)\end{array}$ & $+*$ & ++ & + \\
\hline & Capacty & $\begin{array}{l}\text { Passengers } \\
\text { (mil//km/yr) }\end{array}$ & 30 & 20 & 40 \\
\hline \multirow{2}{*}{$\begin{array}{l}\text { Emvironme } \\
\text { ntal } \\
\text { impacts }\end{array}$} & Pollution & $\begin{array}{l}\text { NOx emtsatons } \\
\text { (tonshyr) }\end{array}$ & 1000 & 750 & 100 \\
\hline & Landscape & Visuality $(-\cdots / t++)$ & $\ldots$ & - & . \\
\hline
\end{tabular}
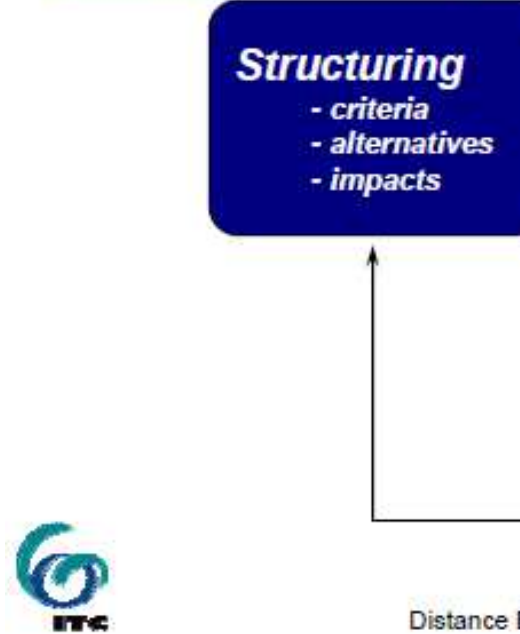

\section{Importance of criteria}

- weights

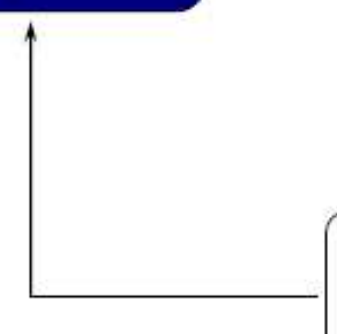

\section{Sensitivity analysis}

\section{Partial} attractiveness

- value functions

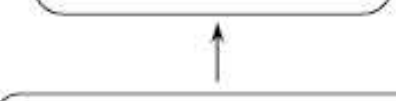

\section{Overall} attractiveness

- Weighted sum

Fonte: ITC, 2008 - DESDSS\Lesson_4\L2\L2_files\4B1 i_files \4B1 introduction to multicriteria evaluation - structuring_files $\backslash$ Slide0372.htm.

Existem vários métodos de transformar as unidades de medida de cada um dos critérios em unidades comparáveis. Neste caso foram utilizados dois métodos apresentados a seguir: 
- Maximum Standardization $\rightarrow$ Padronização máxima

- Interval Standardization $\rightarrow$ Padronização intervalada.

Durante a padronização percebe-se como cada critério é transformado em unidades comparáveis, e como se comportam uns em relação aos outros. Os dois tipos de padronização: a maximum stardardization e a interval stardardization apresentam resultados diferentes, que devem ser comparados, para ver qual o é método mais indicado para análise. As seguintes equações transformam os valores dentro de razão de proporção, em uma escala que varia entre 0-1.

- Padronização máxima: Este método transforma os valores reais para um valor adimensional entre 0 e 1 . Sendo que nas condições de benefício, por exemplo, quanto maior o valor melhor. O maior valor da serie estudada dessa variável será considerado igual a 1 e o pior será considerado igual a 0 . Quando existir na serie um valor igual a zero, caso do número de pontos para a UGRHI 1 no ano de 1980 (tabela 14) o valor zero da tabela de padronização vai ficar igual ao seu número original. É regida pelas seguintes equações:

\section{Equação de Padronização Máxima para Custos:}

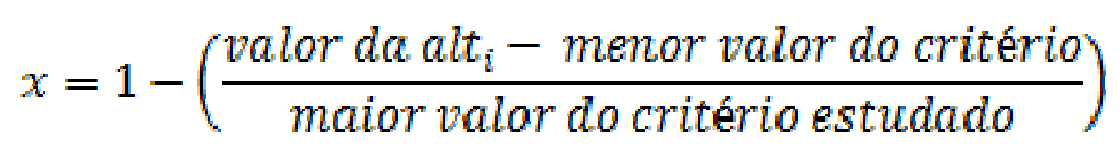

e

Equação de Padronização Máxima para Benefícios:

$$
x=\frac{\text { valor da alt }}{\text { maior valor do critério estudado }}
$$


- Padronização Intervalada: Este método transforma os valores dentro de razão de proporção em uma da escala de propriedades intervalada que varia entre $0-1$, conforme pode ser visto na tabela 14. Este método também transforma os valores reais para um valor adimensional entre 0 e 1.

A Equação de Padronização Intervalada para Custos é mostrada a seguir:

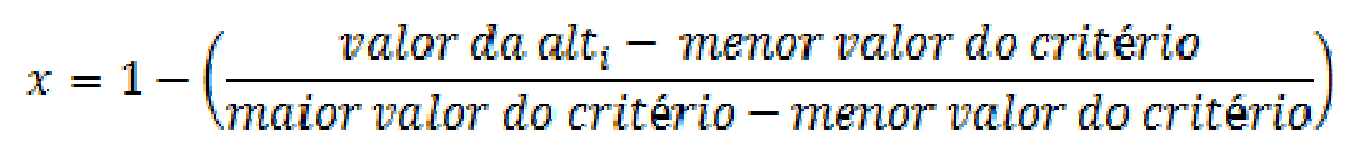

Enquanto a Equação da Padronização Intervalada para Benefícios é:

$$
x=\frac{\text { valor da alt } t_{i}-\text { menor valor do critério }}{\text { maior valor do critério - menor valor do critério }}
$$

A tabela 10 mostra um exemplo simplificado da comparação entre os dois tipos de padronização de uma variável considerada como benefício, p.e. o IQA, que quanto mais próximo do valor 100, melhor traduz a boa qualidade da água e, quanto mais próxima de 0 , pior será a qualidade da água.

\section{Tabela 10 - Exemplo simplificado para os dois tipos de padronização para Benefícios.}

\begin{tabular}{|c|c|c|} 
Valor Real (IQA) & Padronização Máxima & $\begin{array}{c}\text { Padronização } \\
\text { Intervalada }\end{array}$ \\
\hline 40 & 0,4 & 0 \\
\hline 70 & 0,7 & 0,5 \\
\hline 100 & 1 & 1 \\
\hline
\end{tabular}

Tabela elaborada pela autora e E. Tachibana, 2009. 
Em seguida, pode-se ter um exemplo do comportamento do desempenho geral (overall performance) do critério tipo benefício referente as médias do IQA obtidas para o ano 2008, cujo intervalo variou de 44,60 (menor valor da série) obtido para a UGRHI 15, até 76,71 (maior valor) obtido pela UGRHI 16, dentre as 22 UGRHIS do estado. A comparação entre ambas as padronizações está na figura 36 :

Figura 36 - Comparação entre os dois tipos de padronização para o critério valor médio do IQA-2008.

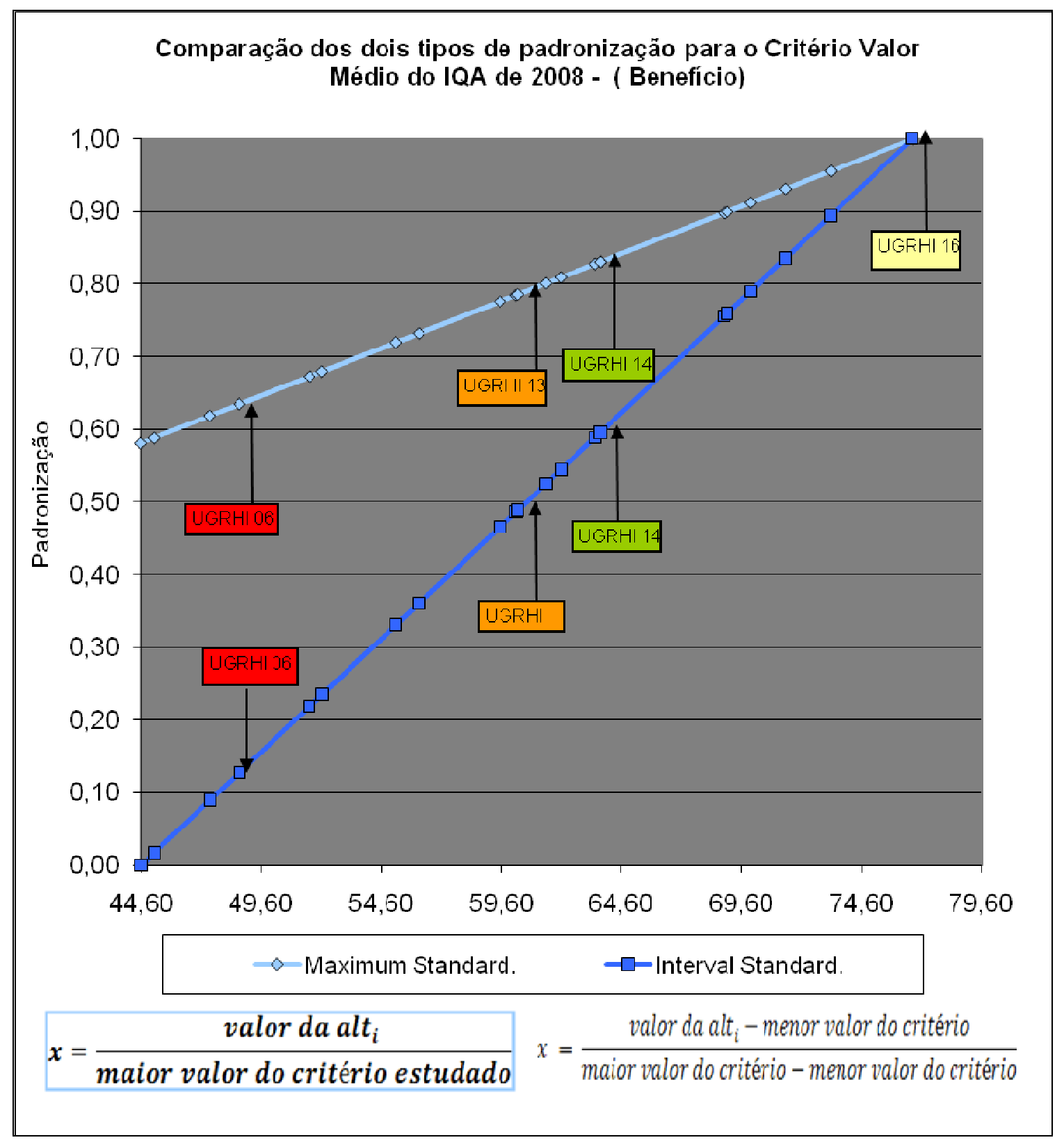

Elaborada por: MIDAGLIA, C. L., 2009. 
Portanto este método transformou os valores reais do IQA para um valor adimensional entre 0 e 1 , saindo do valor zero nas condições de benefício (que quanto maior o valor melhor).E o maior valor dessa variável foi considerado igual a 1 , e o menor valor foi considerado igual a 0 .

\section{A Equação de Padronização Máxima para o critério Benefício é mostrada a seguir:}

$$
x=\frac{\text { valor da alt }}{\text { maior valor do critério estudado }}
$$

Exemplo com a média do IQA 2008 para UGHRI $1=56,17 / 76,71$

(maior valor da série) $\rightarrow 0,73$

\section{Enquanto a Equação da Padronização Intervalada para Benefícios é:}

$$
\begin{gathered}
x=\frac{\text { valor da alt } t_{i}-\text { menor valor do critério }}{\text { maior valor do critério - menor valor do critério }} \\
\text { Exemplo: Média do IQA } 2008 \text { para UGHRI } 1= \\
56,17-44,60 / 73,31-44,60 \rightarrow 0,36
\end{gathered}
$$

Apresenta-se a seguir, outro exemplo simplificado de comparação entre os dois métodos, desta vez para uma variável considerada como custo, p.e. densidade populacional, que quanto maior o seu valor, pior seriam as conseqüências para a qualidade da água, e que quanto menor, menor seria a probabilidade de alterações no seu entorno. Assim, supondo-se que os valores máximos e mínimos do intervalo dos dados estejam entre 10 e 70 hab. $/ \mathrm{km}^{2}$, respectivamente, os valores resultantes da padronização são apresentados na tabela 11. 


\section{Tabela 11 - Exemplo simplificado para os dois tipos de padronização para custo.}

\begin{tabular}{|c|c|c|}
\hline $\begin{array}{c}\text { Valor Real } \\
\text { (Densidade } \\
\text { Populacional) }\end{array}$ & $\begin{array}{c}\text { Padronização } \\
\text { Máxima }\end{array}$ & $\begin{array}{c}\text { Padronização } \\
\text { Intervalada }\end{array}$ \\
\hline 10 hab./km² & 1,00 & 1,00 \\
\hline $22 \mathrm{hab} . / \mathrm{km}^{2}$ & 0,83 & 0,80 \\
\hline $70 \mathrm{hab} . / \mathrm{km}^{2}$ & 0,14 & 0 \\
\hline
\end{tabular}

Elaborada por: MIDAGLIA, C. L. e TACHIBANA, E., 2009.

Neste caso, verifica-se então que quando se usa a Padronização Máxima todos os valores padronizados para a densidade populacional estão variando entre 0,14 e 1 . Já quando se utiliza a Padronização Intervalada, os valores estarão na faixa de 0 a 1.

A seguir, apresenta-se um exemplo real da comparação entre ambas as padronizações referente ao critério uso do solo, aqui considerado como custo, que atribui valores entre 1 a 4 para cada grupo de UGRHI conforme sua atribuição principal, conforme já descrito em outras ocasiões. Este critério permaneceu com seus valores inalterados ao longo de toda a da serie estudada, pois não houve oficialmente nova classificação sobre a atribuição vocacional das Unidades de Gerenciamento de Recursos Hídricos. As diferenças nos valores gerados conforme o tipo de padronização adotado pode ser visualizado na figura 37. 
Figura 37 - Comparação entre os dois tipos de padronização para critério custo-Atribuição da UGRHI.

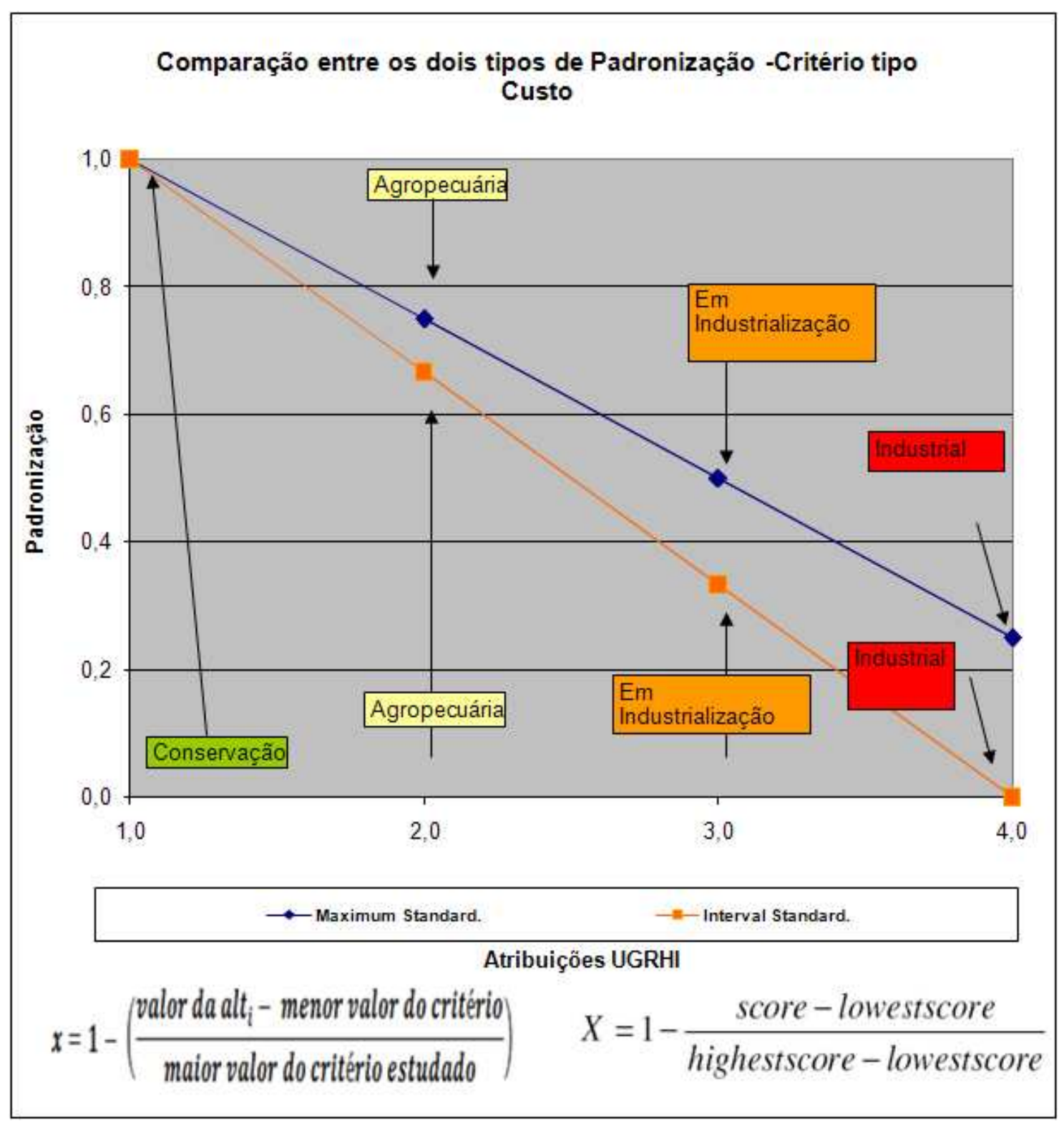

Elaborada por: MIDAGLIA, C. L., 2009.

Então, quando opta-se pelo método da padronização máxima (Maximum Standardization), todos os valores ficam entre 0,25 e 1. Já quando utiliza-se a padronização intervalada (Interval Standardization), os valores normalizados estarão na faixa de 0 a 1 . Salienta-se que, sempre, não importa por qual dos dois métodos de padronização utilizados, nem se a variável é considerada como custo ou benefício, uma vez gerada a tabela com os valores padronizados para os dados, quanto 
mais próximo de 1,0 for o resultado, isto significara que 0 valor de origem é melhor, e quanto mais próximo de 0 , significará que ele é pior.

\section{2 - FASE DE DEFINIÇÃO DE PRIORIDADES E DE ATRIBUIÇÃO DOS PESOS}

Ainda dentro da fase de estruturação, após a fase de normatização dos dados, comparam-se de modo geral os valores obtidos e sua atratividade parcial através de uma somatória (weighted summation). Mas como isto geralmente não é suficiente para uma analise mais detalhada, pois a soma pode mascarar a importância de determinado critério. Para evitar isto, recorre-se, mais adiante a fase de sensibilização. É nesta fase que se expressa qual é a importância que se deseja que cada um dos componentes tenha no compito geral da análise. Nesta etapa, é preciso definir uma ordem de prioridade entre os critérios. Isto é feito com a atribuição de pesos, que levarão em conta, as visões ou opiniões de tanto quantos forem as partes envolvidas. Pode ser que se trate de uma tomada de decisão para grupos de interesses variados. Aqui neste caso de estudo, foram colocadas apenas duas, cada qual dando ênfase a um tipo de foco/visão. Na tabela 12, os critérios foram agregados enquanto custos, uso vocacional das UGRHIS e densidade populacional (em laranja) ou em benefícios, na cor azul, o número de pontos de monitoramento dentro de cada UGRHI, a densidade de pontos-CEE, e a média do IQA de cada UGRHI. Mas, este agrupamento é apenas para um entendimento simplificado de como a soma dos critérios compreendidos enquanto custos ou benefícios podem influenciar a análise. 
Tabela 12 - Síntese das variáveis da Análise Multi-Critério segundo Custos e Benefícios.

\begin{tabular}{|c|c|c|c|}
\hline Critérios & Variável & visao 1 & visao 2 \\
\hline \multirow{2}{*}{$\begin{array}{c}\text { Antrópico } \\
\text { (Pop. e Uso) }\end{array}$} & Dens. Pop. & 0,325 & 0,25 \\
\cline { 2 - 4 } & Atribuição UGHRI & 0,2 & 0,2 \\
\hline Custos & impactos & $\mathbf{0 , 5 3}$ & $\mathbf{0 , 4 5}$ \\
\hline \multirow{2}{*}{$\begin{array}{c}\text { Ambiental } \\
\text { (Monit. Água) }\end{array}$} & Média do IQA & 0,225 & 0,24 \\
\cline { 2 - 4 } & Num. Pontos calc. & 0,15 & 0,17 \\
\cline { 2 - 4 } & Dens. Ptos. (CEE) & 0,1 & 0,14 \\
\hline Beneficios & gestão & $\mathbf{0 , 4 7 5}$ & $\mathbf{0 , 5 5}$ \\
\hline & total & 1 & 1 \\
\hline
\end{tabular}

Elaborada por: MIDAGLIA, C. L., 2009.

Para poder concluir a fase de estruturação da análise multi-critério é preciso então colocar os pesos conforme a ordem de importância ou prioridade destes critérios. Portanto, a maneira como se colocam os pesos vai expressar nossas preferências, demonstrando-se a importância que cada um de nos dá a cada um esses critérios. Como eles já foram préavaliados em fase anterior, o contexto de sua atratividade geral (overall attractiveness), poderá auxiliar na atribuição dos pesos nesta fase. Neste processo, a soma dos pesos nunca pode ser superior a 1 , na verdade, tem que ser igual a 1. Esta é uma fase difícil e que toma bastante tempo, pois uma vez definida a ordem, ela não pode ser alterada sem que haja o reinício de todo processo de distribuição de pesos, ou seja, não é possível alterar a ordem de prioridade ou ranking de importância (Rank Order). E os pesos distribuídos nas diferentes visões ou opiniões devem seguir a mesma ordem, ou seja, não podem ter uma hierarquia diferente.

A tabela 13 a seguir mostra a hierarquização para os critérios de importância para as variáveis utilizadas com os seguintes valores de pesos: 
Tabela 13 - Ranking de critérios conforme as preferências.

\begin{tabular}{|c|l|c|c|} 
& $\begin{array}{c}\text { Ranking de } \\
\text { Preferencias }\end{array}$ & \multicolumn{2}{|c|}{ Compensatory Evaluation } \\
\hline ordem & Prioridades & Peso 1 & Peso 2 \\
\hline 1 & Dens. Pop. & 0,325 & 0,25 \\
\hline 2 & Valor Médio IQA & $\mathbf{0 , 2 2 5}$ & $\mathbf{0 , 2 4}$ \\
\hline 3 & Atribuição UGHRI & $\mathbf{0 , 2}$ & $\mathbf{0 , 2}$ \\
\hline 4 & Num. Pontos calc. & 0,15 & 0,17 \\
\hline 5 & Dens.Ptos Monit. & 0,1 & 0,14 \\
\hline
\end{tabular}

Elaborada por: MIDAGLIA, C. L., 2009.

Assim, para poder avaliar o impacto das atividades antrópicas no processo de evolução da rede, recorreu-se a ponderação destes critérios para comparação conforme os pesos da análise hierárquica, e com isto, os diversos números (a qualidade dos pontos e ao crescimento populacional, etc.) puderam ser correlacionados. As tabelas (14 a 20) a seguir mostram os números originais e também todo o processo de padronização (Maximum e Interval Standardization) para os anos selecionados para a amostra dos anos que dão origem ao índice resultante desta análise muticritério, inclusive com os gráficos mostrando como cada valor colocado em unidades adimensionais se comportou respectivamente dentro da serie estudada através dos dois processos de padronização e com os pesos atribuídos nas duas visões. 
Tabela 14 - Análise Multicriterial do Monitoramento das Águas Superficiais do Estado de São Paulo: Ano 1980.

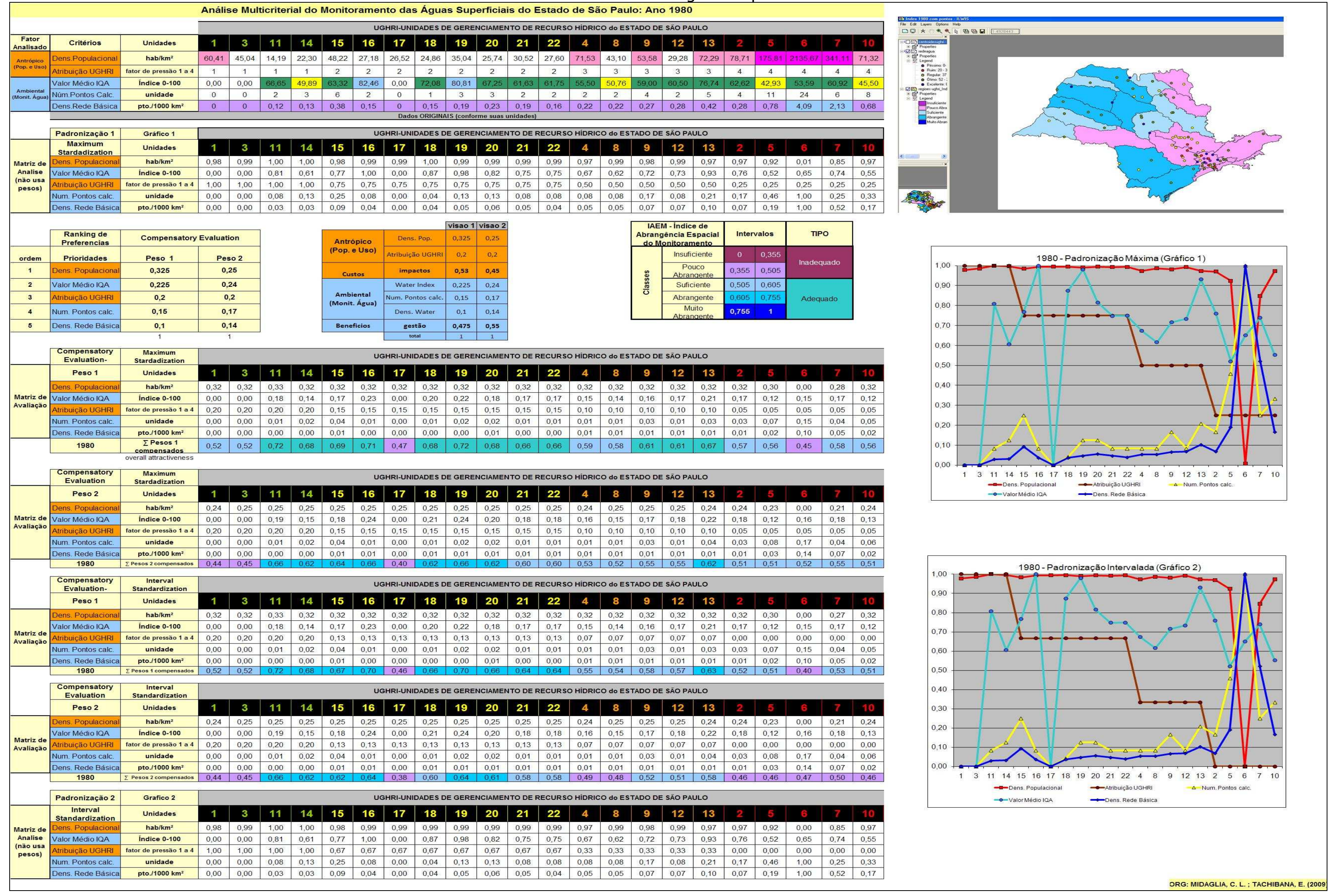


Tabela 15 - Análise Multicriterial do Monitoramento das Águas Superficiais do Estado de São Paulo: Ano 1991.

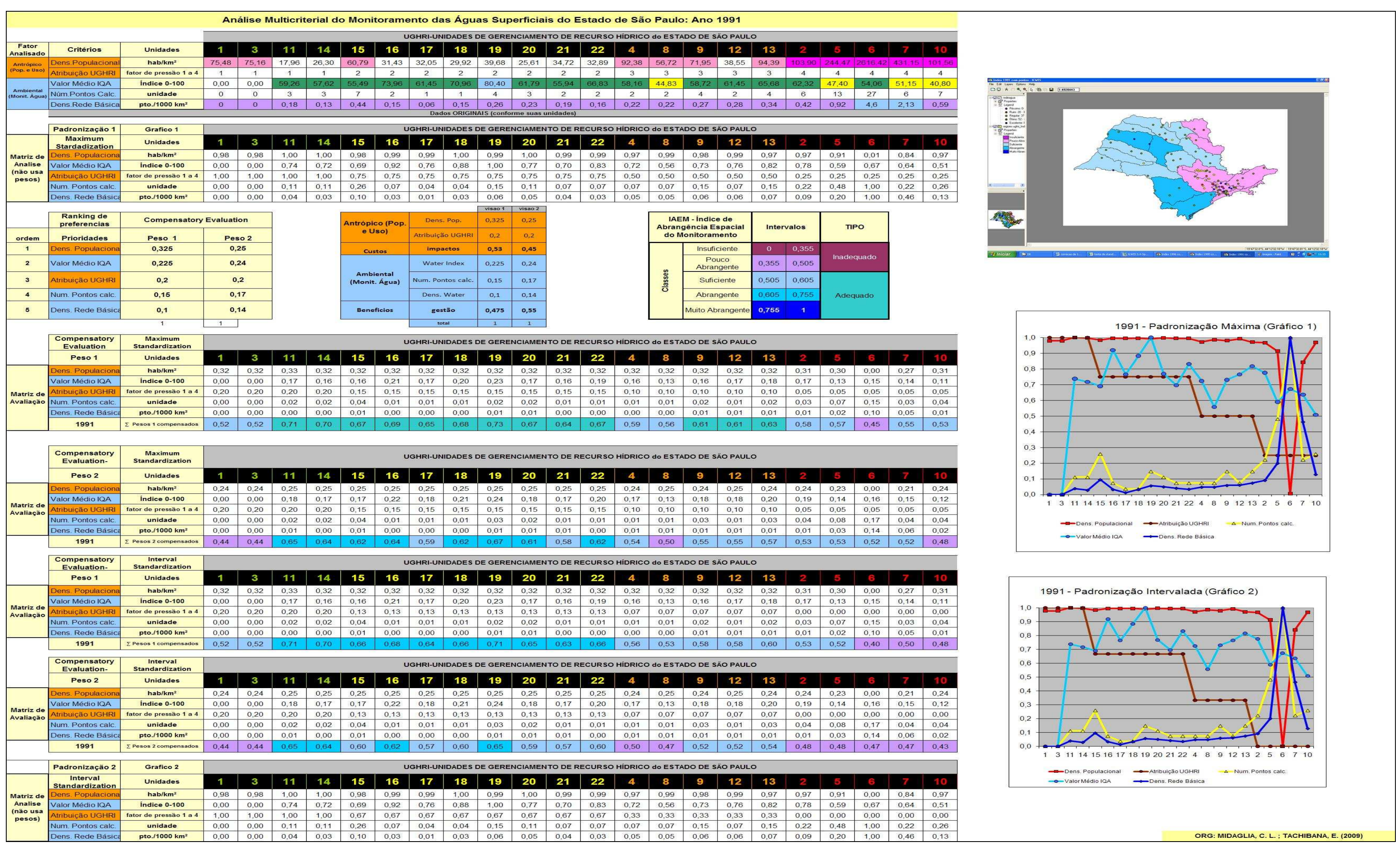


Tabela 16 - Análise Multicriterial do Monitoramento das Águas Superficiais do Estado de São Paulo: Ano 1995.

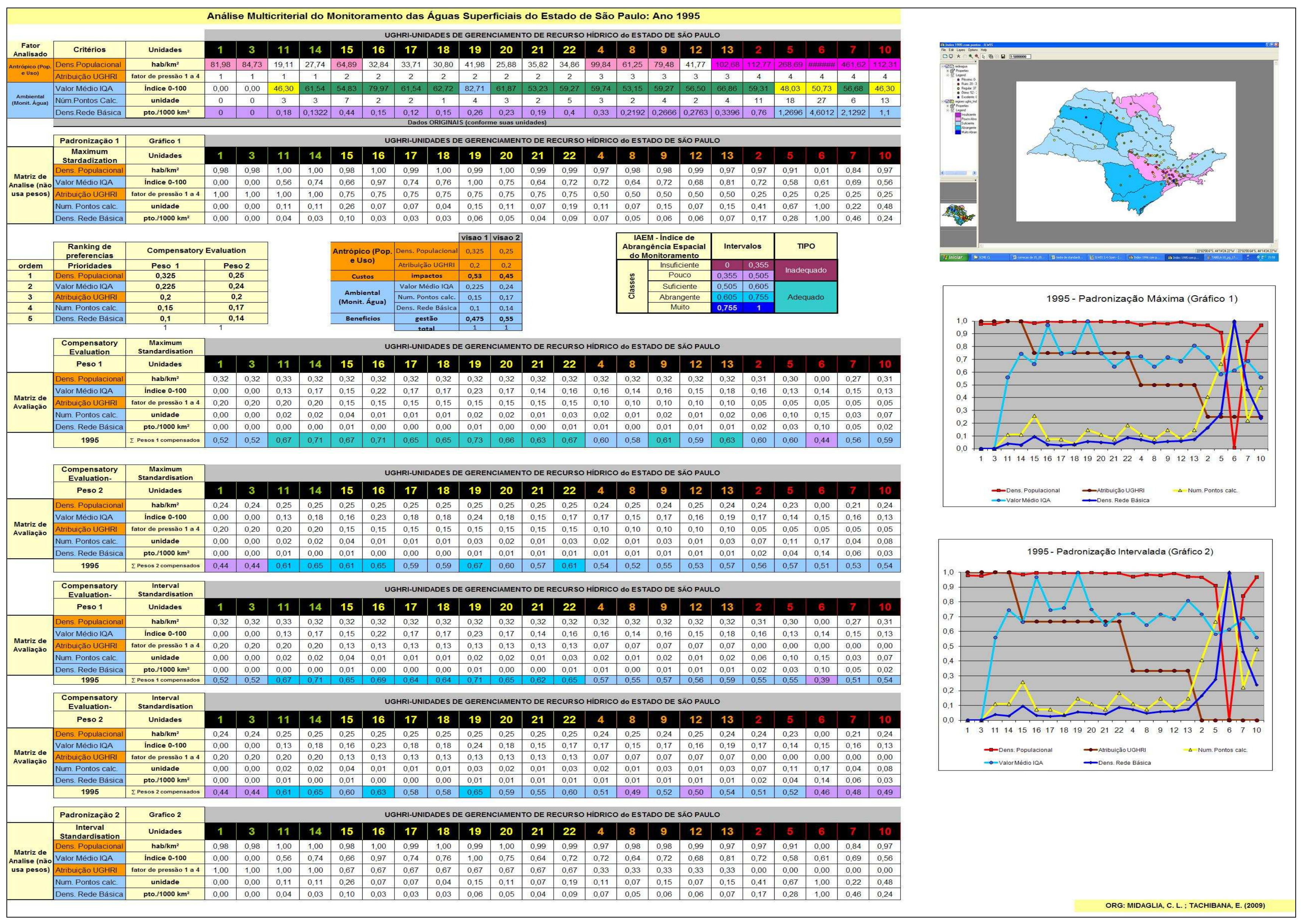


Tabela 17 - Análise Multicriterial do Monitoramento das Águas Superficiais do Estado de São Paulo: Ano 1996.

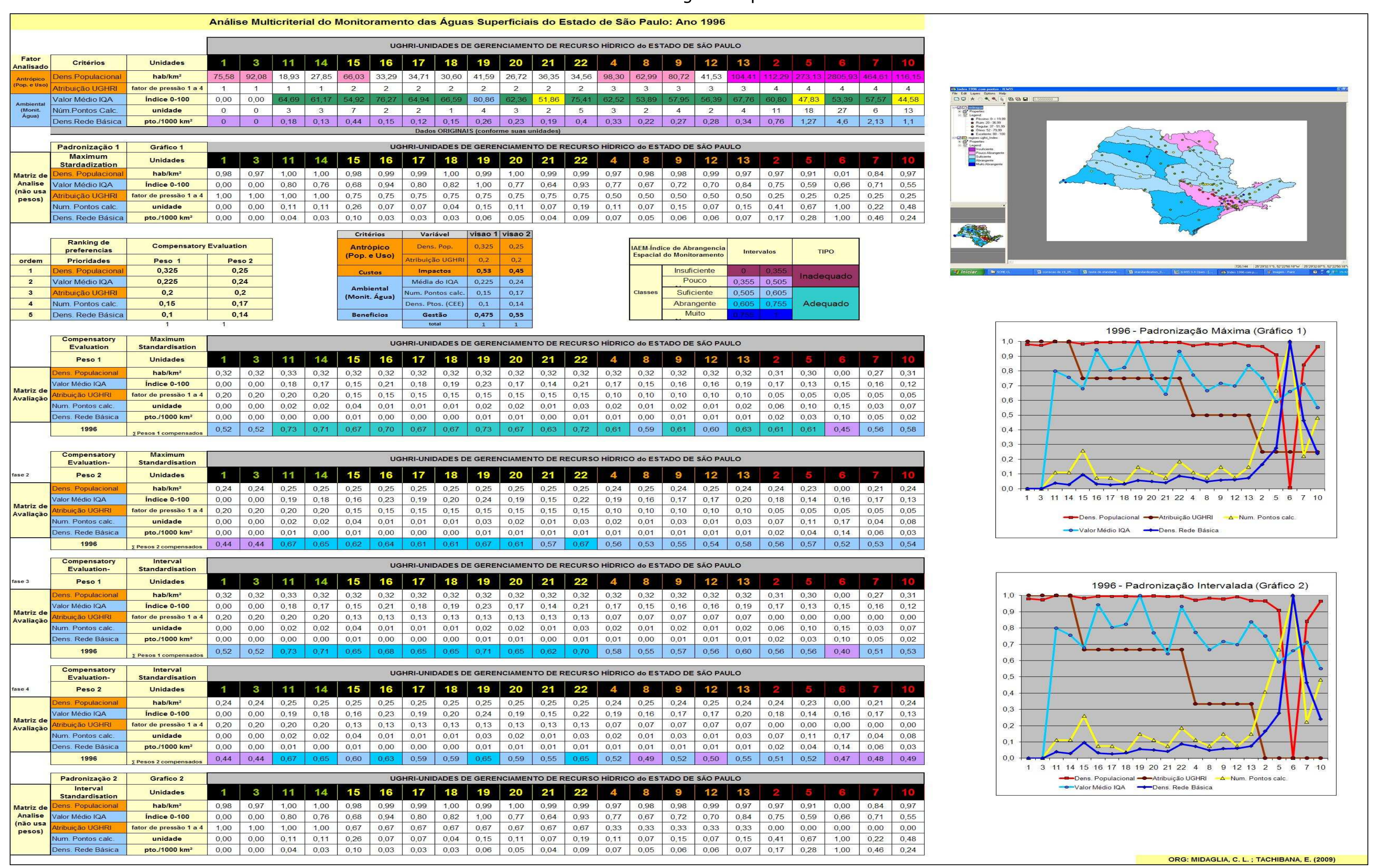




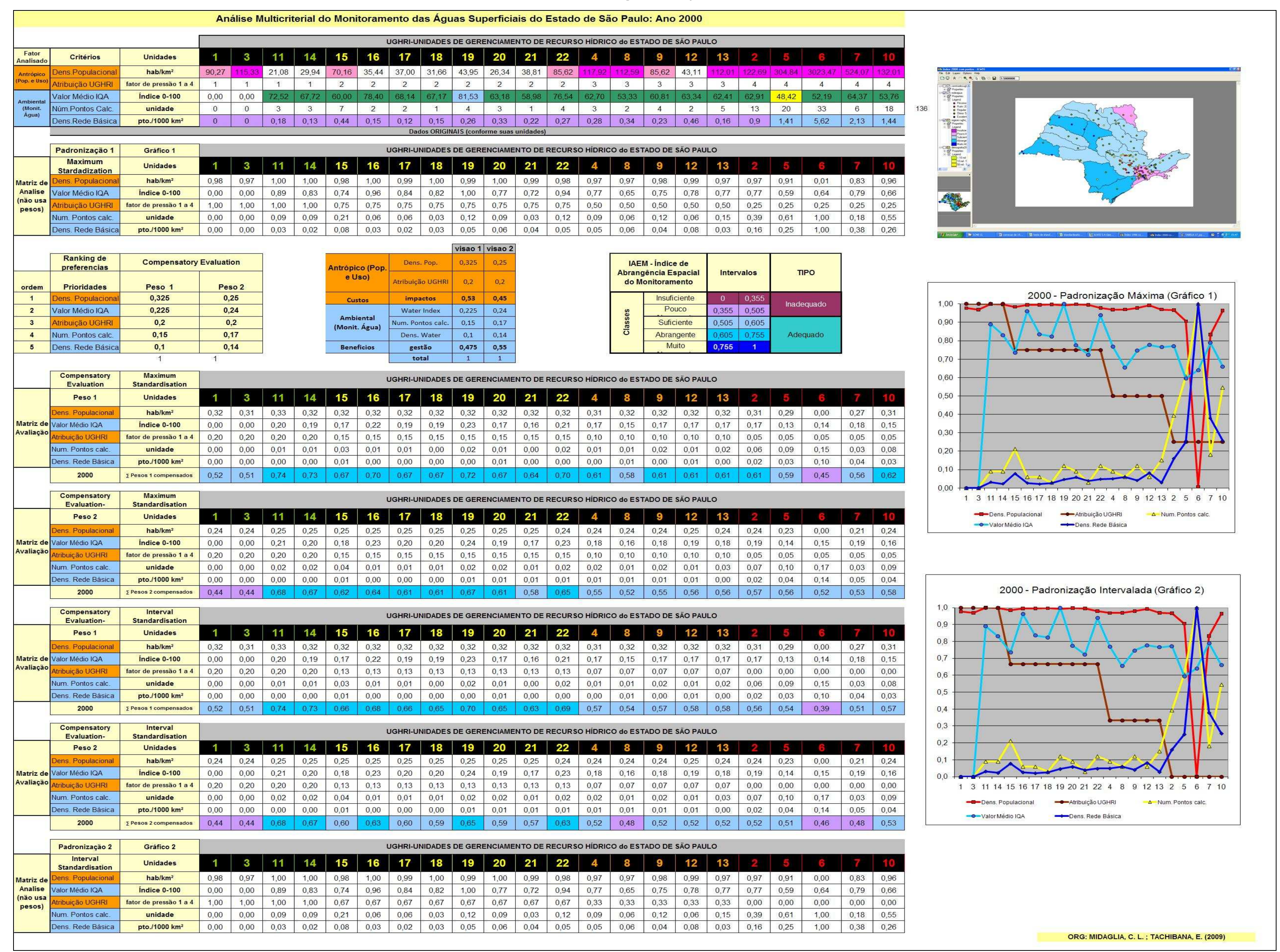




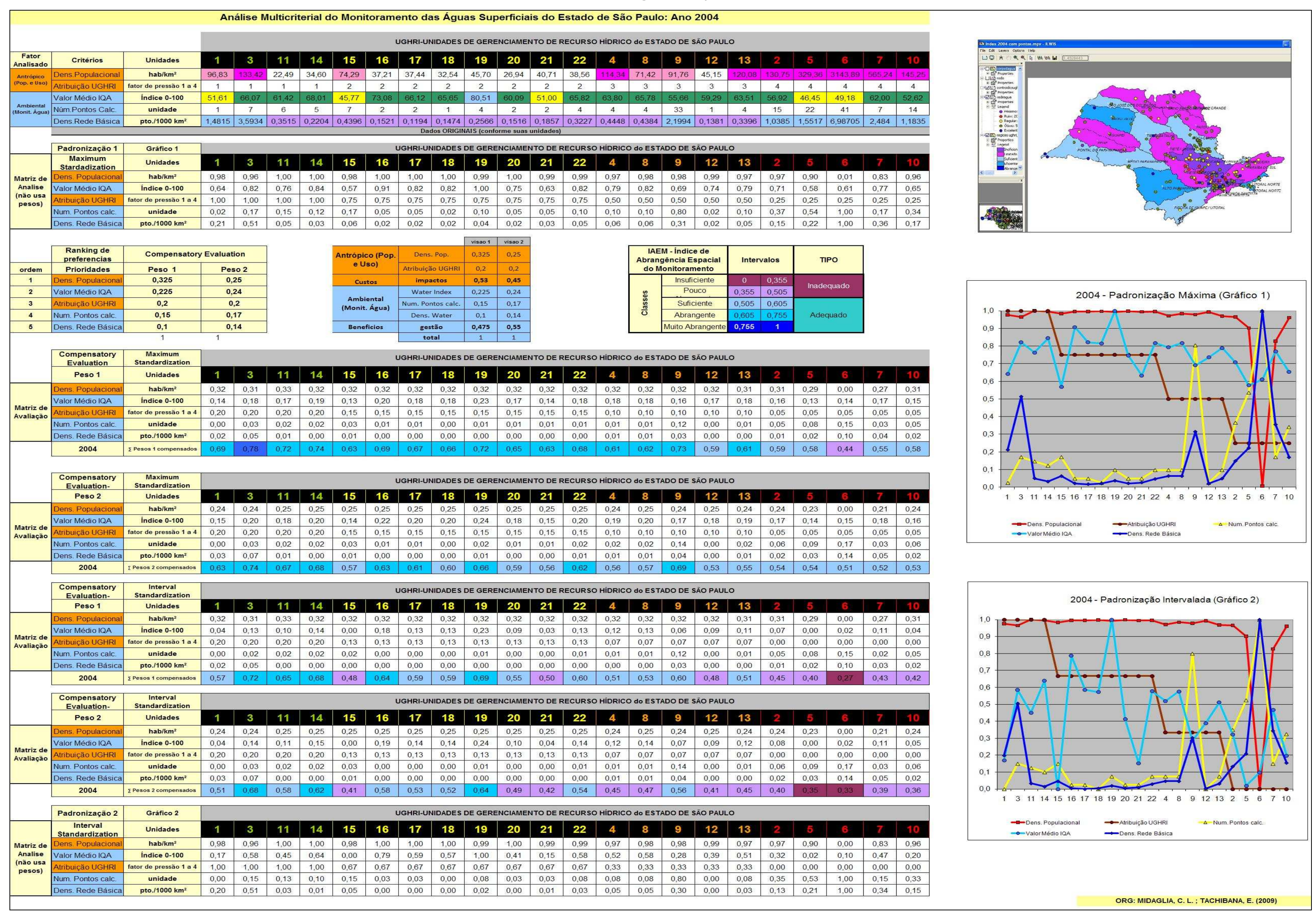


Tabela 20 - Análise Multicriterial do Monitoramento das Águas Superficiais do Estado de São Paulo: Ano 2008.

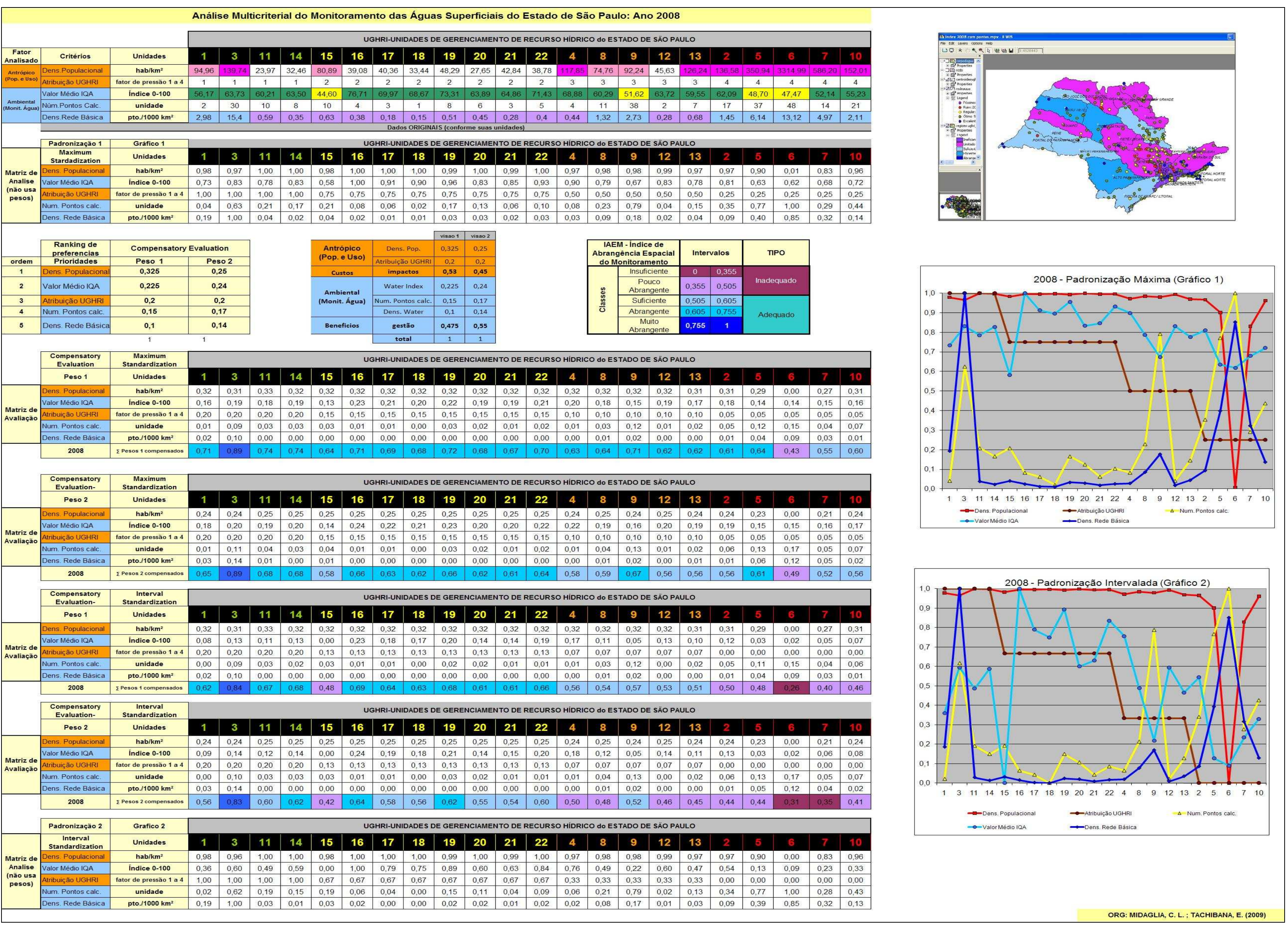


Figura 38 - Índice de Abrangência Espacial do Monitoramento das Águas Superficiais do Estado de São Paulo - Analise Temporal para anos selecionados índice de Abrangencia Espacial do Monitoramento das Aguas Superficiais do Estado de São Paulo - Analise Temporal para anos selecionados
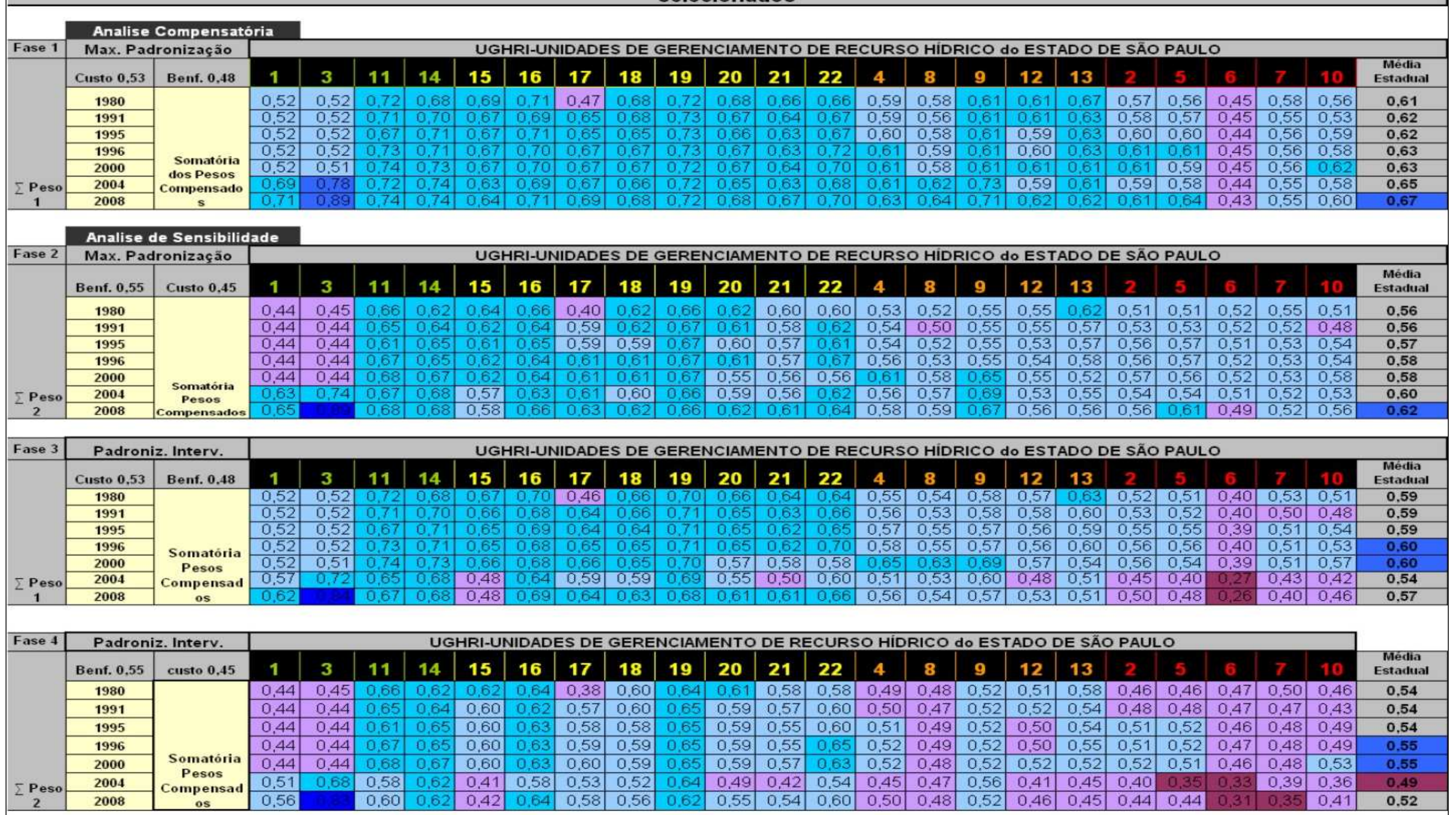
A última fase do processo da análise multi-critério, é chamada de sensibilização, pois consiste em reavaliar as matrizes geradas e testar novos pesos, ou ainda verificar a necessidade de troca de ordem de prioridade de importância dos critérios para verificar os resultados:

\section{Sensitivity on priorities}

Priorities or weights, reflecting the relative importance of the criteria and criterion- scores, have a major impact on the final results. This embodies a large amount of uncertainty, especially when weights are quantitatively assessed. Sensitivity of the ranking for the weights can be examined by 1 ) looking at the overall uncertainty of the weights; 2) looking at the influence on the ranking when changing one criterion weight; 3 ) looking at changes in all weights; and 4) using different sets of weights. (ITC, 2008, p.134)

Esta é uma fase trabalhosa mais bastante interessante, pois se se testa várias hipóteses na forma de alocação dos pesos e prioridades, tais como: e se isto for feito/mudado? Programas tais como "What IF", um software pago, <http://www.whatifinc.biz/> exploram este tipo de geração de cenário para planejamento. Após esta fase de interpretação dos resultados normatizados gerados na serie de tabelas, e uma vez analisadas e aceitas as performances segundo cada uma das visões, é preciso então decidir qual foi a que mais condizente com o problema analisado na realidade. O método escolhido gera por fim, os índices da matriz consolidada e aprovada, e, o processo de análise terminara com a interpretação dos valores gerados pelo índice resultante.

\section{3- O IAEM-ÍNDICE DA ABRANGÊNCIA ESPACIAL DO MONITORAMENTO DA QUALIDADE DA ÁGUA}

Como a mente humana tem capacidade limitada para fazer comparações e armazenar grande quantidade de dados (atributos e variáveis), especialmente quando estão em diferentes unidades foi preciso recorrer a AMC para descobrir a situação de cada ano estudado. 
As planilhas de calculo do Excel da AMC não foram feitas para todos os 30 anos, para reduzir um pouco o universo numérico de comparação. Escolheu-se principalmente, em função dos anos em que houve o levantamento do censo do IBGE, para que os cálculos das densidades populacionais não tivessem que ser retrabalhados, o que provocaria certa imprecisão, pois, como já vimos antes, as incertezas devem ser evitadas ao máximo para não distorcer os resultados finais. Portanto, foram escolhidos os anos de 1980 (Censo), 1991 (Censo), 1995 (Estimativa populacional - IBGE), 1996 (Contagem populacional), 2000 (Censo), 2004 (Estimativa SEADE) e 2008 (contagem populacional) para compor as tabelas de análise. Assim, o intervalo de estudo de 30 anos, dentro do calculo do índice proposto ficou restrito a 28 anos.

Para fins de analise espaço-temporal sobre a abrangência e a eficácia do monitoramento entre as 22 UGRHIs recorreu-se a criação deste novo índice, que foi chamado de IAEM, ou seja, ÍNDICE de Abrangência Espacial de Monitoramento, que tem capacidade de comparar as 22 UGRHIS, que enquanto áreas de gerenciamento são espacialmente adimensionais, ou seja, tem tamanhos variados. Portanto, além da ênfase na unidade territorial geográfica, os demais critérios vão muito alem do critério espacial da CEE, que recomenda 1 ponto por $\mathrm{Km}^{2}$.

O indicador resultante da matriz de análise é um índice que vai se referir a outras informações já consolidadas de forma sintética. Assim, a avaliação multi-critério (Multi Criteria Evaluation - MCE) gerou um índice composto que foi dividido em cinco intervalos que tentam classificar a Representatividade/ Eficiência/ Fragilidade/ Vulnerabilidade/ Cobertura e por fim a Abrangência da rede de monitoramento em termos de espaço (tamanho) frente a pressão antrópica existente neste mesmo espaço (população habitante e usos da terra/água). Os valores resultantes mais altos, conforme mostra a tabela 21, próximos de 1 indicam uma melhor performance do monitoramento, ou seja, uma maior abrangência espacial da rede $\mathrm{e}$ indicam se que a rede e a qualidade ambiental eram apropriadas/adequadas tendo-se em conta as pressões existentes no ano analisado. 
Tabela 21 - Divisão do IAEM em classes de

Abrangência Espacial do Monitoramento.

\begin{tabular}{|c|c|c|c|c|}
\hline \multicolumn{2}{|c|}{$\begin{array}{l}\text { IAEM - Índice de Abrangência } \\
\text { Espacial do Monitoramento }\end{array}$} & \multicolumn{2}{|c|}{ Intervalos } & $\begin{array}{c}\text { TIPO de } \\
\text { Monitoramento }\end{array}$ \\
\hline \multirow{5}{*}{$\begin{array}{l}\mathscr{d} \\
\mathscr{d} \\
\mathscr{D} \\
\frac{\mathbb{\sigma}}{0}\end{array}$} & Insuficiente & 0 & 0,355 & \multirow{2}{*}{$\begin{array}{l}\text { Inadequado/ } \\
\text { Vulnerável }\end{array}$} \\
\hline & Pouco Abrangente & 0,355 & 0,505 & \\
\hline & Suficiente & 0,505 & 0,605 & \multirow{3}{*}{$\begin{array}{l}\text { Adequado/ } \\
\text { Não Vulnerável }\end{array}$} \\
\hline & Abrangente & 0,605 & 0,755 & \\
\hline & Muito Abrangente & 0,755 & 1 & \\
\hline
\end{tabular}

Elaborada por: MIDAGLIA, C. L., 2009.

As cinco classes derivadas do índice IAEM, que é resultante da combinação entre fatores sociais e ambientais, tentam definir e resgatar a analise da evolução histórica do monitoramento das águas superficiais no Estado de São Paulo. Tem poder de analisar as dimensões espaciais da rede, comparar e classificar as UGRHIS em termos de vulnerabilidade de monitoramento. A leitura feita através da interpretação deste índice registra como variou o universo de pontos durante o período estudado, fornecendo resposta a segunda pergunta, de como se comportou a rede diante das pressões ambientais existente a época, sendo possível visualizar as diferenças entre os resultados obtidos tanto para cada ano destacado do estudo quanto para cada UGRHI.

A abrangência espacial adequada da rede significativa da rede pode ser entendida pelo fato de tido uma a boa cobertura da área envolvida, com a colocação dos pontos nos lugares mais estratégicos e que possibilitam resultados compatíveis com o uso da água e do uso do solo do entorno, pelo grau de urbanização e pelo tamanho da área a ser monitorada. A técnica de Avaliação Multi-Critério também revelou onde existiram grandes desigualdades espaciais no monitoramento e por isso poderá ser usada para promover um planejamento e reestruturação da rede de monitoramento nestas UGRHIs. 
Pode-se perceber com a interpretação dos resultados referentes ao recorte temporal proposto neste estudo que algumas ações de gestão de qualidade tomadas, tais como a inclusão de pontos e a melhoria no IQA (qualidade da água) para acompanhar o ritmo das pressões antrópicas no uso da água, frente ao processo de adensamento populacional, podem refletir na classificação em uma categoria melhor, significando melhoria. Portanto, a rede de monitoramento em áreas de diferentes graus de pressão ambiental deve ter diferentes níveis de analise, do que de unicamente a característica da densidade espacial (de tamanho da área), levando em conta a concentração de pessoas que usam o recurso hídrico, e os usos que fazem, e o resíduo que geram, tal como proposto no IAEM.

\section{4 - PRINCIPAIS RESULTADOS DO NOVO ÍNDICE}

A aplicação da análise multi-critério para verificar a conformidade em termos de abrangência espacial da rede de monitoramento apresentou resultados interessantes e consistentes. O método resgatou a espacialização dos dados históricos. A agregação dos diferentes critérios esta representada segundo as classes do IAEM em mapas.

Os produtos resultantes dessa análise foram transpostos para mapas sínteses que registram a variação espacial do IAEM que retratam o panorama temático dos critérios selecionados (Mapas 3 a 7). No Mapa 3 a analise espacial das médias do IQA tem como finalidade discutir um processo de restauração ambiental em áreas com rios em estado crítico. Individualmente outros parâmetros tais como o oxigênio dissolvido, a condutividade, a turbidez, o fósforo poderiam fornecer informações bastante amplas a respeito da qualidade das águas, através de séries históricas, e podem ser analisadas, espacialmente neste tipo de avaliação multi-critério no lugar do IQA. No Mapa 4, registra-se a evolução da densidade populacional nos municípios paulistas. O panorama dos critérios selecionados para 1980 e de 2008 estão sintetizados nos mapas 5 e 6 . O mapa 7 interpreta as UGHRIs segundo a classificação do IAEM ao 
longo do estudo, para entendimento da história do monitoramento paulista.

O potencial de síntese da análise dessas variáveis, densidades espaciais e índices possibilitará uma nova leitura sobre como delinear uma nova rede de amostragem de águas superficiais e destaca a importância do fato de estar em permanente adaptação, aliada a aplicação de políticas públicas mais vigorosas para recuperação dos recursos hídricos. O IAEM pode facilitar ao gestor de recurso hídrico uma visão sintetizada das influências das condições sócio-ambientais com a identificação e a localização espacial das áreas mais vulneráveis em termos de convivência com rios de qualidade comprometida, para o direcionamento de políticas públicas, em especial as voltadas para o saneamento e recuperação de rios.

A especificidade do indicador mostrou que ele corresponde à sua propriedade de refletir alterações na rede estritamente ligadas às mudanças relacionadas à dimensão dos critérios avaliados, pois deu resposta adequada na maioria dos casos, registrando a performance da rede de monitoramento com consistência.

Como o conjunto de suas informações originais já é disponibilizado anualmente poderia se recomendar a inclusão do IAEM como indicador de conformidade da própria rede de monitoramento do estado de São Paulo nos relatórios anuais da CETESB, nos planos PERH, no uso de metas para o planejamento de recursos hídricos, em programas de recuperação de rios, bacias e UGRHIs classificadas com nível critico (insuficiente) e para priorizar sua recuperação, conservação e recomposição de mata ciliar. Portanto o IAEM pode se tornar uma "ferramenta" eficiente para avaliar a presença adequada do monitoramento nas diferentes unidades de gerenciamento, pois esta correlacionada a importantes indicadores de abrangência territorial, social e de gestão da água.

Assim como o IQA e os demais índices de qualidade de água atualmente utilizados que sintetizam a qualidade da água, o IAEM oferece a possibilidade de verificar se este monitoramento é representativo em termos de abrangência geográfica e se tem representatividade no espaço 
ocupado pela população que utiliza este recurso hídrico. Sugere adensar ou desconcentrar a rede em função da pressão existente para corrigir ou diminuir lacunas espaciais do monitoramento dentro do estado de São Paulo onde existem vazios geográficos, e por fim com o passar do tempo pode ser comparado em termos de evolução espacial, tornando-se um bom instrumento de analise temporal.

10.5 - INTERPRETAÇÃO DOS RESULTADOS DA ANÁLISE MULTI-CRITÉRIO PARA O IAEM

É muito comum as pessoas confundirem ou associarem a perda da qualidade ambiental dos recursos hídricos com a falta de monitoramento ou de informação sobre os rios. Mas pode-se verificar pela própria história da rede de monitoramento que ela sempre esteve atenta a qualidade dos principais rios e reservatórios com importância regional. Para melhor compreensão da evolução temporal da rede através do IAEM a tabela 22 apresenta os resultados do peso 2 conforme classificação já estabelecida.

\section{Tabela 22 - Síntese da Evolução do IAEM - Índice de}

Abrangência Espacial do Monitoramento.

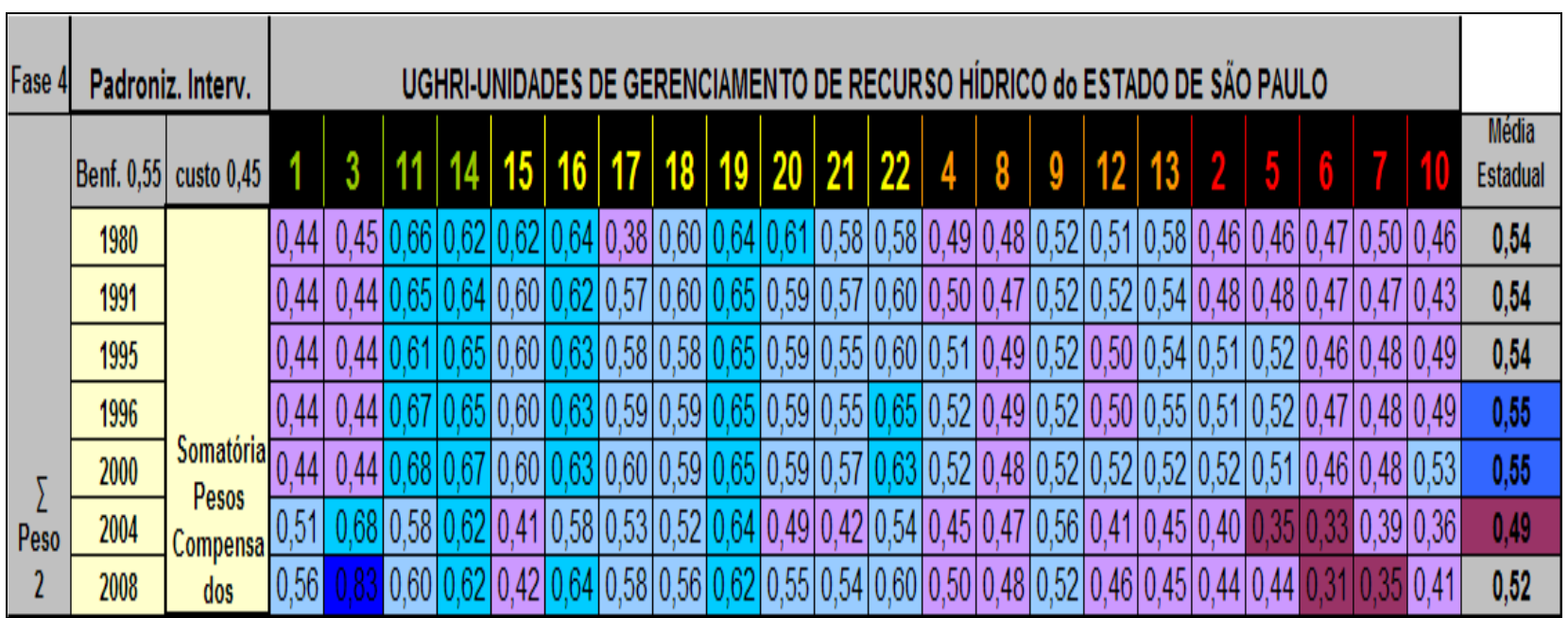

Elaborada por: MIDAGLIA, C. L., 2009.

As planilhas de cálculo para a matriz de normatização dos dados da análise multi-critério formam um importante passo em direção ao que 
pode ser chamado de tradução de dados, de informações segmentadas, de comportamento espacial de fatores isolados e de conhecimento de antigos cenários vistos através de dados jamais agregados espacialmente. Sintetizados por novos arranjos, estes revelam quais foram os padrões de desempenho da rede de monitoramento frente ao crescimento populacional ocorrido neste intervalo de tempo.

A análise das tabelas padronizadas para as diferentes UGRHIs indica que existem unidades que possuem alta vulnerabilidade no tocante a abrangência do monitoramento face às pressões antrópicas: percebe-se que isto predomina em UGRHIs de vocação industrial onde se concentra também a maioria da população do estado. Nestas o problema não é a falta de monitoramento, mas sim a existência de trechos de rios críticos (IQA péssimo ou ruim), muitos deles já detectados pela rede de monitoramento em seus anos iniciais, e que assim permaneceram.

Pelos olhos do novo indicador pode-se ter uma idéia da real necessidade da capacidade de suporte ambiental nas diversas unidades e seus respectivos usos preponderantes. Com isto espera-se que no futuro estes cenários possam auxiliar na tomada de decisões relacionadas ao tamanho ideal que a rede de monitoramento deve ter, qual sua abrangência, e quais seriam os limites ideais de amplitude para uma atuação que produza respostas eficientes, ou seja, qualidade ambiental.

Como produto dos dois métodos de padronização aqui estudados, foram gerados 2 séries normatizadas, as quais foram posteriormente multiplicadas pelo viés de 2 pesos, duas visões ou opiniões, que podem e devem ser discutidos ao máximo. Comparando-se as 4 séries de índices gerados por esta fase passou-se a interpretação dos resultados. Depois de ouvir opiniões e levar em conta a minha própria experiência, e tendo como base a realidade da época de cada ano, entendeu-se que o resultado que melhor representou o período de estudo foi o método da padronização intervalada. E dentre as duas visões ou pesos propostos, entendeu-se que era melhor considerar os resultados obtidos na sensibilização (multiplicação) pelo peso 2 , onde se dá uma importância ligeiramente maior para a parte dos benefícios $(0,55)$, ou seja para a 
gestão da água que englobou o número de pontos, sua densidade espacial e a média do IQA, pois é principalmente para manter esta condição, de boa gestão da qualidade, que este estudo se atem, em detrimento dos custos de uso antrópico $(0,45)$.

Desde os primeiros anos de estudo do IAEM sempre existiram números muito discrepantes dentro de um mesmo critério, como por exemplo, os dados originais referentes à densidade populacional na UGRHI 6-Alto Tiete, que sempre se apresentaram em destaque em relação às demais unidades. Cogitou-se que esta unidade poderia ser considerada um out-lier, ou seja, um valor muito discrepante em relação aos demais, e que poderia ser descartada. Em uma das tentativas feitas em paralelo, foi tentada a retirada desta unidade de gerenciamento, mas entendeu-se que não teria o menor sentido avaliar um espaço fechado como o Estado sem sua maior área de influencia e de pressão ambiental. Portanto, como a padronização intervalada pode reduzir um pouco estas discrepâncias, ela foi escolhida para ser utilizada como geradora do índice que considera a abrangência do monitoramento dentro de um contexto geográfico indissolúvel, apesar das outras unidades apresentarem seus valores parciais puxados para baixo.

Todavia como é uma metodologia nova, só depois de feitos os testes de sensibilização da fase anterior, tem-se os números finais, e não devem existir muitas diferenças entre os pesos para não distorcer ou influenciar resultados. O novo índice proporcionou a geração de cenários passados da história da rede de monitoramento da CETESB, mostrando a sua evolução e sua vulnerabilidade de abrangência no território na qual esta inserida, em uma das regiões com mais pressão pelo uso da água da América Latina.

\section{6 - CENÁRIO DO IAEM PARA O ANO DE 1980}

Em 1980, primeiro ano para qual o IAEM foi calculado, verifica-se que, em função dos resultados sínteses da análise multi-critério, nenhuma 
das unidades foi considerada como tendo monitoramento insuficiente, nem muito abrangente, que são as categorias situadas em extremos opostos do índice.

Das 22 UGRHIS existentes, 10 UGRHIs foram classificadas com o IAEM pouco abrangente, ou vulnerável. Foram elas:

- As UGRHIS 1 e 3 de conservação e

- As UGRHIs 4 e 8 em industrialização

- Todas as UGRHIs industriais $(2,5,6,7$ e 10) e

- A UGRHI 17 (agropecuária).

Mesmo as UGRHIs onde não havia nenhum ponto neste ano, caso das unidades 1, 3 e 17, obtive-se valores do IAEM que as classificavam com o tipo de monitoramento pouco abrangente ou limitado. Tal fato pode ser entendido em função de uma das componentes referente ao potencial de impacto antrópico, neste caso a densidade populacional, que não era muito alta. Ainda dentro desta categoria, a UGRHI 17-Médio Paranapanema teve o pior resultado, pois além de não ter nenhum ponto, estava numa unidade com atribuição vocacional agropecuária, cujo fator individual para o critério uso do solo é ponderado pelo valor 2 . As UGRHIs industriais 05 e 10 foram incluídas nessa categoria devido aos valores das médias para o IQA, classificados como aceitáveis ou regulares (entre 37 e 51). Se considerarmos somente o critério de densidade de pontos da CEE (Comunidade Européia), ou seja, acima de 1 ponto por $1.000 \mathrm{~km}^{2}$, somente as UGRHIs 06 - Alto Tietê e 07 - Baixada Santista seriam consideradas com densidade adequada. Mas, para o novo índice IAEM, atender somente este argumento, não é suficiente para classificálas como adequadas e não vulneráveis.

Em 1980, o Estado de São Paulo já possuía 6 UGRHIS com IAEM considerado como suficiente para a época (UGHRIs 9, 12, 13, 18, 21 e 22) e 6 com 0 IAEM abrangente (UGRHIs 11, UGRHI 14-Alto Paranapanema, 15, UGRHI 16-Tiete/Batalha, 19 e 20). Dentro deste último grupo, a UGRHI 11- Ribeira de Iguape/ Litoral Sul, mesmo com um 
só ponto, obteve o melhor índice para todo o ano de $1980(0,66)$, pois, obteve uma média do IQA considerada boa, apresentou baixa densidade populacional e pertence a uma UGRHI com atribuição vocacional de uso do solo voltado para conservação. Portanto, esteve com menor vulnerabilidade ambiental, ou a ainda com menor probabilidade de impacto por pressão antrópica em sua área de abrangência.

Em resumo, a figura 39 mostra a síntese estadual para a classificação do IAEM 1980: 12 UGRHIS das 22 estavam com índice adequado, ou seja, o monitoramento executado na época tinha competência para medir os recursos hídricos.

\section{Figura 39 - Cenário do IAEM 1980 por UGRHI com médias Por pontos com classificação IQA 1980}

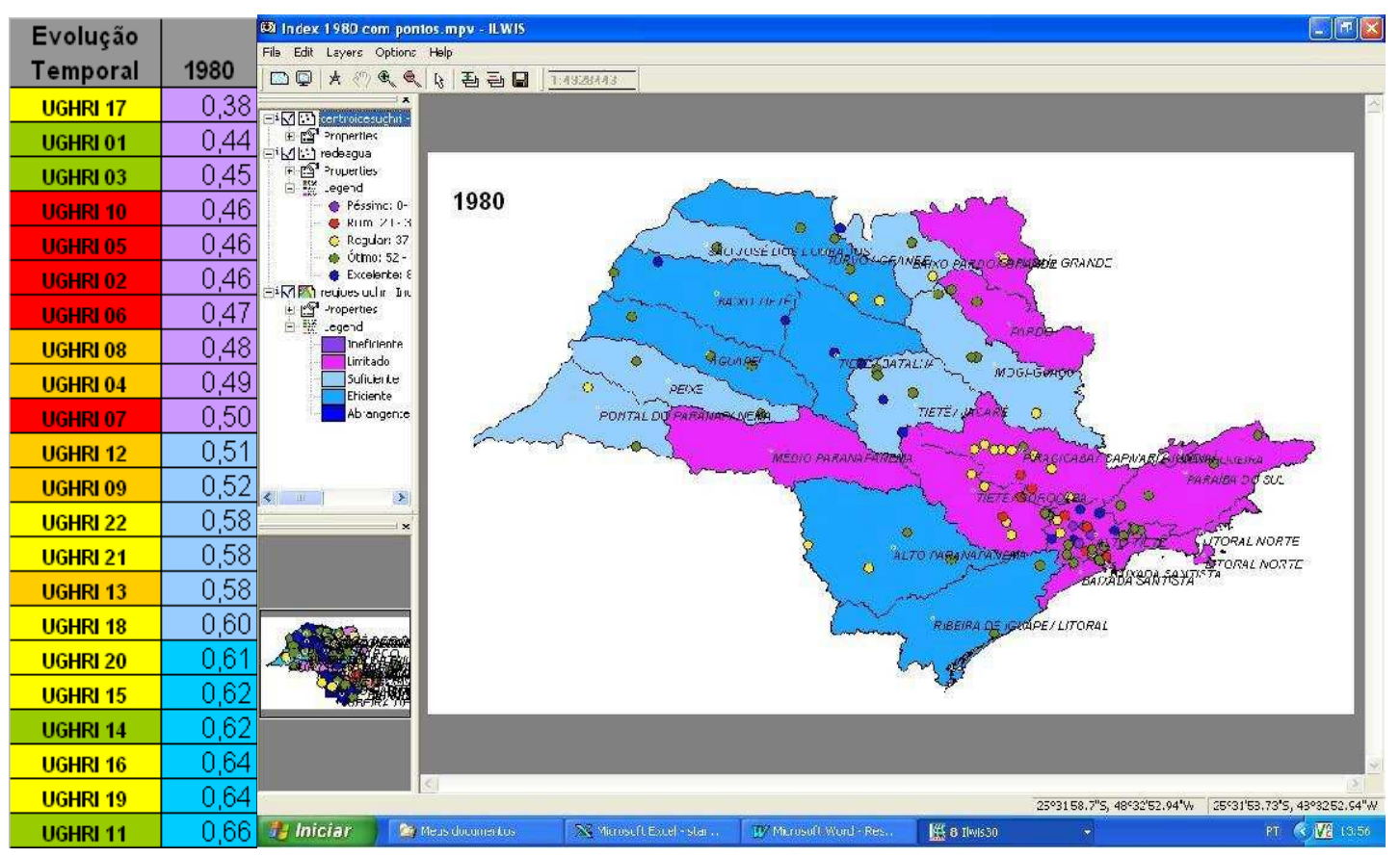

Elaborado: MIDAGLIA,C.L. 2009 -Fonte: SP_WATERNET

\section{7 - CENÁRIO DO IAEM PARA O ANO DE 1991}

Assim como 1980, em 1991, em função dos resultados sínteses da análise multi-critério nenhuma das unidades foi considerada como tendo monitoramento insuficiente nem muito abrangente. 
Neste ano, 9 UGRHIs (01, 02, 03, 04, 05, 06, 07, 08 e 10) foram classificadas como tendo monitoramento pouco abrangente ou vúlneravel. Foram elas:

- As UGRHIs 1 e 3 de conservação, com números muito semelhantes ao ano anteriormente analisado, pois não houve alteração no monitoramento, que permaneceu sem a existência de pontos nestes locais;

- As UGRHIs 04-Pardo e 08-Sapucaí/Grande (em industrialização), conforme já havia acontecido em 1980, devido a baixa densidade de pontos segundo o critério da CEE e por peso da atribuição de uso vocacional do solo que neste caso tem valor de ponderação é 3 .

- E novamente todas as UGRHIs classificadas como industriais $(2,5,6,7$ e 10).

A UGRHI 10-Sorocaba/Médio Tietê foi a que recebeu o pior índice do IAEM para $1991(0,43)$. Isto se deu em função da média do IQA ter ficado entorno de 40 (aceitável), pelo fato da densidade populacional média da UGRHI já ter passado de 100 habitantes por $\mathrm{km}^{2}$, por apresentar um índice de densidade de pontos abaixo do recomendado pela comunidade européia e por último, pelo fato de ter uma atribuição vocacional de uso do solo industrial que neste caso tem valor 4 . Isto demonstra como o conjunto escolhido para compor o índice tem sensibilidade para detectar as alterações na água ou no uso antropico do uso do solo e da água no entorno. Portanto, apresentou monitoramento inadequado, e com nota inferior até mesmo a da UGHRI 6, também classificado na mesma categoria, mas com o IAEM 0,48. A figura 40 resume a situação em 1991. 
Figura 40 - Cenário do IAEM 1991 por UGRHI com médias

Por pontos com classificação IQA 1991.

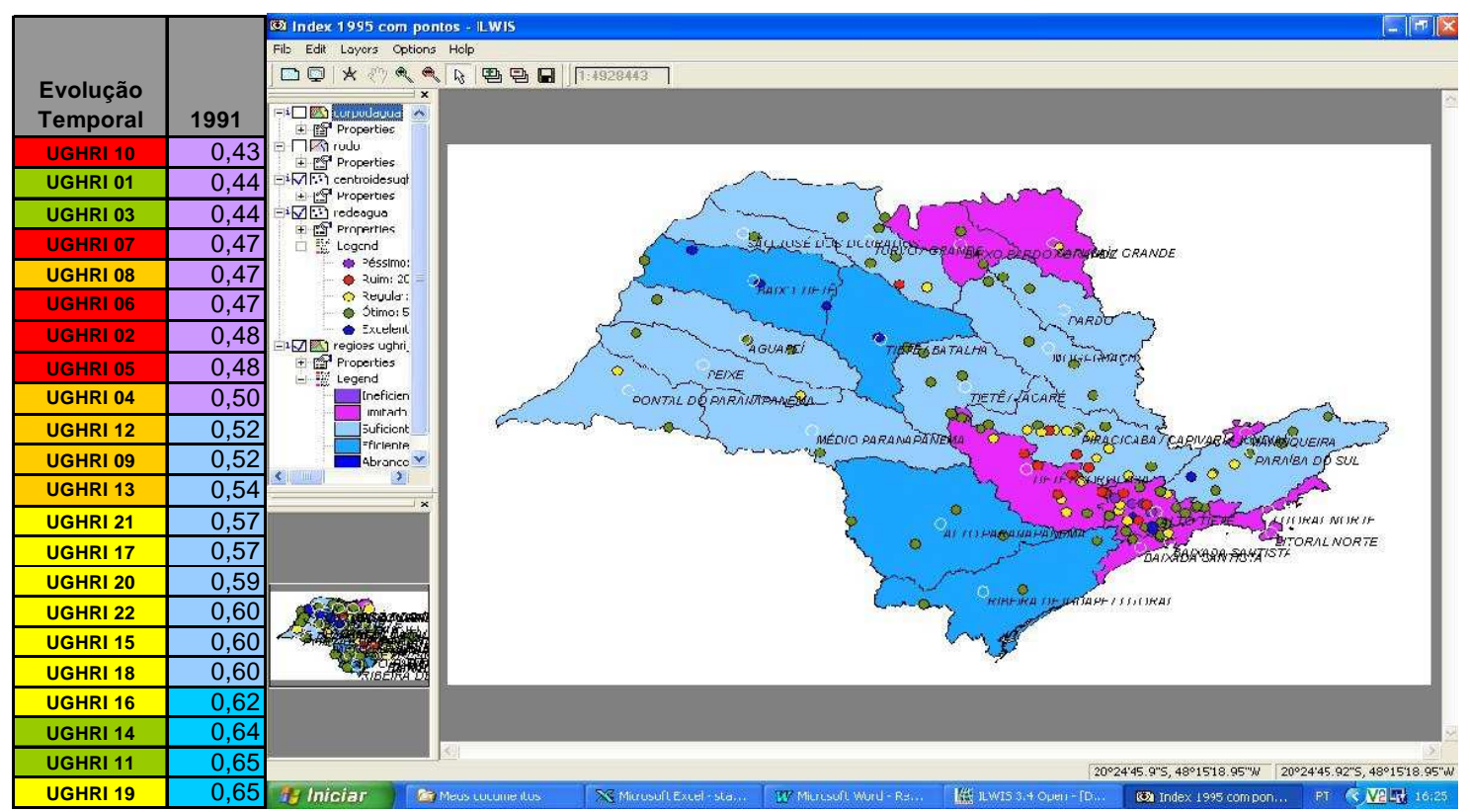

Elaborada por: MIDAGLIA, C. L., 2009. Fonte: SP_WATERNET.

Com relação ao ano anterior analisado (1980), houve neste grupo a subtração da UGRHI 17- Médio Paranapanema, que justamente esteva com o pior índice $(0,38)$. Esta UGRHI deixou a faixa de classificação pouco abrangente, pois recebeu um ponto, cujo índice do IQA foi classificado como de qualidade boa $(61,45)$, e assim, obteve valor do IAEM de 0,57 , passando para a classificação seguinte, que é suficiente. Também foram tidas como suficientes ou não vulneráveis, nesta categoria, em 1991:

- as UGRHIs agropecuárias $15,17,20,21$ e 22 e

- as UGRHIs em industrializações 09, 12 e 13, totalizando então 9 unidades.

Em relação ao ano de 1980, houve diminuição de duas unidades: A UGRHI 15- Turvo-Grande, que mesmo recebendo mais um ponto de monitoramento, teve ligeira queda na média do IQA, além de ter tido aumento da taxa da densidade populacional; e a UGRHI 20- Aguapeí que teve discreto aumento da taxa da densidade populacional, não recebendo 
nenhum ponto novo, e permanecendo com a densidade da CEE muito baixa.

Ainda em 1991, as UGRHIs 11-Ribeira do Iguape, UGRHI 14-Alto Paranapanema, UGRHI 16-Tiete/Batalha, 18- São José dos Dourados e 19-Baixo Tietê permaneceram classificadas com o IAEM com performance de monitoramento abrangente, demonstrando ausência de grandes pressões sobre o recurso hídrico nestas regiões tal qual em 1980.

Novamente, caso fosse considerado somente o critério de densidade-CEE, apenas aquelas duas UGRHIs (06- Alto Tietê e 07Baixada Santista) enquadradas neste critério em 1980, estariam de acordo, mas pelo novo entendimento através do IAEM, 13 delas já se apresentavam monitoramento adequado em função da pressão de uso antrópico existente para este ano, nestas unidades.

\section{8 - CENÁRIOS DO IAEM PARA OS ANOS 1995 E 1996}

Nos anos de 1995 e 1996, conforme os resultados síntese da análise multi-critério, nenhuma das UGRHIs foi considerada como tendo monitoramento insuficiente. Também nenhuma unidade esteve classificação na condição de possuidora de monitoramento muito abrangente. Portanto, até praticamente a metade do período analisado, o IAEM não enquadrou nenhuma UGRHI em suas categorias extremas.

Tanto em 1995, como em 1996, 7 UGRHIs foram classificadas com monitoramento considerado como pouco abrangente ou limitado. São elas:

- As UGRHIs 01-Mantiqueira, e 03-Litoral Norte, ambas com vocação para conservação, que ainda permanecem nesta classe por não possuírem nenhum ponto de monitoramento, e conseqüentemente nenhum valor para o IQA, nem de para a densidade de pontos. Com isto, em razão do aumento da taxa da densidade demográfica, obtiveram o menor índice do IAEM desta categoria $(0,44)$ em ambos os anos. 
- As UGRHIs 8- Sapucaí/Grande e 12-Baixo Pardo/Grande, em industrialização, devido a sua baixa densidade de pontos, inclusive segundo critério CEE, e por causa do peso da atribuição do uso do solo (3), que não varia em função dos anos;

- As UGRHIs industriais 6-Alto-Tiete, 7-Baixada Santista e 10Sorocaba/Médio Tietê que estão com esta classificação, pois obtiveram a média de classificação do IQA entorno de aceitável, alta densidade demográfica e uso do solo considerado como impactante.

Em 1995, 50\% das UGRHIs do Estado apresentaram o IAEM suficiente, são elas:

- as UGRHIs $15,17,18,20,21$ e 22 nas unidades agropecuárias;

- as UGRHIs 4, 9 e 13 (em industrialização);

- e as UGRHIs 2 e 5 nas UGRHIs industriais.

A figura 41 resume o ano de 1995:

Figura 41 - Cenário do IAEM 1995 por UGRHI com médias por pontos com classificação IQA 1995

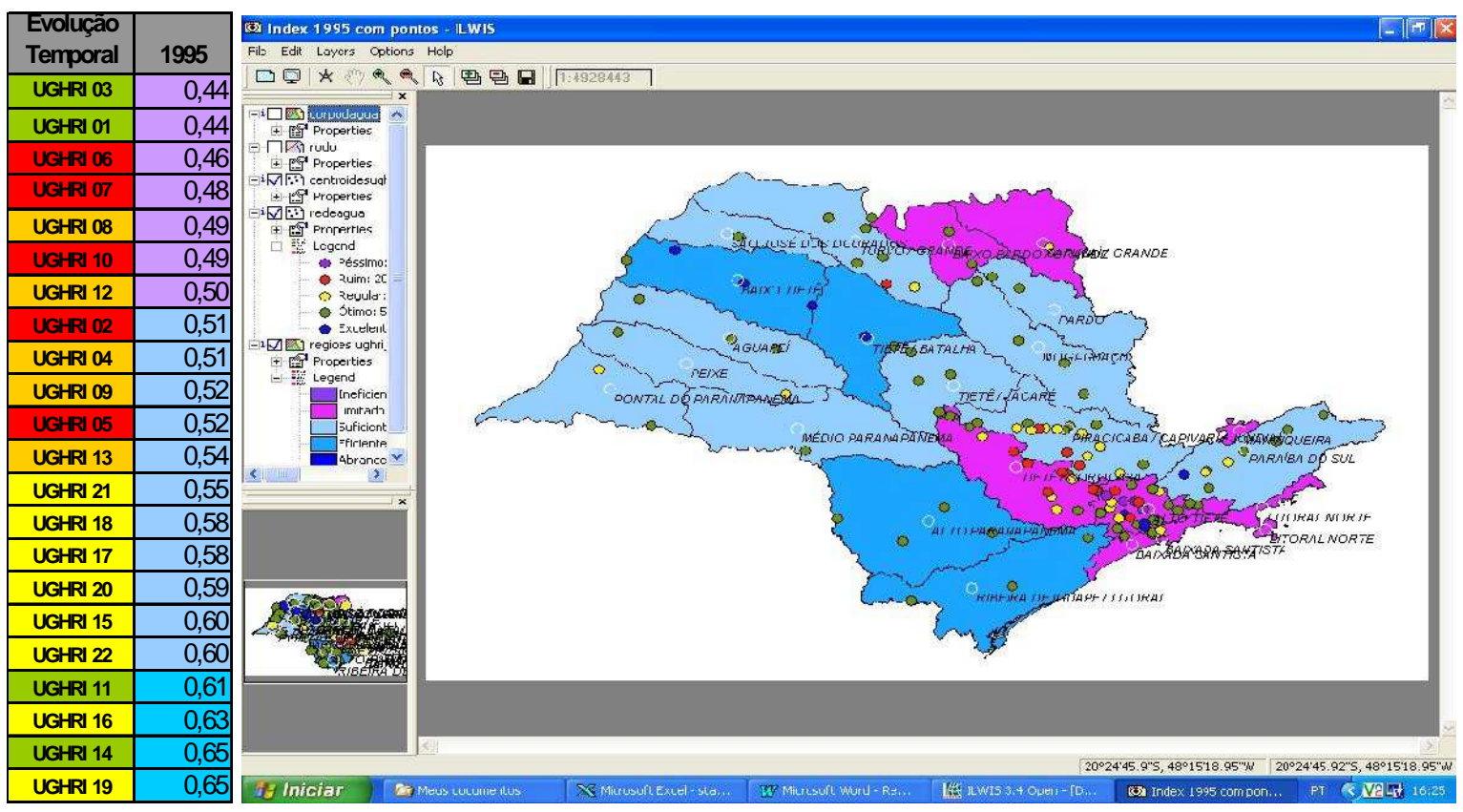

Elaborada por: MIDAGLIA, C. L., 2009. Fonte: SP_WATERNET. 
No ano de 1996, foram classificadas como suficiente 10 UGRHIs. Todas as citadas para o ano de 1995, com exceção da UGRHI 22-Pontal do Paranapanema. A razão foi que a média anual do IQA apresentou sensível melhora, passando de 59,27 (1995) para 75,41 (1996), classificando-se na faixa que demonstra uma boa qualidade da água.

Foram classificadas em 1995 como tendo um IAEM eficiente somente 4 UGRHIs:

- 11-Ribeira do Iguape/Litoral Sul e 14-Alto Paranapanema, (ambas de conservação) e,

- As UGRHIS 16-Tiete /Batalha e 19-Baixo Tietê (agropecuárias)

A figura 42 mostra que o monitoramento esteve adequado na maior parte do estado, com exceção dos casos acima citados.

\section{Figura 42 - Cenário do IAEM 1996 por UGRHI com médias por pontos com classificação IQA-1996}

\begin{tabular}{|c|c|}
\hline $\begin{array}{l}\text { Evolução } \\
\text { Temporal }\end{array}$ & 1996 \\
\hline UGHRI 03 & 0,44 \\
\hline UGHRI 01 & 0,44 \\
\hline UGHRI 06 & 0,47 \\
\hline UGHRI 07 & 0,48 \\
\hline UGHRI 10 & 0,49 \\
\hline UGHRI 08 & 0,49 \\
\hline UGHRI 12 & 0,50 \\
\hline UGHRI 02 & 0,51 \\
\hline UGHRI 09 & 0,52 \\
\hline UGHRI 05 & 0,52 \\
\hline UGHRI 04 & 0,52 \\
\hline UGHRI 13 & 0,55 \\
\hline UGHRI 21 & 0,55 \\
\hline UGHRI 18 & 0,59 \\
\hline UGHRI 17 & 0,59 \\
\hline UGHRI 20 & 0,59 \\
\hline UGHRI 15 & 0,60 \\
\hline UGHRI 16 & 0,63 \\
\hline UGHRI 22 & 0,65 \\
\hline UGHRI 14 & 0,65 \\
\hline UGHRI 19 & 0,65 \\
\hline UGHRI 11 & 0,67 \\
\hline
\end{tabular}

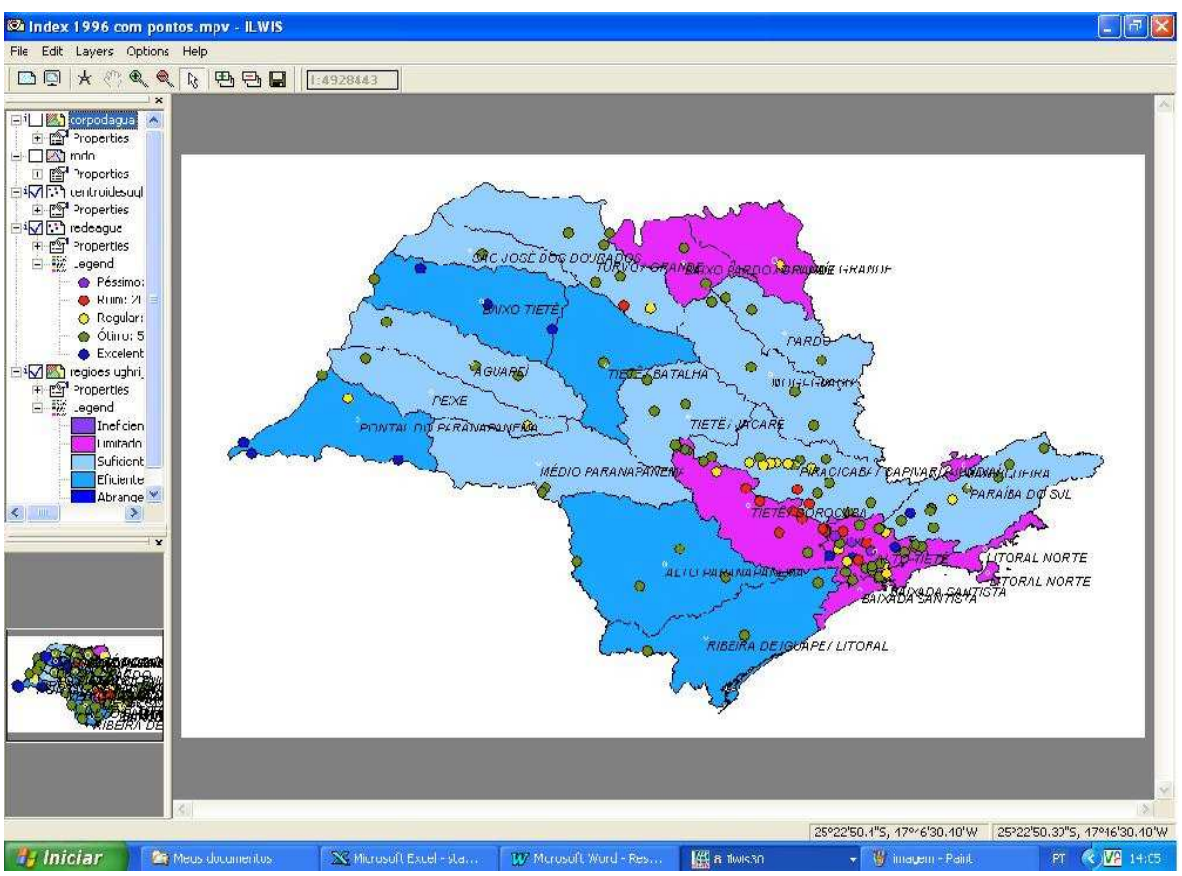

Elaborada por: MIDAGLIA, C. L., 2009. Fonte: SP_WATERNET. 
No ano de 2000 a rede de monitoramento da CETESB possuía 136 pontos. Ainda dentro do período de estudo considerado, novamente nenhuma unidade de gerenciamento de recurso hídrico foi considerada como tendo índice de IAEM insuficiente, nem tampouco como muito abrangente, o que demonstra certa regularidade na evolução da rede em acompanhar o crescimento econômico da região com um monitoramento enquadrado predominantemente classificado como adequado.

Em 2000 O IAEM apresentou-se como pouco abrangente ou limitado em 6 UGRHIs:

- As UGRHIs 1-Mantiqueira e, 3- Litoral Norte (conservação), pelo mesmo motivo citado em anos anteriores e

- A UGRHI 8- Sapucaí/Grande (em industrialização), cujo principal motivo foi o crescimento populacional, apesar de ter duplicado o numero de pontos da rede de monitoramento em relação a 1996.

- As UGRHIs industriais 6-Alto Tietê e a unidade 7- Baixada Santista. Esta última voltou para esta categoria em função do crescimento da densidade populacional, que atingiu respectivamente 524 hab./ $\mathrm{km}^{2}$. Com 3023,47 hab./km², a UGHRI 6 tem densidade populacional muito alta, correspondendo a 3 pessoas por $\mathrm{m} 2$.

- E a UGRHI 21- Peixe (Agropecuária) por ter tido apenas um ponto com IQA calculado, com critério da densidade da CEE muito baixo.

Foram classificadas 12 unidades, como o IAEM suficiente:

- As UGRHIs 11- Ribeira do Iguape/Litoral Sul e 14-Alto Paranapanema, ambas de vocação para conservação e

- As UGRHIs 15, 17, 18, 20 e 22-Pontal do Paranapanema (Agropecuária), 
- As UGRHIs em industrialização 4,9 12 e 13.

- As UGRHIs 2-Paraíba do Sul, 5-Piracicaba/Capivari/Jundiaí e a 10Sorocaba Médio Tiete, de atribuição para uso do solo classificadas como industriais, que ampliaram o número de pontos de amostragem da rede de monitoramento, acompanhando a pressão antrópica.

Ainda no Ano de 2000, 4 UGRHIS apresentaram o índice de monitoramento abrangente:

- As UGRHIs 16-Tiete/Batalha, 19-Baixo Tiete que correspondem ao trecho final do Rio Tiete, depois da barragem de Barra Bonita até a sua foz no Rio Paraná e a UGRHI 22- Pontal do Paranapanema, que apresentou a melhor média do IQA $(81,53)$, com pontos localizados na saída do estado, classificado como ótimo.

Pelo critério exclusivo usado para caracterizar a abrangência da rede anteriormente, que analisava somente o índice da densidade CEE, no ano de 2000, somente 4 das 22 unidades (todas localizadas em UGRHIs industriais) estariam atendendo ao índice CEE. Pelo olhar do índice do IAEM, 18 UGRHIs tem monitoramento classificado como adequado para o cenário deste ano.

Conforme pode ser visualizado na figura 43, deve-se comentar que, juntamente com o ano de 1996, no ano de 2000 o IAEM apresentou a melhor situação de abrangência espacial para a rede de monitoramento frente aos critérios selecionados. Mesmo dentre as 5 UGRHIS industriais, 3 delas, como já foi explicado anteriormente, foram classificadas com monitoramento adequado. A média para o estado de São Paulo como um todo, ficou entorno de 0,55 , o que indica que até aqui a evolução da rede de monitoramento esteve se desenvolvendo bem em função das pressões antropicas existentes na época. 
Figura 43 - Cenário do IAEM 2000 por UGRHI com médias por pontos com classificação IQA-2000.

\begin{tabular}{|c|c|}
\hline $\begin{array}{l}\text { Evoluçä } \\
\text { Temporal }\end{array}$ & 2000 \\
\hline vertfo o1 & 0.44 \\
\hline Brianoz & 0.52 \\
\hline UGHPI 03 & 0.44 \\
\hline UCHIPd 04 & 0.52 \\
\hline 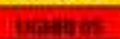 & 0.51 \\
\hline inates os & 0.46 \\
\hline 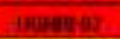 & 0.48 \\
\hline UCHPU 08 & 0.50 \\
\hline UCHFa 09 & 0.58 \\
\hline 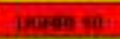 & 0.53 \\
\hline טснеम 11 & 0.68 \\
\hline UGHES 12 & 0.58 \\
\hline UGHES 13 & 0.59 \\
\hline vated 14 & 0.67 \\
\hline VGHPd 15 & 0.60 \\
\hline VGHPS 16 & 0.63 \\
\hline UGHFA 17 & 0.60 \\
\hline UGHPS 18 & 0.59 \\
\hline UCHPS 19 & 0.65 \\
\hline UCHPS 20 & 0.53 \\
\hline UGHPd 21 & 0.50 \\
\hline väps 22 & 0.56 \\
\hline
\end{tabular}

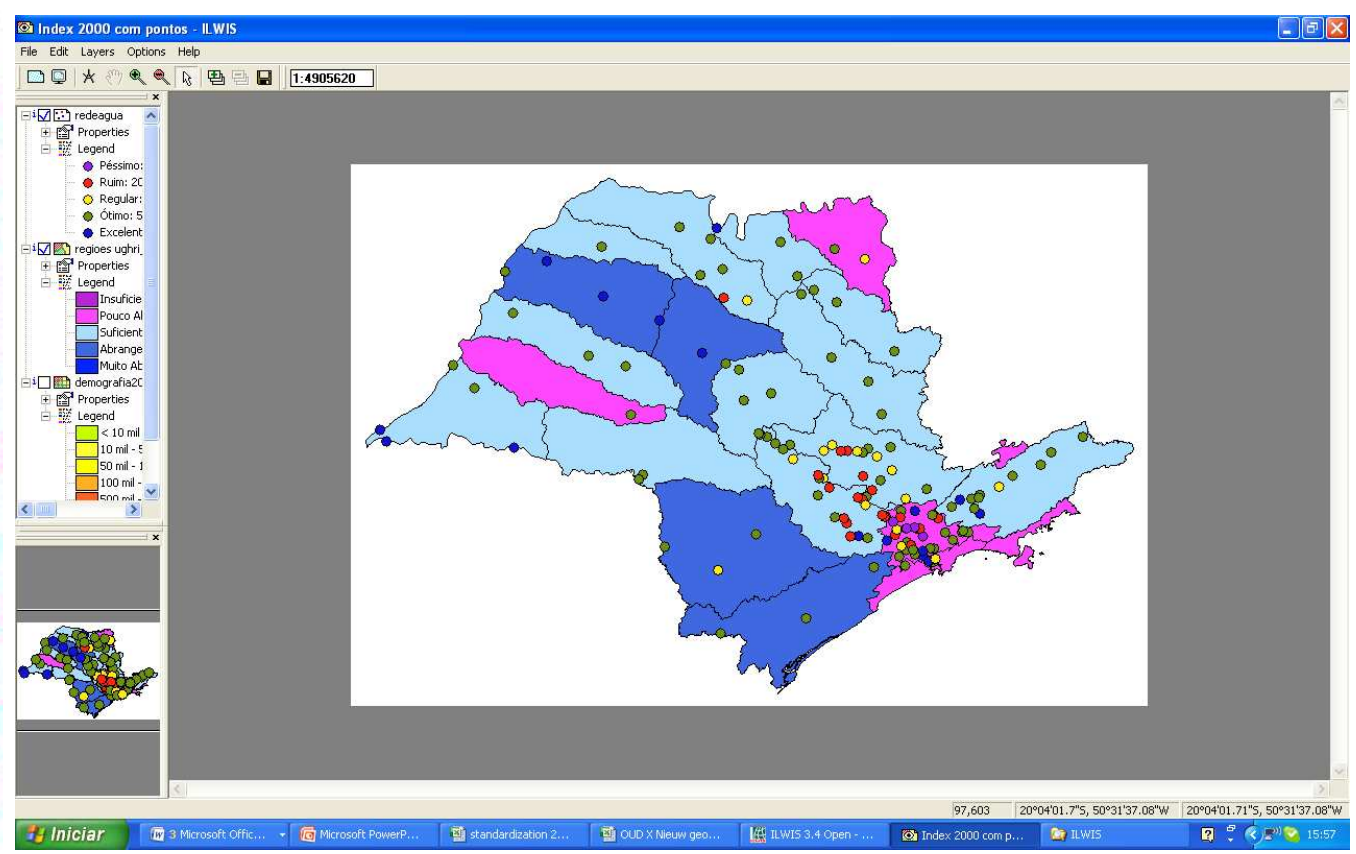

Elaborada por: MIDAGLIA, C. L., 2009. Fonte: SP_WATERNET.

\subsection{0 - CENÁRIO DO IAEM PARA O ANO 2004}

A rede de monitoramento continuava crescendo e neste ano operou com 188 pontos. Este número ainda pode considerado baixo segundo o critério da densidade da CEE, especialmente na porção oeste do estado, que continuava com poucos pontos.

Em 2004, pela primeira vez no estudo, o critério insuficiente foi aplicado para as unidades industriais 5- Piracicaba/Capivari/ Jundiaí e 6Alto Tietê. Mesmo com níveis de densidade espacial-CEE muito acima do recomendável, em ambos os casos, não foi possível acompanhar o ritmo com que as cidades em UGHRIs industriais cresciam e modificam o uso e ocupação do solo, no entorno dos seus rios e reservatórios. Apesar das médias do IQA na UGRHI $5(46,45)$ e UGRHI $6(49,18)$, estarem dentro da classificação de qualidade de água do IQA, classificada como aceitável, 
deve-se lembrar, que este é resultado da soma das médias de pontos que servem a múltiplos propósitos, como por exemplo, locais preservados por serem de captação (usos nobre da água), com pontos em rios de que atendem a interesses diversos. Assim, para o IAEM o monitoramento ficou vulnerável as pressões, sendo inadequado.

Em 2004, a UGRHI 6-Alto Tiete apresentou o maior índice de densidade do critério da $\mathrm{CEE}$, entorno de 7 pontos por $\mathrm{Km}^{2}$, mas em contra partida também apresentou altíssima densidade demográfica, cerca de 3.150 habitantes por $\mathrm{m}^{2}$, concentrados no entorno da cidade São Paulo. Os reflexos da concentração da urbanização e o fato de estar situada dentro de regiões de grande crescimento econômico, fez com que os rios monitorados, continuassem sofrendo alteração em sua qualidade hídrica, devido principalmente, a pressão antrópica ocasionada por falta de tratamento de esgotos, cenário este que pode ser detectado pelo IAEM.

Com este resultado, fica claro que a região está susceptível a forte pressão ambiental, e para se verificar os trechos mais impactados dos recursos hídricos, deve-se recorrer ao mapa de análise espacial de pontos, que mostra com detalhes a situação interna da UGRHI. Pode-se verificar genericamente onde ficam estes trechos, conforme classificação pelo IQA, que foram sobrepostos ao IAEM, com a finalidade de facilitar a visualização de possíveis áreas impactadas nos principais rios destas unidades, caso do rio Piracicaba e Rio Tietê. Com isto ressalta-se que a rede de monitoramento não deve ser avaliada apenas pela densidade do critério CEE. Nesta situação, seria desejável uma maior intervenção para correção dos problemas que estão afetando a qualidade da água, pois a quantidade de pontos existente não indica que exista propriamente falta de monitoramento, mas sim falta de controle.

Foram classificadas com o IAEM pouco abrangente ou limitado 10 UGRHIs: 
- As UGRHIs 4-Pardo, 8-Sapucaí/Grande, 12-Baixo Pardo/Grande e 13Tiete/Jacaré (em industrialização), cujo principal motivo foi o crescimento populacional, desacompanhado do aumento da rede. As médias do IQA estavam todas classificadas como boas.

- As UGRHIs industriais 2-Paraíba do Sul, 7- Baixada Santista e 10Sorocaba/Médio Tiete, em função do crescimento da densidade populacional

- E a UGRHI 15-Turvo/Grande, por ter média a do IQA classificada como aceitável (45,77), 20-Aguapeí e 21- Peixe (Agropecuária) por ter tido o critério da densidade da CEE muito baixo, indicando que estas áreas precisam ter mais pontos dentro do contexto.

Com O IAEM suficiente foram classificadas 7 unidades de gerenciamento:

- As UGRHIs 1- Mantiqueira e 11- Ribeira do Iguape/Litoral Sul, ambas de vocação para conservação; e

- A UGRHI 9 em industrialização, em função do grande aumento de pontos de amostragem de 4 para 33, permaneceu nesta categoria.

Em 2004, segundo o IAEM somente três UGRHIS apresentaram a denominação abrangente:

- As UGRHIs 3-Litoral Norte, que recebeu 7 novos pontos de monitoramento e a UGRHI 14-Alto Paranapanema (ambas de vocação para conservação) que apesar de ter baixa densidade de pontos pelo critério -CEE apresenta também baixa densidade demográfica, com 34,60 habitantes por $\mathrm{km}^{2}$.

- A UGRHI 19-Baixo-Tiete (agropecuária) que obteve ótima media para o IQA, 80,51. Esta unidade possuía somente 4 pontos, que quando analisados somente pelo índice da densidade espacial-CEE, estaria apresentando um grande déficit de pontos, pois deveria ter deveria ter no 
mínimo 15 pontos. O IAEM não justifica a falta de pontos e considera que a densidade espacial pode ser uma referencia em termos de distribuição de pontos, mas dentro dos cenários existentes deve-se considerar as necessidades individualmente, especialmente quando há limitação para inclusão de novos pontos, quer seja em termos de distancia, acesso, disponibilidade de análise em laboratório, coleta ou custos.

Em síntese, em 2004, o IAEM detectou uma inversão da predominância do tipo de monitoramento de adequado para inadequado, uma que mais da metade das UGRHIs estava com monitoramento classificado como inadequado,ou vulnerável a pressão antrópica (2 foram insuficientes e 10 pouco abrangente) e, constata-se que algo precisa mudar na abrangência rede. Na figura 44 esta o cenário para este ano.

Figura 44 - Cenário do IAEM 2004 por UGRHI com médias por pontos com classificação IQA-2004.

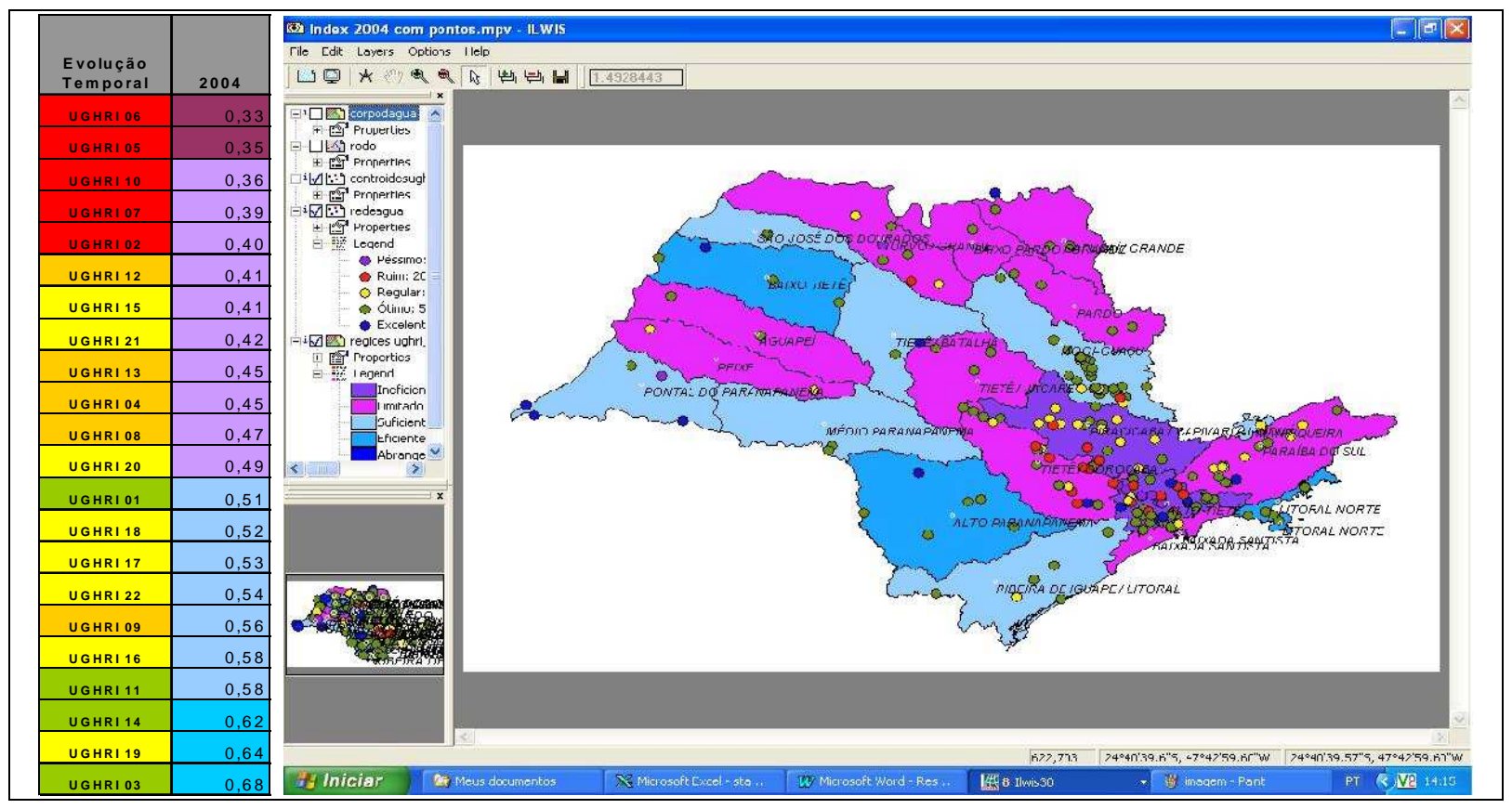

Elaborada por: MIDAGLIA, C. L., 2009. Fonte: SP_WATERNET. 


\subsection{1 - CENÁRIO DO IAEM PARA OS ANOS 2008}

Considerando os 289 pontos para qual foi possível fazer o cálculo do índice do IQA, a rede de monitoramento estadual da CETESB, superou em termos estaduais, o critério de densidade recomendado pela CEE. Apesar de continuar havendo desigualdade espacial. A forte concentração da rede na parte leste do estado, de dá justamente onde habita cerca de 2/3 da população do Estado de São Paulo. As UGRHIs agropecuárias, situadas na parte oeste do Estado, continuam mesmo em 2008, bem abaixo deste critério como já foi visto anteriormente.

Tal como no ano de 2004, a classe do IAEM insuficiente, foi novamente obtida, sendo que desta vez para as unidades industriais 6 Alto Tietê e 7- Baixada Santista. A unidade 5- Piracicaba/ Capivari/ Jundiaí, também industrial, que esteve assim classificada em 2004, retornou à classificação pouco abrangente ou limitada, pois aumentou o número de pontos que geram o IQA. Com os mesmos problemas citados anteriormente, a UGRHI 6 - Alto Tietê obteve em 2008 a pior somatória $(0,31)$ em todo o período de estudo e está portanto, classificada também como vulnerável.

O cenário indica que a rede de monitoramento estava apresentando sintomas contínuos de falta de eficiência diante do quadro de pressão ambiental existente. É importante ressaltar que, somente o monitoramento, não consegue dar conta dos inúmeros problemas que afetam os recursos hídricos nesta região, mesmo tendo uma grande quantidade de pontos. É preciso intervir e corrigir os problemas já detectados. Pode-se fazer uma análise pontual das médias do IQA, para identificar e comparar anos anteriormente monitorados. Como já explicado, a área da RMSP agrega grande diversidade de uso do solo, com reflexos na qualidade dos pontos. Apesar de ter nesta área uma rede volumosa há bastante tempo, o Estado ainda não conseguiu mobilizar 
esforços para solucionar os inúmeros problemas de poluição que afetam os recursos hídricos da região metropolitana. Os rios estão muito antropizados e poluídos, desprovidos de diversidade de vida aquática.

A UGRHI 7 - Baixada Santista, que em todos os anos anteriores analisados esteve classificada com IAEM pouco abrangente, ficou pela primeira vez durante o período estudado, com o IAEM insuficiente. Verifica-se que a média do IQA caiu 10 pontos em relação ao ano de 2004, passando de 62 para 52. Embora, neste período, tenha havido a inclusão de novos pontos de monitoramento, duplicando o número de pontos e a abrangência espacial da UGRHI, O IAEM diminui, provavelmente, por causa de estes pontos terem sido colocados em áreas sensíveis para detectar trechos mais impactados pela poluição.

O número de UGRHIs com O IAEM pouco abrangente para 0 cenário do ano de 2008 diminuiu de 10 para 8 em relação ao ano 2004 . Foram classificadas com o IAEM pouco abrangente:

- As UGRHI industriais 2- Paraíba do Sul, 5-Piracicaba, e 10Sorocaba/Médio Tietê devido ao fato de terem alta densidade demográfica, uso do solo ponderado pelo fator 4., apesar da média do IQA estar classificado como ótima, precisariam termais pontos.

- As UGRHIs 4-Pardo, 8-Sapucaí/Pardo, 12-Baixo Pardo/Grande e 13Tiete/Jacaré (em industrialização) que estão assim classificadas pelo fato de continuarem a ter uma rede de monitoramento pequena frente às necessidade que se apresentam. Neste caso é preciso que as UGRHIs 4 e 12 e 13 atinjam pelo menos a densidade recomendada pela CEE.

A figura 45 apresenta o resumo da situação: 


\section{Figura 45 - Cenário do IAEM 2008 por UGRHI com médias por pontos com classificação IQA-2008.}

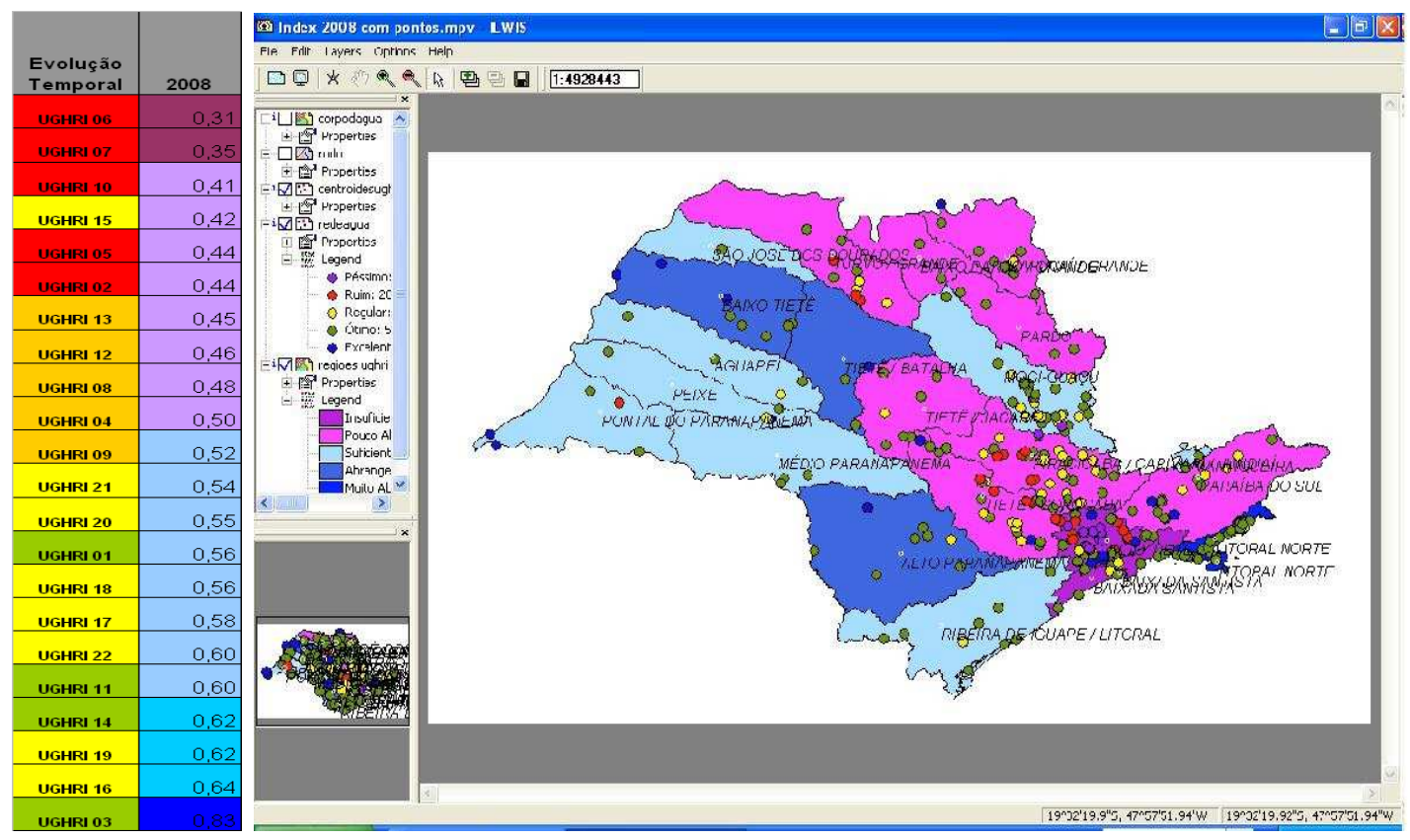

Fonte: SP_WATERNET.

Em 2008, 8 UGRHIs ficaram enquadradas com o IAEM Suficiente:

- As unidades de conservação 1-Mantiqueira e 11- Ribeira do Iguape/Lit. Sul, cujas médias de IQA estavam boas, conforme motivos já citados anteriormente;

- A UGRHI 9- Mogi-Guaçu (em industrialização), que apesar de ter média do IQA regular $(51,62)$, e possuir em contrapartida, uma cobertura de rede que atende os critérios da $\mathrm{CEE}$, mas, que está muito concentrada no médio Mogi-Guaçu, entorno das cidades de Araras e Mogi-Mirim, trecho em que está submetido às pressões urbanas e industriais.

- As UGRHI 16-Tiete Batalha, 17-Médio Paranapanema, 18-São José dos Dourados, 19-Baixo Tiete, 20-Aguapeí, 21-Peixe e 22-Pontal do Paranapanema do grupo das agropecuárias apresentaram em relação ao ano anterior um aumento de uma unidade, pois a UGHRI 21 voltou a esta categoria. 
Em 2008 o IAEM avaliou como tendo monitoramento abrangente somente três unidades:

- A UGRHI 14-Alto Paranapanema (atribuição de conservação) com baixa densidade populacional, e boa média de IQA, em torno de 63 .

- As UGRHIs 16-Tiete /Batalha e 19-Baixo Tietê (agropecuárias), que correspondem ao trecho do Rio Tietê localizado longe da área de influência das contribuições metropolitanas de São Paulo e de Campinas, que apresentaram boas médias de IQA, apesar de que na UGRHI 16Tiete/Batalha existem problemas de eutrofização na represa de Promissão. A UGRHI 19, que possui menos de 1 milhão de habitantes (IBGE, 2008), é servida por um bom percentual de coleta de tratamento de esgoto (CETESB, 2008) capaz de atender a população residente.

Pela primeira vez em todo histórico analisado, a UGRHI 3-Litoral Norte atingiu a classificação do IAEM Muito abrangente, cujo valor ficou em 0,83, em virtude do aumento do número de pontos, de 7 para 30, colocados nos trechos finais do rios que drenam para o mar. Nas cabeceiras, estes rios estão protegidos pelas escarpas da Serra do Mar, local teoricamente livre de influência antrópica. Como são rios exorréicos, cuja área de drenagem é pequena, não podem ter seus pontos distribuídos ao longo do seu curso, e assim precisa ter pontos espalhados ao longo da costa. Com isto, utilizando o critério CEE, a densidade do monitoramento tornou-se elevada, com 15 pontos por $1.000 \mathrm{~km}^{2}$, ou seja, a maior densidade de todo o período estudado. Além disto, estes rios têm em média bons resultados para as médias do IQA, sendo sujeitos apenas às influências sazonais das épocas de temporada, cujo reflexo de uma eventual má qualidade das águas poderia ser inferido pela condição de balneabilidade das praias. No entanto, a presença de muitos pontos também pode se vista como um sistema de monitoramento de ocupação 
indevido de áreas da encostas da Serra do Mar, sinalizando que a área esta em processo de urbanização, caso o IQA destes rios caia.

Em termos gerais, para o ano de 2008, a análise do IAEM indica 12 unidades com monitoramento adequado. Tal fato comprova que o índice foi capaz de representar a evolução da rede (Tabela 23), teve sensibilidade para retratar oscilações de entrada e saída de pontos, variações das médias do IQA e o aumento da densidade populacional. Mas para que ganhe maior credibilidade estuda-se a possibilidade de inclusão do IET para compor o cálculo do novo índice.

Tabela 23 - Evolução do IAEM por classes no período de estudo.

\begin{tabular}{|r|r|r|r|r|r|r|}
\hline $\mathbf{1 9 8 0}$ & $\mathbf{1 9 9 1}$ & $\mathbf{1 9 9 5}$ & $\mathbf{1 9 9 6}$ & $\mathbf{2 0 0 0}$ & $\mathbf{2 0 0 4}$ & $\mathbf{2 0 0 8}$ \\
\hline 0,38 & 0,43 & 0,44 & 0,44 & 0,44 & 0,33 & 0,31 \\
\hline 0,44 & 0,44 & 0,44 & 0,44 & 0,44 & 0,35 & 0,35 \\
\hline 0,45 & 0,44 & 0,46 & 0,47 & 0,46 & 0,36 & 0,41 \\
\hline 0,46 & 0,47 & 0,48 & 0,48 & 0,48 & 0,39 & 0,42 \\
\hline 0,46 & 0,47 & 0,49 & 0,49 & 0,50 & 0,40 & 0,44 \\
\hline 0,46 & 0,47 & 0,49 & 0,49 & 0,50 & 0,41 & 0,44 \\
\hline 0,47 & 0,48 & 0,50 & 0,50 & 0,51 & 0,41 & 0,45 \\
\hline 0,48 & 0,48 & 0,51 & 0,51 & 0,51 & 0,42 & 0,46 \\
\hline 0,49 & 0,50 & 0,51 & 0,52 & 0,52 & 0,45 & 0,48 \\
\hline 0,50 & 0,52 & 0,52 & 0,52 & 0,53 & 0,45 & 0,50 \\
\hline 0,51 & 0,52 & 0,52 & 0,52 & 0,53 & 0,47 & 0,52 \\
\hline 0,52 & 0,54 & 0,54 & 0,55 & 0,56 & 0,49 & 0,54 \\
\hline 0,58 & 0,57 & 0,55 & 0,55 & 0,58 & 0,51 & 0,55 \\
\hline 0,58 & 0,57 & 0,58 & 0,59 & 0,58 & 0,52 & 0,56 \\
\hline 0,58 & 0,59 & 0,58 & 0,59 & 0,59 & 0,53 & 0,56 \\
\hline 0,60 & 0,60 & 0,59 & 0,59 & 0,59 & 0,54 & 0,58 \\
\hline 0,61 & 0,60 & 0,60 & 0,60 & 0,60 & 0,56 & 0,60 \\
\hline 0,62 & 0,60 & 0,60 & 0,63 & 0,60 & 0,58 & 0,60 \\
\hline 0,62 & 0,62 & 0,61 & 0,65 & 0,63 & 0,58 & 0,62 \\
\hline 0,64 & 0,64 & 0,63 & 0,65 & 0,65 & 0,62 & 0,62 \\
\hline 0,64 & 0,65 & 0,65 & 0,65 & 0,67 & 0,64 & 0,64 \\
\hline 0,66 & 0,65 & 0,65 & 0,67 & 0,68 & 0,68 & 0,83 \\
\hline $\mathbf{1 1 , 7 7 6}$ & $\mathbf{1 1 , 8 6 8}$ & $\mathbf{1 1 , 9 2 4}$ & $\mathbf{1 2 , 1 2 5}$ & $\mathbf{1 2 , 1 4 8}$ & $\mathbf{1 0 , 6 8 8}$ & $\mathbf{1 1 , 4 8 9}$ \\
\hline
\end{tabular}


Durante os 30 anos estudados, verificaram-se as seguintes particulariedades, em UGRHIs que mantiveram um comportamento estável em relação ao índice IAEM (figura 46). São elas:

- A UGHRI 6-Alto Tiête, que sempre teve o maior número de pontos, nunca teve um índice do IAEM considerado adequado frente às pressões antrópicas.

- A UGRHI 8- Sapucaí/ Grande, que somente em 2007 atingiu o critério da densidade CEE sempre apresentou o IAEM entorno de 0,48, a 0,50 e foi assim classificada como pouco abrangente.

- UGRHI 9- Mogi-Guaçu, manteve-se entorno de 0,52, sempre foi classificada como suficiente, pois conseguiu neutralizar o avanço populacional com a inclusão de novos pontos.

- A UGRHI 14- Alto Paranapanema manteve-se classificada com IAEM abrangente, devido a baixa densidade populacional e boas médias do IQA. - A UGRHI 18- São José dos Dourados, que é monitorada com um único ponto há 30 anos, manteve-se na categoria como suficiente, mas poderia ter mais pontos, pois durante este período, o IQA de seu único ponto caiu 10 pontos. Como a densidade populacional desta unidade não cresceu muito, a queda foi compensada dentro da matriz de análise. E por fim, - A UGRHI 19- Baixo Tietê, que também sempre foi classificada como abrangente, significando que foi preservada dos impactos antrópicos ao longo dos anos. 
Figura 46 - Somatória Geral do IAEM para o Estado de São Paulo.

\begin{tabular}{|c|c|c|c|c|c|c|c|}
\hline Evolução & & & & & & & \\
Temporal & $\mathbf{1 9 8 0}$ & $\mathbf{1 9 9 1}$ & $\mathbf{1 9 9 5}$ & $\mathbf{1 9 9 6}$ & $\mathbf{2 0 0 0}$ & $\mathbf{2 0 0 4}$ & $\mathbf{2 0 0 8}$ \\
\hline UGHRI 01 & 0,44 & 0,44 & 0,44 & 0,44 & 0,44 & 0,51 & 0,56 \\
\hline UGHRI 02 & 0,46 & 0,48 & 0,51 & 0,51 & 0,52 & 0,40 & 0,44 \\
\hline UGHRI 03 & 0,45 & 0,44 & 0,44 & 0,44 & 0,44 & 0,68 & 0,83 \\
\hline UGHRI 04 & 0,49 & 0,50 & 0,51 & 0,52 & 0,52 & 0,45 & 0,50 \\
\hline UGHRI 05 & 0,46 & 0,48 & 0,52 & 0,52 & 0,51 & 0,35 & 0,44 \\
\hline UGHRI 06 & 0,47 & 0,47 & 0,46 & 0,47 & 0,46 & 0,33 & 0,31 \\
\hline UGHRI 07 & 0,50 & 0,47 & 0,48 & 0,48 & 0,48 & 0,39 & 0,35 \\
\hline UGHRI 08 & 0,48 & 0,47 & 0,49 & 0,49 & 0,50 & 0,47 & 0,48 \\
\hline UGHRI 09 & 0,52 & 0,52 & 0,52 & 0,52 & 0,58 & 0,56 & 0,52 \\
\hline UGHRI 10 & 0,46 & 0,43 & 0,49 & 0,49 & 0,53 & 0,36 & 0,41 \\
\hline UGHRI 11 & 0,66 & 0,65 & 0,61 & 0,67 & 0,68 & 0,58 & 0,60 \\
\hline UGHRI 12 & 0,51 & 0,52 & 0,50 & 0,50 & 0,58 & 0,41 & 0,46 \\
\hline UGHRI 13 & 0,58 & 0,54 & 0,54 & 0,55 & 0,59 & 0,45 & 0,45 \\
\hline UGHRI 14 & 0,62 & 0,64 & 0,65 & 0,65 & 0,67 & 0,62 & 0,62 \\
\hline UGHRI 15 & 0,62 & 0,60 & 0,60 & 0,60 & 0,60 & 0,41 & 0,42 \\
\hline UGHRI 16 & 0,64 & 0,62 & 0,63 & 0,63 & 0,63 & 0,58 & 0,64 \\
\hline UGHRI 17 & 0,38 & 0,57 & 0,58 & 0,59 & 0,60 & 0,53 & 0,58 \\
\hline UGHRI 18 & 0,60 & 0,60 & 0,58 & 0,59 & 0,59 & 0,52 & 0,56 \\
\hline UGHRI 19 & 0,64 & 0,65 & 0,65 & 0,65 & 0,65 & 0,64 & 0,62 \\
\hline UGHRI 20 & 0,61 & 0,59 & 0,59 & 0,59 & 0,53 & 0,49 & 0,55 \\
\hline UGHRI 21 & 0,58 & 0,57 & 0,55 & 0,55 & 0,50 & 0,42 & 0,54 \\
\hline UGHRI 22 & 0,58 & 0,60 & 0,60 & 0,65 & 0,56 & 0,54 & 0,60 \\
\hline Somatória & $\mathbf{1 1 , 7 8}$ & $\mathbf{1 1 , 8 7}$ & $\mathbf{1 1 , 9 2}$ & $\mathbf{1 2 , 1 2}$ & $\mathbf{1 2 , 1 5}$ & $\mathbf{1 0 , 6 9}$ & $\mathbf{1 1 , 4 9}$ \\
\hline
\end{tabular}

\section{- Considerações da aplicabilidade do Índice IAEM}

A utilização de alguns recursos das Geotecnologias combinado com a análise espacial constituem-se atualmente em instrumentos valiosos na avaliação de cenários, pois facilitam a visualização geográfica desta espacialização na ótica do gerenciador ou do tomador de decisão de recursos hídricos de forma integrada. Os efeitos da urbanização e da ocupação do solo sobre a qualidade das águas superficial foi comprovado.

Deve-se ressaltar que a proposição de novos indicadores não dispensa as observações de campo, a consulta aos usuários e demais interessados, e a discussão entorno dos resultados obtidos por um grupo 
maior de pessoas. Além disto, procedimentos complementares tais como reavaliações técnicas e relatos sobre episódios que indiquem que existam problemas pontuais de poluição, tal como a mortandade de peixes, eutrofização são igualmente valiosos.

O Índice de Abrangência Espacial do Monitoramento- IAEM resgata e valoriza a importância da variável espacial com capacidade de relacioná-lo com estudos de impacto ambiental. Como possui escala flexível por estar baseado na relação de áreas, permite comparar desde pequenas bacias ou regiões de gerenciamento hídrico como foi feito aqui, e pode ser também expandido para outros níveis de organização, tais como municípios que tenham planos diretores, zoneamento e mapeamento de uso do solo e até estados e países.

Os mapas sobre a evolução deste índice no estado de São Paulo constarão do anexo 4.

Ou seja, resumindo-se:

- A história do monitoramento das águas superficiais no Estado de São Paulo foi repassada através destas 5 classes derivadas do índice resultante da matriz de combinação pareada entre fatores sociais e ambientais.

- O índice pode analisar dimensões territoriais diferentes e indicadores ambientais, classificando as UGRHIs em termos de vulnerabilidade de monitoramento no que diz respeito a sua espacialização, pois mostrou as desigualdades na abrangência da rede de monitoramento.

- Pode proporcionar ao gestor de recurso hídrico uma visão sintetizada das influencias dos efeitos da urbanização desprovida de infra-estrutura ambiental, com a identificação e a localização espacial das áreas que abrigam os segmentos populacionais mais vulneráveis, facilitando a definição de prioritárias no direcionamento de políticas públicas.

A análise dessas variáveis que compõem o IAEM provocou a uma nova leitura sobre a importância de delinear uma nova rede de amostragem de águas superficial mais dinâmica face as constantes mudanças, e lembra a 
importância de estar em permanente adaptação sem perder necessariamente referencias históricas (pontos antigos).

$O$ indicador proposto e sua especificidade corresponderam às expectativas de refletir alterações estritamente ligadas às mudanças relacionadas à dimensão sócio-ambiental através dos critérios elegidos. E como possíveis providencias para aumentar a sua nota geral, podemos esperar ações nos seguintes campos:

- Criar novas redes de monitoramento para fins de controle de efluentes domésticos, a jusante das cidades dos lançamentos de tratamentos não estejam em conformidade com lei;

- Exercer a atividade de controle nos locais já identificados como críticos;

- Aumenta a porcentagem de coleta, de tratamento e a eficiência de tratamento de esgotos;

- Preservar as margens e as áreas de várzea e promover a recomposição de matas ciliares;

- Utilizar o solo com manejo adequado e reduzir o uso de fertilizantes agrícolas;

- Elaborar propostas para o crescimento sustentável das cidades, que deveriam ter limites de crescimento. 


\section{CONCLUSÕES}

Em relação à HIPÓTESE PRINCIPAL:

Após concluir este estudo, verificou-se que a rede de monitoramento de águas interiores da CETESB, agora com mais de 30 anos de existência, acompanhou de modo adequado a maior parte do período avaliado, mas teve seu desempenho enfraquecido nos últimos 5 anos devido à grande pressão antrópica sobre os recursos hídricos, causada principalmente pelo adensamento populacional, pelo múltiplo uso do recurso água e pelas atividades econômicas existentes na região de maior desenvolvimento econômico do pais. Estes motivos resultaram na perda do status da qualidade das águas, principalmente nas UGRHIs de vocação industrial, cujo desempenho da rede, quando avaliado pelo IAEM mostrou-se insuficiente/inadequado e vulnerável a pressão urbana, principalmente na UGRHI 6-Alto Tietê. Portanto existe sim correlação entre os dois fatos e baseado nisto, atendendo a HIPÓTESE SUBJACENTE, um novo índice foi criado, apresentado, analisado e mapeado.

O conhecimento deste panorama é um fator chave de interpretação no processo de gerenciamento e governança da água, termo que se refere a vários tipos de manifestação de relacionamento entre alianças e parceiros, ou ainda de submissão e obediência. $O$ número de negociadores e mercadores de água e sua importância no cenário mundial definem a relevância do assunto, especialmente, quando este bem esta a um passo de se tornar uma commodity, e ter seu valor econômico definido no mercado internacional. O discurso de falta de água para consumo humano e produção de alimentos é cada vez mais entoado pela Organização das Nações Unidas, e com isto o futuro da gestão da água poderá ser discutido em termos de soberania. Isto para um país como o Brasil, com grande patrimônio hídrico pode-ser politicamente muito discutível a nível transnacional, pois, suas maiores bacias são a Amazônia, que esta em situação de jusante, e a Bacia do Rio Paraná em 
posição de montante. Além disto, conta com a reserva subterrânea, que não é avaliada neste estudo.

O termo Governança da água e o discurso de que a água não conhece fronteiras requer que estejamos cada vez mais atualizados e preparados para poder dar respostas consistentes e eficientes sobre nossa própria competência em gerenciar a riqueza brasileira.

MELHORAR A QUALIDADE DOS RIOS É MELHORAR A QUALIDADE DO AMBIENTE QUE ENVOLVE TODOS OS SERES VIVOS PARA GARANTIR UM FUTURO ADEQUADO PARA OS QUE ESTAO PARA CHEGAR!

CLEAN WATER IS A RIGHT!!! LIFE IS 100\% WATER, SO USE IT AND CONSERVE IT RIGHTEOUSLY!!! CLEAN UP THE RIVERS! 


\section{REFERÊNCIAS BIBLIOGRÁFICAS}

BRANCO, S. M. Hidrobiologia aplicada a Engenharia Sanitária. São Paulo: CETESB, Companhia de Tecnologia de Saneamento Ambiental, 1978. $620 \mathrm{p}$.

. Hidrobiologia aplicada a Engenharia Sanitária. São Paulo: ABES, 1986. 640 p.

BRASIL. Ministério do Meio Ambiente. ANA - Agência Nacional de Águas. Panorama da Qualidade das Águas Superficiais no Brasil. Cadernos de Recursos Hídricos. Brasília, 2005. Disponível em: <http://www.ana. gov.br/sprtew/1/1-ANA.swf>.

. Ministério do Meio Ambiente. CNRH - Conselho Nacional de Recursos Hídricos. Resolução no 22, de 24 de maio de 2002. Brasília, maio de 2002. Disponível em:

$<$ http://www.cnrh.gov.br/sitio/index.php?option=com_content\&view=arti cle\&id=14>. Acesso em: 11 de maio de 2010.

- Ministério do Meio Ambiente. Conselho Nacional do Meio Ambiente - CONAMA. Resolução no 357, de 17 de março de 2005. Brasília, março de 2005. Disponível em: <http://www.mma.gov.br/port/conama/legiabre.cfm?codlegi=459>.

- Ministério do Planejamento, Orçamento e Gestão. Instituto Brasileiro de Geografia e Estatística. Disponível em: <http://www.ibge. gov.br>. 
BURROUGH, P. A. Principles of Geographical Information Systems for Land Resources Assessment. Oxford: Clarendon Press, 1986.

CÂMARA, Gilberto (et al.). Análise Espacial e Geoprocessamento. 2002. Disponível em: <www.dpi.inpe.br/gilberto/livro/analise/cap1intro.pdf>. Acesso em: 23 de setembro de 2009.

CANADIAN COUNCIL OF RESOURCE AND ENVIRONMENTAL MINISTERS. Canadian water quality guidelines. Ontário, CA: Environment Canada, 1994.

CASTRO, Paulo Sant'Anna (et al.). Recuperação e conservação de nascentes. DVD. Produção de José Dermeval Lopes Saraiva. 64 min. Série saneamento e meio ambiente. Viçosa, CPT, 2001.

CENTRO DE PRODUÇÕES TÉCNICAS - CPT. Esgoto sanitário e meio ambiente. DVD. Roteiro e Direção de José Mauro Souza Lima. 35 min. Série saneamento e meio ambiente. Viçosa, CPT, 1998.

CETESB - COMPANHIA AMBIENTAL dO ESTAdO DE SÃO PAULO. Relatório de Qualidade das Águas Interiores do Estado de São Paulo - 1988. Série Relatórios. São Paulo, 1989. 166 p.

. Relatório de Qualidade das Águas Interiores do Estado de São Paulo - 1989. Série Relatórios. São Paulo, 1990. 164 p.

. Relatório de Qualidade das Águas Interiores do Estado de São Paulo - 1990. Série Relatórios. São Paulo, 1991. 155 p.

. Relatório de Qualidade das Águas Interiores do Estado de São Paulo - 1991. Série Relatórios. São Paulo, 1992. 163 p. 
Relatório de Qualidade das Águas Interiores do Estado de São Paulo - 1992. Série Relatórios. São Paulo, 1993. 251 p.

. Relatório de Qualidade das Águas Interiores do Estado de São Paulo - 1994. Série Relatórios. São Paulo, 1995. 273 p.

. Relatório de Qualidade das Águas Interiores do Estado de São Paulo - 1995. Série Relatórios. São Paulo, 1996. 286 p.

- Reavaliação dos pontos de amostragem da rede de monitoramento da qualidade das águas interiores do estado de São Paulo. Vol.1: UGRHI 02 - Paraíba do Sul (69 p.). Vol.2: UGRHI 05 Piracicaba/ Capivari/ Jundiaí - complementação (29 p.). Vol.3: UGRHI 04 - Pardo, UGRHI 08 - Sapucai/ Grande, UGRHI 09 - Mogi-Guacu, UGRHI 12 - Baixo Pardo/ Grande. Vol.4: UGRHI 13 - Tiete/ Jacare, UGRHI 16 Tiete/ Batalha, UGRHI 18 - São Jose dos Dourados, UGRHI 19 - Baixo Tiete. São Paulo, 1996.

. Relatório de Qualidade das Águas Interiores do Estado de São Paulo - 1999. Notas Relatórios Ambientais. São Paulo, 2000. $391 \mathrm{p}$.

Relatório de Qualidade das Águas Interiores do Estado de São Paulo - Período de 1988 a 2001 . Série Relatórios. São Paulo, 2000.

. Relatório de Qualidade das Águas Interiores do Estado de São Paulo - 2000. Série Relatórios. Vols.1 (214 p.) e 2 (137 p.). São Paulo, 2001. $351 \mathrm{p}$. 
Relatório de Qualidade das Águas Interiores do Estado de São Paulo - 2001. Série Relatórios. Vols.1 (227 p.) e 2. (155 p.). São Paulo, 2002. 382 p.

. Relatório de Qualidade das Águas Interiores do Estado de São Paulo - 2002. Série Relatórios. Vols. 1 (271p.) e 2 (CD). São Paulo, 2003.

. Relatório de Qualidade das Águas Interiores do Estado de São Paulo - 2003. Série Relatórios. Vol.2 (CD). São Paulo, 2004.

. Relatório de Qualidade das Águas Interiores do Estado de São Paulo - 2004. Série Relatórios. Vols.1 (297p.) e 2 (CD). São Paulo, 2005.

. Relatório de Qualidade das Águas Interiores do Estado de São Paulo - 2005. Série Relatórios. Vols. 1 (488p.) e 2 (CD). São Paulo, 2006.

. Relatório de Qualidade das Águas Interiores do Estado de São Paulo - 2006. Série Relatórios. Vols. 1 (327 p.) e 2 (CD). São Paulo, 2007.

. Relatório de Qualidade das Águas Interiores do Estado de São Paulo - 2007. Série Relatórios. São Paulo, 2008. 537 p.

. Relatório de Qualidade das Águas Interiores do Estado de São Paulo - 2008. Série Relatórios. São Paulo, 2009. 528 p. 
Publicações / Relatórios. Disponível em: <http://www.cetesb.sp.gov.br/agua/aguas-superficiais/35-publicacoes-/relatorios>. Acesso em: 10 de maio de 2010.

CHAPMAN, D.; HALL. Water Quality Assessments. $2^{\mathrm{a} e d .}$ London: E\&FN SPON, 1996. $626 \mathrm{p}$.

CHRISTOFOLLETTI, A. Geomorfologia Fluvial. São Paulo: Edgard Blücher- Edusp, 1974.

; TEIXEIRA, A. L. A. Sistema de Informação Geográfica (Dicionário Ilustrado). São Paulo, 1999.

CONSELHO ESTADUAL DE RECURSOS HÍdRICOS (SÃO PAULO). Legislação sobre Recursos Hídricos. São Paulo, s/d. 48 p.

. Plano Estadual de Recursos Hídricos: 2004-2007. São Paulo: DAEE, 2006. 92 p.

DJI - ÍNDICE FUNDAMENTAL DO DIREITO. Disponível em: <http://www. dji.com.br/decretos/1934-024643ca/codigo_de_aguas.htm>. Acesso em: 23 de setembro de 2009.

DREW, D. Processos Interativos Homem-Meio Ambiente. Tradução de João Alves dos Santos. Revisão de Suely Bastos. Coordenação editorial de Antonio Christofoletti. 3aed. Rio de Janeiro: Bertrand Brasil, 1994. $224 p$.

EAU INTERNATIONAL. Water and the planet. France: Données sur l'eau, s/d. Disponível em: <http://www.eau-internationalfrance.fr/article.php3?id_article=195\&idRubSel=210\&id_parent=\&id_rubri que=211\&id_pere $=>$ Acesso em: 10 de maio de 2011 . 
ENVIRONMENTAL HEALTH DIRECTORATE. Recreational water quality. Minister of National Health and Welfare, s/d. 44 p.

ESTONIA. Report on the implementation of Nitrate Directive 20002003. Tallinn University of Technology, 2005.

EUROPEAN COMMISSION. Water framework directive: Common implementation strategy - 2005 updated version. CD. Brussels, 2006.

The EU Water Framework Directive - integrated river basin management for Europe. S.I., 19 de agosto de 2009. Disponível em: <http://ec.europa.eu/environment/water/water-framework/index_en.html>. Acesso em: 10 de maio de 2011.

EUROPEAN ENVIRONMENT AGENCY - EEA. EUROWATERNET - The European Environment Agency's Monitoring and Information Network for Inland Water Resources. Technical report no 7. Copenhagen, junho de 1998. Disponível em: <www.eea.europa.eu/publications/TECH07/tech07. pdf $>$. Acesso em: 23 de setembro de 2009.

GANZELI, J. P. "Aspectos Ambientais do Planejamento dos Recursos Hídricos: a Bacia do Rio Piracicaba". In: TAUK, S. M. (Org.). Análise

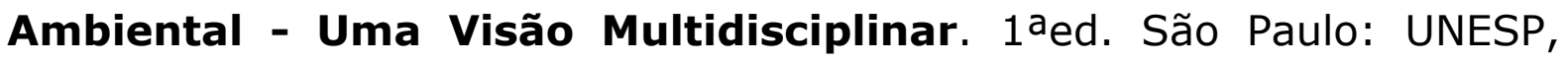
1991. 169p.

GIUPPONI, C.; MYSIAK, J.; FASSIO, A.; COGAN, V. "MULINO-DSS: a computer tool sustainable use of water resources at catchment scale". Jounal of Mathematics and Computers in Simulation. Vol.64. S.I., 2004. p.13-24. Disponível em: <http:www.elsevier.com/locate/matcom>. Acesso em: 19 de outubro de 2009. 
HAVEKES, H. (et al.). Water governance: the dutch water board model. The Hague: Dutch Association of Water Boards; Unie van Waterschapen, (2005?).

HERWIJNEN, M. van. Spatial Decision Support for Environmental Management. Amsterdam: Vrije Universiteit, 1999. 274 p.

INAG - INSTITUTO NACIONAL DA ÁGUA. Reestruturação da Rede de Monitorizarão de Recursos Hídricos - Aspectos Metodológicos. Agosto de 1996. Disponível em: <http://snirh.inag.pt/snirh/estudos_proj/ portugues/docs/download/redesnac.zip $>$.

INSTITUTO GEOGRÁFICO E CARTOGRÁFICO. Municípios criados a partir de $1990 . \quad$ s/d. Disponível em: <http://www.igc.sp.gov.br/novmunicip.htm>. Acesso em: 03 de setembro de 2009.

ITC - INTERNATIONAL INSTITUTE FOR GEO-INFORMATION SCIENCE AND EARTH OBSERVATION. Principles of Remote Sensing and Geographic Information Systems. CD. $3^{a}$ ed. Enschede, NL, 2004.

Spatial Decision Support Systems: Distance Education. 2 CD's. Curso a distância de especialização. Enschede, NL, 2008.

. ILWIS - Remote Sensing and GIS software. . Enschede, NL, 20 de agosto de 2009. Disponível em: <www.itc.nl/ilwis>.

ILWIS - Documentation version 3. Enschede, NL, s/d. Disponível em: <http://www.itc.nl/ilwis/documentation/version3.asp>. 
JORNAL DA USP. n.596. São Paulo, Universidade de São Paulo, 07 maio 2002. Disponível em: <http://www.usp.br/jorusp/arquivo/2002/jusp596/ pag05.htm>. Acesso em: 23 de setembro de 2009.

KESHKAMAT, S. S.; LOOIJEM, J. M.; ZUIDGEeST, M. H. P. "The formulation and evaluation of transport route planning alternatives: a spatial decision support system for the Via Baltiva project, Poland". Journal of Transport Geographic. Vol.17. S.I., 2009. p.54-64. Disponível em:

http://www.sciencedirect.com/science/article/pii/S0966692308000379>. Acesso em: 10 de maio de 2011.

LAM, D. C. L.; SWAYNE, D. A; BOWEN, G. S. "A Teamwork Approach to Decision Support System Development for Watershed Management Problems". In: DENZER, R.; SCHIMAK, G.; RUSSELL, D. (Orgs.). Environmental Software Systems. Hardcover, 1995.

LAMPARELLI, M. C. Grau de trofia em corpos d'água do Estado de São Paulo - avaliação dos métodos de monitoramento. Tese (Doutorado em Ecologia Aplicada), Instituto de Biociências da Universidade de São Paulo, São Paulo, 2004.

MARTINELLI, Marcello. Comunicação cartográfica e os atlas de planejamento. Tese (Doutorado), FFLCH/USP, São Paulo, 1984.

Curso de cartografia temática. São Paulo: Contexto, 1991. 180 p. Disponível em: <http://sibicce.usp.br:4500/ALEPH/POR/FFL/FFL/ MONOFFL/FIND-ACC/0006585>. 
Gráficos e mapas: construa-os você mesmo. Assessoria didática de Graça Maria Lemos Ferreira. São Paulo: Moderna, 1998. 120 p. Disponível em: <http://sibicce.usp.br:4500/ALEPH/POR/FFL/FFL/ MONOFFL/FIND-ACC/0006582>.

- Mapas da geografia e cartografia temática. São Paulo: Contexto, 2003. Disponível em: <http://sibicce.usp.br:4500/ALEPH/POR/ FFL/FFL/MONOFFL/FIND-ACC/0006582>.

MARTINEZ JR., Francisco. Aplicação de instrumentos econômicos a gestão ambiental: introdução da cobrança pela utilização dos recursos hídricos no estado de São Paulo. Tese (Doutorado em Engenharia Civil), Escola Politécnica - USP, São Paulo, 1997. 271 p.

MCNEELY, R. N.; NEIMANIS, V. P.; DWYER, L. Water quality sourcebook: a guide to water quality parameters. Ottawa, CA: Environment Canada, 1979. 89 p.

MENEGON JR., Nelson. Aplicação do modelo matemático de qualidade de água - SIMOX-III na bacia do Rio Camanducaia. Dissertação (Mestrado em Engenharia Civil), Universidade de São Paulo, São Paulo, 2005.

MIDAGLIA, C. L. V. Turismo e meio ambiente no litoral paulista Dinâmica da Balneabilidade nas Praias Paulistas. Dissertação (Mestrado em Geografia Humana), FFLCH - Universidade de São Paulo, São Paulo, 1994.

Políticas públicas para a água na Holanda em tempos de mudanças climáticas. Vol.2. n.1. Rio Claro (SP), jan.-jun / 2007. p.2542. Disponível em: <http://www.pluridoc.com/Site/FrontOffice/default. asp ? Module=Files $/$ FileDescription\&ID $=3471$ \&lang $=\mathrm{pt} \#>$. 
; RAMIREZ, M.; NADER, R. "Propuesta de ampliación de la red de monitoreo de aguas interiores del estado de Sao Paulo, en UGRHI's agropecuarias con los recursos del Google Earth". In: XII Encontro de Geógrafos de América Latina (EGAL) - Anais. n.7091. Montevidéu: Universidad de la República, 2009.

MONBEING, Pierre. Pioneiros e Fazendeiros de São Paulo. São Paulo: Hucitec-Polis, 1984.

MORATO, R. G.; KAWAKUBO, F. S.; LUCHIARI, A. Mapeamento da Qualidade de Vida em Áreas Urbanas: conceitos e metodologias. Vol.21. n.2. São Paulo: Terra Livre, 2003.

; KAWAKUBO, Fernando S.; LUCHIARI, Aílton. Avaliação da qualidade de vida urbana no município de Embu por meio de técnicas de Geoprocessamento. GEOUSP, n.23. São Paulo: Espaço e Tempo, 2008. p.149-63.

NATIONAL WATER COUNCIL. River quality: the 1980 survey and future outlook. London, GB, 1981. 39 p.

NOVOTNY, Vladimir. Water Quality: Diffuse Pollution and Watershed Management. Hoboken (NJ): J. Wiley, 2003.

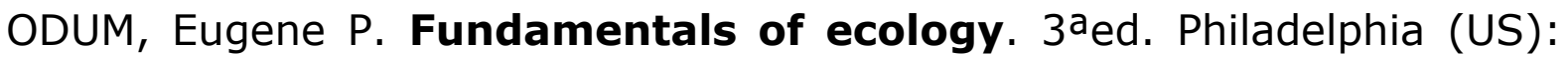
W. B. Saunders Company, 1971. 574 p.

- Ecologia. $3^{a}$ ed. Tradução de Kurt G. Hell. São Paulo: Pioneira, 1977. 201 p. 
ON HABITAT - ORGANIZAÇÃO DAS NAÇÕES UNIDAS PARA HABITAÇÃO, 2006.

Disponível

em:

http://www.unhabitat.org/documents/media_centre/sowcr2006/SOWCR\% 205.pdf . Acesso em: 2 de setembro de 2009.

ONU - ORGANIZAÇÃO DAS NAÇÕES UNIDAS. Disponível em: < http:// www.un.org/ waterforlifedecade/wdlogo.html>. Acesso em: 23 de setembro de 2009.

PÁDUA, H. B. (et al.). "Qualidade das Águas do Estado de São Paulo para Desenvolvimento e Preservação de Peixes". Revista DAE. n.138. São Paulo, Companhia de Tecnologia de Saneamento Ambiental, set. 1984. p.181-98.

PHILIPPI JR., Arlindo (et al.). Saneamento do Meio. Fundacentro Universidade de São Paulo, Faculdade de Saúde Pública. São Paulo: Departamento de Saúde Ambiental, 1992.

PIVELI, Roque Passos (et al.). Qualidade das águas e poluição: aspectos físico-químicos. São Paulo: ABES, 2006. 285 p.

QUADRADO, F.; GOMES, F.; CARMONA RODRIGUES, A. Restruturação das Redes de Monitorização. III - Rede de Qualidade da Água a Sul do Tejo. S.I., 1998. Disponível em: <http://www.aprh.pt/congressoagua98/ files/com/033.pdf>.

R\&D TECNOLOGIA. Conversor de Coordenadas - Localização no Mapa. Disponível em: <http://www.rdtec.com.br/rdgeomg/localmaster.htm>. Acesso em: 23 de setembro de 2009. 
RIO DE JANEIRO (ESTADO). Secretaria de Estado do Ambiente. FEEMAFundação Estadual de Engenharia e Meio Ambiente. Vocabulário Básico

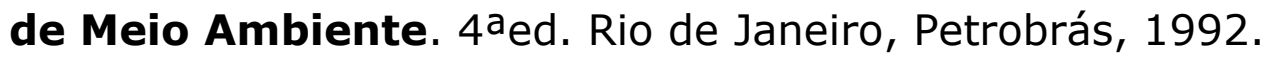

ROEST, C. W. J. "Trade, a simple water quality model for transport, adsorption and decomposition of solutes in the soil". ICW Technical Bulletins. New Series. n.039. 1986.

ROSS, Jurandyr L. Sanches. "Análise Empírica da fragilidade dos ambientes naturais ou antropizados". Revista do Departamento de Geografia. n.8. São Paulo, FFLCH/USP, 1994. p.63-74.

- "Análises e sínteses na abordagem geográfica da pesquisa para planejamento ambiental". Revista do Departamento de Geografia. n.9. São Paulo, FFLCH/USP, 1995. p.65-74.

(Org.). Geografia do Brasil. São Paulo: Edusp, 1996.

ROSSETTI, R. Evolução da carga orgânica de origem doméstica no rio Paraíba do Sul, no trecho paulista, no período de 1998-2007. Dissertação (Mestrado), FFLCH-USP, São Paulo, 2009.

SAATY, T. L. The Analytic Hierarchy Process. NY: McGraw Hill, 1980.

SANDERS, Thomas G.; WARD, R. C.; LOFTIS, J. C. Design of networks for monitoring water quality. Littleton, Colo., USA: Water Resources Publications, 1987. 
SÃO PAULO (ESTADO). Comitê de Bacia Hidrográfica dos rios Piracicaba, Capivari e Jundiaí. Plano Estadual de Recursos Hídricos - Estado de São Paulo. RSP - Relatório Síntese do Plano. PERH 2004-2007. São Paulo, 2008b. Disponível em: <http://www.comitepcj.sp.gov.br/ download/PERH/04-07_Sint_Cap-11.pdf>. Acesso em: 15 de setembro de 2009.

Secretaria de Saneamento e Energia. DAEE- Departamento de Águas e Energia Elétrica. Plano Estadual de Recursos Hídricos: relatório de situação dos recursos hídricos do Estado de São Paulo. São Paulo, 2002. 119 p.

. Secretaria de Saneamento e Energia. DAEE- Departamento de Águas e Energia Elétrica. Relatório de situação dos recursos hídricos do Estado de São Paulo - síntese - relatório zero - 1999. Sao Paulo, 2002. 53 p.

. Secretaria de Saneamento e Energia. DAEE- Departamento de Águas e Energia Elétrica. Plano Estadual de Recursos Hídricos: 20042007. CD. São Paulo, 2005.

Secretaria de Saneamento e Energia. DAEE- Departamento de Águas e Energia Elétrica. Situação das UGRHIs. São Paulo, 2008a.

Disponível em: <http://www.daee.sp.gov.br/fotos/5/ perh08.pdf>. Acesso em: 25 de setembro de 2009. 
. Secretaria do Meio Ambiente. Gestão das Águas: 6 anos de percurso. São Paulo, 1997. 128 p.

- Secretaria do Meio Ambiente. SEADE - Fundação Sistema Estadual de Análise de Dados. Atlas da população do Estado de São Paulo. São Paulo, 1991.

- Secretaria do Meio Ambiente. SEADE - Fundação Sistema Estadual de Análise de Dados. Perfil Ambiental do Estado de São Paulo. São Paulo, 1999.

- Secretaria do Meio Ambiente. SEADE - Fundação Sistema Estadual de Análise de Dados. Índice Paulista de Vulnerabilidade Social - IPVS. CD. São Paulo, 2004.

- Secretaria do Meio Ambiente. SEADE - Fundação Sistema Estadual de Análise de Dados. Projeção da população dos municípios e distritos pertencentes à região II de planejamento da SABESP, segundo a situação de domicílio urbano e rural, até o ano 2010: relatório síntese. São Paulo, s/d.

. Secretaria do Meio Ambiente. SIGRH- Sistema de Informações para o Gerenciamento de Recursos Hídricos do Estado de São Paulo. O Plano Estadual de Recursos Hídricos. São Paulo, setembro de 1990. Disponível em: <http://www.sigrh.sp.gov.br/sigrh/basecon/perh90/ Perh9009.htm>. Acesso em: 25/09/2009.

- Secretaria dos Transportes Metropolitanos. Disponível em: <www.stm.sp.gov.br/rmc/htm>. Acesso em: 23 de setembro de 2009. 
STEPHEN P. MORSE. Jewish Calendar Conversions in One Step. Disponível em: <http://www.stevemorse.org/jcal/dms.htmlsiteb>. Acesso em: 23 de setembro de 2009.

THE VORONOI GAME. Disponível em: <http://www.voronoigame.com>. Acesso em: 23 de setembro de 2009.

THOMANN, Robert $V$. Systems analysis and water quality management. New York, US, Environmental Science Services Division, 1971. 285 p.

; MUELLER, John A. Principles of surface water quality modeling and control. New York: Harper \& Row, 1987.

UNEP/WHO. Water Quality Monitoring - A Practical Guide to the Design and Implementation of Freshwater Quality Studies and Monitoring Programmes. Edited by Jamie Bartram and Richard Ballance. United Nations Environment Programme and the World Health Organization, 1996. Disponível em: <http://www.who.int/water_sanitation_health/ resourcesquality/waterqualmonitor.pdf $>$.

UNIE VAN WATERSCHAPPEN (Netherlands). Wegen naar 2010: integraal, regionaal en doelmatig wegenbeheer door waterschappen. Strategische Beleidsvisie Wegenbeheer. Den Haag, NL, 2000.

Water boards. $11^{\mathrm{a} e d .}$ Den Haag, NL, 2006. 
UNITED NATIONS - HABIT. State of the World's Cities 2006/7. s/d. Disponível em: <http://ww2.unhabitat.org/mediacentre/documents/ sowcr2006/SOWCR\%205.pdf>. Acesso em: 2 de setembro de 2009.

UNIVERSIDADE DE SÃO PAULO. Faculdade de Saúde Publica. Departamento de Saúde Ambiental. Saneamento do Meio. São Paulo, Departamento de Saúde Ambiental - USP, 1976.

WESTEN, C.; FARIFTEH, J. User's Guide: ILWIS- Integrated Land and Water Information System. Enschede: International Institute for Aerospace Survey \& Earth Sciences, 1997. 511 p.

ZEE, D. van der. The use of GIS in the study of nature-culture interactions in landscapes. Enschede, NL: ITC, 1998.

. Specialist and local knowledge as essential input in change detection. Enschede, NL: ITC, 2001.

; ZONNEVELD, Issak S. Landscape Ecology Applied in Land Evaluation, Development and Conservation: Some Wordline Selected Examples. ITC publication n.81 and IALE publication MM-1. Enschede, NL, August de 2001. $412 \mathrm{p}$.

Planning in the Netherlands. Enschede, NL: ITC, 2004.

ZONNEVELD, I. The Land unit. A fundamental concept in landscape ecology and its applications Landscape Ecology. Vol.3. n.2. The Hague: SPB Academic Publishing bv, 1989. 